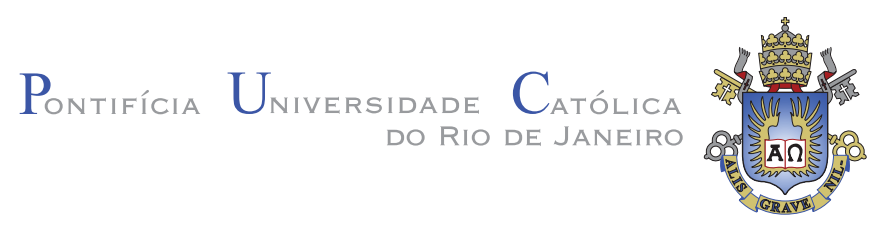

Gustavo Vianna Cezar

\title{
Desenvolvimento de uma Bancada de Testes para Motores a Combustão Interna
}

Dissertação apresentada como requisito parcial para a obtenção do grau de Mestre pelo Programa de Pós-Graduação em Engenharia Mecânica do Departamento de Engenharia Mecânica da PUC-Rio

Orientador : Prof. Sérgio Leal Braga Co-Orientador: Prof. Julio Cesar Cuisano Egúsquiza 


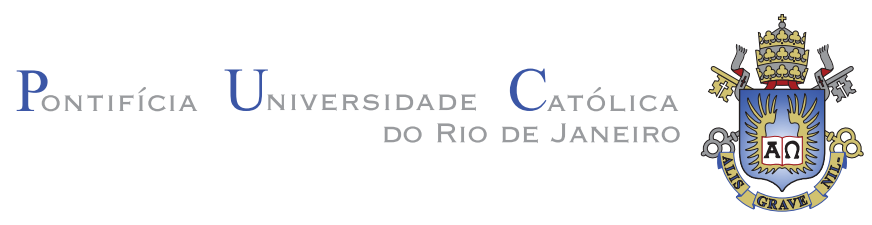

Gustavo Vianna Cezar

\title{
Desenvolvimento de uma Bancada de Testes para Motores a Combustão Interna
}

Dissertação apresentada como requisito parcial para a obtenção do grau de Mestre pelo Programa de Pós-Graduação em Engenharia Mecânica do Departamento de Engenharia Mecânica do Centro Técnico Científico da PUC-Rio. Aprovada pela Comissão Examinadora abaixo assinada.

\author{
Prof. Sérgio Leal Braga \\ Orientador \\ Departamento de Engenharia Mecânica - PUC-Rio \\ Prof. Julio Cesar Cuisano Egúsquiza \\ Co-Orientador \\ Departamento de Engenharia Mecânica - PUC-Rio
}

Prof. Mauro Speranza Neto

Departamento de Engenharia Mecânica - PUC-Rio

Prof. Tadeu Cavalcante Cordeiro de Melo CENPES - PETROBRAS

Prof. José Eugênio Leal

Coordenador Setorial do Centro Técnico Científico - PUC-Rio 
Todos os direitos reservados. É proibida a reprodução total ou parcial do trabalho sem autorização da universidade, do autor e do orientador.

\section{Gustavo Vianna Cezar}

Graduou-se em Engenharia de Controle e Automação pela PUC-Rio em Julho de 2010. Como estagiário do Laboratório de Sensores a Fibra Ótica, da PUC-Rio, atuou no desenvolvimento de projetos ligados à sensoriamento, monitoração e controle de processos. Desde 2010 é pesquisador do Laboratório de Engenharia Veicular - LEV - da PUC-Rio onde, inicialmente, atuou na área de testes de motores Diesel utilizando a técnica de combustão por compressão de carga homogênea (HCCI) e posteriormente atuou em testes de motores do ciclo Otto com o objetivo de analisar desempenho com diferentes combustíveis. Atualmente é engenheiro de pesquisa do LEV atuando na automação e testes de motores em bancadas dinamométricas.

Ficha Catalográfica

Cezar, Gustavo Vianna

Desenvolvimento de uma Bancada de Testes para Motores a Combustão Interna / Gustavo Vianna Cezar; orientador: Sérgio Leal Braga; co-orientador: Julio Cesar Cuisano Egúsquiza. - Rio de Janeiro PUC-Rio, Departamento de Engenharia Mecânica, 2012.

v., 143 f: il. (color) ; $30 \mathrm{~cm}$

Dissertação (mestrado) - Pontifícia Universidade Católica do Rio de Janeiro, Departamento de Engenharia Mecânica.

Inclui referências bibliográficas.

1. Engenharia Mecânica - Tese. 2. Dinamômetro;. 3. Banco de Prova;. 4. Motores de Combustão Interna;. 5. Controle;. 6. Automação. I. Braga, Sérgio Leal. II. Egúsquiza, Julio Cesar Cuisano. III. Pontifícia Universidade Católica do Rio de Janeiro. Departamento de Engenharia Mecânica. IV. Título. 


\section{Agradecimentos}

Aos Professores Sérgio Leal Braga e Julio Cesar Cuisano Egúsquiza pela oportunidade, confiança, estímulo e apoio durante o desenvolvimento de toda a dissertação.

Ao Professor Mauro Speranza Neto pela ajuda disponibilizada.

À PUC-Rio pelos auxílios concedidos, sem os quais este trabalho não poderia ter sido realizado.

Ao Departamento de Engenharia Mecânica da PUC-Rio, através de seus Professores de graduação e pós graduação e do corpo administrativo.

Ao $\mathrm{CNPq}$ pelo suporte financeiro no presente trabalho.

À WEG Automação pela parceria no desenvolvimento do trabalho.

À Maroni Indústria Mecânica Ltda pelo suporte no projeto e desenvolvimento da base de testes.

À Overload pelo suporte elétrico.

Ao ITUC (Instituto Tecnológico da PUC-Rio), através de seus funcionários administrativos e da oficina mecânica.

Aos amigos e engenheiros do Laboratório de Engenharia Veicular (LEV) Leonardo Braga, Fernando Zegarra, Juan Valdez e Marvin Chancán pela colaboração e companheirismo.

Aos futuros engenheiros da PUC-Rio, Augusto Correia, Lucas Almeida, Jorge Ricardo, Rodolfo da Paixão e Alfredo Fontoura pela amizade e apoio no trabalho desenvolvido.

Aos amigos e engenheiros eletrônicos do LEV Severino Wanderley e Nestor Cotelo pela amizade e suporte eletrônico.

Ao técnico em mecânica Gilson Pradanoff e ao auxiliar de serviços gerais Gerson Silvério pela amizade e suporte em toda a parte experimental e logística do projeto.

Aos antigos funcionários do LEV José Alberto Franco, Anthony Roque, Pedro Romano e Gabriel Werpel pela amizade, companheirismo e ajuda no desenvolvimento da tese.

À minha família e amigos por todo o suporte, ajuda e confiança ao longo do trabalho. 


\section{Resumo}

Cezar, Gustavo Vianna; Braga, Sérgio Leal; Egúsquiza, Julio Cesar Cuisano. Desenvolvimento de uma Bancada de Testes para Motores a Combustão Interna. Rio de Janeiro, 2012. 143p. Dissertação de Mestrado - Departamento de Engenharia Mecânica, Pontifícia Universidade Católica do Rio de Janeiro.

Com o aumento das restrições às emissões veiculares e uma busca contínua pela melhora no desempenho dos motores a combustão interna, a necessidade de realizar testes em bancos de prova de motor se torna cada vez maior. Porém, devido ao alto investimento inicial e custo de manutenção desses sistemas, a execução de ensaios confiáveis torna-se restrita a determinadas empresas e instituições acadêmicas. Neste cenário, o presente trabalho visa projetar, construir e integrar equipamentos e instrumentos, em sua grande maioria nacionais, através do desenvolvimento de um sistema de controle que seja capaz de operar o conjunto desenvolvido. O projeto pretende contribuir com a redução de custos dos bancos de prova e, ao mesmo tempo, possibilitar a realização de testes confiáveis. Serão descritas as etapas do projeto e construção de uma bancada para ensaios de motores de até $175 \mathrm{cv}, 587 \mathrm{Nm}$ e $4.620 \mathrm{rpm}$. Testes foram conduzidos a fim de verificar o comportamento do banco de provas em diferentes situações de operação. Os resultados obtidos mostram que o sistema é capaz de realizar os mais diversos ensaios que um banco de provas está sujeito com precisão e robustez.

\section{Palavras-chave}

Dinamômetro; Banco de Prova; Motores de Combustão Interna; Controle; Automação 


\section{Abstract}

Cezar, Gustavo Vianna; Braga, Sérgio Leal(Advisor) ; Egúsquiza, Julio Cesar Cuisano (Co-Advisor). Development of an Engine Test Bench. Rio de Janeiro, 2012. 143p. MSc Dissertation - Departamento de Engenharia Mecânica, Pontifícia Universidade Católica do Rio de Janeiro.

With increasing restriction on emission and a continuous search for improvement and development of new engines, a need for internal combustion engines test bed is becoming greater. However due to high initial investments and maintenance costs of these systems, the execution of reliable tests becomes restricted to certain companies and academic institutions. In this scenario, this present work aims at the integration of equipment and instruments, mostly national, by the development of a control system. This project aims to contribute with test benches cost reduction and at the same time, allow for reliable testing. Will be described the project steps of a test bench for engines up to $175 \mathrm{hp}, 587 \mathrm{Nm}$ and $4.620 \mathrm{rpm}$ and will be shown the results obtained.

\section{Keywords}

Dynamometer; Test Bench; Internal Combustion Engine; Control; Automation 


\section{Sumário}

1 Introdução $\quad 15$

$\begin{array}{lll}1.1 & \text { Justificativa } & 16\end{array}$

$\begin{array}{lll}1.2 & \text { Objetivos } & 18\end{array}$

$\begin{array}{ll}1.2 .1 & \text { Objetivo Geral } \\ 1.2 & 18\end{array}$

$\begin{array}{lll}1.2 .2 & \text { Objetivos Específicos } & 18\end{array}$

$\begin{array}{lll}1.3 & \text { Descrição da Dissertação } & 19\end{array}$

2 Fundamentação Teórica $\quad 21$

2.1 Conceitos Teóricos 21

2.1.1 Dinamômetros 21

2.1.2 Modos de Controle do Sistema Dinamômetro-Motor 28

2.1.3 Tipos de Testes 31

2.2 Estado da Arte 31

3 Bancada Experimental $\quad 41$

3.1 Seleção do Motor de Combustão 41

3.2 Seleção do Dinamômetro 42

3.3 Acoplamento $\quad 42$

3.3.1 Transmissão 43

3.3.2 Medição de Torque 44

3.4 Medição de Velocidade Angular 47

3.5 Desenvolvimento da Base de Testes e Dimensionamento dos Isoladores de Vibração 48

3.5.1 Desenvolvimento da Base de Testes 48

3.5.2 Seleção dos Isoladores de Vibração 53

3.6 Atuadores do Controle de Velocidade Angular dos MCl's 55

3.6.1 Motores de Passo $\quad 57$

3.6.2 Servomotores 58

3.7 Transdutores de Pressão e Temperatura 58

$\begin{array}{lll}3.8 & \text { Inversor de frequência } & 60\end{array}$

3.9 Isolamento Elétrico do Sistema $\quad 61$

3.9.1 Balanceamento 63

3.9.2 Blindagem 64

$\begin{array}{lll}3.9 .3 & \text { Aterramento } & 65\end{array}$

$\begin{array}{lll}3.9 .4 & \text { Filtragem } & 66\end{array}$

$\begin{array}{lll}\text { 3.9.5 Considerações para o Projeto } & 67\end{array}$

4 Desenvolvimento do Sistema de Aquisição de Dados e do Programa de $\begin{array}{ll}\text { Monitoramento e Controle } & 70\end{array}$

4.1 Desenvolvimento do Sistema de Aquisição de Dados 70

4.1.1 Tempo e Frequência de Aquisição 70

4.1.2 Tipos e Quantidades de Transdutores $\quad 70$

4.1.3 Quantidade de Canais Necessários $\quad 71$

4.2 Desenvolvimento do Programa de Monitoramento e Controle 71 
4.2.1 Sistema Operacional em Tempo Real 72

4.2.2 Hardware e Software de Controle do Banco de Provas 74

$\begin{array}{lll}\text { 4.2.3 Desenvolvimento da Programação } & 77\end{array}$

4.2.4 Pós Processamento e Análise dos Dados 84

5 Procedimento Experimental $\quad 85$

5.1 Capacidade de Seguimento de Trajetória 85

5.2 Tempo de Resposta 86

5.2.1 Determinação do Tempo Máximo de Resposta para Testes em Motores 86

5.3 Limitações da Bancada de Testes 91

5.4 Redução dos Dados $\quad 93$

5.4.1 Potência 93

6 Resultados e Discussões $\quad 94$

6.1 Análise do Comportamento do Sistema 94

$\begin{array}{lll}6.1 .1 & \text { Torque } & 94\end{array}$

$\begin{array}{lr}6.1 .2 \text { Velocidade } & 99\end{array}$

6.2 Testes em Condições Extremas 102

6.2.1 Teste em Plena Carga 104

7 Conclusões e Sugestões $\quad 119$

$\begin{array}{ll}\text { Referências Bibliográficas } & 123\end{array}$

$\begin{array}{ll}\text { A Análise de Propagação de Incertezas Experimentais } & 127\end{array}$

$\begin{array}{lll}\text { A.1 Incerteza da Potência Efetiva } & 128\end{array}$

B Desenvolvimento do Modelo Motor-Dinamômetro 129

B.1 Dinamômetro 129

B.2 Elementos de Conexão 130

B.3 Motor de Combustão Interna 131

B.3.1 Mapa Estático Não Linear 132

B.3.2 Reformulação do Modelo Matemático e Malha de Controle 135

B.4 Conclusão e Recomendações 141

C Planilhas 142 


\section{Lista de figuras}

2.1 Quadrantes de operação dos dinamômetros

2.2 Princípio de operação - Dinamômetro Hidráulico: (a) seção vertical; (b) vista frontal; (c) seção a-a do rotor e estator; (d) representação do vortex toroidal.

2.3 Vista em corte motor de indução: 1-Carcaça, 2-Núcleo de Chapas do Estator, 3-Núcleo de Chapas do Rotor, 4-Tampa, 5-Ventilador, 6-Tampa Defletora, 7-Eixo, 8-Enrolamento Trifásico, 9-Caixa de Ligação, 10-Terminais, 11-Rolamentos, 12-Barras e Anéis de CurtoCircuito. (Fonte: WEG)

2.4 (a) - Tensão $\times$ Frequência; (b) - Potência $\times$ Frequência; (c) Torque $\times$ Frequência. (Fonte: WEG)

2.5 Diagrama de blocos do sistema de controle do conjunto dinamômetro-motor. (Fonte: Robust Inverse Control of a Class of Nonlinear Systems - [1])

2.6 Resposta da curva de torque do sistema de controle de um banco de provas. (Fonte: Robust Inverse Control of a Class of Nonlinear Systems - [1])

2.7 Resposta da curva de rotação do sistema de controle de um banco de provas. (Fonte: Robust Inverse Control of a Class of Nonlinear Systems - [1])

3.1 Vistas frontal e lateral do motor MWM 42

3.2 Curvas de torque do motor elétrico e de motores Diesel típicos. 43

3.3 Curvas de potência do motor elétrico e de motores Diesel típicos. 43

3.4 Transdutor de torque do tipo flange.

3.5 Conexão por simples e múltiplas chavetas.

3.6 Campos de pressão - vistas lateral e frontal 47

3.7 Disco de pressão e camisa

3.8 Conjunto de transmissão: (a)disco de pressão, (b)camisa, (c)transdutor de torque e (d)eixo cardan.

3.9 Encoder instalado no eixo do dinamômetro.

3.10 Concepção em software CAD da base com dinamômetro.

3.11 Forças desbalanceadas produzidas na rotação máxima.

3.12 Simulação por elementos finitos das forças desbalanceadas de um $\mathrm{MCl}$ e da força estática do dinamômetro sobre base.

3.13 Simulação por elementos finitos das forças desbalanceadas de um $\mathrm{MCl}$ e das forças estáticas do dinamômetro e do segundo $\mathrm{MCl}$ sobre a base.

3.14 Desenho Esquemático do posicionamento dos componentes sobre a base.

3.15 Isoladores de vibração.

3.16 Vista dianteira da base instalada no laboratório. 56

3.17 Vista traseira da base instalada no laboratório.

3.18 Servomotor utilizado como atuador da bomba de combustível do $\mathrm{MCl}$. 
3.19 Termopares instalados no $\mathrm{MCl}$ (da esquerda para a direita: óleo, água e escapamento).

3.20 Tomada do transdutor de pressão e transdutor utilizado no $\mathrm{MCl}$.

3.21 Padrão de chaveamento de tensão e corrente (PWM) de um motor

de indução alimentado por inversor de frequência.

3.22 Esquema elétrico do inversor de frequência regenerativo.

3.23 Painel com inversor de frequência regenerativo instalado no laboratório.

3.24 Relação entre Passo de torção, perda por absorção e frequências.

3.25 Efeito da blindagem dos cabos - perda por absorção.

3.26 Blindagem em uma das extremidades e diferença de potencial entre terras.

3.27 Blindagem em ambas as extremidades e baixa impedância entre terras.

3.28 Detalhe do cabo do encoder com dupla blindagem.

3.29 Terra de medição e de alta potência utilizados no projeto.

3.30 Base do estator do transdutor de torque isolado com suporte de borracha e papelão.

3.31 Módulos isoladores de sinais analógicos utilizados nos cabos de comando e controle.

4.1 Composição de um sistema PXI da National Instruments.

4.2 Sistema PXI com módulos auxiliares e placa de aquisição de dados DAQ.

4.3 Comportamento do jitter sobre várias iterações.

4.4 Esquema de uma árvore de projeto para aplicações em LabVIEW RT. 75

4.5 Arquitetura de um sistema RT.

4.6 Esquema do controle PID de um processo. 78

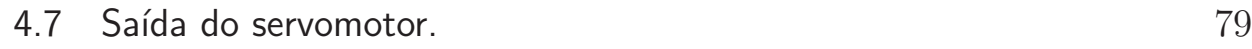

4.8 Interface do usuário desenvolvida. $\quad 80$

4.9 Botão de emergência do banco de provas. 83

5.1 Curva do teste de emissões ESC para motores. 88

5.2 Curva do teste de emissões ELR para motores.

5.3 Curva do teste de emissões ETC para motores. 90

5.4 Ciclo urbano ETC e faixas adotadas para ciclo simulado ( $\mathrm{rpm} \times$ tempo)

5.5 Curvas de rotação e alpha por tempo do ciclo simulado baseado nos pontos do ETC.

6.1 Torque e rotação do sistema para corrente de torque igual a 50\% (verde: motor quente, vermelho: motor frio).

6.2 Torque e rotação do sistema para corrente de torque igual a 40\% (verde: motor quente, vermelho: motor frio).

6.3 Torque e rotação do sistema para corrente de torque igual a 30\% (verde: motor quente, vermelho: motor frio).

6.4 Torque e rotação do sistema para corrente de torque igual a $20 \%$ (verde: motor quente, vermelho: motor frio). 
6.5 Torque e rotação do sistema para corrente de torque igual a 10\% (verde: motor quente, vermelho: motor frio).

6.6 Rampa de aceleração e desaceleração de 6 segundos. 101

6.7 Rampa de aceleração e desaceleração de 5.3 segundos. 102

6.8 Rampa de aceleração e desaceleração de 4.5 segundos. 103

6.9 Teste automático de seguimento de trajetória. 107

6.10 Teste automático de seguimento de trajetória - Rampas 6,4 e 6,7 seg. $\quad 108$

6.11 Pontos estabilizados com alpha igual a 100\%. 109

6.12 Curvas de rotação, torque e potência com alpha igual a 100\% e rampa de 5,5 segundos.

6.13 Curva de rotação com alpha igual a $100 \%$ e rampa de 5,5 segundos. 111

6.14 Respostas de rotação, torque e pressão para ciclo simulado - rampa de $6,5 \mathrm{~s}$

6.15 Respostas de rotação, torque e pressão para ciclo simulado - rampa de 6,5 s.

6.16 Respostas do sistema para perfil de rotação do ciclo simulado rampas de 5,5 e 6 s.

6.17 Curva de potência máxima real e interpolada do motor Diesel MWM 4.10TCA em função da rotação.

6.18 Curva de torque máximo real e interpolada do motor MWM 4.10TCA em função da rotação.

6.19 Curva de potência do motor MWM 4.10TCA em função da rotação com barra de incertezas.

6.20 Temperaturas de água e óleo do motor Diesel durante ensaio em plena carga.

6.21 Temperaturas de escapamento do motor Diesel durante ensaio em plena carga.

6.22 Temperatura de água do motor Diesel em teste a plena carga tendência crescente.

6.23 Detalhe da mangueira do turbo

B.1 Superfície gerada a partir dos valores de rotação, alpha e torque. 134

B.2 Curvas do mapa estático.

B.3 Curvas do mapa estático linearizado.

B.4 Curvas do mapa estático real e linearizado superpostas.

B.5 Diagrama de blocos em malha aberta do modelo para as entradas de controle $\alpha$ e $V_{D}$.

B.6 Resposta da rotação em malha aberta. 138

B.7 Resposta do torque em malha aberta. 139

B.8 Malha utilizada na simulação. 139

B.9 Diagrama de blocos de malha fechada do sistema de controle. $\quad 140$ 


\section{Lista de tabelas}

2.1 Quadrantes de operação 22

2.2 Velocidade síncrona de acordo com o número de pólos 26

2.3 Nomenclatura dos Modos de Controle 29

$\begin{array}{lll}4.1 & \text { Ganhos do controlador PID } & 78\end{array}$

6.1 Valores de temperatura da água e óleo e pressão de admissão para valores de corrente de torque. 100

B.1 Constantes do modelo. 131

B.2 Pólos em malha aberta. 138

B.3 Pólos de malha fechada das regiões com rotações abaixo da nominal.141 


\section{Lista de símbolos}

\begin{tabular}{|c|c|}
\hline $2 p$ & Número de Pólos \\
\hline$c$ & Amortecimento Torcional \\
\hline$C C$ & Corrente Contínua \\
\hline$C A$ & Corrente Alternada \\
\hline$C E$ & Compatibilidade Eletromagnética \\
\hline$d B$ & Decibéis \\
\hline$E C U$ & Unidade de Controle Eletrônica \\
\hline$E M I$ & Eletromagnetic Interference \\
\hline$f$ & Frequência da Rede Elétrica \\
\hline$f_{1}$ & Frequência do Motor Elétrico \\
\hline$H I L$ & Hardware in the Loop \\
\hline$H z$ & Hertz \\
\hline$I_{2}$ & Corrente Rotórica \\
\hline$I D$ & Índice de Desempenho \\
\hline$I G B T$ & Insulated Gate Bipolar Transistor \\
\hline$k$ & Rigidez Torcional \\
\hline$k_{1}$ & Constante Elétrica do Motor \\
\hline$k_{2}$ & Constante Elétrica do Motor \\
\hline$K_{c r}$ & Ganho Crítico \\
\hline$K_{p}$ & Ganho Proporcional \\
\hline$M$ & Mega (1.000.000) \\
\hline$M C I$ & Motor de Combustão Interna \\
\hline$M I M O$ & Multiple Input Multiple Output \\
\hline$M R A C$ & Model Reference Adaptive Control \\
\hline$M R A S$ & Model Reference Adaptive Systems \\
\hline$n_{s}$ & Velocidade Síncrona \\
\hline$N P L$ & Loop de Prioridade Normal \\
\hline$O S$ & Sistema Operacional \\
\hline$P a$ & Pascal \\
\hline$P_{c r}$ & Período Crítico \\
\hline$P D$ & Proporcional-Derivativo \\
\hline$P I D$ & Proporcional-Integral-Derivativo \\
\hline psi & pound per square inch \\
\hline psia & pound per square inch absolut \\
\hline$P W M$ & Pulse Width Modulation \\
\hline$P$ & Período \\
\hline
\end{tabular}




$\begin{array}{ll}s & \text { Segundos } \\ T_{D} & \text { Torque do Dinamômetro } \\ T_{d} & \text { Tempo Derivativo } \\ T_{E} & \text { Torque do MCI } \\ T_{\text {Eixo }} & \text { Torque no Eixo } \\ T_{\text {Estat }} & \text { Torque do Mapa Estático } \\ T_{i} & \text { Tempo Integral } \\ T C L & \text { Loop de Tempo Crítico } \\ T H D & \text { Total Harmonic Distortion } \\ T_{m e} & \text { Torque do Motor Elétrico } \\ V_{1} & \text { Tensão Estatórica }\end{array}$

\section{Símbolos Gregos}

$\begin{array}{ll}\delta & \text { Efeito Pelicular } \\ \Delta \phi & \text { Torção do Eixo } \\ \epsilon & \text { Espessura } \\ \omega_{E} & \text { Velocidade de Rotação do MCI } \\ \omega_{D} & \text { Velocidade de Rotação do Dinamômetro } \\ \dot{\omega}_{E} & \text { Aceleração do MCI } \\ \dot{\omega}_{D} & \text { Aceleração do Dinamômetro } \\ \phi_{m} & \text { Fluxo Magnetizante } \\ \theta_{D} & \text { Inércia Combinada do Dinamômetro } \\ \theta_{D 1} & \text { Inércia do Dinamômetro } \\ \theta_{D 2} & \text { Inércia das Flanges } \\ \theta_{E} & \text { Inércia Combinada do MCI } \\ \theta_{E 1} & \text { Inércia do MCI } \\ \theta_{E 2} & \text { Inércia das Flanges }\end{array}$




\section{Introdução}

A matriz energética brasileira possui uma melhor qualidade, sob o ponto de vista de fontes renováveis, com relação ao restante do mundo. Essas fontes provêem 44,1\% da produção de energia do Brasil, muito acima da média mundial que foi de 13,3\% em $2011[2,3]$.

Dentre as fontes não renováveis, o óleo diesel e a gasolina continuam representando uma parcela essencial para a economia brasileira (16,7\% e 6,7\%, respectivamente, do consumo de energia total) devido ao emprego, quase que exclusivo, na área de transporte de cargas (marítimo e terrestre) e no transporte público de passageiros [4]. Outra fonte não renovável que vem se destacando no cenário nacional é o gás natural. Em 2009, apesar da queda em sua demanda no setor industrial, devido à crise mundial, sua participação na composição das fontes primárias de energia utilizadas no país atingiu o patamar de $8,7 \%$, ocupando a quinta colocação dos energéticos mais demandados $[4,5]$. Porém, esta participação deverá aumentar nos próximos anos a partir do desenvolvimento das reservas do pré-sal, no qual o Brasil poderá passar de importador a exportador deste combustível.

No caso das fontes renováveis, o etanol vem apresentando crescimento significativo, não apenas devido ao aumento da frota de veículos flex, mas também em função do crescimento das exportações do etanol renovável. Segundo as projeções da UNICA - União das Indústrias de Cana de Açúcar a produção de etanol no Brasil deve atingir na safra de 2015/16 o patamar de 46,9 bilhões de litros, um valor $82,5 \%$ superior à produção da última safra (25,7 bilhões de litros). Por outro lado, o Brasil continua investindo no desenvolvimento da segunda geração deste combustível renovável, procurando um maior aproveitamento energético da cana de açúcar através da produção utilizando o bagaço e a palha da cana (etanol celulósico), o que pode aumentar em até $30 \%$ a oferta do insumo [4].

Diante do exposto nos parágrafos anteriores, é notório um crescimento significativo destes combustíveis no país, nos próximos anos. Por outro lado, sabe-se que o transporte no Brasil é predominantemente rodoviário. Estima-se que $60 \%$ da malha brasileira seja deste tipo. Segundo Fred Carvalho, diretor e editor da Autodata Editora, em palestra concedida no XIX Simpósio de Engenharia Automotiva, o Brasil ocupa a sexta posição no ranking mundial de produção de veículos e é o quinto maior mercado consumidor destes produtos. Críticas ao modelo rodoviário se deve principalmente aos elevados custos, 
se comparado com o ferroviário e hidroviário, devido à direta dependência com o preço dos combustíveis. Com o aumento na produção dessas fontes de energia, seu custo será reduzido e, por conseguinte, os referentes a este tipo de transporte também.

A relação de dependência do transporte rodoviário com os combustíveis se deve à utilização de um sistema capaz de transformar a energia térmica, proveniente da queima dos combustíveis, em energia mecânica. Tal equipamento é chamado de Motor de Combustão Interna $(M C I)$.

OS MCI são utilizados em uma grande variedade de aplicações, desde o setor agrícola, passando pelo industrial, até os setores de transporte e geração elétrica. A sua grande utilização deve-se ao fato de serem extremamente confiáveis, eficientes, bastante versáteis e, em sua maioria, de manutenção simples.

O estudo das inúmeras variáveis que influenciam o motor e de novas tecnologias tornam-se essenciais para empresas e países. Tendo em vista as estimativas de crescimento da produção do etanol e gás natural, estudos que buscam verificar a potencialidade de aproveitamento destas fontes de energia a fim de substituir, parcialmente ou totalmente, a utilização do óleo diesel em $M C I$ estão sendo realizados. Dentre os principais estudos nesta área, dois merecem destaque, $[4,6]$. Nestes trabalhos, foram analisadas, em um primeiro momento, as influências do etanol e gás natural em relação aos parâmetros característicos da combustão, desempenho e emissões. Em um segundo momento, operando o motor no modo bicombustível, foram avaliadas duas técnicas conhecidas em $M C I$ : o avanço da injeção no modo diesel (utilizado em motores do ciclo Diesel) e restrição parcial do ar de admissão (utilizado em motores do ciclo Otto), com objetivos de melhorar desempenho e reduzir emissões dos modos Diesel/etanol e Diesel/gás.

Com o objetivo de realizar estudos em $M C I$, sistemas robustos e confiáveis, capazes de propiciarem os mais variados tipos de testes se fazem necessários. Estes sistemas são conhecidos como Bancos de Prova ou Bancos de Ensaio.

\section{1}

\section{Justificativa}

Bancos de prova, além de realizarem testes tais como os de desempenho, amaciamento, durabilidade e emissões dos $M C I$, são essenciais na parametrização das unidades de controle eletrônicas. Estas são responsáveis, além de outros fatores, pelo controle do momento da injeção de combustível, da quantidade a ser inserida e da abertura e fechamento de válvulas. Fatores estes que 
estão diretamente ligados ao desempenho, eficiência e emissões.

A utilização dos bancos de prova não se limita somente a testar um MCI mas, em um primeiro momento, qualquer tipo de motor (mecânico ou elétrico) pode ser testado. Devido à esta grande flexibilidade, pesquisadores e empresas, focando no desenvolvimento de tecnologias híbridas e elétricas, principalmente para o setor automobilístico, estão necessitando cada vez mais da versatilidade destes equipamentos. Seus objetivos são os de desenvolver novos produtos que atendam as especificações e exigências, do que será o futuro da indústria automobilística.

Fabricantes desses equipamentos oferecem basicamente três modelos para o caso de testes em MCI: hidráulico, correntes de Foucault (ou de corrente parasitas) e elétrico (ou de indução). Os hidráulicos possuem um custo de aquisição inferior aos demais porém, além de apresentarem diversas limitações com relação a testes possíveis, requerem uma constante manutenção das instalações hidráulicas do equipamento. Apesar de possuírem custos de aquisição mais elevados que os hidráulicos os de correntes de Foucault e de indução são os mais utilizados atualmente. Os de corrente de Foucault são mais baratos em comparação aos de indução e mais simples de serem operados. Porém, ensaios onde haja a necessidade de transições rápidas entre um ponto de operação e outro ou que tenham a necessidade de motorizar o MCI em teste (testes transientes), estes equipamentos não são capazes de realizá-los. Por fim, os de indução são os de maior tecnologia, capazes de executar praticamente todos os ensaios demandados, porém altos custos estão envolvidos.

A principal diferença entre os bancos de prova equipados com dinamômetros do tipo corrente de Foucault e de indução, com relação ao acionamento, é pelo fato dos de corrente de Foucault serem considerados passivos, ou seja, não conseguem movimentar cargas acopladas em seu eixo (executam somente operações de frenagem), além de necessitarem de motores de partida para o acionamento dos MCIs. Os de indução são considerados ativos pois além de conseguirem trabalhar como geradores, ou seja, capazes de impor diferentes cargas no MCI em teste, também trabalham como motores, acionando cargas em sua extremidade onde, dentre outras funções, conseguem simular situações reais de uso do $M C I$ e são capazes de partir o motor não havendo a necessidade de um motor de partida.

$\mathrm{Na}$ indústria e nos centros de pesquisas brasileiros estes equipamentos são predominantemente estrangeiros. As líderes neste setor concentram-se, basicamente, na Europa e nos Estados Unidos. Pelo fato dos bancos de prova serem constituídos por diversos equipamentos que requerem alto investimento, muitas vezes torna-se inviável sua aquisição junto aos fabricantes. Consequen- 
temente, o desenvolvimento de pesquisas, principalmente no setor acadêmico e nas pequenas e médias empresas, ficam prejudicados. Por outro lado, na literatura são raras as informações disponíveis sobre projetos integrais visando à construção de bancos de prova, para ensaios confiáveis de motores, seguindo recomendações das normas nacionais e internacionais. Dentre os escassos trabalhos, destaca-se o de [7]. Neste trabalho, valiosas informações sobre bancos de prova são fornecidas.

Neste caminho, o presente projeto pretende preencher não somente a lacuna no setor acadêmico, como por exemplo a relacionada à pouca infraestrutura existente neste setor, mas também as necessidades do setor industrial, com a inserção de um novo produto no mercado nacional. Para tanto, grande parte dos equipamentos são provenientes de indústrias brasileiras. O primeiro motivo é o de reduzir custos. Esta redução, em um primeiro momento, é imediata devido a não necessidade de importação, que nos dias de hoje é um dos fatores que encarecem o preço final destes equipamentos. Em um segundo momento, com o crescente número de pesquisas na área de motores, uma maior demanda por estes produtos irá ocorrer e, consequentemente, uma diminuição dos preços. O segundo motivo, mas não menos importante, é o de incentivar o crescimento da tecnologia nacional, nas diferentes áreas que envolvem o desenvolvimento de um banco de provas.

\section{2}

\section{Objetivos}

Esta seção é constituída por dois tópicos: Objetivo Geral e Objetivos Específicos.

\subsection{1}

Objetivo Geral

O objetivo geral do trabalho proposto é o de desenvolver um sistema de controle para bancos de prova de $M C I$, que seja robusto e confiável, a fim de realizar testes característicos, de maneira rápida e eficiente.

\subsection{2}

\section{Objetivos Específicos}

Os principais objetivos deste trabalho são:

- construção de uma bancada experimental para realização de testes em $M C I$;

- obtenção de uma metodologia para um projeto integral visando a construção do banco de provas; 
- instrumentação de todo o sistema;

- desenvolvimento do sistema de aquisição dos sinais provenientes dos transdutores;

- desenvolvimento de uma interface gráfica para o operador;

- implementação experimental e posterior validação do banco de provas transiente, equipado com um dinamômetro de corrente alternada acionado por inversor de frequência, e do sistema de controle proposto.

\section{3}

\section{Descrição da Dissertação}

O presente trabalho é composto por sete capítulos. O primeiro capítulo refere-se à introdução e à apresentação dos objetivos da dissertação.

A seguir, no capítulo dois, é apresentado o embasamento teórico necessário para a realização do presente projeto. Para tanto, será dada uma breve introdução sobre os tipos de dinamômetros utilizados em testes de motores, com ênfase no tipo utilizado neste trabalho. Após isto, uma breve introdução sobre os motores a combustão, seus tipos e principais características serão fornecidos. O seguinte tópico irá abordar o tema sobre os principais tipos de testes realizados. Em seguida, uma breve introdução sobre a teoria de controle de sistemas e os softwares utilizados serão fornecidos. Por fim, trabalhos propostos por diferentes pesquisadores serão analisados.

O aparato experimental será abordado no capítulo três. Nesta etapa serão descritas as metodologias utilizadas para a seleção do MCI, do dinamômetro, do acoplamento entre ambos, do desenvolvimento da base de testes e seleção dos isoladores de vibração, da escolha e desenvolvimento do atuador da bomba de combustível, da instrumentação, seleção do inversor de frequência e, por fim, do isolamento elétrico do sistema.

No capítulo quatro são descritos o sistema de aquisição e controle, através de seus parâmetros principais tais como a escolha dos tempos e frequência de aquisição e tipos e quantidades de transdutores, e o desenvolvimento do programa de monitoramento e controle. No desenvolvimento do programa, as funções criadas, os modos de operação e suas características são abordadas detalhadamente. Por fim serão fornecidas informações sobre o pós-processamento dos dados aquisitados.

O procedimento e a metodologia utilizada na realização dos ensaios é apresentada no capítulo cinco. Esta etapa foi dividida em três pontos: capacidade de seguimento de trajetória, tempo de resposta e limitações da 
bancada de testes. Neste capítulo também é detalhado o equacionamento empregado para a redução de dados.

A apresentação dos resultados experimentais seguindo a metodologia apresentada no capítulo anterior constituem o sexto capítulo. Também neste capítulo são feitas análises detalhadas dos resultados apresentados de modo a esclarecer os pontos relevantes de cada teste.

A dissertação é concluída com o capítulo sete onde são apresentadas ainda as sugestões para trabalhos futuros. A análise das incertezas experimentais e planilhas são mostradas nos Anexos A e C, respectivamente. No Anexo B estão descritos os passos iniciais do desenvolvimento de uma metodologia para a modelagem bem como o desenvolvimento posterior de um sistema de controle para bancos de prova. 


\section{2 \\ Fundamentação Teórica}

Este capítulo tem por objetivo descrever os aspectos teóricos que formam a base do sistema dinamômetro-motor e suas fontes bibliográficas.

Portanto, a primeira parte deste capítulo se concentra em analisar os aspectos mais importantes para um correto entendimento do projeto de pesquisa desenvolvido. Para tanto, serão descritos os tipos mais comuns de dinamômetros utilizados em bancos de prova, fornecendo maiores detalhes para o caso utilizado no presente trabalho. Além disso, serão apresentados os modos de controle possíveis para o sistema e alguns tipos de ensaios realizados seguindo normas estipuladas pelos órgãos responsáveis.

A segunda parte apresentará os estudos teóricos e experimentais que produziram resultados relevantes à respeito do tema proposto. Diferentes abordagens serão apresentadas com o objetivo de demonstrar a não unicidade da metodologia para o desenvolvimento do sistema, cabendo ao pesquisador optar por aquela que mais lhe convém respaldado em conhecimentos prévios, objetivo do projeto e disponibilidade de recursos.

\section{1 \\ Conceitos Teóricos}

\subsection{1}

\section{Dinamômetros}

Dinamômetro é o equipamento capaz de medir o torque produzido pelo motor em teste em todas as suas condições de operação. Ele atua como uma espécie de freio impondo diferentes valores de carga. A sua correta seleção é de fundamental importância em um banco de provas pois ele será o responsável por realizar os mais variados testes que um MCI estará sujeito. Além disto, sua escolha deve ser realizada não somente de modo a abranger a maior gama possível de motores mas também deve-se levar em conta a sua influência direta na medição de diversas grandezas, dentre elas o torque, e na forma de controle do banco.

Segundo [7], estes equipamentos podem ser separados em quadrantes, de acordo com o modo de operação, conforme a Figura 2.1. Basicamente, os dinamômetros que operam no primeiro ou segundo quadrante, são os chamados dinamômetros passivos ou freio. Em contra-partida, os que operam nos quatro quadrantes são chamados de dinamômetros ativos. Estes últimos podem funcionar tanto como geradores, quanto como motores. Suas vantagens 
são, além de serem capazes de realizarem testes dinâmicos, podem partir o MCI, sem haver a necessidade de acoplar um motor de partida no mesmo.

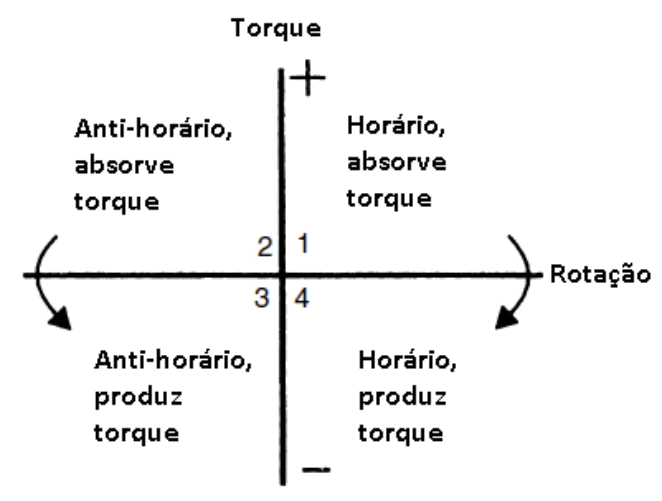

Figura 2.1: Quadrantes de operação dos dinamômetros

A Tabela 2.1 mostra em quais quadrantes os principais tipos de dinamômetros, que serão descritos na próxima seção, podem operar.

Tabela 2.1: Quadrantes de operação

\begin{tabular}{|cc|}
\hline Tipo de Dinamômetro & Quadrante \\
\hline Hidráulico & 1 \\
Corrente Parasita & 1 e 2 \\
Elétrico C.C. & $1,2,3,4$ \\
Elétrico A.C. & $1,2,3,4$ \\
\hline
\end{tabular}

Os principais tipos de dinamômetros utilizados com o propósito de testar MCI são:

- Hidráulico;

- Correntes Parasitas;

- Motores Elétricos

Corrente Contínua (CC);

Corrente Alternada (CA). 


\subsubsection{1}

\section{Dinamômetros Hidráulicos}

Segundo [8], dinamômetros hidráulicos são dispositivos capazes de absorver e medir a potência produzida por uma fonte motora capaz de acioná-los. Para serem capazes de produzirem torque, é necessário que haja fluxo de algum fluido em seu interior (geralmente utiliza-se água). O princípio de funcionamento, segundo [7], ocorre da seguinte maneira: o eixo motriz possui um rotor que é envolto, com uma pequena folga, pelo estator. Ambos possuem aletas com recessos formando uma espécie de toróide (Figura 2.2).

Conforme o rotor gira, forças centrífugas provocam uma circulação toroidal do fluido (Figura 2.2(d)), indicada pelas setas na Figura 2.2(a). O efeito desta circulação é a transferência de momento do rotor para o estator e, consequentemente, a produção de um torque resistivo no eixo. Um vortex toroidal é formado, como consequência deste movimento, produzindo grandes turbulências no escoamento do fluido, no interior do dinamômetro. Outra consequência deste movimento é a dissipação de potência na forma de calor no fluido.

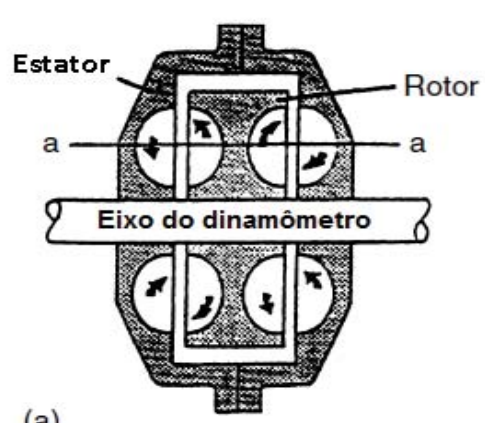

(a)

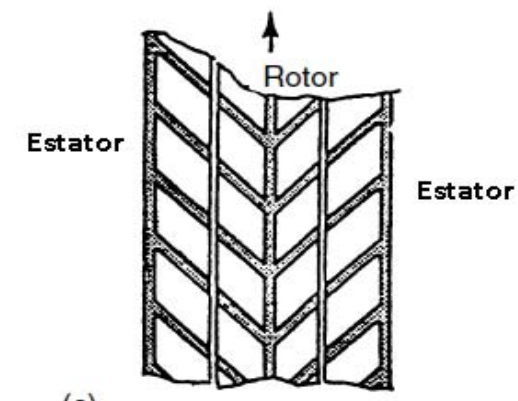

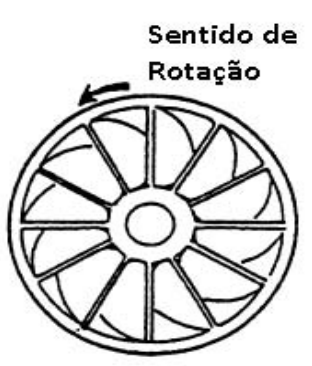

(b)

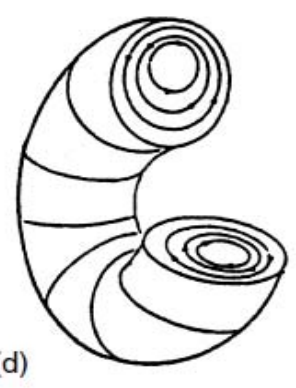

Figura 2.2: Princípio de operação - Dinamômetro Hidráulico: (a) seção vertical; (b) vista frontal; (c) seção a-a do rotor e estator; (d) representação do vortex toroidal.

Estes tipos de dinamômetros, geralmente, são bastante difíceis de serem controlados, possuem um sistema de medição pouco preciso ao longo de uma 
grande faixa de operação, além de não serem capazes de motorizar o MCI. Seu uso está sendo diminuído devido a maior versatilidade dos elétricos.

\subsubsection{2}

\section{Dinamômetros de Corrente Parasita}

Também conhecidos por Corrente de Foucault ou, do inglês, EddyCurrent, esses dinamômetros são bastante utilizados em bancos de prova.

Essas máquinas fazem o uso do princípio de indução eletromagnética para assim, serem capazes de produzir torque e dissipar energia. Esses dinamômetros são compostos por um rotor metálico condutor, geralmente dentado, muito próximo a placas refrigeradas por um fluido (geralmente água) funcionando como um trocador de calor. Um campo magnético, paralelo ao eixo do dinamômetro, é gerado por duas bobinas e, a partir do movimento do eixo, variações do fluxo magnético das placas que constituem o trocador de calor ocorrem. Consequentemente, correntes (parasitas) passam a percorrer as placas e, a energia proveniente das primeiras, é dissipada na forma de perdas elétricas (resistivas). Esta energia dissipada é transferida, em forma de calor, para o fluido do sistema de arrefecimento.

O torque, e por consequência, a potência, são controlados através da variação de corrente fornecida às bobinas. Com isso, este tipo de dinamômetro, é capaz de gerar rápidas mudanças nos valores de torque. Esses equipamentos são bastante robustos e simples de serem controlados. Além disso possuem baixa inércia e são capazes de gerar altos valores de torque e velocidade.

\subsubsection{3}

\section{Dinamômetro de Corrente Contínua}

Este tipo de dinamômetro nada mais é do que um motor elétrico de corrente contínua, muito utilizado em diversas aplicações. Ele é composto basicamente pelo estator (imã permanente) e pelo rotor (enrolamento de armadura).

Segundo [9], o estator é composto de uma estrutura ferromagnética com pólos salientes aos quais são enroladas as bobinas que formam o campo, ou de um ímã permanente. Já o rotor é um eletroímã constituído de um núcleo de ferro com enrolamentos em sua superfície que são alimentados por um sistema mecânico de comutação. Esse sistema é formado por um comutador, solidário ao eixo do rotor, que possui uma superfície cilíndrica com diversas lâminas às quais são conectados os enrolamentos do rotor e por escovas fixas, que exercem pressão sobre o comutador e que são ligadas aos terminais de alimentação. O 
propósito do comutador é o de inverter a corrente na fase de rotação apropriada de forma a que o conjugado desenvolvido seja sempre na mesma direção.

O controle destes tipos de motores é bastante flexível e preciso. É realizado por fontes de corrente contínua ou por um dispositivo conversor CACC e funcionam com velocidades ajustáveis entre amplos limites.

As principais vantagens destes tipos de motores são o modo de operação nos quatro quadrantes (vide Tabela 2.1), facilidade no controle da velocidade e simplicidade dos conversores CA-CC. As desvantagens são seu tamanho elevado e altos custos, se comparados com motores de indução de mesma potência, maior necessidade de manutenção (principalmente devido aos comutadores) e potenciais problemas com arcos e faíscas devido a comutação ser realizada por componente mecânico.

\subsubsection{4}

\section{Dinamômetro de Corrente Alternada}

Dentre os diferentes tipos de motores CA, o principal, que é utilizado no presente trabalho, é o motor de indução trifásico ou "gaiola de esquilo". Atualmente são os mais utilizados para esse tipo de aplicação, pois além da vantagem da rede elétrica ser $\mathrm{CA}$, com o advento dos inversores de frequência tornou-se possível o controle de velocidade e, em alguns casos, o controle de torque.

O motor de indução trifásico é composto, assim como o motor CC, fundamentalmente por duas partes, o estator e o rotor. Na Figura 2.3 é mostrado uma vista em corte de um motor assíncrono de indução, semelhante ao utilizado no presente trabalho.

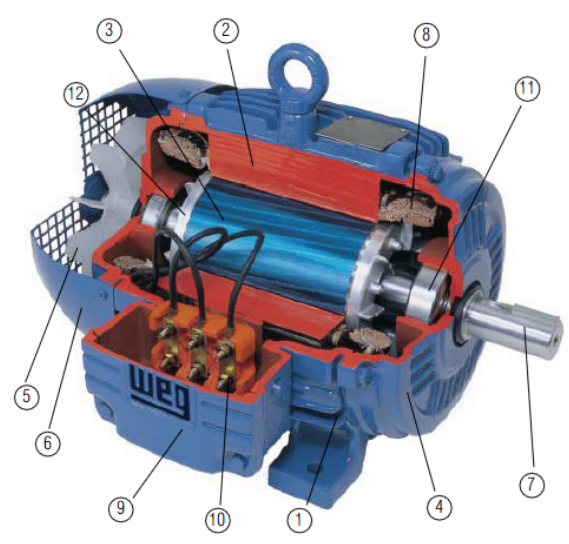

Figura 2.3: Vista em corte motor de indução: 1-Carcaça, 2-Núcleo de Chapas do Estator, 3-Núcleo de Chapas do Rotor, 4-Tampa, 5-Ventilador, 6-Tampa Defletora, 7-Eixo, 8-Enrolamento Trifásico, 9-Caixa de Ligação, 10-Terminais, 11-Rolamentos, 12-Barras e Anéis de Curto-Circuito. (Fonte: WEG) 
O funcionamento desses equipamentos é baseado no princípio do campo girante [10], ou seja, quando uma bobina é percorrida por uma corrente elétrica, é criado um campo magnético dirigido conforme o eixo da bobina e de valor proporcional à corrente. Assim, quando um enrolamento trifásico é alimentado por correntes trifásicas, cria-se um "campo girante", como se houvesse um único par de pólos girantes, de intensidade constante. Este campo girante, criado pelo enrolamento do estator, induz tensões no rotor, as quais geram correntes e, consequentemente, um campo de polaridade oposta. Como o campo do estator está girando, o rotor tende a acompanhá-lo, gerando assim o movimento de rotação do mesmo. Maiores informações sobre o entendimento deste princípio podem ser encontradas em [11].

Os motores de indução são caracterizados pelo número de pólos (norte e sul). Eles são originados a partir das bobinas que constituem um motor, que quando são submetidas a uma corrente elétrica, produzem um campo magnético composto pelo pólo norte e pólo sul. Como o campo girante percorre um par de pólos a cada ciclo, com uma frequência especificada pela rede elétrica (50 ou $60 \mathrm{~Hz}$, no Brasil), a velocidade deste, conhecida como velocidade síncrona " $n_{s}$ " é dada por:

$$
n_{s}=\frac{120 f}{2 p}
$$

onde $n_{s}$ é dada em rpm, $f$ é a frequência da rede elétrica e $2 p$ é o número de pólos. Outro termo bastante utilizado é a velocidade nominal " $n$ ", que é dada por:

$$
n=n_{s}(1-s)
$$

onde, $n$ é dada em rpm e $s$ é o termo referente ao escorregamento, que é a diferença entre a velocidade do motor e velocidade síncrona.

A partir da Equação 2-1, pode-se chegar aos valores das velocidades síncronas dos motores de indução mais comuns. Estes são mostrados na Tabela 2.2 .

Tabela 2.2: Velocidade síncrona de acordo com o número de pólos

\begin{tabular}{|c|cc|}
\hline \multirow{2}{*}{ Número de Pólos } & \multicolumn{2}{|c|}{ Rotação Síncrona por Minuto } \\
\cline { 2 - 3 } & $60 \mathrm{~Hz}$ & $50 \mathrm{~Hz}$ \\
\hline 2 & 3600 & 3000 \\
4 & 1800 & 1500 \\
6 & 1200 & 1000 \\
8 & 900 & 750 \\
10 & 720 & 600 \\
\hline
\end{tabular}

A grande preferência pela utilização dos motores assíncronos de indução, 
não só para ensaios de motores, mas para as diferentes demandas do setor industrial, se deve ao advento dos inversores de frequência. Com eles, tornouse possível controlar, com bastante precisão, a velocidade dos mesmos. Pelas Equações 2-1 e 2-2, as únicas formas de regular a rotação, sem a utilização de componentes externos, tais como variadores mecânicos, hidráulicos dentre outros, é atuando nos parâmetros $2 p, s$ ou $f$. A alteração, tanto do número de pólos, quanto do escorregamento, são bastante complicadas do ponto de vista físico, pois requerem alteração do projeto dos motores, aumento de carcaça, além de serem bastante limitadas [10]. Porém, a variação por meio da frequência tornou-se viável com a avanço da tecnologia e a consequente redução dos custos de tais equipamentos.

O inversor de frequência transforma a tensão da rede elétrica, de amplitude e frequência fixas, em uma tensão de amplitude e frequência variáveis. Com isso varia-se a velocidade do campo girante que por conseguinte varia a velocidade mecânica de rotação da máquina. possibilitando a obtenção de diversas velocidades. Além de ser possível o ajuste da rotação dos motores assíncronos de indução, é também possível o ajuste do torque.

Segundo [10], o torque desenvolvido por uma máquina assíncrona de indução é dado por:

$$
T=k_{1} \phi_{m} I_{2}
$$

e seu fluxo magnetizante, desprezando-se as quedas de tensão dos enrolamentos estatóricos, é dado por:

$$
\phi_{m}=k_{2} \frac{V_{1}}{f_{1}}
$$

onde: $T$ é o torque disponível na ponta do eixo $(\mathrm{Nm}), \phi_{m}$ é o fluxo magnetizante $(\mathrm{Wb}), I_{2}$ é a corrente rotórica (A), que depende da carga, $V_{1}$ é a tensão estatórica $(\mathrm{V}), f_{1}$ é a frequência do motor elétrico, $k_{1}$ e $k_{2}$ são constantes que dependem do material e do projeto da máquina.

A fim de manter o torque constante para diferentes velocidades, para uma determinada carga, a razão $V_{1} / f_{1}$ deve ser mantida constante, mantendo-se constante o fluxo magnetizante. Esta variação é mantida linear até a frequência nominal do motor, quando sua tensão atinge o máximo. Após este valor, $V_{1}$ se mantém constante, porém a frequência ainda pode ser variada. A análise para a potência é análoga.

Análise semelhante pode ser realizada para o valor do torque: até a frequência nominal do motor, como $\phi_{m}$ se mantém constante, o conjugado também permanece o mesmo. Após este valor, o fluxo começa a diminuir pois $V_{1}$ permanece constante e $f_{1}$ aumenta. Esta região, delimitada pela redução 
do valor do torque é denominada de região de enfraquecimento de campo.

$\mathrm{Na}$ Figura 2.4, são apresentadas as curvas referentes à Tensão $\times$ Frequência, Potência $\times$ Frequência e Torque $\times$ Frequência, típicas de um motor de indução acionado por inversor de frequência.

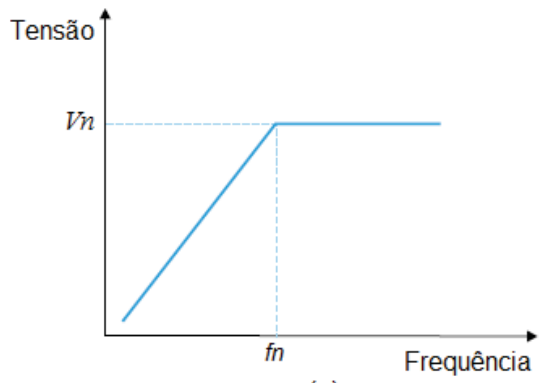

(a)

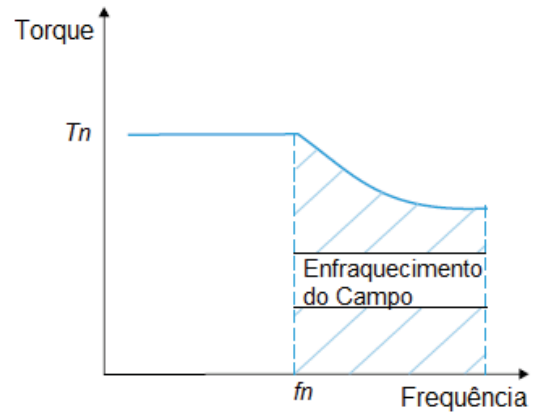

(c)

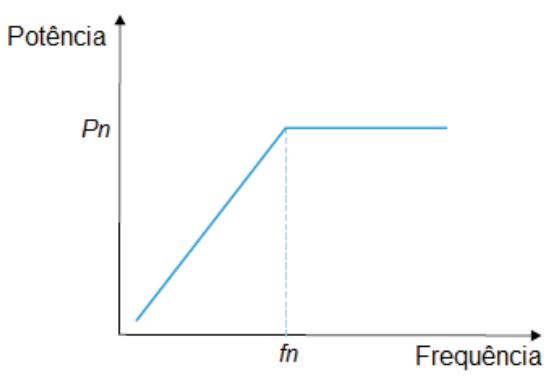

(b)

Figura 2.4: (a) - Tensão $\times$ Frequência; (b) - Potência $\times$ Frequência; (c) Torque $\times$ Frequência. (Fonte: WEG)

Pelo fato desses motores serem aptos a operar nos quatro quadrantes (vide 2.1), são os mais indicados para bancos de prova pois, além de permitirem ensaios estacionários, podem realizar transientes com bastante confiabilidade. Além disso, se comparados com os dinamômetros CC, estes possuem uma inércia rotacional menor, o que favorece melhor desempenho em todos os tipos de testes, principalmente nos dinâmicos e requerem uma menor manutenção.

\subsection{2}

Modos de Controle do Sistema Dinamômetro-Motor

Os testes realizados no sistema dinamômetro-motor são, primeiramente, uma sequência de valores desejados de torque e rotação para MCI. Estas sequências são alcançadas manipulando somente dois controles: rotação do MCI ("acelerador") e torque do dinamômetro.

Para qualquer posição do acelerador, o MCI tem sua curva "torquerotação" característica, assim como qualquer dinamômetro possui a sua própria 
curva. A interação entre essas duas curvas determina se o conjunto será estável para um determinado ensaio.

A nomenclatura adotada para referenciar os modos de controle, neste trabalho, segue a norma alemã. Na Tabela 2.3 são mostradas as duas principais formas utilizadas e suas características, de acordo com [7].

Tabela 2.3: Nomenclatura dos Modos de Controle

\begin{tabular}{|cc|}
\hline Inglês & Alemão \\
\hline Speed (Rotação) & $\mathrm{n}$ \\
Position (Posição) & Alpha $(\alpha)$ \\
Torque & Torque \\
\hline
\end{tabular}

O controle do MCI pode ser manipulado em três diferentes modos:

- posição do acelerador constante (modo posição);

- rotação constante (modo velocidade);

- torque constante (modo torque).

Em contrapartida, o controle do dinamômetro pode ser feito de quatro maneiras diferentes:

- ajuste de controle constante (modo posição);

- rotação constante (modo velocidade);

- torque constante (modo torque);

- reproduzir uma curva característica de torque x rotação (modo de potência).

Diferentes combinações desses modos são possíveis. A nomenclatura alemã diz que estas combinações são descritas em termos de modo $D i$ namômetro/modo MCI. Já a norma inglesa utiliza o oposto.

Portanto, os modos de controle utilizados nos bancos de prova podem ser os seguintes: posição/posição, rotação/posição, torque/posição, potência/posição, torque/rotação e rotação/torque. 


\subsubsection{1}

\section{Posição/Posição}

Neste modo, a posição do acelerador $(\alpha)$ e o ajuste do dinamômetro (curva Torque $\times$ Rotação) são mantidos fixos. Segundo [7], este é o modo de operação clássica de um banco de testes equipados com dinamômetros hidráulicos. Por ele trabalhar em malha aberta, não existe nenhuma informação de como o conjunto está respondendo e, por isso, nem sempre o sistema atinge um ponto de operação estável. Alguns tipos de dinamômetros hidráulicos podem apresentar comportamentos instáveis em baixas cargas.

Este modo é bastante utilizado a fim de verificar os pontos de operação em que o sistema pode trabalhar independente da influência do sistema de controle adotado.

\subsubsection{2}

\section{Potência/Posição}

De acordo com [7], este modo é uma variação do anterior onde o ajuste do dinamômetro é manipulado a fim de fornecer uma curva de Torque $\times$ Rotação característica, da forma: Torque $=\operatorname{cte} \times \operatorname{rotaça\tilde {a}o^{n}}$, onde $n \geq 1$.

\subsubsection{3}

\section{Rotação/Posição}

Neste modo, o dinamômetro, a partir de um sistema de controle, mantém a rotação do conjunto constante, independente da posição de $\alpha$. É geralmente utilizado com o propósito de levantar curvas de Torque $\times$ Rotação de MCI à plena carga $(\alpha=100 \%)$ e à cargas parciais.

\subsubsection{4}

\section{Torque/Posição}

Este modo é análogo ao anterior porém o controle é realizado sobre o torque do dinamômetro para diferentes posições de $\alpha$. Deve-se ter bastante cuidado com este modo para não impor um valor de torque maior do que o MCI pode gerar, a fim de evitar a parada repentina do sistema, podendo causar danos aos equipamentos.

\subsubsection{5}

\section{Torque/Rotação}

Neste caso, uma parte do controle do sistema é encarregado de fixar o valor do torque, pelo dinamômetro, enquanto que a outra é encarregada de controlar a rotação do MCI, atuando no $\alpha$. 
Um exemplo de utilização é no amaciamento de MCI quando não se recomenda a imposição de elevadas cargas. Conforme o atrito das partes móveis vão diminuindo, maior potência é transmitida ao sistema que, pelo fato do torque estar constante devido ao controle sobre o dinamômetro, a rotação do conjunto tende a aumentar. Neste momento, o controle de rotação atua na posição de $\alpha$ fazendo com que ocorra uma redução da mesma, a fim de manter os valores de torque e rotação dentro dos estipulados previamente.

\subsubsection{6}

\section{Rotação/Torque}

Este modo pode ser associado com um veículo em um aclive. O dinamômetro controla a rotação do sistema, a fim de mantê-la constante, enquanto o controle sobre o motor atua em $\alpha$, com o objetivo de ajustar o valor do torque produzido.

Precauções devem ser tomadas para os modos em que o dinamômetro (somente aqueles que operam nos quatro quadrantes) controla a rotação do sistema. Nestes casos, o controle será realizado mesmo que o MCI esteja sendo motorizado. Isto pode ser ocasionado ou por problemas no MCI, como por exemplo falha de ignição, ou por operação em um ponto instável.

\subsection{3}

\section{Tipos de Testes}

Segundo [12], alguns dos principais testes realizados em bancos de prova, em MCI's são:

- testes de emissões;

- teste de consumo de combustíveis;

- teste de amaciamento de motores;

- teste de desempenho de lubrificantes.

\section{2}

\section{Estado da Arte}

O trabalho mais extenso e completo sobre a concepção de um banco de provas é encontrado em [7]. Inicialmente os autores fornecem uma ideia geral sobre o tema abordando tópicos tais como a especificação do, e sobre, o local onde será alocada o conjunto dinamômetro-motor, visão macro sobre a integração do sistema e organização geral do projeto. É realizada também, 
uma análise termodinâmica detalhada sobre a sala de testes, levando em consideração variáveis tais como a energia elétrica fornecida para o conjunto, balanço de energia no motor considerando os parâmetros mais relevantes, perdas pelo teto e paredes da sala de testes, dentre diversos outros fatores. Como exemplo, foi utilizado, para efeito de cálculo, um banco de provas com um motor de $100 \mathrm{~kW}$ e chegou-se a conclusão que a energia consumida no ensaio e a dissipada para o ambiente é aproximadamente $300 \mathrm{~kW}$. Ou seja, o gasto de energia em um ensaio é o triplo do que é produzido pelo motor. Segundo os autores, caso o conjunto esteja equipado com um dinamômetro AC regenerativo, aproximadamente um terço da energia produzida pelo combustível será convertida em energia elétrica, implicando assim em uma redução de consumo da mesma.

Também, estudos sobre vibração e ruídos são abordados. A principal fonte de vibração, o motor, é abordada com detalhes. Cálculos são feitos a fim de demonstrar sua influência, tanto no sistema propriamente dito, quanto nas redondezas da sala de testes. Tipos de bases para suportar o conjunto dinamômetro-motor também são abordadas, atentando para isoladores de vibração, no caso de bases móveis, ou para a fundação no caso de bases fixas. Com relação aos ruídos, normas e limites permissíveis são abordados, as principais fontes de ruído são apontadas, assim como soluções para sua minimização e construção de sala de testes anecóicas (salas projetadas para conter reflexões, tanto de ondas sonoras quanto eletromagnéticas).

Informações sobre potenciais fontes de perigo e equipamentos necessários para segurança são fornecidos. Estrutura e disposição dos equipamentos, tanto da sala de controle, quanto da sala de testes são focados com o objetivo de minimizar eventuais problemas. Análise sobre ventilação e armazenamento de óleo e combustível são referenciados. Questões relacionadas as diferentes medições realizadas em bancos de prova são abordados, apontando vantagens e desvantagens. Referências são feitas ao problema do acoplamento dinamômetro-motor, aos tipos de controle e dinamômetros utilizados. Além disso, tipos de testes realizados, estacionários e transientes, de acordo com normas, são brevemente descritos. Neste trabalho são descritos ainda métodos para a análise de perdas mecânicas do conjunto.

Por fim, este trabalho aborda temas relacionados à aquisição de dados, tal como a precisão necessária para não comprometer a medição e ainda fornece uma breve introdução sobre simulações Hardware in the Loop (HIL) e protocolos de comunicação de veículos e unidades de controle eletrônicas (ECU).

O trabalho apresentado em [13] apesar de antigo, ainda é considerado 
uma excelente referência na área de modelagem e controle de sistemas dinamômetro-motor. Neste trabalho, o foco foi na atualização do hardware e software necessários para realizar operações mais complexas, dentre elas testes transientes. A bancada é composta por um dinamômetro de correntes parasitas e o controle do MCI é realizado através do comando enviado a um motor de passo. Três microprocessadores compõem o sistema, um mestre e dois escravos. O primeiro, o mestre, é responsável pelo sequenciamento dos testes e aquisição de dados. Um segundo é usado para efetuar o controle, em malha aberta, do motor de passo que atua no MCI. Por fim, o terceiro é responsável pelo controle do dinamômetro, através de uma eletrônica semelhante a de sistemas de tensão DC chopperizados, onde o duty cycle de um sinal em tensão corresponde a uma corrente RMS (Root Mean Square) - valor eficaz - desejada. O objetivo maior desta eletrônica é alcançar respostas rápidas do sistema.

Cinco modos de teste são possíveis:

- teste estacionário: Pontos de torque e rotação fixos e a aquisição realizada;

- teste transiente com seguimento de trajetória: trajetória previamente definida e utilização de métodos de predição para otimizar o controle de torque (offline);

- teste transiente sem seguimento de trajetória: não utiliza métodos de predição para otimizar o controlador;

- lei potência-rotação: torque é função da rotação utilizando um polinômio do terceiro grau;

- controle de rotação pelo torque: o acelerador percorre uma trajetória especificada previamente, enquanto o controle de torque ajusta seu valor a fim de obter uma rotação desejada.

O modelo matemático representativo do dinamômetro foi aproximado por uma equação diferencial de segunda ordem, com a variável sendo o fluxo magnético. O governador do MCI, atuado pelo motor de passo, possui sua aceleração e desaceleração controlada via software, através do modelamento por uma equação diferencial de primeira ordem. As trajetórias a serem seguidas, são definidas matematicamente através de uma equação diferencial de segunda ordem e ajustada pela técnica dos mínimos quadrados para satisfazer condições desejadas.

Os controladores adotados para o torque e acelerador são baseados na teoria de controle ótimo. Além disso, para o controle do último, um PID (Proporcional-Integral-Derivativo) adaptativo é utilizado. O ajuste dos 
ganhos é realizado com o objetivo de minimizar os erros de rotação em testes transientes, em diferentes condições de operação.

O controlador ótimo necessita de um mapa estacionário do fluxo magnético do dinamômetro como entrada. Este mapa é obtido como um vetor de três dimensões: rotação, torque e excitação do sistema (proporcional ao fluxo magnético do dinamômetro). Ele é utilizado pelo controlador a partir de uma interpolação linear.

Os testes foram realizados em dois tipos de MCI (Diesel, 4 cilindros, aspirado e 6 cilindros turbo), em duas bancadas equipadas com diferentes dinamômetros, a fim de validar, primeiramente, o desempenho do controle proposto e, posteriormente, a flexibilidade do sistema para diferentes bancos de prova. No primeiro teste realizado, aplicaram-se degraus, inicialmente mantendo fixo a rotação e depois variando-a. No caso do primeiro MCI, o controle de torque gerou respostas satisfatórias, apesar de pequenas oscilações, provocadas, segundo o autor, pelo controle do acelerador, que foi do tipo integral. Quando utilizou-se um controle do tipo PD, a oscilação foi reduzida. No caso do motor 6 cilindros turbo, a resposta para o controle de torque foi bastante oscilatória, devido à flutuações da rotação, onde utilizou-se um controle PID. Neste caso, esta oscilação deve-se principalmente ao incremento (pertubação), no controle de rotação, da influência do turbo sobre a rotação do MCI. Em um segundo momento, valores de torque e rotação eram modificados simultaneamente, através de degraus, com taxas mais elevadas. Nesta situação, o controle de torque não se mostrou satisfatório como nos casos anteriores. No caso dos testes transientes, apesar de não ser possível a reprodução completa dos mesmos devido a não capacidade do dinamômetro motorizar o MCI, o controle de rotação obteve uma resposta mais satisfatória que o de torque, para o primeiro motor, devido às vibrações excessivas no conjunto, causadas pela instalação rígida do motor e a má qualidade do balanceamento do mesmo, gerando assim ruídos na leitura de torque. No caso do segundo MCI, respostas melhores do controle de torque foram conseguidas devido à menor vibração desta bancada de teste. Porém erros ocorreram no controle de rotação devido à influência do turbo.

O trabalho realizado por [14] utiliza um software gráfico para simulação de sistemas dinâmicos. Neste software, Matlab/Simulink, um modelo não linear, previamente validado, para a predição do torque produzido pelo MCI foi implementado. Este modelo, que utiliza métodos de controle baseados em modelos físicos (model-based), é importante principalmente sobre o aspecto de entender os fenômenos que ocorrem no funcionamento de um MCI a fim de atender as regulamentações das leis de emissões de poluentes. Este modelo 
simula um motor do ciclo Otto com injeção no pórtico de admissão e inclui as dinâmicas do ar, combustível e EGR no coletor. Além disso, inclui os atrasos do sistema inerentes a um motor quatro tempos do ciclo Otto. Na implementação dos sistemas de controle e do MCI foram utilizadas técnicas de programação modulares com a criação de diversos subsistemas de modo a reduzir a complexidade dos sistemas. Apesar do modelo proposto ter sido validado, segundo o autor, para um MCI específico, o modelo é genérico o suficiente para ser utilizado em uma grande variedade de motores de ignição por centelha.

Segundo o autor, o modelo pode ser utilizado em cinco formas distintas: como um modelo de motor testar algoritmos de controle; como um modelo em tempo real para testes HIL; como um modelo embarcado de um algoritmo de controle ou observador; como um sistema de avaliação de modelos de sensores e atuadores e como um subsistema em um modelo de powertrain ou na dinâmica de um veículo.

As simulações realizadas ilustram a utilidade destes modelos em predizer diversas variáveis importantes para o funcionamento do MCI. Nas simulações foi utilizado um perfil do tipo degrau para o comportamento da atuador da borboleta. A partir deste perfil diversos parâmetros foram analisados. Primeiramente, uma relação entre a posição da borboleta e o fluxo de ar que passa por ela foi analisado. Em seguida, compararam-se os valores do fluxo de ar e do fluxo de combustível. É observado um atraso na atuação da abertura da borboleta, atuada mecanicamente, em relação à injeção de combustível. É analisado também o cálculo da relação ar-combustível e pressões de admissão e exaustão. O torque produzido pelo MCI também é analisado e observa-se que no instante em que o acelerador é acionado ocorre uma falha na combustão (misfire) indicando assim que o torque, momentaneamente iguala a zero. Com o aumento da velocidade de rotação o torque aumenta até um valor onde a força produzida pela combustão iguala a força de atrito das partes móveis, fazendo com que a rotação do motor pare de aumentar.

Outras análises tais como a influência do tempo e do momento de injeção, com relação à abertura e fechamento das válvulas, no processo de combustão e consequente produção de torque são analisadas. Por fim, os tempos que o software leva para realizar os cálculos de todos os parâmetros do modelo são fornecidos. No melhor caso obtido pelo autor, uma simulação de 3 segundos reais levou 40 segundos para o sistema realizar os cálculos do modelo. Porém, utilizando técnicas de integração tais como o método de Runge-Kutta ou o método de Euler, o tempo para a simulação foi reduzido a 9 segundos, com um pequena perda na precisão do modelo. Por fim o autor indica que utilizando 
um computador com tempo de processamento mais elevado este número pode ser reduzido drasticamente.

Seguindo a linha de trabalhos de atualização de bancos de prova, o desenvolvido em [15] remete ao desenvolvimento e implementação de um algoritmo de controle capaz de realizar testes transientes. Este trabalho utiliza uma metodologia de controle multivariável robusto a fim de controlar torque e rotação do sistema dinamômetro-MCI. O modelo do sistema foi desenvolvido utilizando técnicas de estimadores espectrais e respostas ao degrau a fim de capturar as não linearidades do sistema. O desenvolvimento dos controladores foi realizando utilizando uma abordagem no domínio da frequência de maneira sequencial, onde foi aplicado a teoria de feedback quantitativo (Quantitative Feedback Theory), QFT. Esta técnica garante que o sistema em malha fechada, apesar de sua natureza temporal não linear, seja robusto.

O algoritmo proposto para o controle do sistema dinamômetro-MCI foi implementado em um motor turbo-Diesel e em um dinamômetro de correntes parasitas. Este algoritmo foi avaliado baseado na sua capacidade de acompanhar variações do tipo degrau e um ciclo transiente utilizado em ônibus. Para o modelo foi utilizada a técnica do tipo caixa-preta, em que a partir de entradas conhecidas e respostas medidas, estima-se o modelo representativo do sistema. Para estimar o modelo foram utilizadas quatro funções de transferência com parâmetros variáveis dependentes do ponto de operação, duas de primeira ordem e duas de segunda ordem. Estas funções de transferência relacionam as duas entradas do sistema, posição do atuador da bomba de combustível e tensão enviada ao dinamômetro, com as saídas desejadas de torque e rotação. O desempenho do controlador foi baseado na capacidade do sistema de seguir pontos pré especificados de torque e rotação.

Os resultados obtidos para o teste de seguimento de trajetórias pré especificadas de torque e rotação demonstraram um pequeno erro durante as rampas de aceleração e desaceleração. Com relação aos testes realizados com entradas do tipo degrau, foi observado que o controle realizado pelo controle do rotação foi mais rápido do que o obtido pelo controle de torque. Um ponto que compromete o desempenho do sistema de controle é considerar o sistema desacoplado através da utilização da técnica de controle QFT.

O trabalho realizado em [16], segue a mesma linha do trabalho anterior porém trabalha com equações de estado representativas do sistema. Neste, o modelo do dinamômetro é descrito através de uma equação diferencial de primeira ordem. Em contrapartida, o MCI é representado como função instantânea de seus pontos de operação. A diferença entre o torque produzido pelo dinamômetro e o produzido pelo motor em teste, dividido pela inércia do 
conjunto, fornece a aceleração angular do eixo.

A maior deficiência deste modelo é não considerar os efeitos dinâmicos produzidos pelo turbo. Porém a autora deixa claro que se houver a necessidade de um modelo mais preciso, o primeiro passo seria a inserção do termo dinâmico gerado pelo turbo.

O controle utilizado é do tipo adaptativo através da técnica conhecida como controle adaptativo do modelo de referência, MRAC - Model Reference Adaptive Control, utilizando a teoria de estabilidade de Lyapunov. Nos sistemas MRAC, o desempenho desejado é expresso através de um modelo de referência. Com isso, o mesmo pode ser alterado pelo usuário a fim de satisfazer os diferentes tipos de testes.

Os resultados das simulações apresentados mostraram um bom desempenho do controlador para o problema de seguimento de trajetória, de torque e rotação, tanto para ensaios estacionários, quanto para transientes.

O trabalho mais relevante na área de controle de bancos de prova é encontrado em [1]. Deste trabalho surgiu uma grande quantidade de artigos científicos tais como [17], [18], [19], [20] dentre outros.

Neste trabalho é considerado o problema de rastreamento de trajetória para uma classe de sistemas não lineares caracterizados por estados e entradas estáticas - mapa não linear estático representativo do motor e posição da borboleta do acelerador, torque e velocidade angular do dinamômetro - e por uma função não linear representativa das não linearidades do motor turbo, central eletrônica, dentre outros [1]. Este modelo foi utilizado por conseguir capturar as características essenciais de diversos sistemas reais, dentre eles o modelo de um banco de provas para motores a combustão interna, e conseguir aproximar muitos outros [1]. O sistema descrito pertence a classe de sistemas Hammerstein que é caracterizado por uma parte estática não linear representativa das entradas do sistemas seguido por um modelo dinâmico linear [21].

O problema de rastreamento de trajetória, torque e rotação, é realizado em duas etapas. Primeiramente três técnicas de inversão de modelos foram utilizadas: cancelamento das dinâmicas internas, abordagem por inversão estável e rastreamento da saída através de sinais exógenos. Essas três inversões são adaptadas ao problema assumindo um conhecimento exato de seu modelo. Cada uma dessas técnicas assume a inversão de um mapa estático não linear, o que as tornam imprecisas. Os erros associados a estas inversões são considerados como perturbações ao modelo e tratados na segunda etapa.

Na segunda etapa um compensador de retroalimentação de estados é introduzido no sistema afim de torná-lo robusto devido à imprecisão do controle 
feedforward (inversão do mapa - primeira etapa). Dois tipos de compensadores foram utilizados, o primeiro responsável por compensar os erros da dinâmica do sistema (rápida) enquanto que o segundo é responsável por realizar a adaptação do algoritmo de feedfoward que inclui a inversão do modelo não linear (lento).

A realização do controle por retroalimentação é de fundamental importância pois ele é o responsável por ajustar o erro de rastreamento da trajetória devido à imprecisão da inversão do modelo. A trajetória ótima, que deve ser seguida pelo sistema, é dada pelo modelo do feedforward. Um ponto abordado pelo autor com relação à este controlador é o fato da sua ação ter que ser limitada afim de não afetar o sistema negativamente quando o erro de trajetória for zero, ou seja, quando a inversão do modelo é exata. Portanto, caso o sistema entre em uma região onde o modelo não pode ser invertido exatamente, como por exemplo um ponto do modelo inverso onde uma entrada corresponde a várias saídas, o controle por retroalimentação é utilizado, caso contrário o compensador não é utilizado.

O modelo representativo do sistema motor-dinamômetro foi realizado através de equações básicas da física dos equipamentos em questão, a saber MCI, dinamômetro e acoplamento. Elas são apresentadas a seguir:

$$
\begin{gathered}
\dot{T}_{\text {Eixo }}=-\rho\left(m\left(\omega_{E}, \alpha\right)\right) T_{E}+\rho\left(m\left(\omega_{E}, \alpha\right), \omega_{E}\right) m\left(\omega_{E}, \alpha\right) \\
\Delta \dot{\phi}=\omega_{E}-\omega_{D} \\
\dot{\omega}_{E}=\frac{1}{\theta_{E}}\left(T_{E}-c \Delta \phi-d\left(\omega_{E}-\omega_{D}\right)\right) \\
\dot{\omega}_{D}=\frac{1}{\theta_{D}}\left(c \Delta \phi+d\left(\omega_{E}-\omega_{D}\right)-\eta_{1}\right) \\
\dot{\eta}_{1}=\eta_{2} \\
\dot{\eta}_{2}=-a_{0} \eta_{1}-a_{1} \eta_{2}+T_{D s e t}
\end{gathered}
$$

onde $T_{E}$ é o torque produzido pelo MCI, $\omega_{E}, \theta_{E}, \omega_{D}$ e $\theta_{D}$ são as velocidades angulares e momentos de inércia do MCI e do dinamômetro, respectivamente, $\rho$ é a função aproximada do modelo do MCI, $m\left(\omega_{E}, \alpha\right)$ é o mapa estático não linear, $c$ e $d$ são a rigidez e o amortecimento do acoplamento, $\Delta \phi$ é a diferença entre a posição do MCI e do dinamometro, $\eta_{1}$ e $\eta_{2}$ são as variáveis representativas da dinâmica do dinamômetro e $a_{0}$ e $a_{1}$ são as constantes do modelo do dinamômetro.

Conforme é mostrado através da análise dos pólos do sistema, pelo fato da dinâmica do dinamômetro ser significativamente mais rápida do que a dos outros equipamentos, seu modelo dinâmico pode ser desprezado (equações 2-9 
e 2-10). Com isso o sistema se reduz a quarta ordem [1].

O diagrama de blocos do sistema de controle pode ser visto na Figura 2.5:

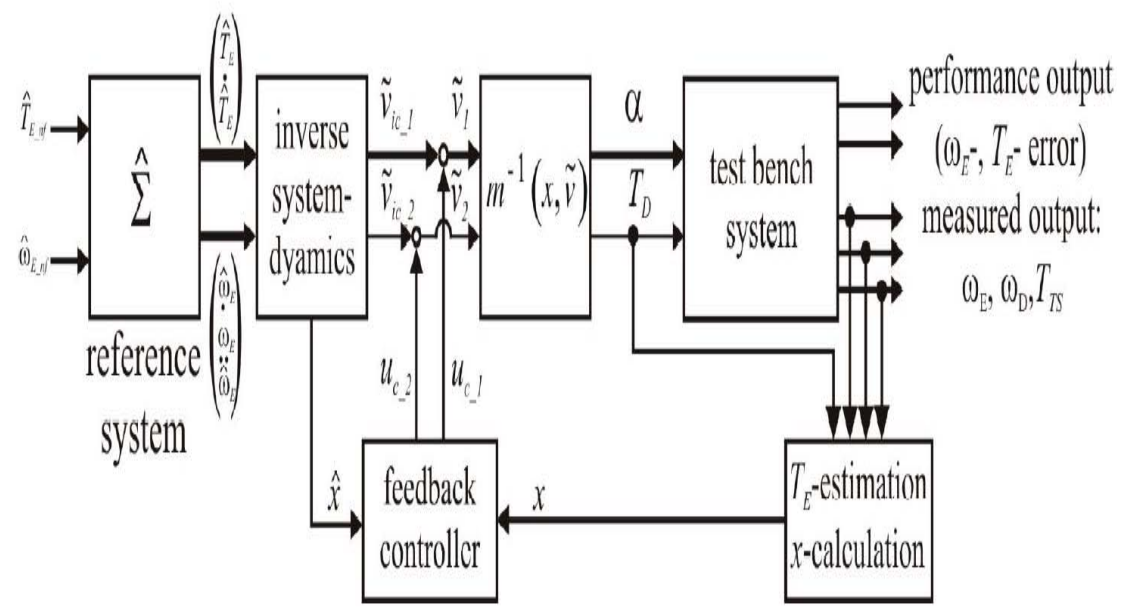

Figura 2.5: Diagrama de blocos do sistema de controle do conjunto dinamômetro-motor. (Fonte: Robust Inverse Control of a Class of Nonlinear Systems - [1])

O sistema de controle desenvolvido é aplicado em uma bancada de teste de motores dinâmica, ou seja, capaz de realizar testes transientes, e o motor testado foi um BMW M47D. Nas Figuras 2.6 e 2.7 são apresentadas as curvas de torque e rotação, respectivamente, da resposta do sistema em relação a uma trajetória pré determinada.

Como pode-se observar o sistema foi capaz de seguir as trajetórias pré determinadas dentro de uma pequena tolerância com relação a entrada tanto para torque quanto para rotação.

Os resultados deste trabalho e de outros na mesma área publicados pelo autor geraram as patentes dos dinamômetros da fabricante AVL Gmbh [20]. 


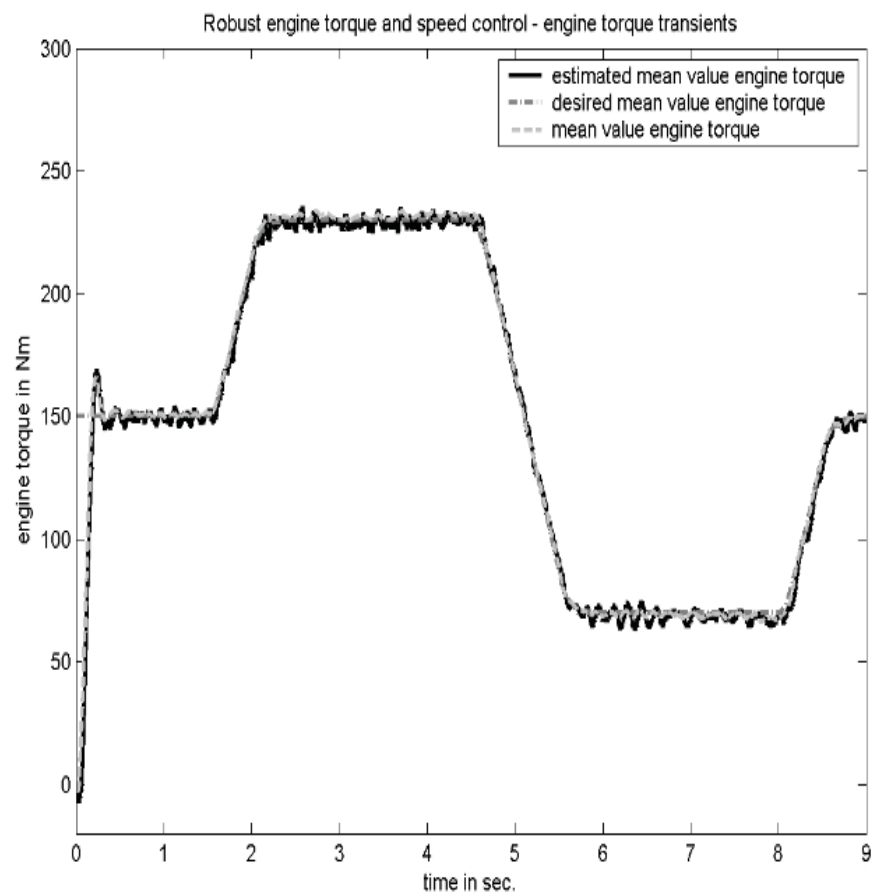

Figura 2.6: Resposta da curva de torque do sistema de controle de um banco de provas. (Fonte: Robust Inverse Control of a Class of Nonlinear Systems [1])

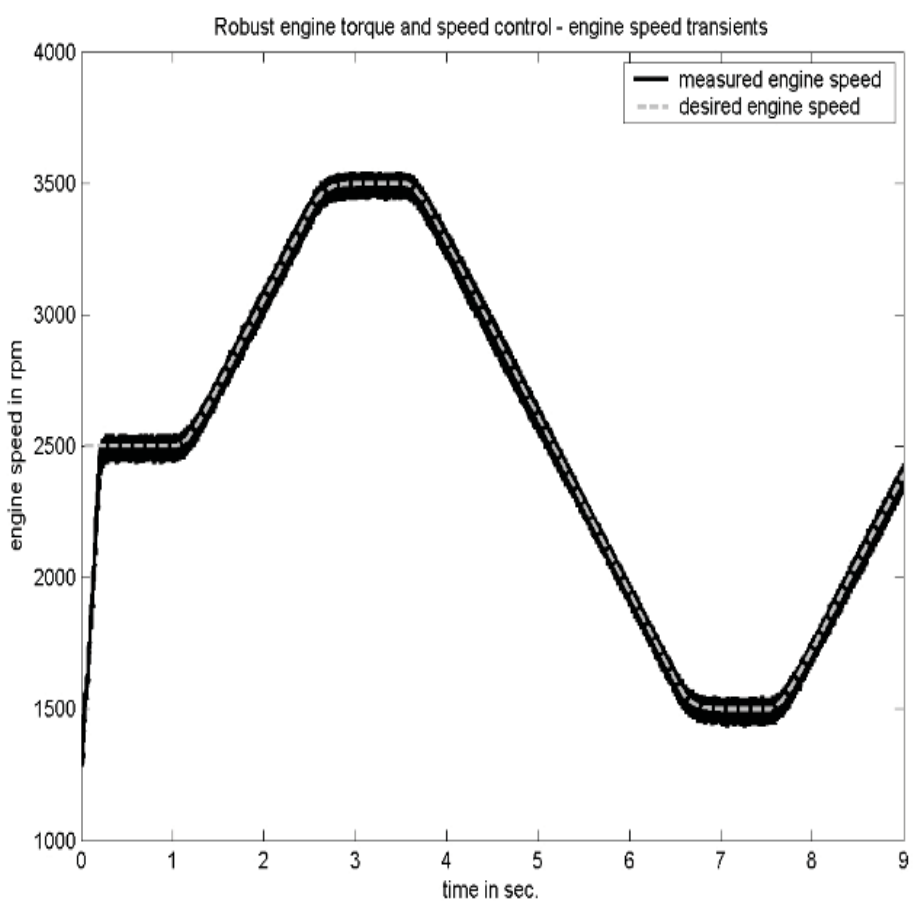

Figura 2.7: Resposta da curva de rotação do sistema de controle de um banco de provas. (Fonte: Robust Inverse Control of a Class of Nonlinear Systems [1]) 
3

\section{Bancada Experimental}

O desenvolvimento da bancada experimental utilizada na implementação do projeto seguiu os seguintes passos:

- seleção do motor de combustão;

- seleção do dinamômetro;

- acoplamento;

- desenvolvimento da base de testes e dos berços dos motores;

- seleção dos isoladores de vibração;

- atuador do acelerador;

- isolamento elétrico do sistema.

A seguir, cada etapa será descrita com maiores detalhes a respeito de cada elemento que as compõem.

\section{1}

Seleção do Motor de Combustão

O principal elemento do banco de provas é o motor a ser testado. Dentre os tipos de motores testados, os mais comuns são do ciclo Otto e do ciclo Diesel. Com o crescente aumento de pesquisas em veículos híbridos e elétricos, os motores elétricos também estão sendo bastante requisitados para realizarem diferentes tipos de testes em bancos de prova.

Neste trabalho, o motor escolhido é do ciclo Diesel, da fabricante MWM, modelo 4.10 TCA, com potência máxima declarada de 107 kW a 2.600 RPM e torque máximo declarado de $500 \mathrm{Nm}$ a 1.600 RPM. Este motor é comumente empregado na propulsão de caminhões leves e veículos comerciais. Trata-se de um modelo com turbo-alimentação e arrefecimento do ar de admissão. Vistas frontal e lateral do motor MWM são mostradas na Figura 3.1. 

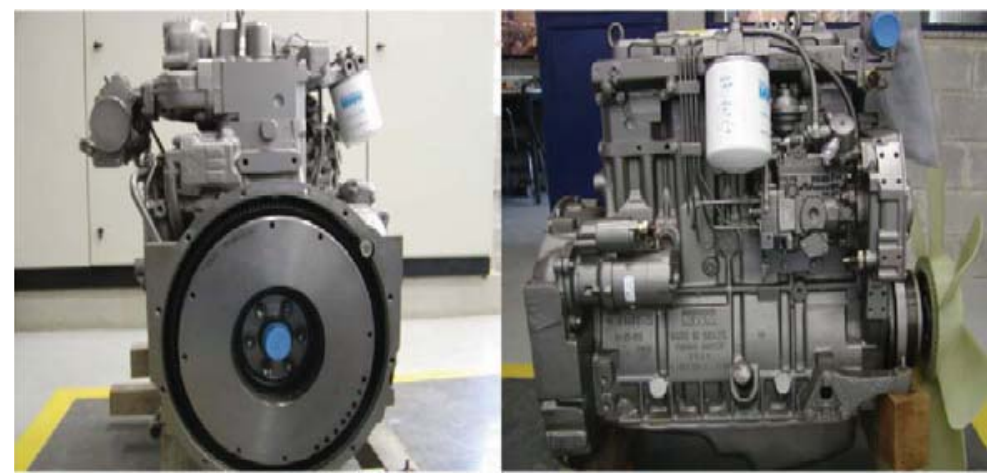

Figura 3.1: Vistas frontal e lateral do motor MWM

\section{2}

\section{Seleção do Dinamômetro}

Para seleção do motor elétrico de corrente alternada (dinamômetro) foi realizada uma avaliação das curvas de desempenho a plena carga de diferentes motores de combustão interna utilizados em diversas aplicações. Nas Figuras 3.2 e 3.3 são apresentadas as curvas de torque e potência, respectivamente, de três motores do ciclo Diesel, representativos das demandas requeridas nos setores industrial, marítimo e veicular. Também, nessas figuras, foram incluídas as respectivas curvas do motor elétrico WEG, selecionado para atender os requerimentos dos testes de motores a combustão. O motor de indução selecionado é trifásico, de 4 pólos, com potência máxima de $175 \mathrm{cv}$, torque máximo de 587 Nm e rotação máxima de 4.620 RPM, quando atuado por inversor de frequência.

A experiência da equipe do Laboratório de Engenharia Veicular (LEV) da PUC-Rio tem constatado que um elevado tempo é gasto quando é necessário realizar a troca de motores. Tempo este que também inclui, principalmente, alinhamento e instrumentação do conjunto dinamômetro-motor. Pensando na redução deste tempo ocioso, foi feita uma escolha por um motor elétrico com eixo de dupla ponta (um eixo em cada extremidade), com a finalidade de ter um motor em teste, e outro instalado no outro extremo da bancada, devidamente instrumentado e pronto para ser acoplado ao dinamômetro.

\section{3}

\section{Acoplamento}

O acoplamento entre o motor em teste e o motor elétrico (dinamômetro) pode ser dividido em duas partes principais: Transmissão e Medição de Torque. 


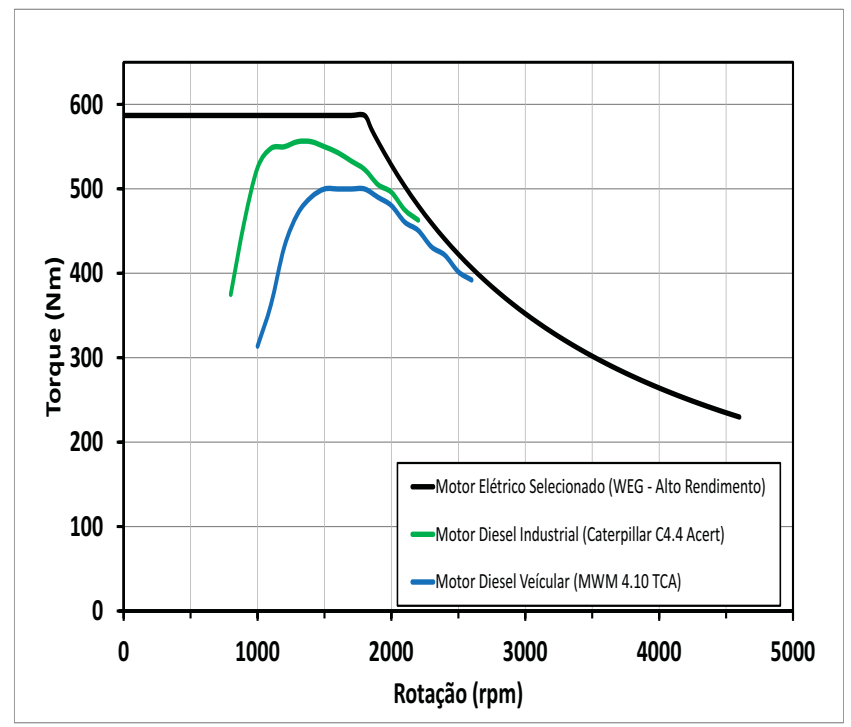

Figura 3.2: Curvas de torque do motor elétrico e de motores Diesel típicos.

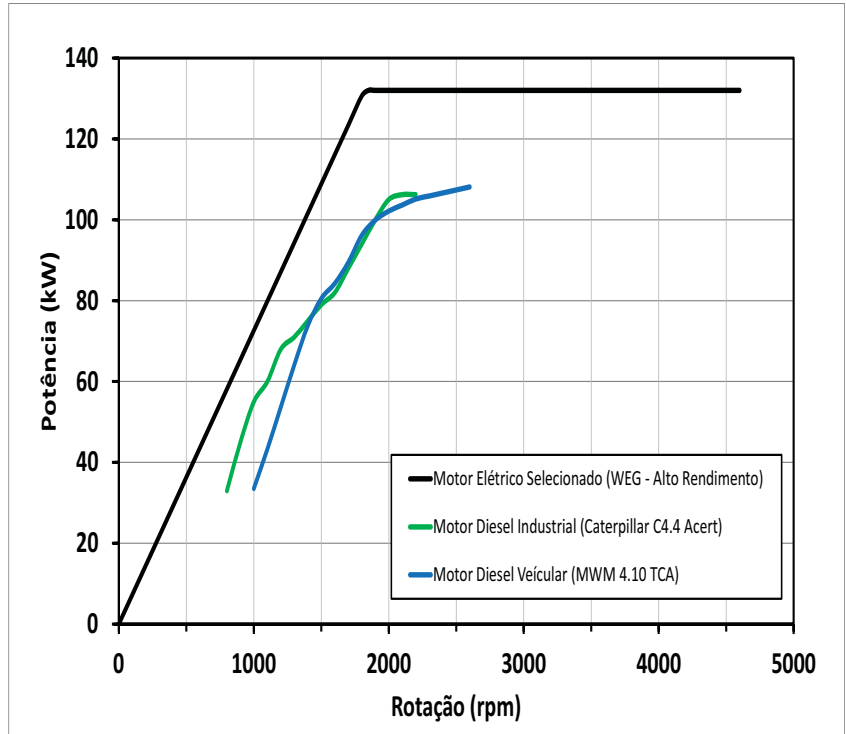

Figura 3.3: Curvas de potência do motor elétrico e de motores Diesel típicos.

\subsection{1}

Transmissão

A conexão entre o motor em teste e o dinamômetro é feita diretamente através de um conjunto de transmissão da fabricante VULKAN, modelo $C N$ - 
50, com capacidade de momento máximo igual a $610 \mathrm{Nm}$. Este conjunto é constituído de dois elementos elásticos, interligados por um eixo tubular e providos de flanges de conexão em alumínio (vide Figura 3.8). Segundo a fabricante, o eixo tubular central é conectado aos elementos elásticos através de junção estriada, sendo que, em um dos lados, o elemento elástico fica livre para se deslocar axialmente, o que permite não só um certo ajuste do comprimento total do conjunto, como também, um simples e rápido engate/desengate. Este conjunto de transmissão tem sua principal aplicação em bancos de teste de motores de combustão interna, conectando o motor ao dinamômetro.

\subsection{2}

\section{Medição de Torque}

A escolha do motor elétrico (dinamômetro) implica diretamente na escolha do tipo de medição de torque. Caso o motor seja sem pés de fixação (motor em balanço), o método de medição de torque é conhecido como Indireto. Caso o motor tenha pés de fixação, o método é o Direto.

O tipo de medição indireta é aquele em que, a partir da medida da força e do braço de alavanca, previamente conhecido, obtém-se o torque. O caso mais comum em bancadas de teste é a medição da força através de células de carga. Esta forma de medição do torque requer um projeto minucioso, tanto da célula de carga, quanto do braço de alavanca. Além disso deve ser feita uma calibração precisa do conjunto a fim de evitar erros. Segundo [22], pensando na redução de erros de medições deve-se atentar para uma constante preocupação com relação a calibração do conjunto, expansão do braço de alavanca devido a mudanças de temperatura e os diferentes modos de operação. Este tipo de medição é problemática quando há grandes massas e a necessidade de obter medidas dinâmicas. O momento de inércia das massas atuam como um filtro passa baixas. Porém situações onde não hajam a necessidade de medidas dinâmicas, esta se torna vantajosa.

O tipo de medição direta, também conhecido como "em linha", foi o método adotado no presente trabalho devido ao fato do motor possuir pés de fixação. O transdutor, conhecido como flange de torque, é da fabricante $H B M$, modelo T40, com capacidade de medir torques de até $2 \mathrm{kNm}$. É possível medir o torque de duas formas, a saber: tensão (0 a $10 \mathrm{~V})$ e frequência (30 a $90 \mathrm{kHz}$, onde $60 \mathrm{kHz}$ representa torque nulo e a frequência de $-3 \mathrm{~dB}$ igual a $3 \mathrm{kHz}$ ). O método de medição por tensão é bastante usual e de simples implementação, porém está suscetível a interferências eletromagnéticas. A medição por frequência é utilizada em ambientes sujeitos a grandes interferências eletromagnéticas, como é o caso do presente trabalho, devido à utilização dos 
inversores de frequência e do motor de indução.

Este transdutor é composto por um rotor (parte móvel) e um estator (parte fixa). A medição é realizada através de extensômetros (Strain Gages) em uma configuração de ponte de Wheatstone e a transmissão dos dados é feita sem contato mecânico. A tensão utilizada para alimentar o strain gage é induzida no rotor, pelo estator, e o valor medido é transmitido/induzido de volta ao estator. O equipamento também possui um resistor de calibração (Shunt cal). A Figura 3.4 mostra o transdutor utilizado.

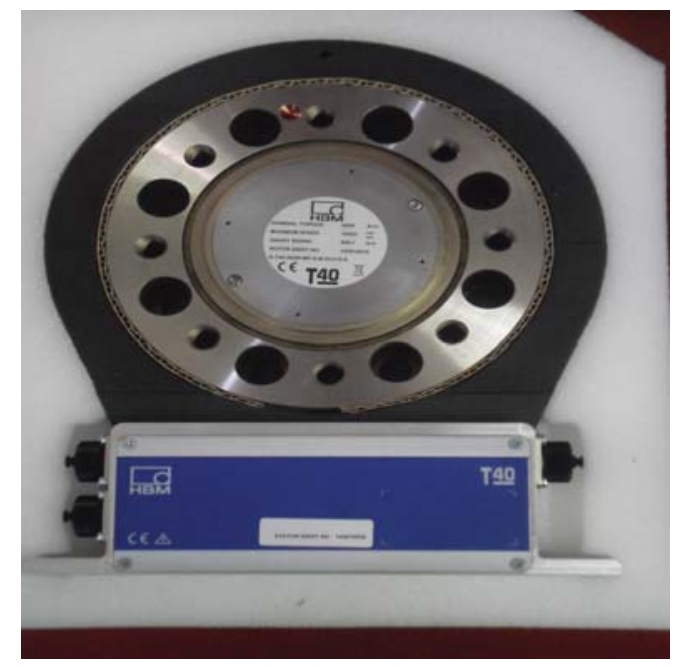

Figura 3.4: Transdutor de torque do tipo flange.

Outro ponto que deve ser observado com atenção é a forma de conexão mecânica da flange de torque. Dentre os diversos métodos existentes os dois principais são a conexão por chaveta e a por interferência. A conexão por chaveta com o intuito de conectar o eixo e o acoplamento é um dos métodos mais antigos utilizados pela indústria. Apesar do simples princípio de funcionamento este método é pouco eficaz no que diz respeito ao seu propósito. Ao contrário do que muitos pensam, usinar o rasgo da chaveta no eixo não é algo de baixo custo, principalmente pela máquina utilizada para tal procedimento. Um dos grandes problemas causados pelo rasgo da chaveta no eixo é conhecido como notch factor. Ele contribui para a redução da área de trabalho efetiva e aumenta a fadiga dos materiais em questão, diminuindo assim a vida útil dos mesmos. Para tentar diminuir esses efeitos geralmente o superdimensionamento do eixo se faz necessário. Porém este superdimensionamento acarreta em uma maior quantidade de material, maior peso e, por fim, em um maior custo.

Além desses problemas apresentados, é necessário que haja folgas no rasgo da chaveta, para poder encaixá-la devidamente, e no acoplamento 
que será utilizado. Essas folgas causam um efeito chamado de backlash. Em aplicações onde ocorrem partidas e paradas frequentes, mudanças de direções de movimento e variação de velocidade e torque produzidos, este efeito pode gerar o deslocamento da chaveta no rasgo, aumento de estresse causado pelas partes em contato, além de causar corrosão [22]. Uma variante da chaveta simples é a conexão por múltiplas chavetas, semelhante a uma engrenagem. Na Figura 3.5 são apresentadas as conexões por simples e múltiplas chavetas.
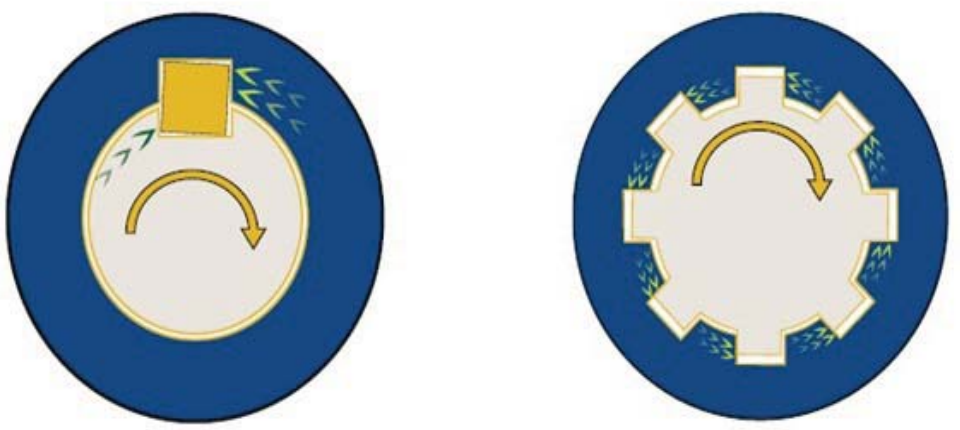

Figura 3.5: Conexão por simples e múltiplas chavetas.

A conexão por interferência ou pressão, do termo em inglês "Shrink", é obtido através da usinagem precisa, tanto do eixo, quanto da "camisa". Segundo [23], as tolerâncias referentes ao eixo e a camisa são j6 e $H$ \%, respectivamente. Essas duas peças, eixo e camisa, são pressionadas, uma contra outra, através de um disco de pressão. A deformação elástica que ocorre nos materiais (eixo e "camisa"), age de forma a criar uma elevada força normal e de atrito entre as partes. A força de atrito é responsável por transmitir o torque da, ou para, a "camisa" [24]. A Figura 3.6 mostra o princípio de funcionamento e os campos de pressão, com vistas lateral e frontal. Somente uma pequena parte da "camisa" precisa ficar em contato com o eixo. Estudos recentes na área [25], indicam que a "camisa" e o eixo devem manter contato somente na região sob o anel interno do disco de pressão (comprimento $L$ da Figura 3.6). Esta abordagem elimina efeitos corrosivos entre os materiais o que, dentre outras coisas, dificulta a separação dos componentes. A Figura 3.7 mostra o disco de pressão utilizado, da fabricante Fenner Drives, modelo SD100-10 e a "camisa", fabricada em aço 1020, seguindo recomendações da própria empresa. Por fim, na Figura 3.8 é mostrado todo o conjunto do acoplamento entre o MCI e o dinamômetro. 

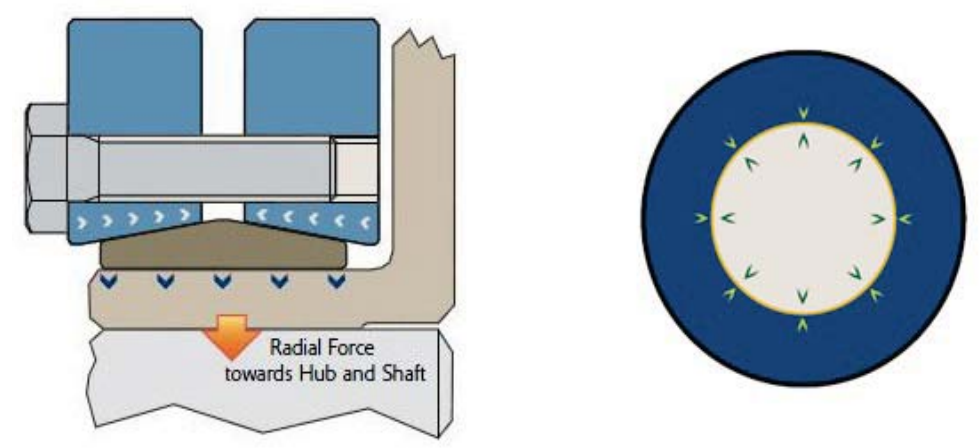

Figura 3.6: Campos de pressão - vistas lateral e frontal

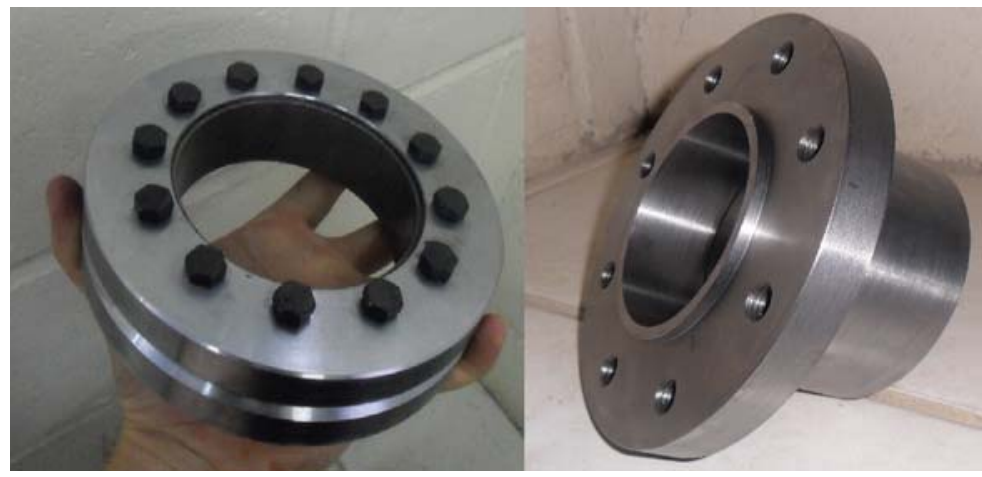

Figura 3.7: Disco de pressão e camisa

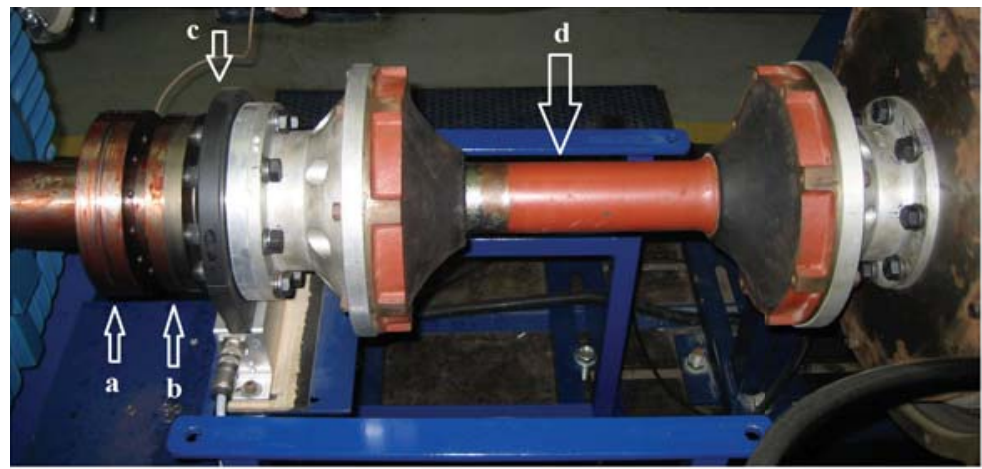

Figura 3.8: Conjunto de transmissão: (a)disco de pressão, (b)camisa, (c)transdutor de torque e (d)eixo cardan.

\section{4}

\section{Medição de Velocidade Angular}

A medição de velocidade angular no sistema dinamômetro-motor é feita normalmente, ou por um sistema composto por uma roda dentada (roda fônica) e um transdutor, geralmente um pick-up magnético, ou um transistor foto sensível, ou por encoders.

Encoders são transdutores capazes de medir velocidade de rotação 
através de pulsos luminosos. Existem dois tipos: absoluto e incremental. O primeiro se diferencia do segundo na medida em que a posição de cada pulso é codificada e, com isso, torna-se possível saber sua posição angular mesmo que ocorra algum evento inesperado (queda de energia ou movimento enquanto está desenergizado). Estes equipamentos somente são utilizados quando há a necessidade de saber a posição precisa de um elemento a cada instante de tempo, pois são bastante custosos se comparados com o incremental. Estes por sua vez não são capazes de fornecer a posição angular, somente um certo número de pulsos por revolução, previamente especificados. Os encoders incrementais, em sua grande maioria geram, pelo menos, três sinais usualmente caracterizados como A, B e Z. Os dois primeiros são trem de pulsos defasados de 90 graus onde fornecem o sentido de giro. Já o terceiro é utilizado como referência. Com ele, sabe-se quando o equipamento realizou uma volta completa.

No presente trabalho foi utilizado um encoder do tipo incremental para medir a velocidade rotacional. Este equipamento, da fabricante Baumer Hü̈ner, modelo HOG-161, com resolução de 1024 pulsos por rotação, foi instalado no eixo do motor elétrico (vide Figura 3.9).
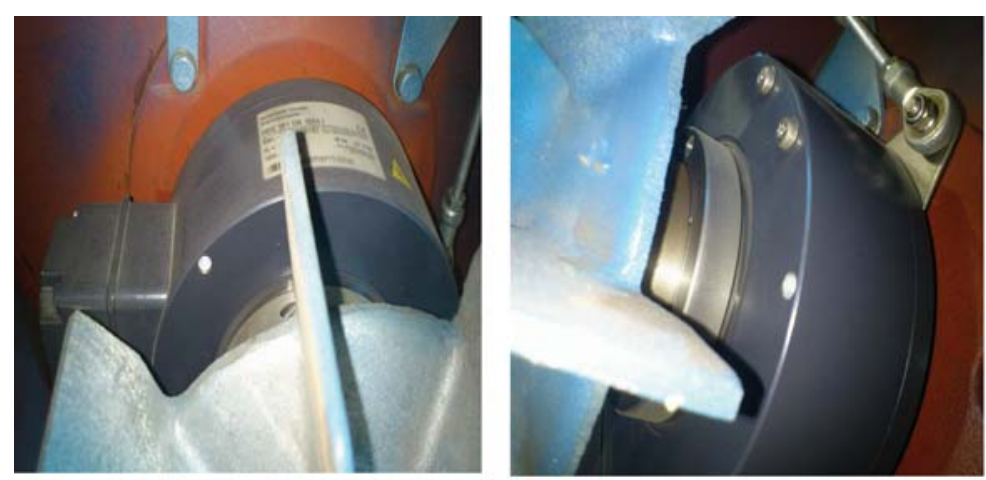

Figura 3.9: Encoder instalado no eixo do dinamômetro.

\section{5}

Desenvolvimento da Base de Testes e Dimensionamento dos Isoladores de Vibração

\subsection{1}

\section{Desenvolvimento da Base de Testes}

Por se tratar de um dinamômetro para ensaios de motores, um projeto de uma base para assentar os mesmos deve ser executado rigorosamente. Falhas no projeto podem ocasionar diversos problemas tanto para o ensaio, afetando medições, como para a estrutura da construção onde a sala de testes está alocada $[7,13]$. A base deve ser suficientemente resistente a ponto de suportar 
todos os esforços gerados durante os testes. Portanto, um desenvolvimento criterioso da base é de fundamental importância para o sucesso de todo o projeto.

Certamente, a seleção do motor elétrico de duas pontas acarreta em um tamanho de base significativamente maior. Geralmente, o comprimento de uma bancada para testes de motores automotivos varia, em média, de 2,5 a 3,0 metros de comprimento (assumindo que o conjunto dinamômetromotor está sobre a mesma base). Entretanto, neste trabalho, a base possui um comprimento de 4,5 metros. O modelo geométrico da base possui formato de um paralelepípedo, cujas dimensões são: 4,5 m x 1,5 m x 0,24 m. Este suporte é basicamente formado por estruturas em aço ASTM A36 e concreto. A Figura 3.10 mostra a concepção da base realizada no software CAD Solid Works 2010.

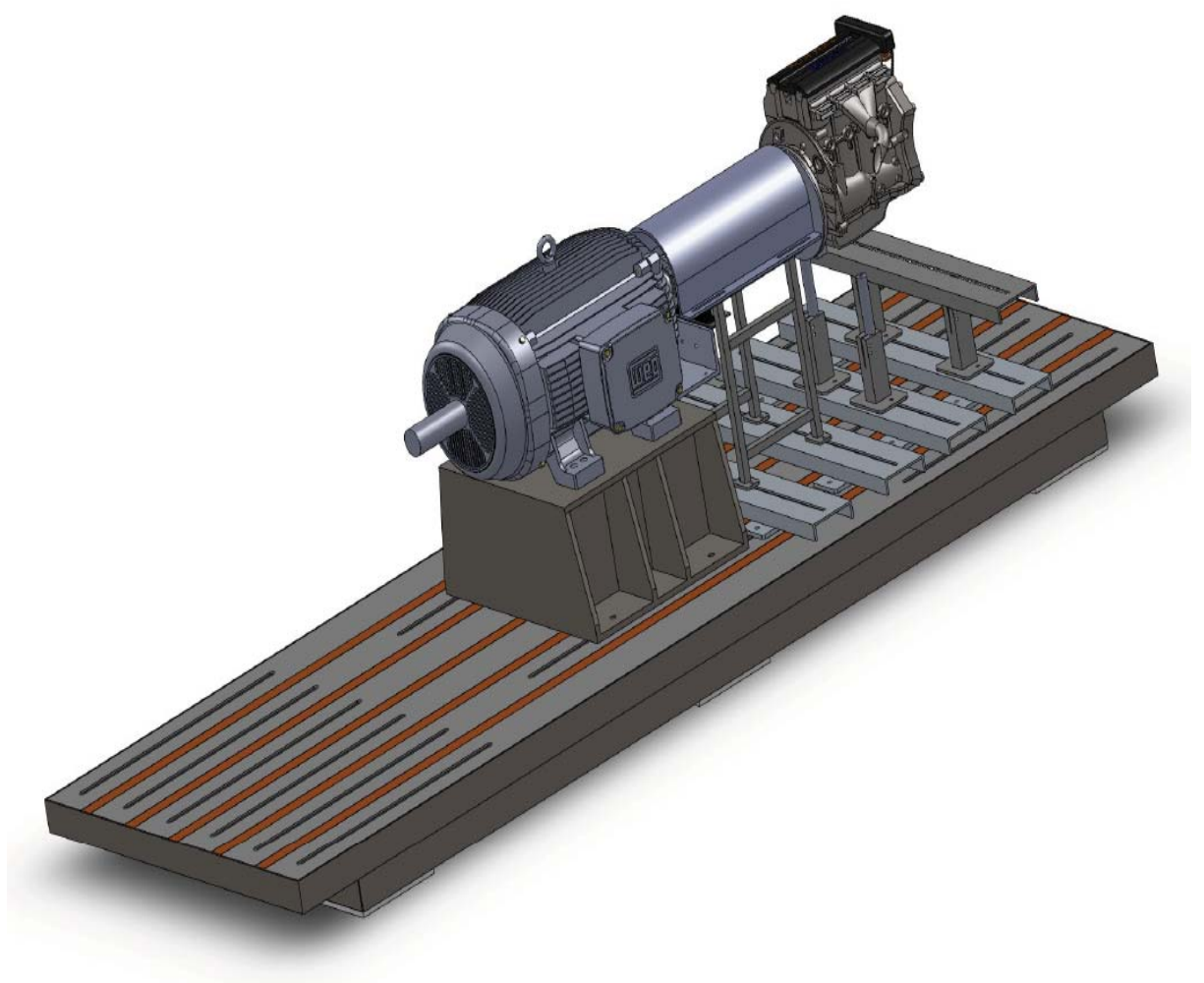

Figura 3.10: Concepção em software CAD da base com dinamômetro.

Com o protótipo definido, recorreu-se a literatura com o objetivo de determinar outras características essenciais para o projeto tais como massa, frequência natural, influência de carregamentos externos, tipos de isoladores de vibração e simulações. Na literatura encontra-se grande quantidade de artigos na área de maquinários industriais e de grande porte [26, 27], porém a relacionada à máquinas rotativas não é muito extensa. Em [28] bastante informação é fornecida sobre tal tópico. 
Vibrações são atenuadas e até mesmo absorvidas por completo quando a base se comporta como corpo rígido. Quanto maior for a massa da base onde o elemento vibrante se encontrar, menor será a freqüência de ressonância do conjunto. Bases para máquinas rotativas devem possuir uma massa de pelo menos 2,5 a 3 vezes maior que a massa do equipamento [27] com a intenção de afastar a frequência de ressonância do conjunto da frequência de excitação do motor.

Para o cálculo da massa da base, no software Solid Works, foi definido o valor da densidade dos materiais utilizados em sua construção. O aço ASTM A36 possui uma densidade de $7850 \mathrm{~kg} / \mathrm{m}^{3}$ enquanto que o concreto possui uma densidade próxima a $2300 \mathrm{~kg} / \mathrm{m}^{3}$. Esses valores foram inseridos no programa que forneceu uma massa aproximada de $3290 \mathrm{~kg}$. Para o cálculo das massas dos MCI's, dinamômetro e suportes foi estimado um valor total de $2120 \mathrm{~kg}$ (dinamômetro + suporte: $1260 \mathrm{~kg}$; MCI + suporte: 2 x $430 \mathrm{~kg}$ ). Portanto, a massa do conjunto pode chegar a um valor de $5480 \mathrm{~kg}$, com os dois MCI's.

Após o cálculo da massa, o próximo passo foi a obtenção dos possíveis esforços aos quais a base estará sujeita. Dentre os quais podemos destacar dois tipos, cargas estáticas e dinâmicas. Os primeiros são basicamente o peso dos equipamentos, em contrapartida, os segundos são os gerados pelos motores a combustão tais como forças e momentos devido a inércia e combustão dos gases. Segundo [27], para bases com formas geométricas simples, a análise dos carregamentos pode ser simplificada utilizando o que o autor chama de carregamento estático equivalente, ao invés de analisar a dinâmica completa. Este carregamento equivalente, F, é expresso por:

$$
F=\frac{F(t)}{\left|1-\eta^{2}\right|}
$$

onde $F(t)$ são as forças não balanceadas e $\eta$ é a razão entre a freqüência de operação do motor e a freqüência natural da base mais próxima da freqüência de operação. No caso do presente trabalho, utilizou-se uma faixa de frequência de trabalho de $10 \mathrm{~Hz}$ a $50 \mathrm{~Hz}$, que corresponde a 600 RPM e 3000 RPM. Para o caso da base, cálculos realizados no software ANSYS 12.1, a partir do modelo 3D desenvolvido, apontaram uma frequência própria vertical de $3 \mathrm{~Hz}$ e, portanto, chega-se a uma faixa de valores de $\eta$ entre 3,33 e 17,85.

Analisando a fórmula e a faixa de valores obtidos para a razão entre frequências, observa-se que o denominador da Equação 3-1 será sempre superior a unidade implicando em um valor de $F$ menor do que $F(t)$.

A equação das forças desbalanceadas de inércia de um motor multicilindrico é deduzida a partir da geometria do pistão e do ângulo de manivelas [29]. 
Esta é dada por:

$$
\begin{gathered}
F i(t)=m_{b} r \omega^{2}\left[\cos (\omega t) \sum_{i=1}^{n} \cos \left(\phi_{i}\right)+\sin (\omega t) \sum_{i=1}^{n} \sin \left(\phi_{i}\right)\right. \\
\left.+\frac{r}{l}\left(\cos (2 \omega t) \sum_{i=1}^{n} \cos \left(2 \phi_{i}\right)+\sin (2 \omega t) \sum_{i=1}^{n} \sin \left(2 \phi_{i}\right)\right)\right]
\end{gathered}
$$

onde $m_{b}$ é a massa equivalente das partes rotativas (pistão com anéis, massa equivalente da extremidade superior da biela e pino do pistão) [30], $r$ é o raio do virabrequim, $\omega$ é a velocidade angular e $\phi$ é a fase do pistão.

Esta equação somente considera forças até a segunda ordem pelo fato das ordens superiores serem desprezíveis [30]. O ângulo $\phi$ é determinado pela ordem de ignição, que no caso do motor a ser testado é 1-3-4-2. Esta é, geralmente, a ordem para um motor 4 cilindros em linha e é comumente utilizada pois leva em consideração o balanceamento do mesmo.

Diante do equacionamento matemático dos esforços dinâmicos apresentado anteriormente, utilizou-se o software Matlab R2009a, da fabricante MathWorks, para obter os valores representativos do MCI testado. Para tanto, a fim de realizar um estudo completo e ser capaz de dimensionar corretamente a base do dinamômetro, calculou-se em qual rotação do MCI, dentro de sua faixa de operação, ocorriam os maiores esforços dinâmicos. Como era esperado, os maiores esforços ocorrem nas maiores rotações e portanto o valor de $\omega$ utilizado foi referente a rotação máxima do MCI testado, 2600 RPM. O perfil da curva das forças desbalanceadas do MCI em teste pode ser visto na Figura 3.11 .

De acordo com a Figura 3.11 observa-se um esforço máximo de $20 \mathrm{kN}$ na rotação máxima. Porém, a Equação 3-1 informa que o valor do carregamento estático que deve ser utilizado a fim de validar o projeto da base é inferior ao esforço máximo produzido $F(t)$. No entanto, com o objetivo de se realizar uma abordagem conservadora, o esforço utilizado para a validação da base deverá ser calculado baseado em uma situação de emergência, em outras palavras, deverá ser adotado um valor superior aos esforços teóricos, como fator de segurança. Portanto, o valor adotado para o carregamento estático equivalente foi de $25 \mathrm{kN}$.

O passo seguinte foi a realização de simulações no software de análises por elementos finitos ANSYS. Em [31] e [32] informações sobre os passos iniciais e o funcionamento do programa são fornecidas. O desenvolvimento da malha para a realização das simulações pode ser encontrado em [23]. 


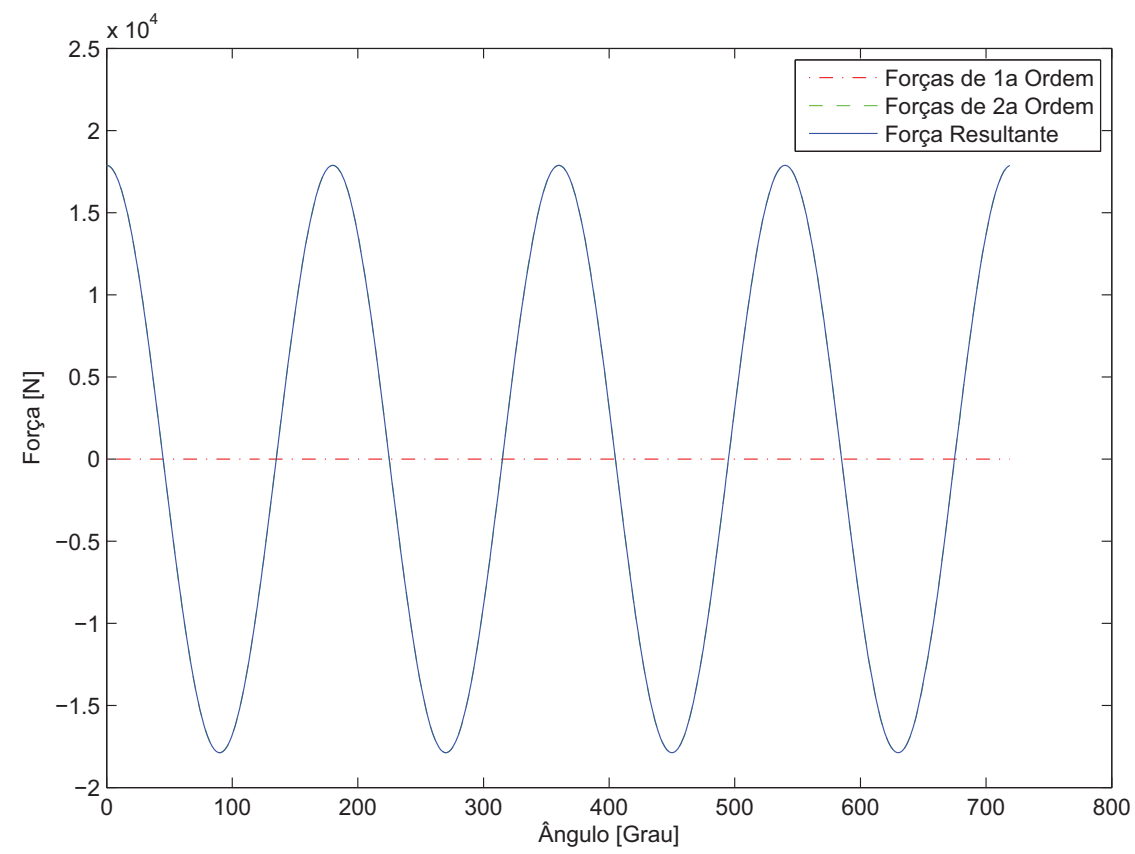

Figura 3.11: Forças desbalanceadas produzidas na rotação máxima.

Diversas simulações foram realizadas em função dos valores de força obtidos, em diferentes configurações, a fim de verificar a validação da estrutura da base.

Uma vez que o banco de prova poderá operar, ou com dois $M C I$ 's, ou somente um sobre a base, esses casos tiveram que ser analisados separadamente. Como a base ficará assentada sobre isoladores de vibração do tipo viscoelástico, da fabricante $G E R B$, foi necessário obter, junto à empresa, as constantes elásticas dos mesmos $(0,32 \mathrm{kN} / \mathrm{mm})$ com o objetivo de tornar as simulações mais realistas.

Os resultados são apresentados a seguir, atentando para o fato de que a tensão máxima de Von-Mises, obtido na simulação com valor de 72,5 MPa para o caso mais crítico, fica abaixo de $60 \%$ do limite de escoamento do aço (250 $\mathrm{MPa}$ ), que é utilizado por muitos especialistas como fator de segurança para este tipo de material e assim, validando o modelo do ponto de vista estrutural. Além disso, se obteve com esta simulação o valor de inclinação máxima do conjunto $(1,75 \mathrm{~mm} / \mathrm{m})$ e do deslocamento dos isoladores na condição com dois MCI's, para a constante elástica fornecida, de aproximadamente $3 \mathrm{~cm}$. A Figura 3.12 , representa o caso em que existe somente um motor a combustão sobre a base e funcionando. A Figura 3.13, representa o caso em que os dois motores a combustão estão sobre a base, sendo que um esta funcionando. 


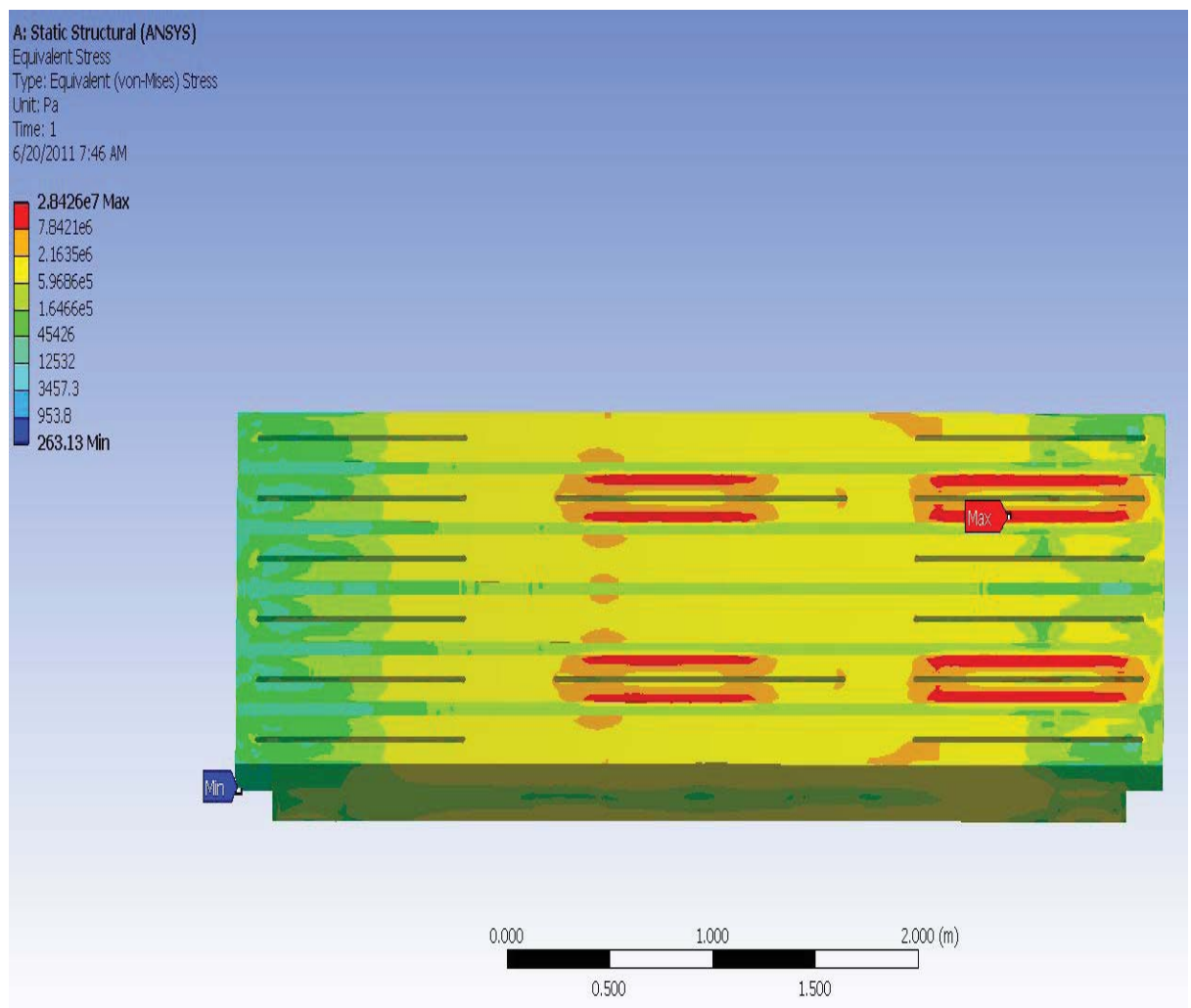

Figura 3.12: Simulação por elementos finitos das forças desbalanceadas de um MCI e da força estática do dinamômetro sobre base.

\section{5 .2}

\section{Seleção dos Isoladores de Vibração}

A seleção dos isoladores de vibração é de fundamental importância para o sucesso do projeto como um todo. Uma escolha errada destes equipamentos poderá comprometer todo o esforço despendido no desenvolvimento da base de testes. Dentre as principais funções que exercem, as que mais justificam o investimento são: reduzir significativamente a transmissão das vibrações provenientes do motor em teste para o meio e evitar o desnivelamento da base de testes devido às cargas móveis (diferentes motores requerem posicionamentos diversos, devido ao tamanho, comprimento do acoplamento etc).

Para que uma fundação rígida possua um elevado grau de isolamento, superior a $85 \%$, e que não haja uma preocupação com o desnivelamento do sistema, é recomendado uma base inercial de 10 a 20 vezes a massa do motor [26], [27].

Para o caso do presente projeto, visto que a base poderá possuir um ou dois motores a combustão, o desnivelamento é um ponto que requer bastante atenção. Além disso, esta variação no número de motores, influencia o grau de isolação devido à menor ou maior massa do conjunto. 


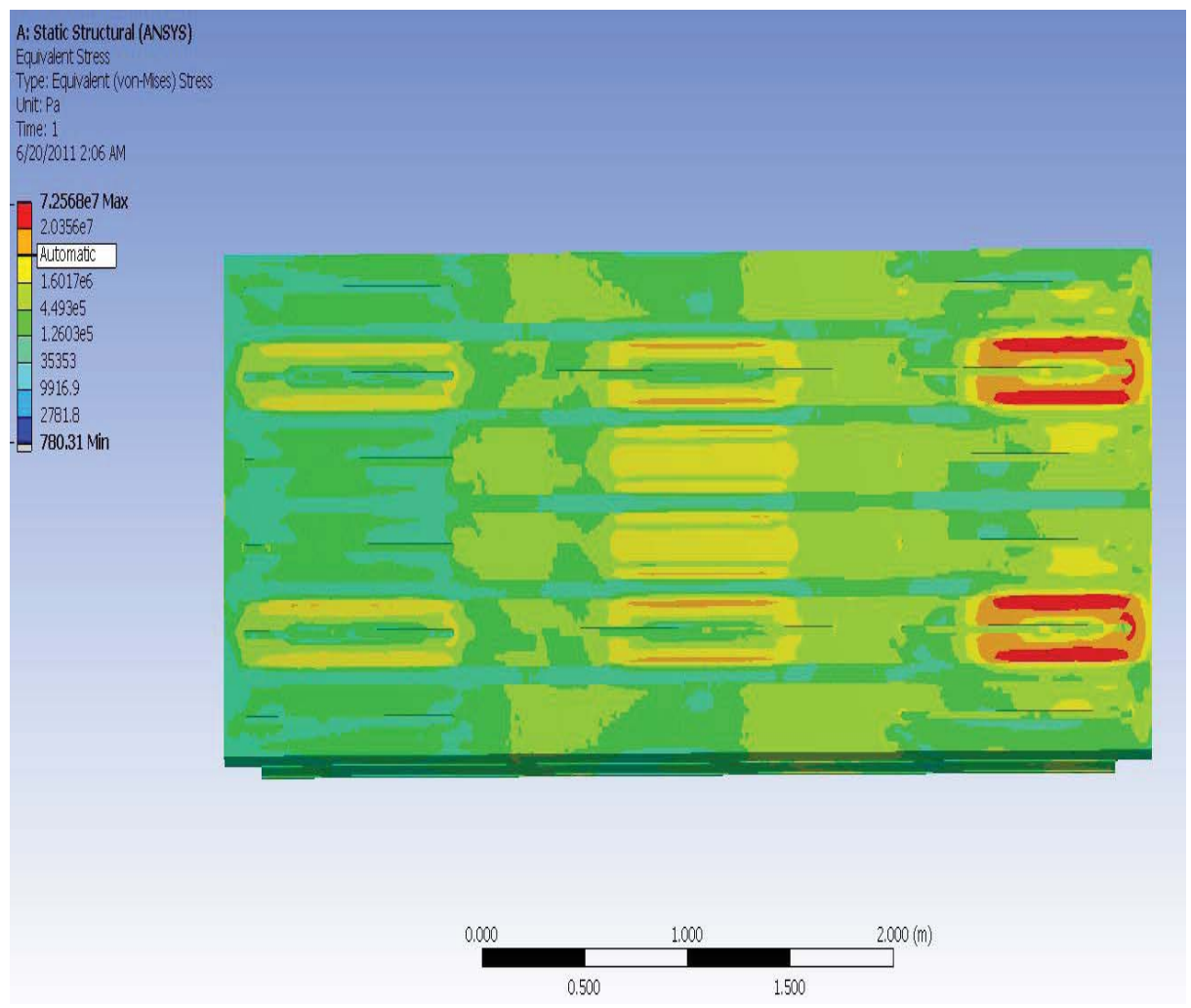

Figura 3.13: Simulação por elementos finitos das forças desbalanceadas de um MCI e das forças estáticas do dinamômetro e do segundo MCI sobre a base.

O dimensionamento desses equipamentos foi realizado junto à fabricante GERB, líder mundial em soluções para vibrações. Para tanto, além das simulações realizadas, foi enviado um desenho esquemático com o posicionamento esperado dos motores em relação a base e as massas de cada um, aproximadamente (vide Figura 3.14).

Uma análise das frequências correspondentes às faixas de operação do motor, em relação a frequência própria vertical da base, foi realizada a fim de determinar o grau de isolamento. O valor obtido para o grau de isolamento mínimo foi de 90,1\%. Foram adquiridos seis isoladores de vibração desta empresa cujo modelo é KB1V-452 (vide Figura 3.15).

Após a validação do projeto da base e dimensionamento dos isoladores de vibração sua construção foi efetivada. As Figuras 3.16 e 3.17, mostram a base instalada no Laboratório. 


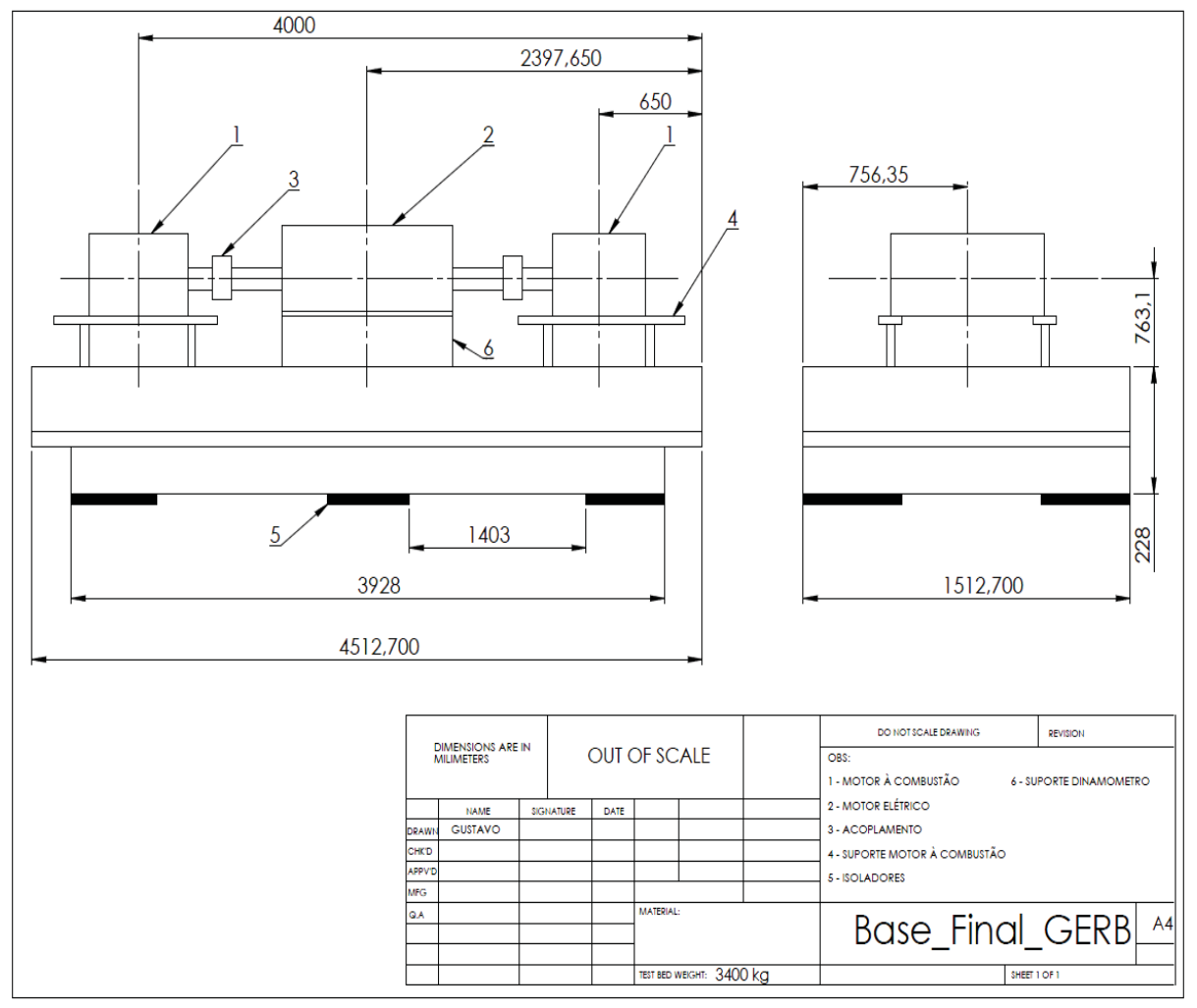

Figura 3.14: Desenho Esquemático do posicionamento dos componentes sobre a base.

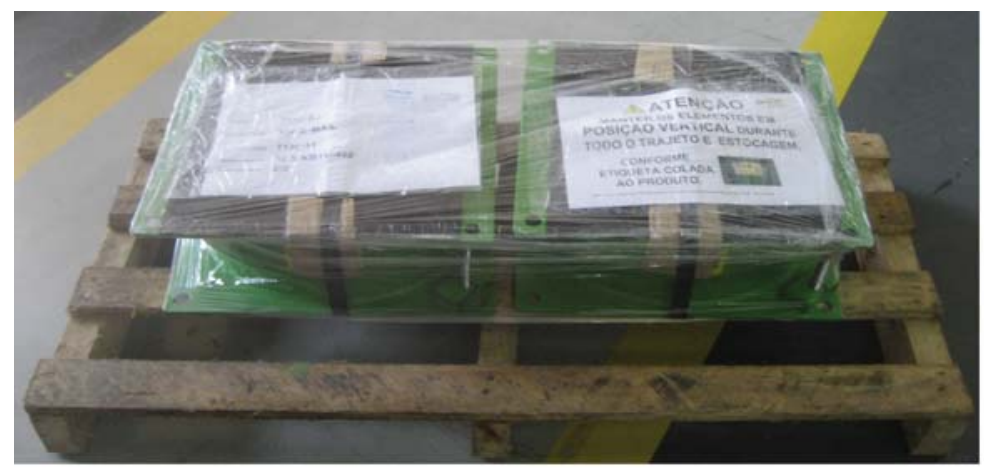

Figura 3.15: Isoladores de vibração.

\section{6}

\section{Atuadores do Controle de Velocidade Angular dos MCl's}

Normalmente MCI's possuem algum tipo de atuador responsável por controlar a rotação do mesmo. Em motores do ciclo Otto de injeção eletrônica, o pedal do acelerador (aplicações veiculares) ou haste do governador (aplicações não veiculares), em função de sua posição e "mapa" da unidade de gerenciamento, comandam basicamente: a abertura/fechamento (parcial ou total) da borboleta do ar de combustão; a quantidade de combustível; o avanço da 


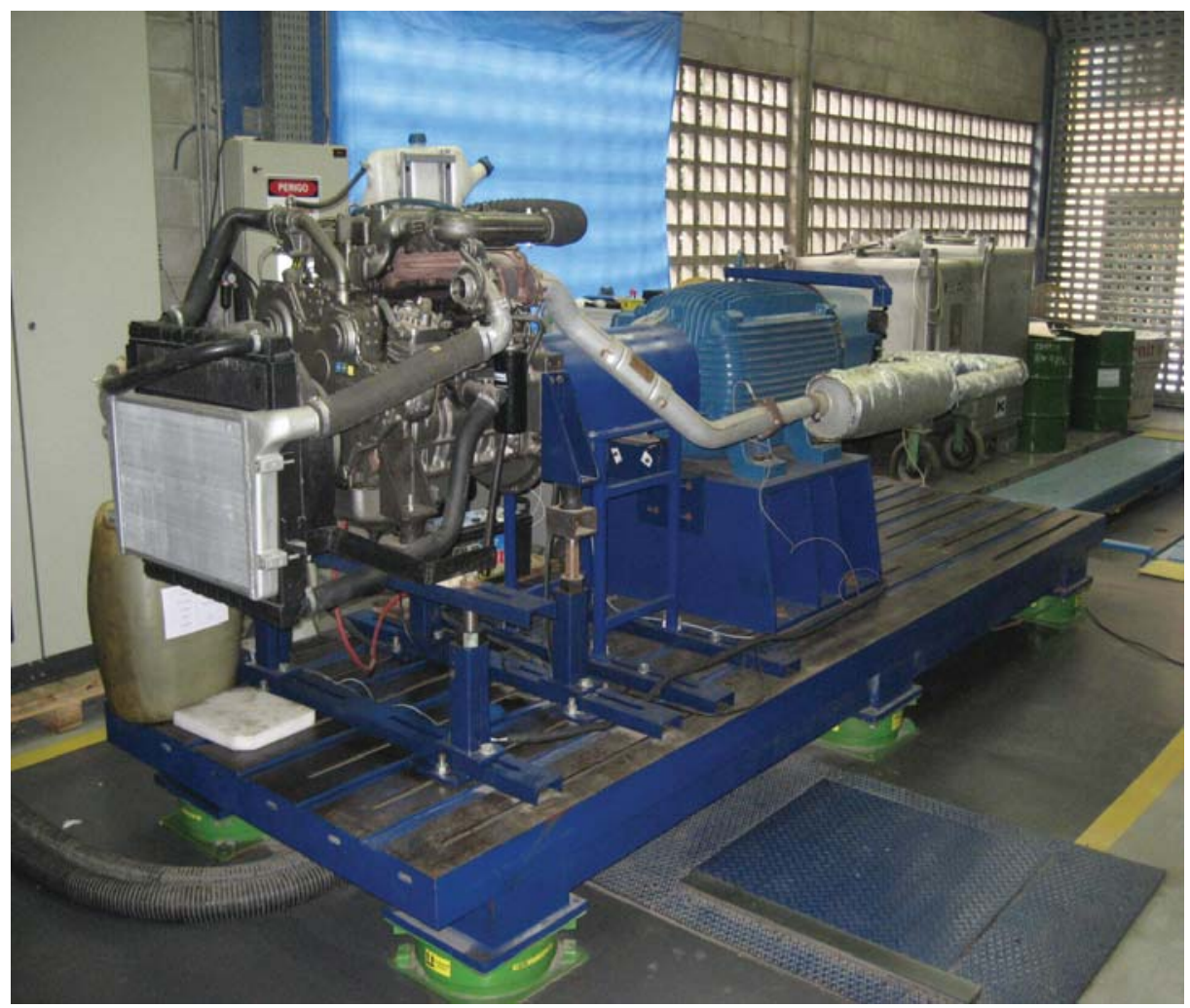

Figura 3.16: Vista dianteira da base instalada no laboratório.

ignição; etc. Tais variáveis são, finalmente, responsáveis pela rotação do eixo do MCI do ciclo Otto. Caso semelhante ocorre nos motores de ignição por compressão, porém nos motores Diesel a posição da borboleta é empregada para controlar o diferencial de pressão necessária para a admissão do EGR (gases que recirculam do escapamento para a admissão) no coletor de admissão junto ao ar de combustão. Cabe mencionar também que no caso dos motores de geração mais antiga (não eletrônicos), o controle é apenas na borboleta de ar, para os motores Otto, ou na haste da bomba injetora para os Diesel. No motor Otto, a borboleta gerará um determinado nível de vácuo necessário para a dosagem do combustível. Já no motor Diesel mecânico, a bomba de combustível poderá ou não controlar, indiretamente, a massa de ar de combustão (quando utilizado turbo-compressor).

Dentre os atuadores mais utilizados em bancos de prova destacam-se dois tipos:

- motores de passo

- servomotores 


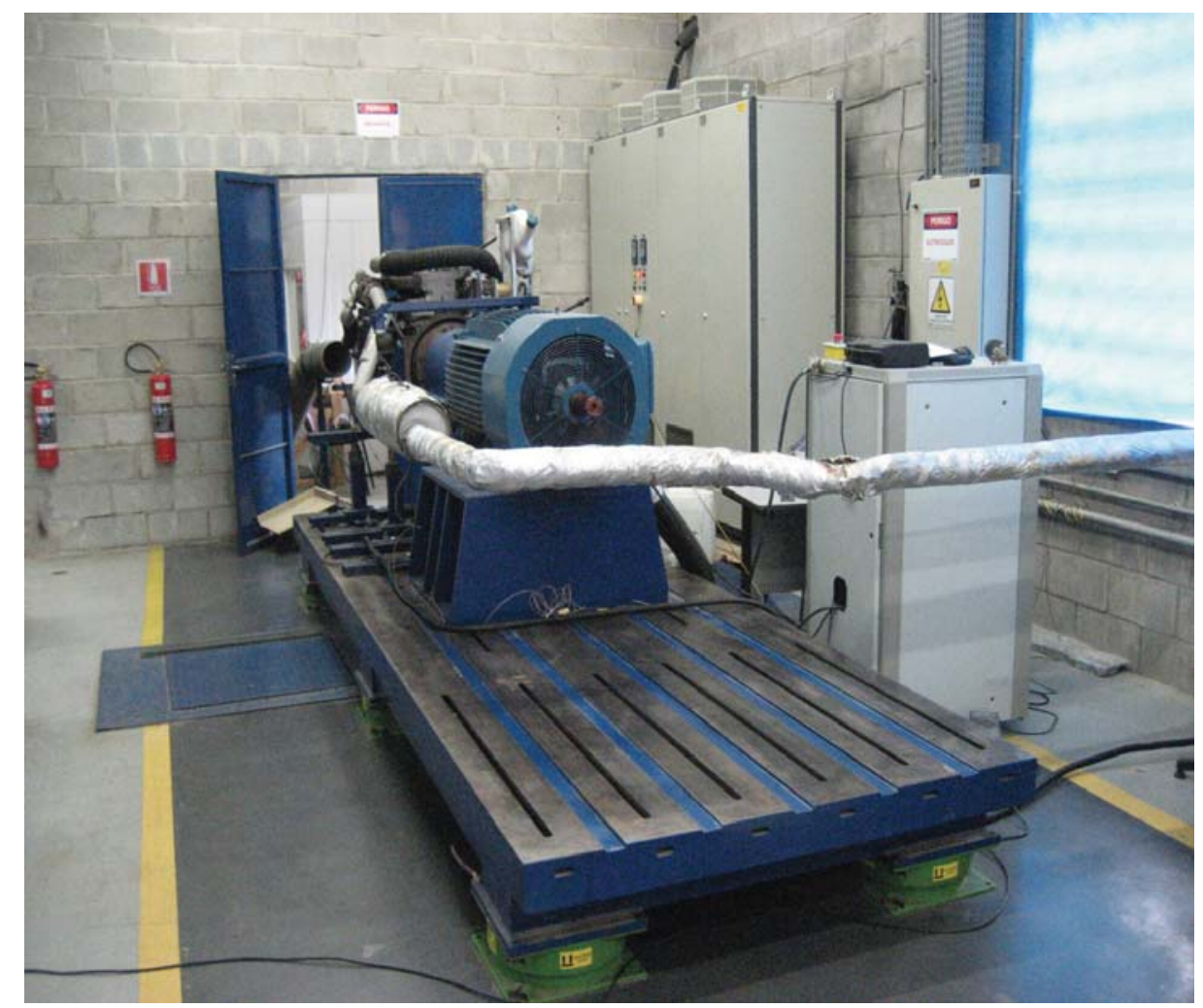

Figura 3.17: Vista traseira da base instalada no laboratório.

\subsection{1}

\section{Motores de Passo}

Motores de passo são motores elétricos que transformam pulsos elétricos em movimentos rotacionais precisos. Ele é composto por um rotor e um número fixo de pares de solenóides. Quando um sinal elétrico é aplicado a um dos pares de solenóides, o rotor é atraído e, consequentemente, move-se. Este movimento do rotor é denominado passo e depende do número de alinhamentos possíveis entre o rotor e as solenóides.

A velocidade de rotação do motor de passo é diretamente proporcional a frequência com que os sinais elétricos são enviados às solenóides, assim como o sentido de rotação, que é dependente da ordem em que esses sinais são aplicados às bobinas. $\mathrm{O}$ torque aplicado por um motor de passo possui um valor constante, que é igual a força eletromagnética gerada entre o rotor e as solenóides, porém varia (diminui) quanto maior for o número de pulsos por unidade de tempo gerados. Devido a esta característica, motores de passo não são recomendados para situações em que haja necessidade de rápidos deslocamentos.

Os principais tipos de motores de passo são: Unipolares e Bipolares. Apesar de os motores unipolares possuírem uma forma de controle mais 
simples, não havendo necessidade de inversão de corrente, a relação torque e velocidade angular é menor se comparado com os bipolares. Em contrapartida, os motores bipolares possuem grande capacidade de torque para uma grande faixa de velocidade porém, seu circuito de controle, é bastante complexo pois deve ser capaz de inverter o sentido da corrente que circula pelas suas bobinas.

\subsection{2}

\section{Servomotores}

Servomotores são motores que se movimentam proporcionalmente a partir de um comando fornecido. Diferentemente da maioria dos motores, este trabalha em malha fechada, ou seja, a partir de um comando de controle enviado ao motor, a posição atual do mesmo é verificada, através de um encoder ou resolver, e a posição desejada é atingida. Uma característica que os diferenciam dos motores C.C. e C.A. é o fato de seu eixo não ser capaz de girar 360 graus.

Estes motores possuem três sistemas principais: Sistema Atuador, Sensor e Circuito de Controle.

O Sistema Atuador é constituído pelo motor, geralmente utiliza-se um de corrente contínua, e um conjunto de engrenagens que formam a caixa de redução visando aumentar o torque.

O Sensor é, geralmente, constituído por um potenciômetro solidário ao eixo do servo. A posição do servo é determinada a partir da leitura da resistência elétrica obtida sobre o potenciômetro.

O Circuito de Controle é formado por diferentes componentes eletrônicos e normalmente possuem um oscilador, responsável por gerar os pulsos em $P W M$, e um controlador PID (proporcional-integral-derivativo) que recebe o sinal do potenciômetro e o sinal de controle e atua no motor.

No presente projeto foi escolhido o servomotor, pelas vantagens técnicas acima mencionadas (vide Figura 3.18).

\section{7}

\section{Transdutores de Pressão e Temperatura}

Para a execução do projeto foram utilizados três transdutores de temperatura e um de pressão. Os transdutores de temperatura eram termopares do tipo K (NiCr-NiAl), da fabricante Omega, com uma faixa de operação de 0 a 1250 graus Celsius. Estes transdutores foram colocados em pontos estratégicos para a aferição das temperaturas essenciais para o funcionamento do motor: água, óleo e escapamento (vide Figura 3.19). 


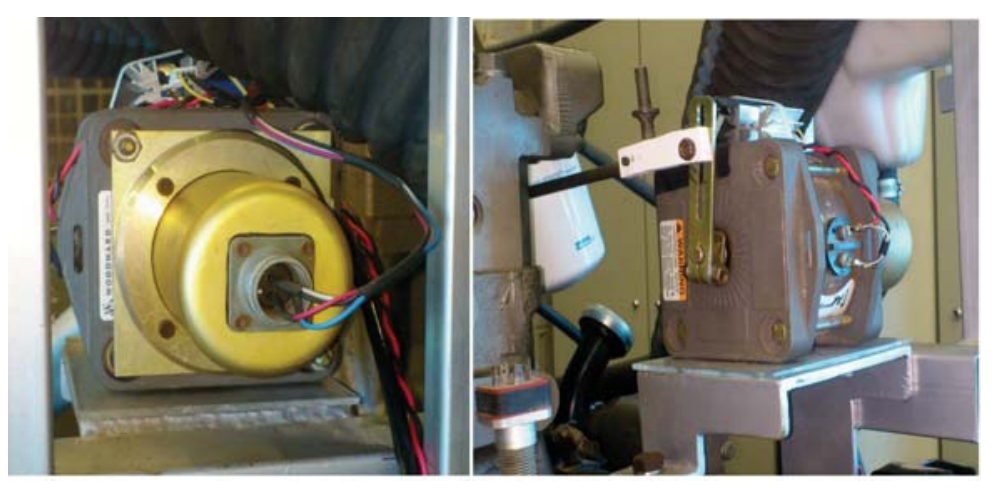

Figura 3.18: Servomotor utilizado como atuador da bomba de combustível do MCI.
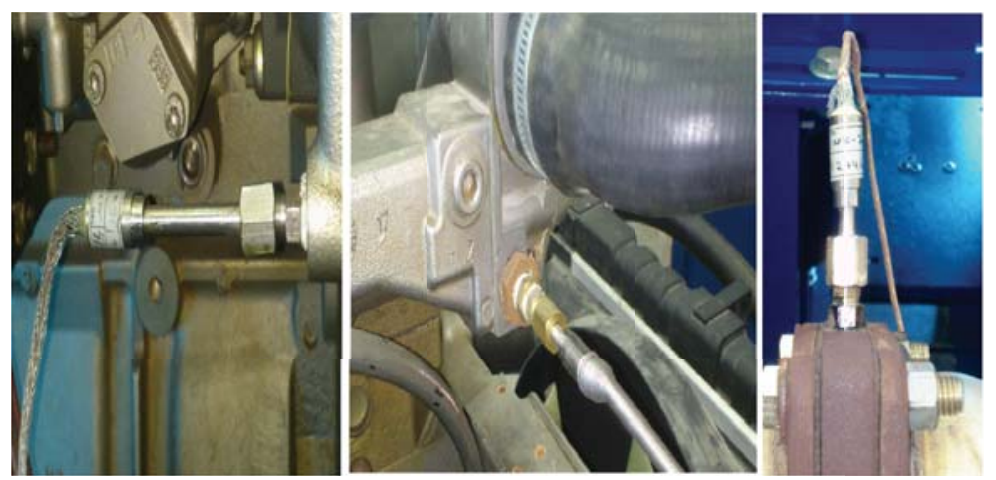

Figura 3.19: Termopares instalados no MCI (da esquerda para a direita: óleo, água e escapamento).

Para o caso da pressão foi utilizado um transdutor do tipo absoluto da fabricante Omegadyne, com faixa de operação de 0 a 60 psi. Este transdutor também foi colocado em local estratégico a fim de verificar a pressão do coletor de admissão do motor (vide Figura 3.20).

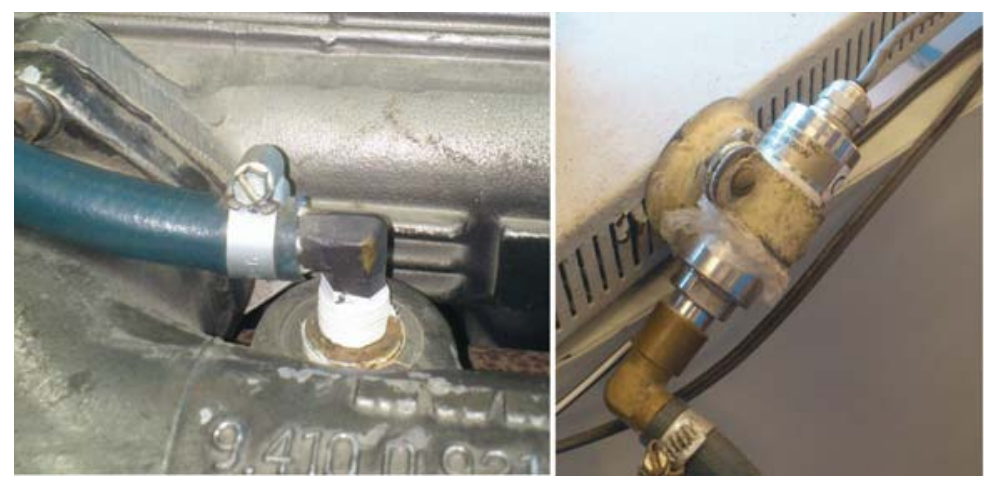

Figura 3.20: Tomada do transdutor de pressão e transdutor utilizado no MCI. 


\section{8}

\section{Inversor de frequência}

Inversores de frequência são dispositivos eletrônicos que convertem a tensão da rede alternada senoidal, em tensão contínua e, finalmente, convertem esta última em uma tensão de amplitude e frequência variáveis. Sua invenção é considerada um marco histórico no setor industrial pois possibilitou a variação da rotação de motores de indução, que antes eram feitas a partir de polias e engrenagens. Este equipamento é composto por basicamente três módulos: seção retificadora, barramento CC e ponte inversora de saída.

O primeiro módulo é o responsável por transformar a tensão de alimentação trifásica em contínua. Basicamente é formado por diodos de potência. O segundo módulo faz a ligação entre o primeiro e o terceiro módulos. Também conhecido como circuito intermediário, é basicamente composto por capacitores. O último módulo é responsável por novamente transformar a tensão retificada CC em trifásica CA. É composta por tiristores (IGBT) que funcionam como uma chave eletrônica, aberta ou fechada. Estes chaveiam várias vezes por ciclo, gerando um trem de pulsos com largura variável senoidalmente (PWM). Esta saída de tensão (pulsada), ao ser aplicada em um motor de indução, irá gerar uma forma de onda de corrente bem próxima da senoidal através dos enrolamentos do mesmo. Na Figura 3.21 um exemplo da saída em tensão e em corrente para um motor de indução é mostrado.

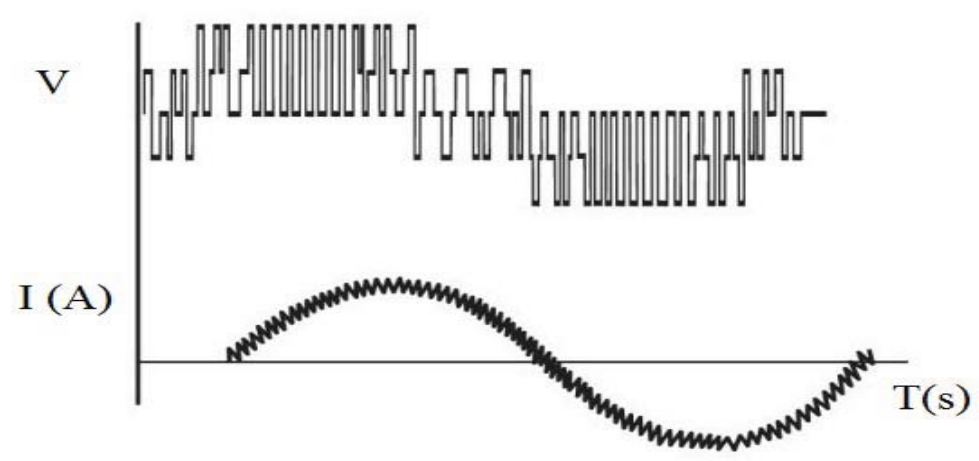

Figura 3.21: Padrão de chaveamento de tensão e corrente (PWM) de um motor de indução alimentado por inversor de frequência.

Uma das vantagens do motor de indução é o fato de poder trabalhar, tanto como motor, quanto como gerador. No primeiro caso, o inversor de frequência fornece energia ao mesmo. Porém no segundo, o motor, que agora é gerador, produz energia e a devolve para o inversor através da ponte inversora. Esta tensão CC proveniente da ponte, ou é dissipada em forma de calor, como por exemplo em bancos de resistores, ou são regeneradas para a rede elétrica. No primeiro caso, IGBT's de frenagem são utilizados 
para comandar o ligamento do resistor de frenagem. Este só ocorre quando o nível de tensão do barramento $\mathrm{CC}$ atinge um certo patamar, previamente estabelecido. No segundo caso, a tensão no barramento é direcionada para uma ponte retificadora regenerativa, que a envia à rede elétrica.

No presente projeto, é utilizado um painel com um inversor de frequência regenerativo, da fabricante $W E G$. Ele é constituído pelo inversor de frequência (inversor de saída), modelo $C F W$-11, com alimentação CC, e um conversor regenerativo (unidade retificadora regenerativa), modelo $C F W-11-R B$, de alimentação trifásica.

Basicamente, o funcionamento deste painel, quando atua na motorização do motor de indução, ocorre da seguinte maneira: a unidade $C F W$-11-RB que está conectada diretamente à rede elétrica, transforma a tensão de entrada (terminais R, S e T), obtida após o filtro de entrada, em contínua, através de um retificador. A tensão de saída é conectada ao barramento CC (circuito intermediário do conversor regenerativo que alimenta o inversor de saída), pelos seus terminais (UD+, UD-). Já no inversor de saída, esta tensão passa pela ponte inversora de saída, onde tem sua tensão e frequência variadas (transformada novamente, de CC para CA), a fim de produzir diferentes torques e rotações, e é enviada ao motor de indução.

Quando o motor de indução atua como gerador, o funcionamento do painel ocorre de maneira inversa ao caso mencionado no parágrafo anterior. Saindo do motor de indução, esta energia entra nos terminais do $C F W$-11 $(\mathrm{U}, \mathrm{V}, \mathrm{W})$ e passa pela ponte inversora, onde é transformada de trifásica para contínua. Desta forma, é enviada ao $C F W-11-R B$ pelo barramento CC. Dentro da unidade retificadora regenerativa, esta tensão contínua é transformada novamente em trifásica, ajustando seus valores de tensão e frequência para adequá-los à rede.

Um esquema elétrico geral do painel com o inversor regenerativo é mostrado na Figura 3.22. A escolha pelo inversor de frequência regenerativo se deve, principalmente, às rápidas respostas que possuem para aplicações com elevadas dinâmicas, como é o caso dos bancos de prova. Segundo o fabricante, a frequência máxima gerada é de 154 Hz. Na Figura 3.23 é mostrado o painel com o inversor regenerativo.

\section{9}

\section{Isolamento Elétrico do Sistema}

Todo o projeto de integração de equipamentos de diferentes naturezas requer atenção por parte do executor. A interação entre equipamentos elétricos e mecânicos, caso não seja bem realizada, poderá levar a resultados imprecisos 


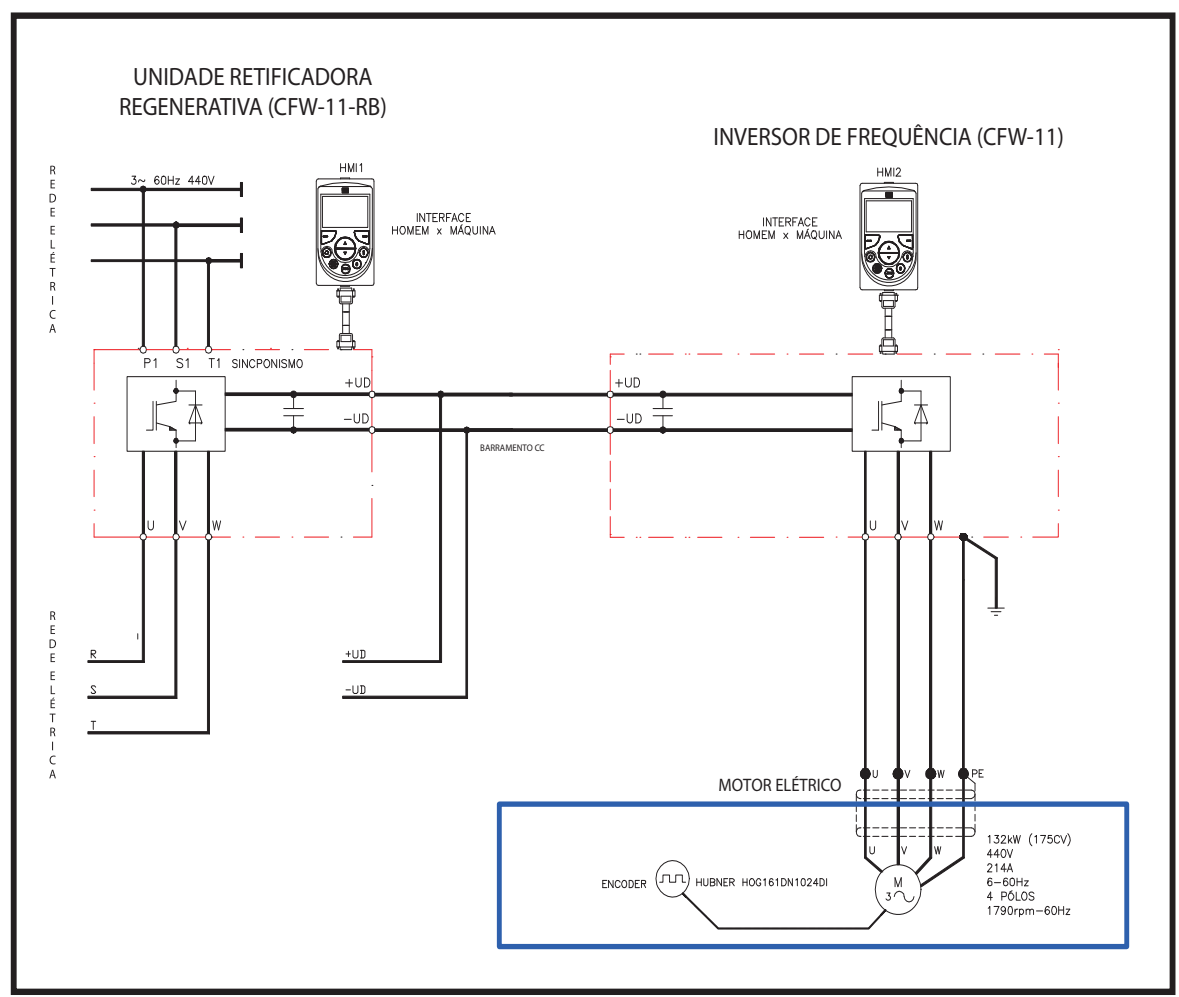

Figura 3.22: Esquema elétrico do inversor de frequência regenerativo.

e até incorretos. Bancos de prova, por natureza, são sistemas particularmente vulneráveis a interferências elétricas.

As metodologias estipuladas pelas normas vigentes em cada país relacionadas a instalação de equipamentos elétricos e, mais precisamente, dinamômetros mudou bastante a partir da descoberta da interferência eletromagnética $(E M I)$, também conhecida como interferência de rádio frequência, como sendo a principal fonte de distorção de sinais.

A tecnologia de $P W M$ baseado nos IGBT's, utilizados no acionamento de motores elétricos a partir do inversor de frequência, reduziu bastante a distorção harmônica total (THD) na linha de alimentação. A tecnologia antiga, baseada em tiristores CC, possui um valor para THD de até $30 \%$ dependendo da carga, enquanto que o valor para a tecnologia dos IGBT's é menor do que $5 \%$ [7]. Apesar destes últimos terem reduzido drasticamente o valor de THD em bancos de prova equipados com dinamômetros CA, eles introduziram a interferência eletromagnética, que é independente da carga, na faixa de 150 a $30 \mathrm{MHz}$. Os IGBT's produzem um sinal que causa fluxos de corrente imprevisíveis ao longo do terra da sala de testes.

A redução dos efeitos da EMI em sistemas e em seus cabeamentos pode ser obtida pela aplicação de uma ou mais técnicas [33]: 


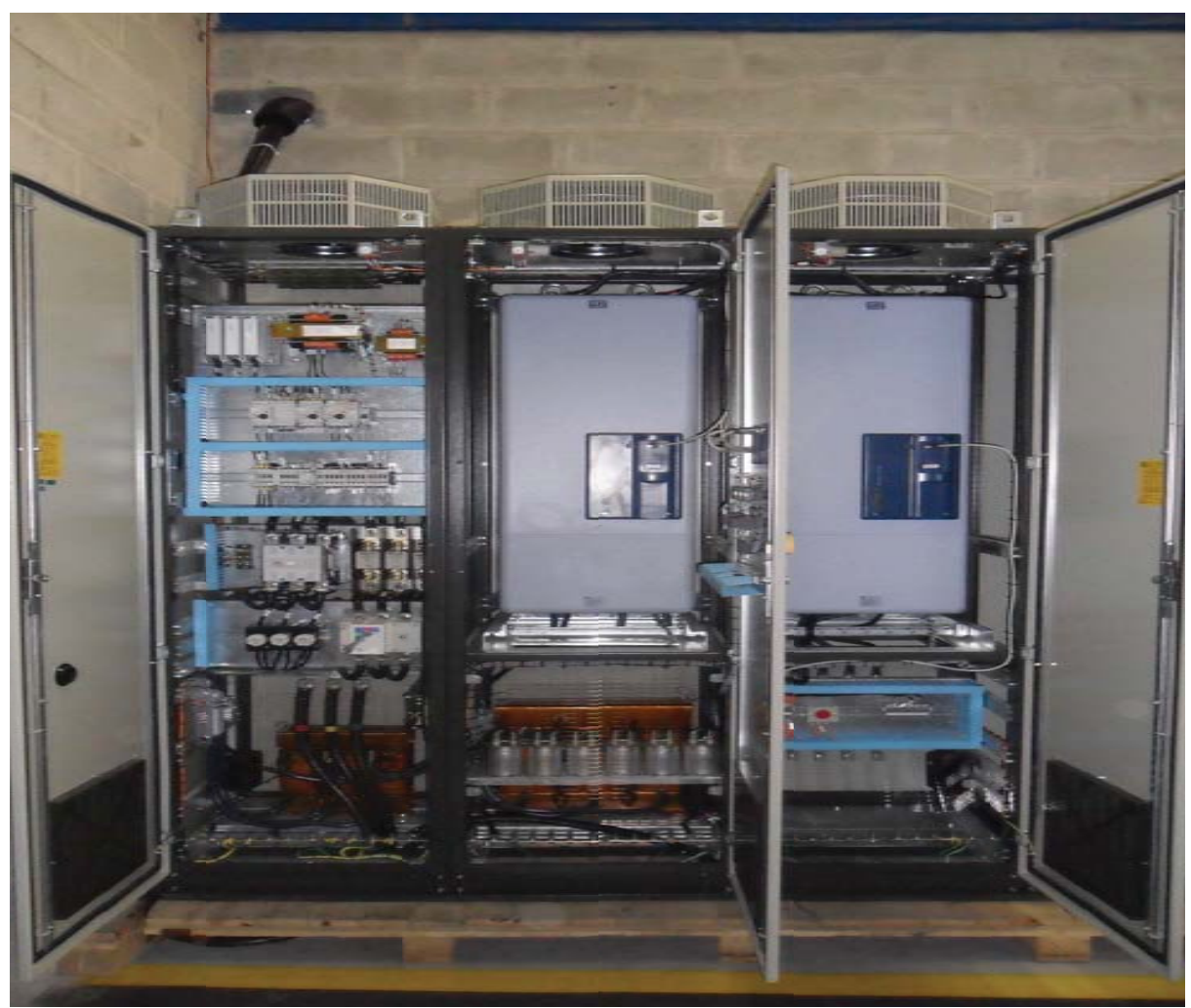

Figura 3.23: Painel com inversor de frequência regenerativo instalado no laboratório.

- Balanceamento

- Blindagem

- Aterramento

- Filtragem

\subsection{1}

\section{Balanceamento}

A técnica do balanceamento se obtém quando os condutores são trançados em pares. Esta técnica, que visa a redução dos efeitos da EMI, é geralmente utilizada em conjunto com a técnica de blindagem, que será vista a seguir.

A Figura 3.24 mostra a relação entre o passo de torção $(\mathrm{mm})$ e a perda por absorção (dB). Quanto maior a perda por absorção menor será o efeito da EMI na trasmissão dos dados.

Esta técnica oferece boa proteção contra EMI para ruídos em baixas frequências (30 e $40 \mathrm{MHz})$. 


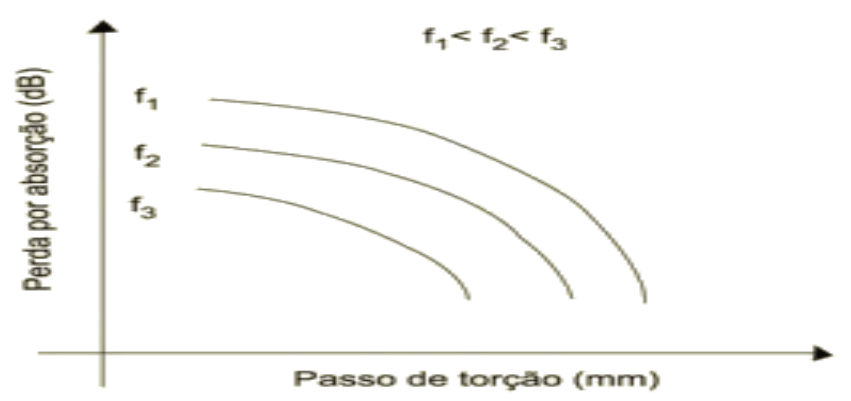

Figura 3.24: Relação entre Passo de torção, perda por absorção e frequências.

\subsection{2}

\section{Blindagem}

A blindagem eletromagnética é utilizada para minimizar os sinais indesejados em um sistema. Assim como tenta evitar que um sinal sofra interferência de outro externo, a blindagem, quando utilizada em um sinal ruidoso, tenta evitar que o mesmo emita seu ruído para outro meio. Esta técnica abrange uma ampla faixa de valores de frequência desde as mais baixas até as de microondas. Vale ressaltar que normalmente a técnica do Balanceamento e da Blindagem são utilizadas em conjunto. Por conta disso, em baixas frequências, os pares trançados absorvem a maior parte da energia proveniente dos efeitos da $E M I$, enquanto que em altas frequências a blindagem do cabo é o principal responsável por absorver esta energia.

Um dos principais tipos de perdas é a Perda por Absorção. Esta ocorre quando uma onda eletromagnética tem sua amplitude diminuída ao atravessar um meio físico, devido as perdas ôhmicas e consequente aquecimento do material. Esta perda pode ser entendida de maneira simples de acordo com a Figura 3.25. Nesta figura, a blindagem tem o papel de isolar o meio 2 do meio 1. Para tanto, ela tem que ter a capacidade de refletir a onda incidente. Na prática, o que ocorre é que uma parte da onda incidente é refletida, outra parte atravessa a blindagem, porém de forma atenuada, até o meio 2 e por fim uma parte fica contida na blindagem até ser absorvida.

O material e a forma da blindagem definirão quanto da onda incidente será refletida, absorvida e ou ficará contida. Esta definição depende da espessura da blindagem e de seu efeito pelicular, que representa a profundidade de penetração da onda contida no interior da mesma. Matematicamente, a perda por absorção (dB) é calculada como:

$$
A_{\text {loss }}=8,686\left(\frac{\epsilon}{\delta}\right)
$$

onde $\epsilon$ é a espessura da blindagem e $\delta$ é o efeito pelicular. 


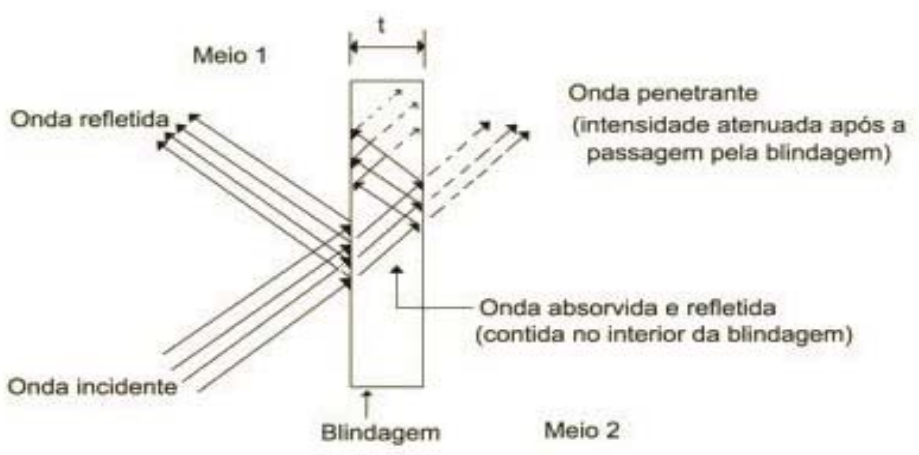

Figura 3.25: Efeito da blindagem dos cabos - perda por absorção.

Como mencionado anteriormente, quanto maior a perda por absorção menor será a intensidade do campo da onda que irá afetar o sinal medido.

Além da perda por absorção, a perda por reflexão é também um parâmetro importante associada a eficiência da blindagem. Esta perda é uma relação entre a impedância da onda que penetra a blindagem (variável) e a impedância da blindagem (constante). Campos elétricos (alta impedância e baixa corrente) possuem uma maior perda por reflexão do que campos magnéticos (baixa impedância e alta corrente). Portanto, o tipo de campo determina a resposta da blindagem com relação a perda por reflexão.

\subsection{3}

\section{Aterramento}

Vários parâmetros determinam a eficiência do aterramento. Fatores como as características da fonte geradora de EMI, características do ambiente e estrutura do aterramento são alguns dos pontos que devem ser levados em conta na execução de qualquer projeto. A questão do aterramento pode ser subdividida em dois grupos: aterramento do sistema e equipamentos e aterramento da blindagem dos cabos.

\subsubsection{1}

\section{Aterramento do Sistema e Equipamentos}

O aterramento do sistema e equipamentos eram utilizados como forma de proteção para as pessoas. Porém, questões relacionadas aos requisitos de compatibilidade eletromagnética $(C E)$ fez com que sua função deixasse de ser somente esta. A fim de cumprir os requisitos de $C E$, é necessário que o sistema seja provido de diferentes pontos de terra onde todos estão conectados a uma malha comum, com a menor impedância possível. 


\subsubsection{2}

\section{Aterramento da Blindagem dos Cabos}

Uma solução única de aterramento, quando se trabalha com cabos blindados e o aterramento da blindagem, é algo difícil de se implementar visto que o projetista tem de lidar com duas fontes diferentes de problemas: o ruído gerado por campos elétricos e os gerados por campos magnéticos [33].

Os campos elétricos $(\mathrm{V} / \mathrm{m})$ são gerados em sistemas de cabos em razão do acoplamento capacitivo (quando cabos são conduzidos paralelamente) e induzem uma tensão de ruído no canal interferido. Por outro lado, os campos magnéticos $(A / m))$ são gerados em sistemas de cabos por causa do acoplamento indutivo (fluxo magnético proveniente da passagem de uma corrente por um cabo gerando uma tensão de ruído devido a indutância mútua) e levam uma corrente de ruído no canal interferido.

Alguns métodos para evitar ruídos provenientes de acoplamentos capacitivos e indutivos são semelhantes. Dentre eles pode-se destacar dois: cabos de sinal devem, obrigatóriamente, ficar afastados de cabos de força; utilização de cabos blindados. Além disso, a fim de evitar acoplamentos indutivos, a utilização de pares de cabos trançados é fundamental.

Com relação a blindagem dos cabos, o ponto divergente é com relação a forma de aterramento da mesma. A fim de evitar o efeito do acoplamento indutivo, a malha deve ser aterrada em apenas uma de suas extremidades. Em contrapartida, o efeito do acoplamento capacitivo é evitado aterrando a malha em ambas as extremidades. O problema do aterramento em ambas as extremidades do cabo é a formação de loops de terra. Loops de terra são gerados por diferentes potenciais no terra, que ocorrem através da blindagem do cabo, induzindo correntes parasitas (acoplamento indutivo). Portanto, a fim de se evitar ambas interferências, além dos loops de terra, deve-se aterrar a blindagem do cabo em ambas as extremidades e possuir terras com diferenças de potencial mínimas. A Figura 3.26 e a Figura 3.27 a seguir mostram a forma de conexão com uma extremidade aterrada e com duas.

\subsection{4}

\section{Filtragem}

A filtragem é aplicada por meio da utilização de circuitos (filtros) que impedem a passagem de sinais interferentes que se propagam em uma dada faixa específica de frequências. Essa técnica é muito eficiente mas é usada em circuito eletrônico no hardware de equipamentos ativos, não sendo adequada para uso em cabos. 


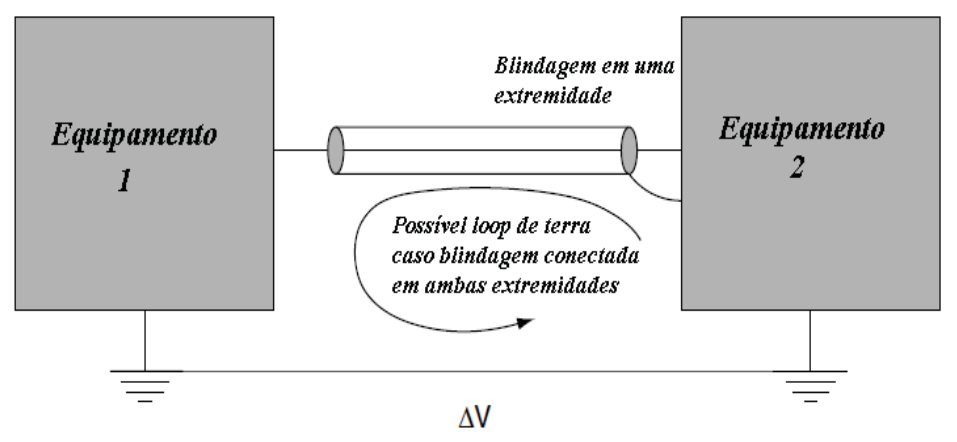

Figura 3.26: Blindagem em uma das extremidades e diferença de potencial entre terras.

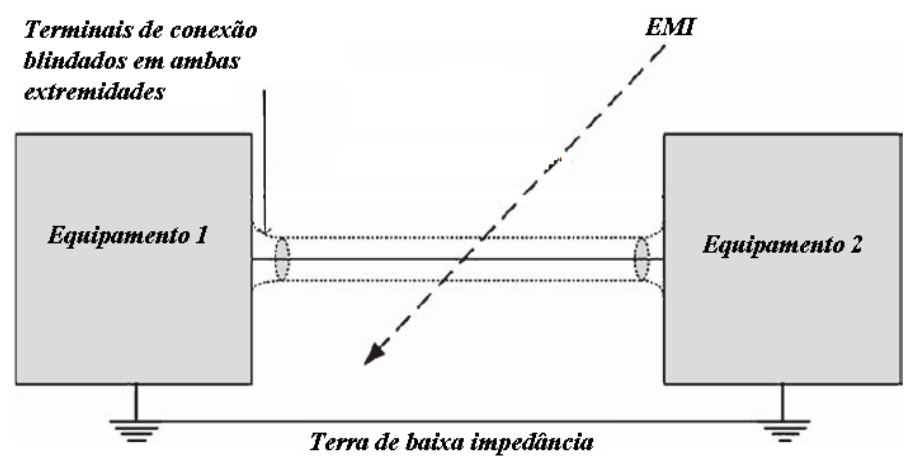

Figura 3.27: Blindagem em ambas as extremidades e baixa impedância entre terras.

3.9.5

\section{Considerações para o Projeto}

No presente projeto, diversas medidas foram adotadas a fim de evitar problemas ocasionados pela EMI. Devido ao elevado custo dos cabos de potência blindados para a conexão entre o motor elétrico e o inversor de frequência, optou-se pela utilização de cabos sem blindagem. Informação relevante à respeito de cabos blindados para inversores de frequência pode ser encontrado em [34]. Com relação aos cabos de comando e controle, foram utilizados cabos trançados e blindados.

Além disso, para o cabo de sinal do enconder foi utilizado um trançado com dupla blindagem (folha e trança metálica). Dois terras foram implementados fisicamente: um responsável por aterrar os equipamentos de elevada potência tais como motor elétrico e inversor, além da base do banco de provas; e outro utilizado como terra de medição para o aterramento da placa de aquisição de dados e blindagem das malhas dos cabos de comando e controle.

Ainda, para o caso do servomotor e do sensor de torque, foram adotadas medidas com o intuito de evitar o contato mecânico (isolamento) entre estes 
equipamentos e os que compõem a base de testes. Para tanto, no caso do servomotor, foi utilizado uma placa de acrílico como suporte, os parafusos de fixação a base foram revestidos com isolante termo retrátil e a conexão entre a haste do servomotor e a bomba de combustível foi utilizado pvc (vide Figura 3.18). No caso do transdutor de torque, foi utilizado um suporte de papelão com um material à base de borracha como suporte e em seus parafusos de fixação também foi utilizado um isolante termo retrátil.

Utilizou-se também neste projeto módulos isoladores de sinais analógicos a fim de evitar que ruídos provenientes de $E M I$ afetasse as medições realizadas. Estes módulos, da fabricante Phoenix Contact modelo MCR-C, além de isolar, tem a capacidade de converter sinais analógicos de tensão para corrente e corrente para tensão, através de chaves selecionadoras.

Nas Figuras 3.28, 3.29, 3.30 e 3.31 são mostradas algumas fotos das medidas adotadas no projeto, mencionadas anteriormente. Dentre elas podese destacar a dupla blindagem utilizada em alguns cabos de dados, os terras utilizados no projeto, medidas paleativas para equipamentos em contato direto com a base de testes e os módulos isoladores de sinais analógicos.

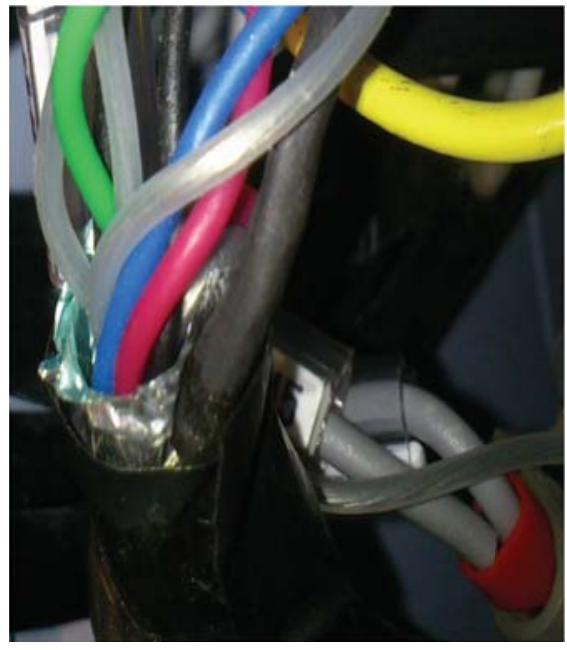

Figura 3.28: Detalhe do cabo do encoder com dupla blindagem.

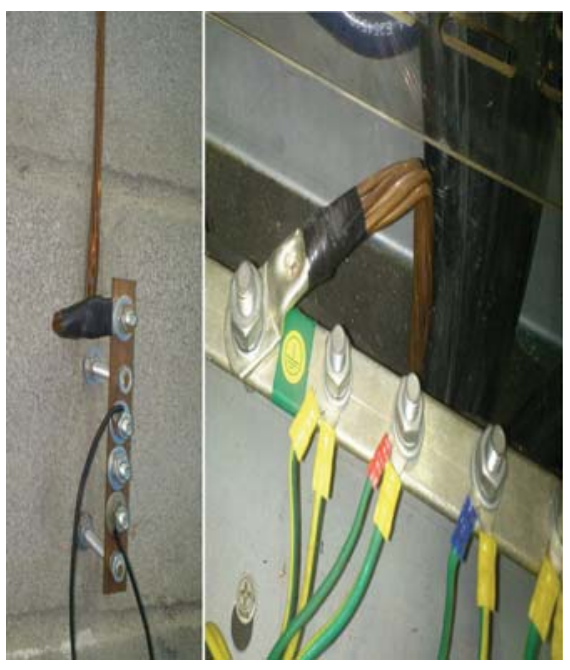

Figura 3.29: Terra de medição e de alta potência utilizados no projeto. 


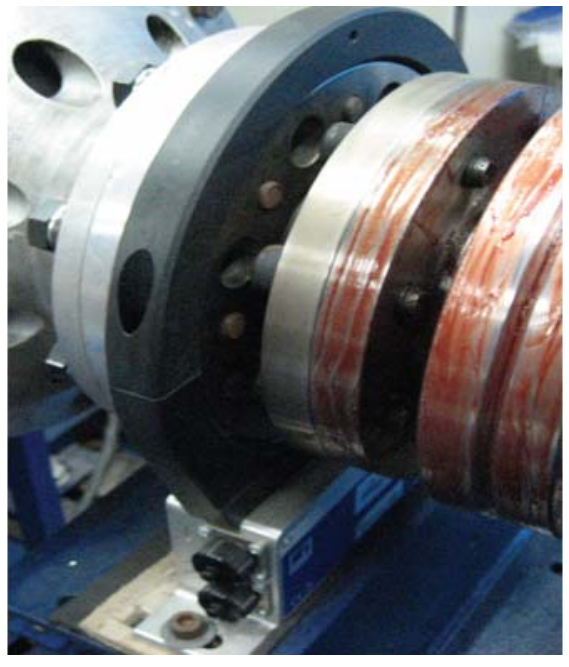

Figura 3.30: Base do estator do transdutor de torque isolado com suporte de borracha e papelão.

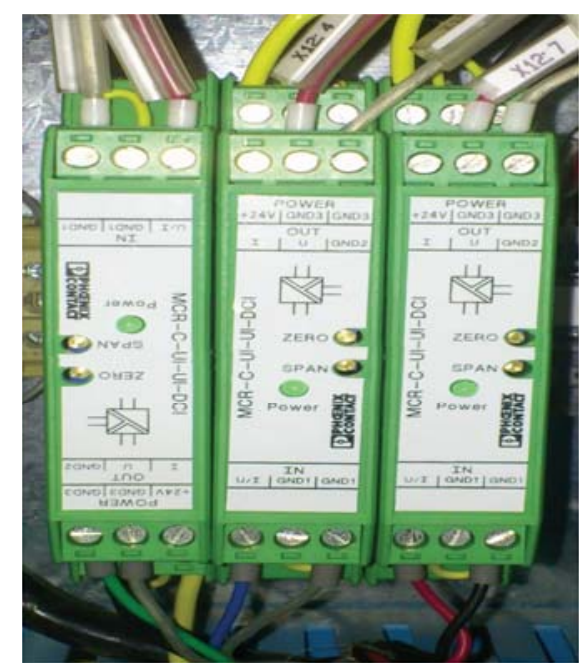

Figura 3.31: Módulos isoladores de sinais analógicos utilizados nos cabos de comando e controle. 
4

\section{Desenvolvimento do Sistema de Aquisição de Dados e do Programa de Monitoramento e Controle}

\section{1 \\ Desenvolvimento do Sistema de Aquisição de Dados}

A escolha e dimensionamento do sistema de aquisição de dados é importante no desenvolvimento do projeto de construção de um banco de provas. O sobredimensionamento, apesar de na maioria das vezes não impactar diretamente no desempenho do sistema, pode vir a acarretar em um gasto desnecessário de verbas; em contrapartida, o subdimensionamento impacta diretamente no desempenho do sistema visto que este não será capaz de suprir todas as necessidades do projeto.

No presente trabalho, a fim de realizar um correto dimensionamento do sistema de aquisição e controle da bancada de testes, os seguintes pontos foram analisados:

- Tempo e Frequência (taxa) de Aquisição;

- Tipos e Quantidades de Transdutores;

- Quantidade de Canais Necessários;

\subsection{1}

Tempo e Frequência de Aquisição

O tempo e a frequência de aquisição são fatores de fundamental importância no dimensionamento dos equipamentos. A fim de ser capaz de dimensionar corretamente o sistema de aquisição, pesquisou-se na literatura os valores utilizados na aquisição das principais variáveis de interesse ([13], [1], [35]). A partir destes valores, e das características do sistema proposto, chegouse a uma taxa de aquisição de $1 \mathrm{kHz}$.

\subsection{2}

Tipos e Quantidades de Transdutores

Os tipos de transdutores utilizados são importantes sob o ponto de vista de como o sinal, recebido ou enviado, deverá ser condicionado. No caso do presente projeto, os transdutores de torque, rotação e temperatura e o sinal de referência do servomotor, que atua na bomba de combustível, enviam sinais em forma de tensão (0 a $10 \mathrm{Vcc}$ ). Já o transdutor de pressão envia os sinais em forma de corrente (4 a $20 \mathrm{~mA}$ ). 


\subsection{3}

\section{Quantidade de Canais Necessários}

A quantidade de canais que serão utilizados é importante pois sistemas de aquisição variam conforme este valor. Porém, nem sempre no início de um projeto se tem a dimensão exata de quantos sensores serão necessários e quais suas características. Além disso, outras formas de acionamentos, como por exemplo relés, entradas e saídas digitais e contadores, são geralmente requisitados. Portanto, o sobredimensionamento no número de canais se faz necessário na maioria dos casos.

No presente projeto, utilizou-se 13 canais, dentre os quais incluem entradas e saídas analógicas, contadores e relés.

Após estas análises optou-se por adquirir um sistema de aquisição e geração de dados da fabricante National Instruments. Este sistema, chamado de PXI, é composto por um gabinete (chassis), que comporta os módulos à serem inseridos; uma unidade central de processamento (CPU), também chamada de controladora, que possui um processador, um disco rígido, memórias, um sistema operacional e o software LabVIEW instalado; uma placa de aquisição de dados multifuncional (DAQ) e seus respectivos acessórios; um módulo de acionamento a relé e um módulo de leitura para termopares.

A Figura 4.1 mostra um esquema de como é composto um sistema PXI e a Figura 4.2 mostra o sistema, e sua placa de aquisição, utilizado no projeto.

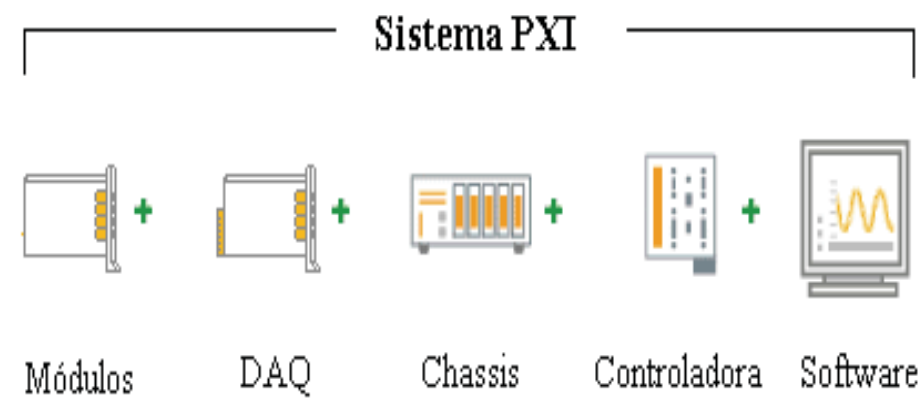

Figura 4.1: Composição de um sistema PXI da National Instruments.

\section{2}

\section{Desenvolvimento do Programa de Monitoramento e Controle}

A fim de ser capaz de unificar todo o aparato experimental e ser possível o monitoramento e controle do mesmo, desenvolveu-se uma rotina de programação onde foi possível realizar tais tarefas. O software utilizado para realizar o controle, aquisição e processamento dos sinais do presente projeto 

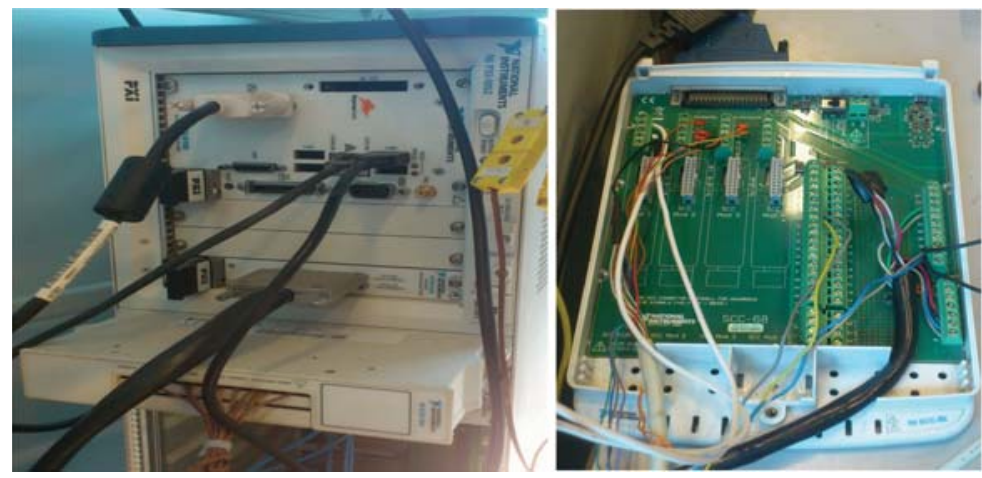

Figura 4.2: Sistema PXI com módulos auxiliares e placa de aquisição de dados DAQ.

foi o LabVIEW RT, versão 2009, da fabricante National Instruments (NI). Além deste, foi utilizado o software Measurement \& Automation Explorer $(M A X)$, também da NI. O software LabVIEW é utilizado, tanto no meio acadêmico quanto no industrial, para aplicações que requerem sensoriamento, monitoração e controle de sistemas devido a sua simplicidade e comprovada robustez. Alguns exemplos de trabalhos onde este software foi utilizado podem ser encontrados em [36] e [37].

Este capítulo irá tratar dos seguintes tópicos:

- Sistema Operacional em Tempo Real;

- Hardware e Software de Controle do Banco de Provas;

- Desenvolvimento da Programação;

- Pós Processamento e Análise dos Dados.

\subsection{1}

\section{Sistema Operacional em Tempo Real}

Sistemas operacionais (OS) são responsáveis por gerenciar tarefas e recursos de hardware além de hospedar aplicativos/programas que são executados no computador (host). OS's em tempo real (RT) também realizam essas tarefas mas são projetados especialmente para executar aplicações/programas com precisão de tempo e confiabilidade. Este fato é de suma importância principalmente em sistemas de automação, controle e medições onde o atraso em uma rotina do programa pode acarretar em situações de perigo.

Muitas vezes, um sistema RT é erroneamente definido como sendo um sistema rápido ou de rápida resposta. Porém, conforme mencionado anteriormente, estes são sistemas onde o tempo para a execução de uma determinada tarefa é assegurado dentro de limites especificados pelo programador além de 
possibilitar a priorização de tarefas. Em contrapartida, OS's de propósito geral não possuem esta confiabilidade no tempo de execução de uma tarefa (estes sistemas são otimizados para executar aplicações simultaneamente, assegurando que todas recebam um tempo de processamento). Por conta disso, suas execuções podem ser finalizadas muito antes, ou depois, do esperado. A flexibilidade de maior controle sobre o tempo de execução e sobre as prioridades das tarefas dos sistemas RT são grandes vantagens, quando usadas corretamente, sobre outros sistemas.

Alguns termos e conceitos utilizados em sistemas RT são descritos a seguir:

- Período de um Ciclo do Loop: tempo necessário para executar um ciclo do loop $(\mathrm{T})$;

- Jitter: diferença entre a variação do tempo de execução de um ciclo e o tempo desejado para esta execução (vide Figura 4.3);

- Determinismo: indica a confiabilidade de resposta a uma tarefa em um determinado tempo (reflete a magnitude do jitter);

- Loop de Tempo Crítico (TCL): Loop que precisa ser executado com maior precisão de tempo possível;

- Prioridade: Característica que define a importância de execução de uma função ou loop relativo a outra.

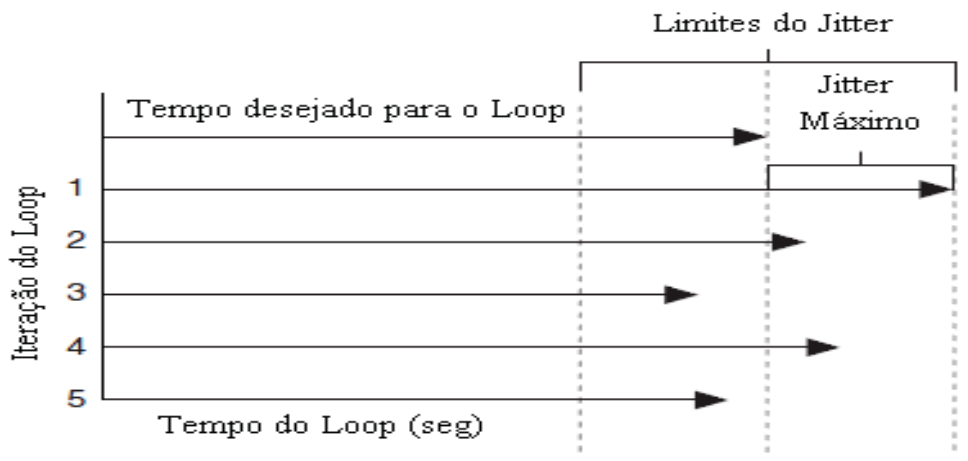

Figura 4.3: Comportamento do jitter sobre várias iterações.

Segundo [38], OS's de tempo real foram criados para duas principais aplicações: respostas a eventos e controle de malha fechada. O primeiro caso representa aplicações onde, após a ocorrência de um evento, uma decisão deve ser tomada baseada no ocorrido. Um exemplo deste tipo de aplicação em bancos de prova é no monitoramento das temperaturas do motor: quando uma determinada temperatura ultrapassar um certo limite especificado, uma 
decisão é tomada (por exemplo, levar o motor à marcha lenta). Por outro lado, a realização do controle de malha fechada (realimentação) também possui grande utilidade em ensaios de motores. Nestes tipos de controle, a realimentação do sistema deve ser constantemente monitorada a fim de se ajustarem as saídas do mesmo. Como a saída depende do processamento dos valores de entrada, este deve ser realizado dentro de um tempo específico para assegurar que as saídas estão corretas (por exemplo, o controle do atuador da bomba de combustível).

Além dessas duas aplicações, sistemas RT são recomendados quando se pretende realizar testes por longos períodos de tempo, como por exemplo, testes de durabilidade em motores e componentes. Pelo fato de usar menos recursos de software, devido ao menor número de aplicativos e programas sendo executados ao mesmo tempo, a chance de ocorrer falhas devido ao longo tempo de funcionamento é bastante reduzida.

\subsection{2}

\section{Hardware e Software de Controle do Banco de Provas}

O desenvolvimento de um sistema de controle RT com desempenho confiável e precisão no tempo (determinismo), requer a integração da programação realizada, um OS RT e módulos, compatíveis com OS's RT, capazes de realizar a leitura e o envio de dados [38].

Diante do exposto anteriormente, decidiu-se, para a execução do presente projeto, transformar os hardwares mencionados na seção 4.1 em sistemas RT (esta possibilidade de migrar de um OS para outro depende de cada equipamento).

O software LabVIEW RT, utilizado para realizar a programação do banco de provas, é bastante semelhante ao já conhecido, nos meios acadêmicos e industriais, LabVIEW. A diferença reside na incompatibilidade de algumas funções disponíveis no segundo, aos OS's RT, e no fato de que no RT existem ferramentas específicas para o desenvolvimento das aplicações RT.

Segundo [39], o LabVIEW é um software que possui uma linguagem de programação gráfica que utiliza ícones, em vez de linhas de texto, para criar aplicações. Em contraste às linguagens de programação baseadas em texto, em que instruções determinam a execução do programa, este utiliza uma programação baseada em fluxo de dados, onde o fluxo determina a ordem de execução.

No LabVIEW, o programador constrói uma interface de usuário, utilizando um conjunto de ferramentas e objetos. A interface de usuário é conhecida como Painel Frontal. O código, construído no Diagrama de Blocos, é adicionado utilizando representações gráficas de funções para controlar os objetos do 
painel frontal. Sob certos aspectos, o diagrama de blocos assemelha-se a um fluxograma. Os programas criados em LabVIEW são chamados de instrumentos virtuais ou, simplesmente, VI (Virtual Instruments). Isto se deve ao fato de sua aparência e operação se assemelharem à instrumentos físicos, tais como tacômetros e multímetros.

Com este software, é possível criar aplicações de teste e medição, aquisição de dados, controle de instrumento, registro de dados, análise de medição e geração de relatório.

No caso específico do software LabVIEW RT [40], ele é composto pelo LabVIEW, RT Engine (software dedicado ao hardware utilizado como RT (Target)) e o Projeto, que inclui todas as funções (VI's) desenvolvidas para a aplicação (vide Figura 4.4).

Nesta figura, a árvore de Projeto é dividida em duas partes: My Computer e pxi-dino (169.254.194.20). Os arquivos inseridos em cada uma dessas partes serão executados somente por esta partição.

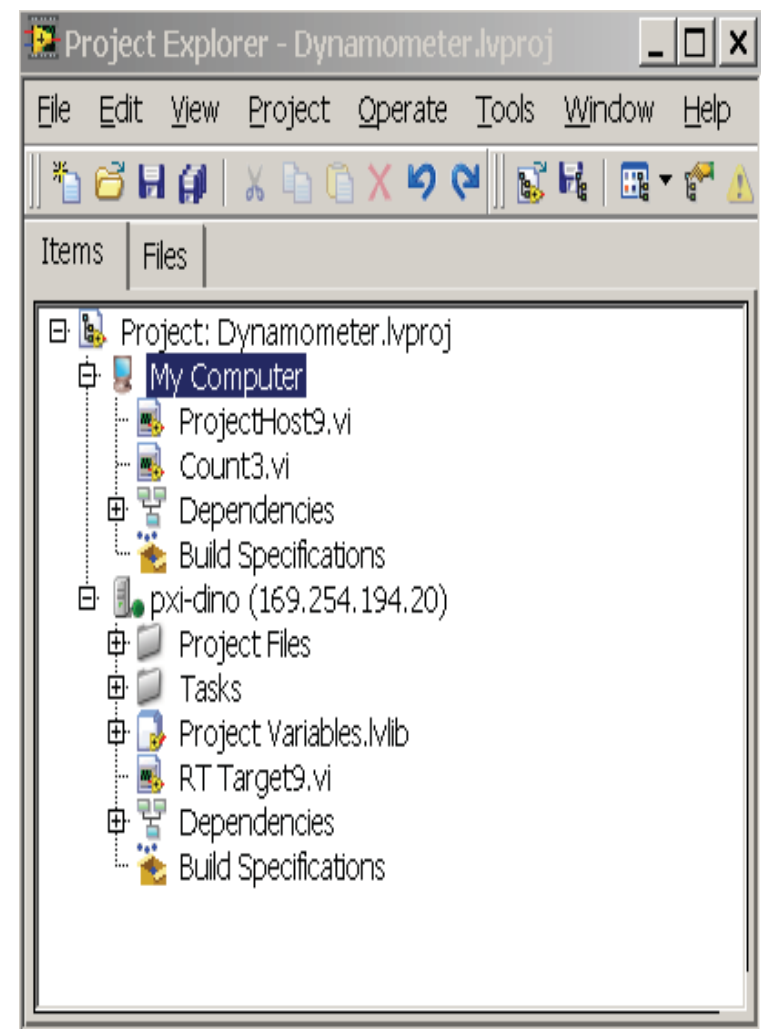

Figura 4.4: Esquema de uma árvore de projeto para aplicações em LabVIEW RT.

No caso do hardware, ele é composto por um computador hospedeiro (Host) e por um Target RT. 
A seguir são explicados as funções de cada um dos componentes mencionados anteriormente.

- Computador host: computador onde o LabVIEW e o LabVIEW RT estão instalados para que o programador desenvolva as aplicações. Responsável também por realizar o download das VI's desenvolvidas e executálas no target. O computador host pode executar VI's para realizar a comunicação entre as funções que estão sendo executadas no target, a fim de prover uma interface para o usuário;

- LabVIEW: as VI's são desenvolvidas no LabVIEW instalado no computador host. O módulo RT extende as capacidades do LabVIEW com ferramentas adicionais tais como criação, debugging e implementação (deploy) de VI's no target;

- RT Engine: versão do LabVIEW que é executada no target RT;

- RT target: hardware que possui um processador e um OS RT instalado. Além disso, possui o software RT Engine instalado e executa as VI's criadas pelo LabVIEW. A comunicação entre o target e o host é feita, no caso do presente projeto, através do protocolo de comunicação TCP/IP.

A Figura 4.5 fornece uma visão geral da arquitetura de um sistema RT, desde o host até o target.

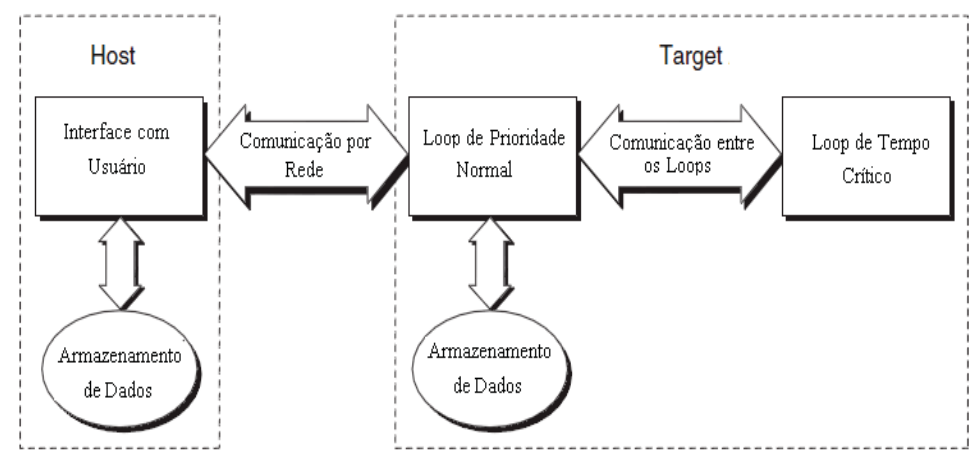

Figura 4.5: Arquitetura de um sistema RT. 


\subsection{3}

\section{Desenvolvimento da Programação}

No caso do presente projeto, a programação foi desenvolvida seguindo o seguinte procedimento:

- Desenvolvimento do programa e sub-rotinas a serem executadas no hardware RT (target);

- Desenvolvimento do programa e sub-rotinas a serem executadas no computador hospedeiro (host);

- Testes de verificação do correto funcionamento do programa.

4.2.3.1

Desenvolvimento do Programa e Sub-Rotinas a Serem Executadas no Hardware RT (Target)

Assim como em qualquer linguagem de programação, todas as funções desenvolvidas fazem parte de uma rotina principal que, dependendo do ponto em que se encontra, "chama" as sub-funções.

A rotina principal do programa executado no target é composta por duas partes: o loop de tempo crítico (TCL) e o loop de prioridade normal (NPL).

Foi escolhido, para os loops TCL e NPL, um período de 50ms para um sistema com taxa de aquisição de $1 \mathrm{kHz}$. Realizando uma simples regra de três chega-se a um valor de 50 amostras por período do loop. Por conta disto, todas as variáveis lidas possuem uma capacidade de armazenamento (buffer) de 50 amostras, a fim de não perder nenhum dado aquisitado. Portanto, percebe-se que a relação entre o período do loop e o tamanho do buffer, para uma taxa de aquisição constante, é diretamente proporcional, assim como a relação entre a taxa de aquisição e o tamanho do buffer, para um período constante. Esta relação é de fundamental importância para o correto dimensionamento das variáveis utilizadas no projeto.

O TCL é responsável pela parte do programa que executa as tarefas determinísticas. Tais tarefas englobam, basicamente, o controle do atuador da bomba de combustível, os sinais enviados e lidos do sistema e os modos de segurança. Em contrapartida, o NPL é responsável por realizar a comunicação entre a VI do target com a VI do Host, ou seja, ele envia os dados do TCL para o host e do host para o TCL. Além disso, é responsável por executar o pré-processamento e gravação dos dados.

Controle do Atuador da Bomba de Combustível: Conforme descrito na seção 3.6.2, utilizou-se um servomotor como atuador da bomba de combustível 
do motor Diesel. A fim de ser capaz de posicioná-lo conforme desejado, foi desenvolvido um controlador do tipo PID. O esquema básico do controle PID para um processo é mostrado na Figura 4.6. Quando se tem o modelo matemático do processo, é possível aplicar várias técnicas visando à determinação dos parâmetros do controlador que atendam às especificações de regimes transitórios e estacionários do sistema a malha fechada [41]. Nos casos, contudo, em que não se possui um modelo matemático representativo do processo, a abordagem analítica deixa de ser viável. Nestes casos deve-se fazer uso de técnicas experimentais para a sintonia dos parâmetros do controlador PID. Para tanto, foi utilizada um conjunto de regras bastante conhecidas e de reconhecida capacidade de sintonização: Regras de Ziegler-Nichols [41].

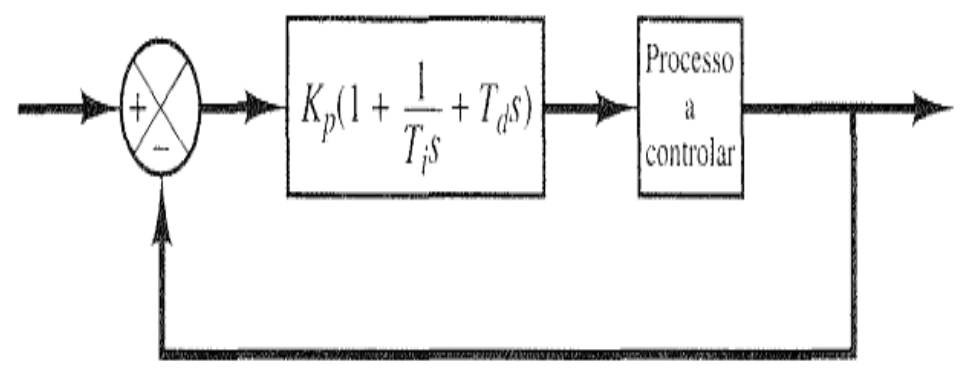

Figura 4.6: Esquema do controle PID de um processo.

Para a aplicação das regras de Ziegler-Nichols, primeiramente são ajustados os valores dos tempos dos controladores integral e derivativo em $T_{i}=\infty$ e $T_{d}=0$. Utilizando somente a ação do controle proporcional, aumenta-se o valor de $K_{p}$ de 0 até um valor crítico $K_{c r}$, quando o sinal de saída, referência da posição do atuador, apresentar oscilações mantidas. Com isso, são determinados os valores do ganho crítico $K_{c r}$ e do Período Crítico $P_{c r}$ correspondente. A Figura 4.7 mostra a curva obtida e o correspondente valor do período crítico, para um $K_{c r}=70$.

De posse destes valores, pode-se determinar os valores dos ganhos $K_{p}, T_{i}$ e $T_{d}$ conforme a Tabela 4.1 .

Tabela 4.1: Ganhos do controlador PID

\begin{tabular}{|c|cc|}
\hline Ganhos & & \\
\hline$K_{p}$ & $0,6 K_{c r}$ & 42 \\
$T_{i}$ & $0,5 P_{c r}$ & $0,00625 \mathrm{~min}$ \\
$T_{d}$ & $0,125 P_{c r}$ & $0,0016 \mathrm{~min}$ \\
\hline
\end{tabular}




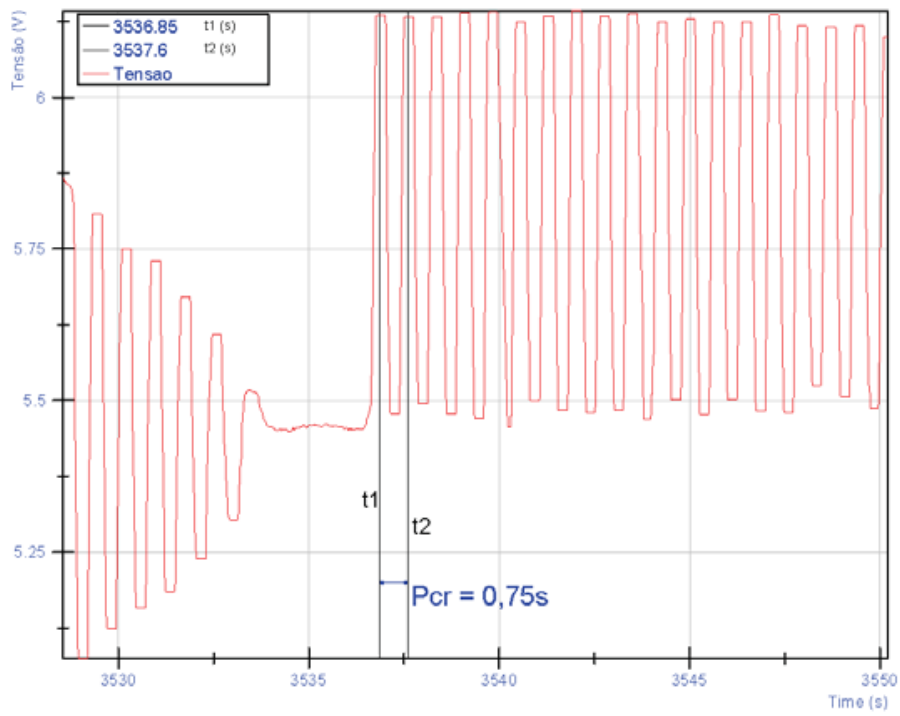

Figura 4.7: Saída do servomotor.

Leitura e Escrita de Dados: Os dados lidos do sistema tais como rotação, torque, dentre outros devem ser convertidos para valores físicos representativos de tais grandezas. Esse pré-processamento é realizado através de uma sub-VI onde todas as variáveis lidas são convertidas para as suas respectivas unidades.

Já os dados a serem escritos, torque e rotação do dinamômetro e posição do atuador da bomba de combustível, são enviados pela VI do host para o NPL que por sua vez os envia ao TCL, no formato compatível com os equipamentos.

Normalmente, em aplicações envolvendo o controle de bancos de prova, é desenvolvido um controlador, semelhante ao proposto para o controle do atuador da bomba de combustível, exclusivo para a rotação imposta pelo dinamômetro. No caso do presente projeto não houve a necessidade de tal implementação pois o controle sobre a rotação do dinamômetro é feito através do inversor de frequência da fabricante WEG. Este já possui um controle do tipo PID, cujos ganhos são 31,5 para o ganho proporcional, 0,205 para o integral e 0,0 para o derivativo, de modo que, para controlar a velocidade, basta apenas enviar a este equipamento a referência desejada.

\subsubsection{2} Desenvolvimento do Programa e Sub-Rotinas a Serem Executadas no
Computador Hospedeiro (host)

Assim como no caso do target, o programa executado no host possui uma rotina principal e sub-funções por ela utilizadas.

O período do loop da rotina principal foi escolhido como sendo de $100 \mathrm{~ms}$. Esta escolha deve-se ao fato de que esta VI não necessita ser atualizada com bastante frequência por se tratar de uma interface com o usuário. Diminuindo 
esse período, a atualização das variáveis mostradas seria realizada de forma mais rápida, dificultando e podendo até confundir a visualização por parte do operador.

Nesta VI, além de ser possível visualizar as variáveis lidas, o envio de comandos para o sistema, as inicializações do programa que é executado no target e do inversor de frequência, os diferentes modos de controle, nome dos arquivos onde serão salvos os dados e os ganhos do controle PID podem ser realizados. A Figura 4.8 mostra a interface do usuário desenvolvida.

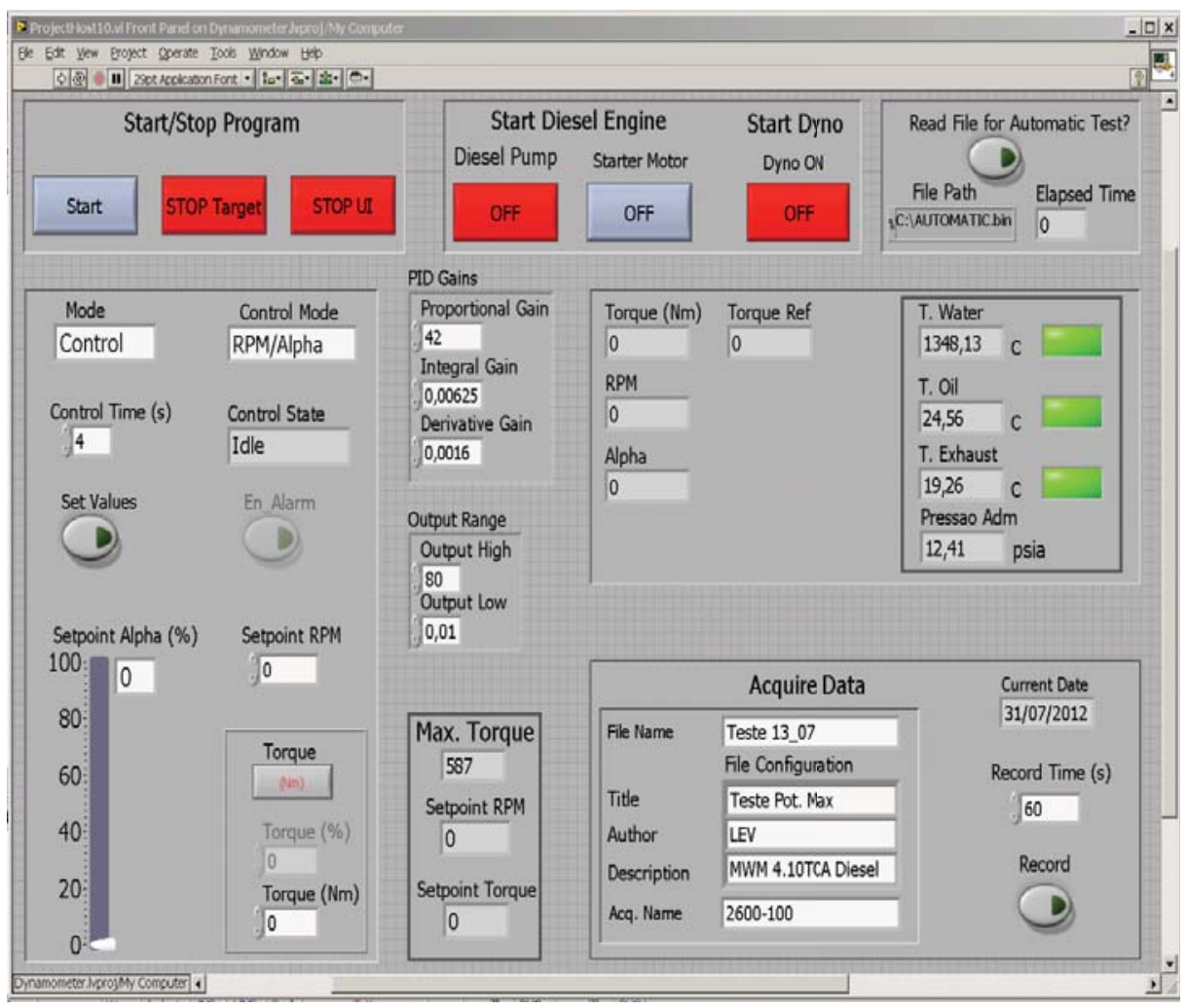

Figura 4.8: Interface do usuário desenvolvida.

A seguir, uma breve descrição dos seguintes comandos será fornecido:

- Start/Stop Program;

- Start Diesel Engine e Start Dyno;

- Mode e Control Mode;

- Setpoint Alpha, Setpoint RPM e Torque;

- Read File for Automatic Test;

- Acquire Data. 
Comando Start/Stop Program: O comando Start é responsável por carregar todos os parâmetros da configuração inicial do programa e iniciar a comunicação com a VI do target.

O comando Stop Target e Stop UI são os comandos responsáveis, respectivamente, por encerrar a comunicação com o target e com a interface do usuário, fechando a rotina principal e suas sub-VI's.

Comando Start Diesel Engine e Start Dyno: Apesar de a bancada de testes desenvolvida neste trabalho ser constituída por um dinamômetro ativo, ou seja, dentre outras características, ser capaz de dar a partida no MCI, optou-se por incluir na programação um comando capaz de acionar o motor de partida do mesmo. Esta é a função do comando Start Diesel Engine.

No mesmo caminho, o comando Start Dyno é responsável por habilitar o inversor de frequência de modo que os comandos de torque e velocidade desejados sejam enviados ao motor elétrico.

Comando Mode e Control Mode: O comando Mode é composto por três funções:

- Manual: este comando libera as funções Setpoint Alpha, Setpoint RPM e Torque para que o operador possa alterá-las dentro de seus limites, em qualquer momento. Pelo fato desta função possibilitar a alteração imediata das variáveis, o operador deve ter bastante cuidado e critério ao utilizá-la;

- Control: este comando habilita a função Control Mode;

- Automatic: este comando habilita o teste automático. Neste teste o operador, antes de iniciar o programa, cria um arquivo de texto com os pontos desejados. Estes pontos são armazenados, pela rotina principal do host, em uma matriz para que quando o comando automatic for selecionado o teste seja iniciado.

O comando Control Mode é composto por duas funções (a nomenclatura adotada segue o mencionado em 2.1.2):

- RPM/Alpha;

- Torque/Alpha.

O primeiro modo de controle é realizado ajustando-se os valores de rotação do dinamômetro e da posição do atuador da bomba de combustível 
(Alpha). Já no segundo modo, o torque imposto pelo dinamômetro e o alpha são controlados.

Em ambos os modos, primeiramente escolhem-se os valores das variáveis a serem controladas, depois o tempo que o sistema irá realizar o controle (Control Time) e, por fim, os valores devem ser enviados aos equipamentos através do comando Set Values.

Comando Setpoint Alpha, Setpoint RPM e Torque: Os comandos Setpoint Alpha e Setpoint RPM são responsáveis por ajustar os valores da posição do atuador da bomba de combustível e da RPM do sistema.

O comando Torque, assim como os anteriores, é responsável por ajustar o valor do torque imposto pelo dinamômetro. Este comando tem duas opções: torque em porcentagem e valor físico. A porcentagem informa quantos porcento do torque máximo do motor elétrico será utilizado. O valor físico informa qual o valor de torque, em Nm, o operador quer que o dinamômetro imponha.

Comando Read File for Automatic Test: Este comando é responsável por ler o arquivo de texto criado e armazená-lo em uma matriz para que o teste automático, quando selecionado, possa ser realizado.

Comando Acquire Data: O comando Acquire Data é responsável por nomear o arquivo e seus subgrupos a serem salvos. Além disso é possível nomear individualmente cada aquisição. Neste comando também é possível alterar o tempo de aquisição, em segundos, de cada teste.

$\mathrm{O}$ arquivo de dados salvos possui a extensão tdms (Technical Data Management Solution). Este formato, definido pela National Instruments, é integrado ao LabVIEW além de possuir um programa Diadem onde é possível realizar diferentes análises e converter os dados para outros formatos. Maiores informações podem ser obtidas em [42] e [43].

\subsubsection{3}

\section{Questões de Segurança para Operação e Operador}

No desenvolvimento de qualquer projeto experimental, especialmente de motores de combustão interna e máquinas rotativas, deve-se, primeiramente, priorizar a integridade física do operador e de qualquer pessoa próxima ao ensaio e, por fim, a integridade dos equipamentos, dentro dos limites especificados pelo fabricante. 
Para o primeiro caso, duas medidas de segurança foram adotadas: criação de uma proteção para o acoplamento entre o dinamômetro e o MCI e um botão de emergência (vide Figura 4.9).

A proteção do cardan foi confeccionada com uma chapa de aço 1020 de $1 / 8$ de polegada de espessura.

O botão de emergência é responsável por desabilitar o inversor de frequência, fazendo o dinamômetro parar, e por abrir o circuito de alimentação da bomba de combustível do MCI, fazendo com que não haja mais fluxo de combustível impedindo a combustão, e consequentemente o motor parar.

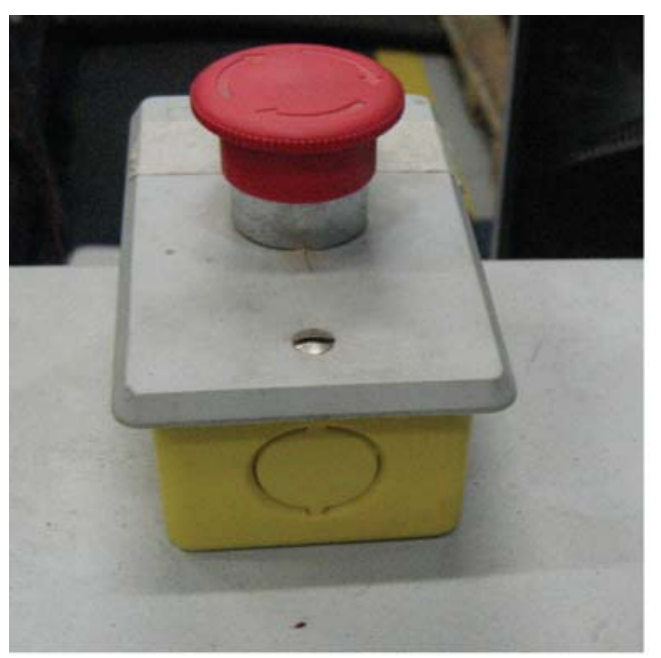

Figura 4.9: Botão de emergência do banco de provas.

Com relação à integridade dos equipamentos, tanto o motor elétrico quanto o MCI possuem mecanismos de segurança.

No caso do motor elétrico, ele possui um transdutor de temperatura em sua carcaça conectado ao inversor de frequência. Caso esta temperatura ultrapasse o limite especificado, o inversor de frequência desabilita o motor de modo a diminuir a mesma.

No caso do MCI, foi desenvolvido um programa que monitora constantemente as temperaturas essenciais para seu correto funcionamento. Caso alguma destas temperaturas ultrapasse o limite previamente ajustado pelo operador, o sistema, primeiramente, vai à marcha lenta (alerta) e, caso continue subindo, o banco é desligado (alarme). Essa rotina desenvolvida pode ser habilitada ou desabilitada pelo operador a qualquer momento do teste pelo comando EnAlarm (vide Figura 4.8).

Além desta medida, adotou-se uma outra para limitar a rotação máxima que o banco pode atingir, que depende das especificações do MCI em teste. Como pode ser observado na Figura 3.3, o valor de rotação do MCI para sua 
potência máxima é de 2600 RPM. Como o dinamômetro pode chegar a 4620 RPM, o limite de segurança para a rotação do conjunto foi ajustado em 2800 RPM.

\subsubsection{4}

\section{Testes de Verificação do Correto Funcionamento do Programa}

A fim de verificar o correto funcionamento do programa desenvolvido, testes preliminares, sem a utilização do dinamômetro e MCI, foram conduzidos a fim de verificar o correto envio dos sinais. Para tanto, o ajuste dos pontos inicial e final dos sinais enviados ao inversor de frequência foram realizados através das regulagens possíveis dos módulos da Phoenix Contact (ZERO e SPAN - vide Figura 3.31).

Após estas verificações, com o MCI desacoplado do dinamômetro, os comandos foram enviados ao sistema real. Com isso, pôde-se verificar o correto funcionamento do sistema e dos pontos desejados comparando os valores lidos de rotação do dinamômetro, pelo programa desenvolvido, com os fornecidos na interface homem-máquina (IHM) do inversor de frequência. Nesta etapa, também, o sistema de segurança foi verificado. Para tanto, o dinamômetro e o MCI foram colocados em funcionamento, desacoplados, e o botão de emergência foi acionado de modo que ambas as máquinas fossem desligadas.

Com estas duas etapas concluídas, o sistema foi acoplado e os testes propostos foram executados.

\subsection{4}

Pós Processamento e Análise dos Dados

Diante da grande quantidade de dados aquisitados, se faz necessária uma análise criteriosa para se ter confiabilidade nos resultados obtidos.

Primeiramente os dados são salvos em formato $t d m s$. Neste formato, uma análise inicial é realizada no software Diadem onde é verificado, de acordo com o ensaio proposto, se o comportamento das variáveis aquisitadas estão dentro do esperado. Após esta primeira análise, os dados são exportados para o software Matlab, da fabricante MathWorks, onde uma rotina computacional foi desenvolvida. Nesta rotina, uma análise mais criteriosa é realizada através da aplicação de um filtro passa baixa do tipo Butterworth de segunda ordem, com uma frequência de corte de $50 \mathrm{~Hz}$, cálculos de fatores estatísticos como média, desvio padrão e variância e a interpolação de pontos de determinadas variáveis a fim de obter curvas representativas das mesmas. 


\section{Procedimento Experimental}

O procedimento adotado para os ensaios foi elaborado de modo a cumprir os objetivos inicialmente propostos. Para tanto, com o motor sobre a bancada de prova, a sequência dos testes foi planejada de modo a avaliar a capacidade do sistema de controle em seguir os pontos desejados, mantendo-os dentro de limites aceitáveis, verificar o tempo de resposta do dinamômetro para variações bruscas de rotação e posição do atuador da bomba de combustível e verificar as limitações, do estágio atual de desenvolvimento, do banco de prova.

Para a realização dos testes, pequenas alterações foram realizadas no motor com relação a sua montagem nos veículos comerciais, como por exemplo a retirada do filtro de ar e da válvula termostática do sistema de arrefecimento de água. Porém, os sistemas de arrefecimento de água, através do radiador, e do ar de admissão, através do aftercooler, além do sistema de exaustão foram mantidos originais.

De modo a facilitar o entendimento do experimento, o procedimento realizado foi dividido em três etapas: capacidade de seguimento de trajetória, tempo de resposta e limitações da bancada de testes.

\section{1}

\section{Capacidade de Seguimento de Trajetória}

Nesta etapa verificou-se a capacidade do banco de seguir pontos específicos de torque e rotação.

No caso do torque, esta etapa foi realizada através do envio de um sinal em tensão (0 a 10V), através do programa de controle do sistema, para o inversor de frequência. Este sinal corresponde ao valor, em porcentagem, da corrente de torque enviada ao motor. Portanto, um valor de, por exemplo, $5 \mathrm{~V}$ tem de corresponder a $50 \%$ do torque nominal do dinamômetro. Conforme consta no manual do fabricante, [44], para o modo de controle do motor elétrico utilizado no trabalho (modo vetorial com encoder), o menor valor que se pode controlar o torque é com $10 \%$ de corrente de torque (1V) e a precisão para o controle da corrente de torque, e consequentemente do torque, é sujeito a uma incerteza de $\pm 5 \%$.

Para o caso da rotação, testes com o sistema desacoplado e acoplado foram realizados. Para cada situação, diferentes valores de rampas de aceleração e desaceleração foram conduzidos. Esses valores, em segundos, são ajustados pela interface homem máquina (IHM) do inversor de frequência e representam 
o tempo que o inversor leva para atingir a velocidade máxima, a partir da velocidade nula, no caso da rampa de aceleração e atingir a velocidade nula, a partir da velocidade máxima, no caso da rampa de desaceleração. Além disso, com o motor acoplado, diferentes pontos de rotação foram fixados com o objetivo de analisar a flutuação dos valores em regime.

\section{2}

\section{Tempo de Resposta}

Diante da crescente necessidade por testes transientes a fim de avaliar, dentre outros fatores, emissões, tempos de resposta curtos do sistema a mudanças de variáveis, se fazem necessárias.

A fim de avaliar as características das respostas do dinamômetro, testes foram conduzidos realizando a variação da velocidade de referência, em diferentes pontos de operação para diferentes intervalos de tempo até este não ser capaz de seguir os pontos especificados ou até atingir o limite do inversor. Este limite ocorre quando a corrente que deve ser enviada ao dinamômetro, pelo inversor, supera o limite configurado no equipamento (corrente máxima do dinamômetro), ocorrendo o bloqueio por sobrecorrente.

\subsection{1}

Determinação do Tempo Máximo de Resposta para Testes em Motores

Dentre os ensaios mais severos, tanto para o MCI testado quanto para o dinamômetro, destacam-se os de determinação de emissões de particulados e fumaça nos motores a combustão. Isto se deve ao elevado nível de transição entre diferentes pontos de torque, rotação e alpha e ao curto espaço de tempo em que as mesmas devem ocorrer. De acordo com a norma brasileira ABNT 15634 [45] e a norma européia [46], três testes são relevantes, cada um analisando tipos diferentes de poluentes:

- ESC - European Stationary Cycle;

- ELR - European Load Response;

- ETC - European Transient Cycle.

\subsubsection{1}

\section{Ciclo ESC}

Segundo [46], o ESC consiste em um ciclo de 13 modos em estado estacionário em que durante uma sequência prescrita de condições de funcionamento do motor aquecido, examinam-se continuamente as quantidades das emissões dos gases de escapamento, como por exemplo monóxido de carbono 
e hidrocarbonetos, retirando uma amostra dos gases brutos. O ciclo de ensaio consiste em um determinado número de modos de velocidade e potência que cobrem a gama de funcionamento típico dos motores Diesel. Durante cada modo, determinam-se a concentração de cada gás poluente, a vazão do escapamento e a potência. Além disso, mede-se a concentração dos óxidos de nitrogênio (NOx) em três pontos do ensaio (determinados por métodos estatísticos aprovados de aleatorização) sendo os valores medidos comparados com os valores calculados a partir dos modos do ciclo de ensaio. A verificação do NOx assegura a eficácia do controle de emissões do motor dentro da gama de funcionamento típica do motor.

\subsubsection{2}

\section{Ciclo ELR}

Segundo [46], durante o ensaio de reação a uma carga prescrita, determinam-se os níveis de fumaça de um motor aquecido através de um opacímetro. O ensaio consiste em submeter o motor, em uma velocidade constante, a uma carga crescente de $10 \%$ a 100\%, em três velocidades diferentes do motor. Além disso, efetua-se um quarto patamar de carga determinados por métodos estatísticos aprovados de aleatorização, sendo o valor comparado com os valores dos patamares de carga anteriores. Determina-se o pico dos níveis de fumaça utilizando um algoritmo de cálculo de médias.

\subsubsection{3}

\section{Ciclo ETC}

Ainda segundo [46], durante um ciclo transiente prescrito de condições de operação do motor aquecido, que é estritamente baseado em padrões específicos da condução rodoviária de motores pesados instalados em caminhões e carros, examinam-se os poluentes após diluição da totalidade dos gases de escape com ar ambiente condicionado. Utilizando os sinais de retroação do torque e da velocidade do dinamômetro, integra-se a potência em relação ao tempo do ciclo para se obter o trabalho produzido pelo motor. Determinam-se as concentrações dos NOx e do HC ao longo do ciclo através da integração do sinal do analisador. As concentrações de $\mathrm{CO}$, de $\mathrm{CO}_{2}$ e dos hidrocarbonetos não-metânicos (NMHC) podem ser determinadas por integração do sinal do analisador ou por recolhimento de amostras em sacos. No que diz respeito às partículas, uma amostra proporcional é coletada em filtros adequados. Determina-se a vazão dos gases de escape diluídos ao longo do ciclo para calcular os valores das emissões mássicas dos poluentes. Esses valores são relacionados com o trabalho do motor para se obter a massa de cada poluente 
emitida por kWh.

A seguir, nas Figuras ??, 5.2 e 5.3, são apresentados os gráficos de torque por velocidade, no teste ESC, e de torque e velocidade por tempo, nos testes ELR e ETC.

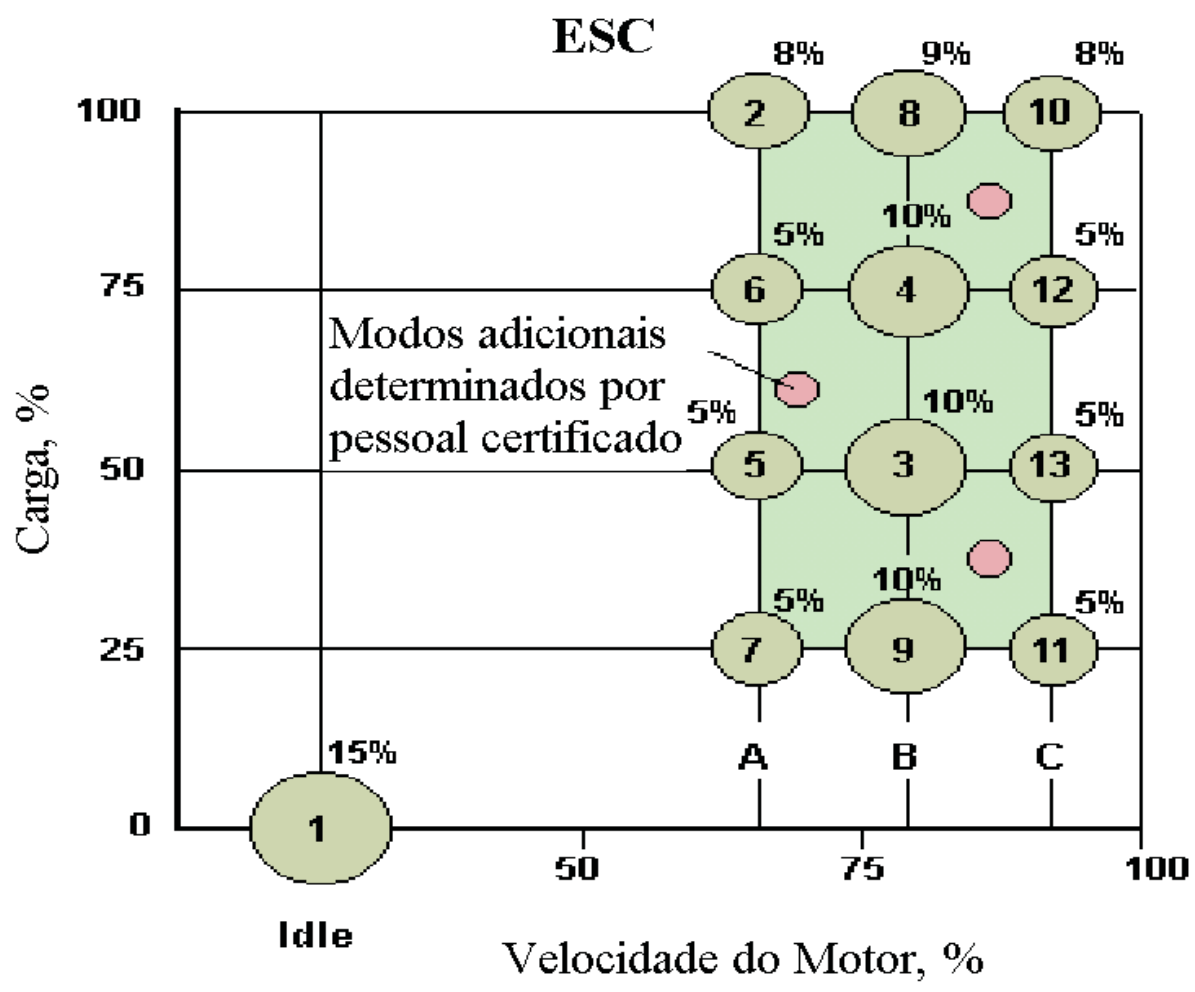

Figura 5.1: Curva do teste de emissões ESC para motores.

Dentre os três testes mencionados anteriormente, o último (ETC) é o mais severo tanto para os motores e acoplamento, quanto para o inversor de frequência, devido às grandes oscilações de rotação e torque em curtos espaços de tempo.

Neste teste, os pontos de rotação são definidos em porcentagens em relação aos valores máximos $\left(n_{h i}\right)$ e mínimos $\left(n_{l o}\right)$ determinados a partir do seguinte procedimento:

- $n_{h i}$ : a rotação mais elevada do motor onde ocorre um valor de $70 \%$ da potência útil máxima declarada;

- $n_{l o}$ : a rotação mais baixa do motor em que um valor de $50 \%$ da potência útil máxima declarada ocorre.

Para o caso do presente projeto utilizou-se $n_{h i}$ igual a $2650 \mathrm{RPM}$ e $n_{l o}$ igual a 1350 RPM. 
Velocidade

\section{ELR}

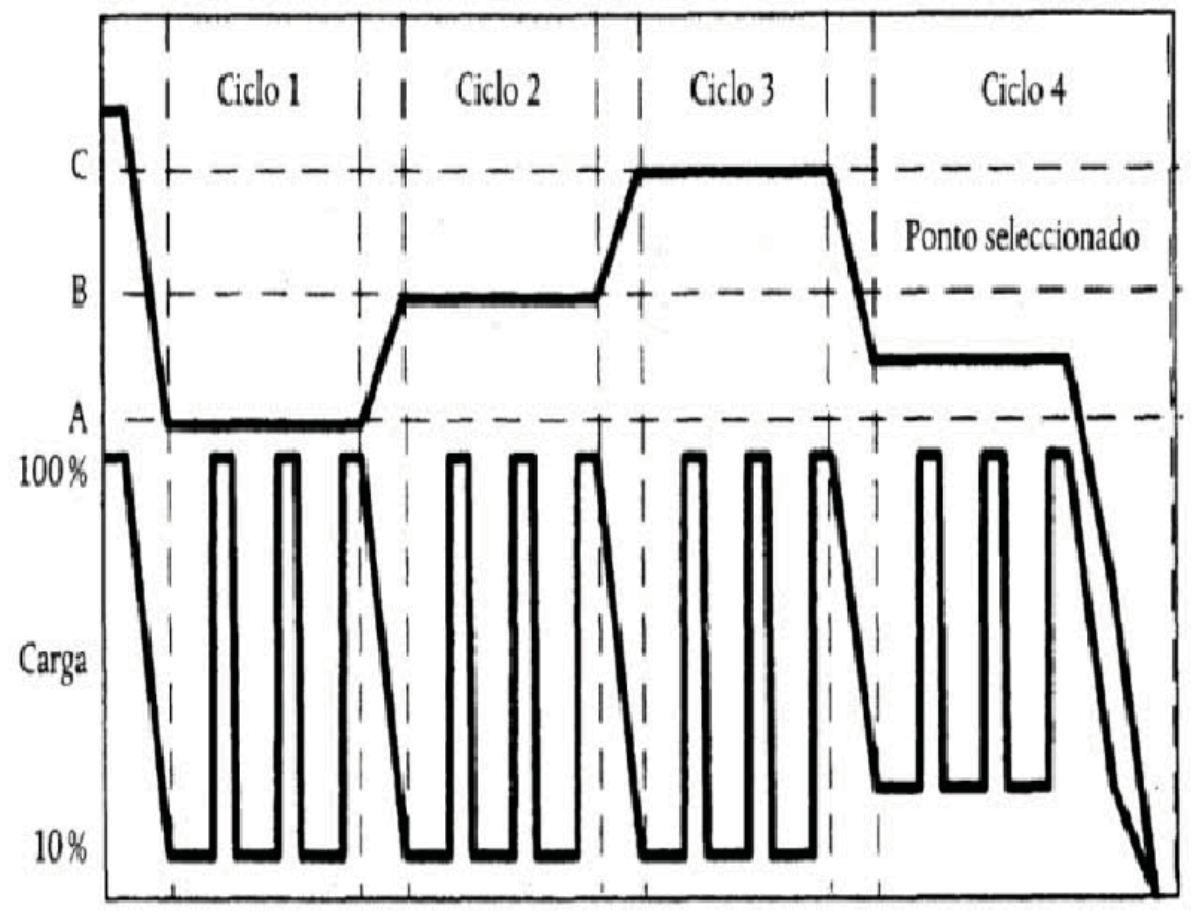

Figura 5.2: Curva do teste de emissões ELR para motores.

A geração do ciclo ETC de referência é feito através do cálculo das velocidades angulares reais, a partir dos valores de velocidades angulares normalizados. A velocidade angular real é obtida através da seguinte equação:

$$
V_{\text {real }}=\frac{1}{100} V_{\%}\left(V_{\text {ref }}-V_{\text {idle }}\right)+V_{\text {idle }}
$$

onde:

- $V_{\text {real }}$ é a velocidade angular real do teste em rpm;

- $V_{\%}$ é a velocidade angular em porcentagem fornecida pela norma;

- $V_{\text {ref }}$ é a velocidade angular de referência. Ela corresponde ao valor da velocidade angular a 100\%. Seu cálculo é dado por 5-2

- $V_{\text {idle }}$ é a velocidade angular em marcha lenta sem carga. No caso do MCI em teste, este valor é de $780 \mathrm{rpm}$.

$$
V_{\text {ref }}=n_{l o}+0,95\left(n_{h i}-n_{l o}\right)
$$




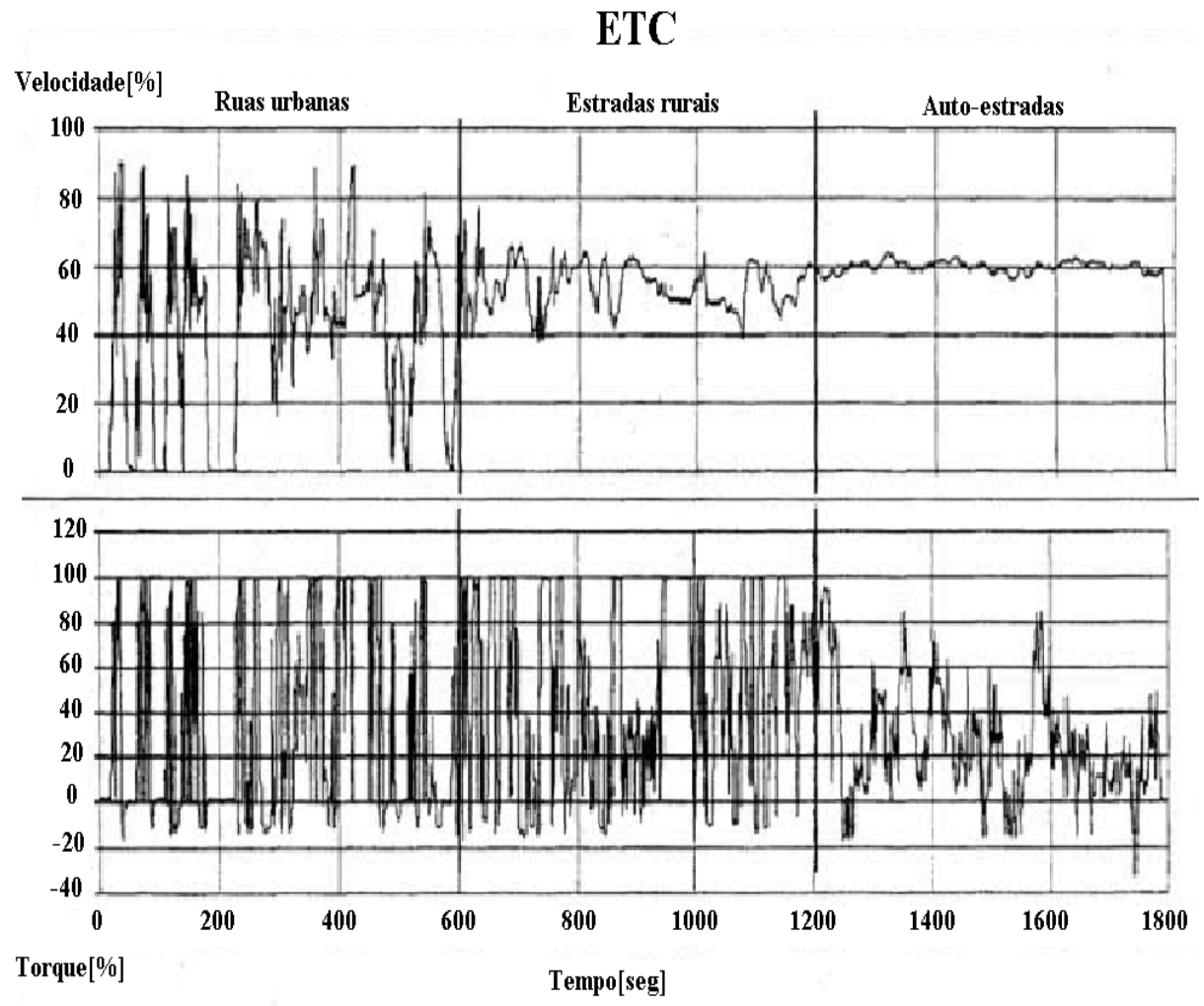

Figura 5.3: Curva do teste de emissões ETC para motores.

Analisando os pontos de rotação normalizados para o teste ETC verificouse qual era a maior variação de velocidade angular positiva (quando o sistema acelera) e qual a maior variação negativa (quando o sistema desacelera) a fim de verificar se o banco, em um primeiro momento, consegue atender as maiores exigências deste ciclo.

O valor obtido para a aceleração, que corresponde aos tempos 20 e 21 segundos, é de 34,9\%, partindo de 1135 rpm e chegando em 1765 rpm. Já o valor obtido para a desaceleração, que corresponde aos tempos de 72 e 73 segundos, é de 36,2\%, partindo de $2381 \mathrm{rpm}$ e chegando em $1727 \mathrm{rpm}$.

A fim de simular uma parte deste ciclo de maneira simples, alguns pontos estratégicos de rotação do $E T C$ foram utilizados com o objetivo de verificar o comportamento do sistema. Vale ressaltar que os pontos utilizados foram somente os referentes à curva de rotação. Os pontos referentes ao torque do sistema, que é controlado pela abertura da bomba de combustível, foi escolhido de modo que se aproximasse dos valores estipulados pela norma, baseado no conhecimento prévio adquirido do motor.

Os pontos escolhidos foram baseados na região do ciclo onde ocorrem as maiores variações de rotação. Esta região corresponde a parte urbana do ciclo. Para o ciclo simulado, duas subregiões foram escolhidas conforme Figura 5.4. 
O ciclo utilizado no ensaio, com os pontos de rotação e alpha, pode ser visto na Figura 5.5.

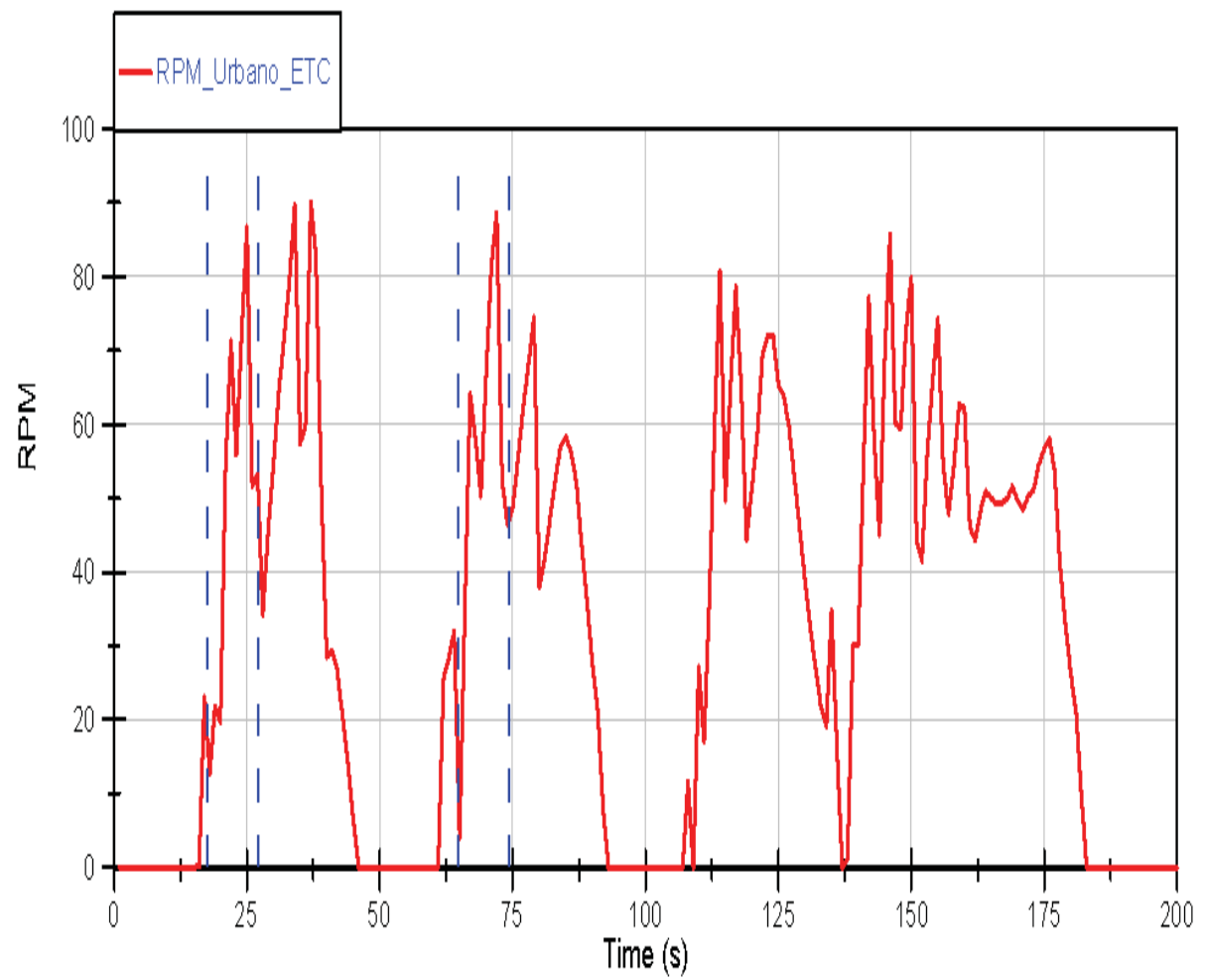

Figura 5.4: Ciclo urbano ETC e faixas adotadas para ciclo simulado (rpm x tempo)

\section{3}

\section{Limitações da Bancada de Testes}

Todo banco de provas possui suas limitações, tanto elétricas quanto mecânicas. Algumas são bastante óbvias, como velocidade e torque máximos, porém outras só são descobertas após diversos ensaios nas mais diferentes condições. Ao desenvolver um novo projeto, o projetista tem que analisar e saber quais são as limitações do mesmo.

Testes que demandam grande quantidade de esforços dos equipamentos são fundamentais para se determinar algumas das limitações. No presente trabalho dois testes foram escolhidos: teste à plena carga e teste com variações abruptas de velocidade para alpha igual a $100 \%$.

O teste a plena carga é utilizado para se obter as curvas de torque e potência máximas do motor a ser testado. Este tipo de ensaio demanda, do equipamento responsável por realizar o teste, grandes níveis de esforços. 

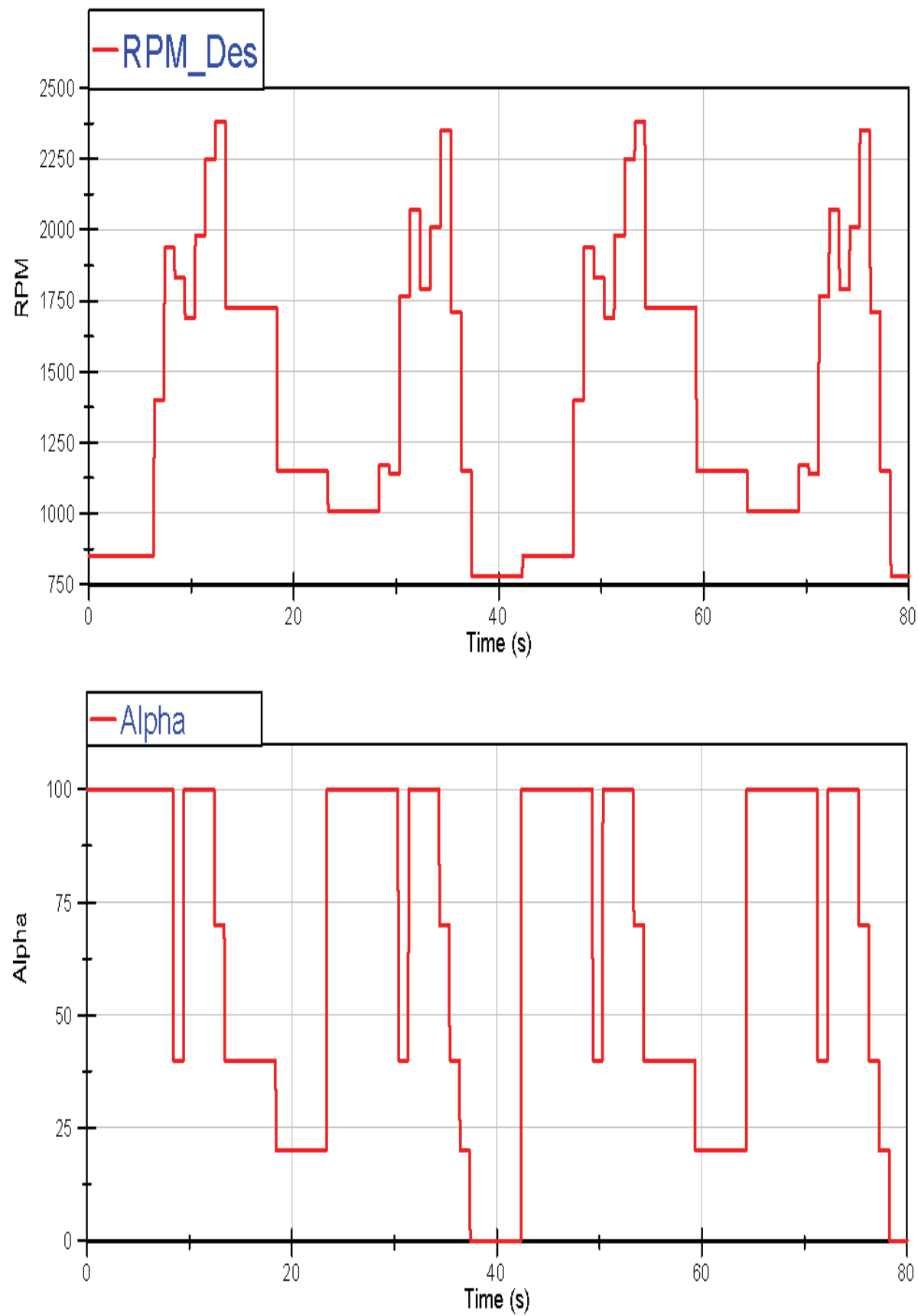

Figura 5.5: Curvas de rotação e alpha por tempo do ciclo simulado baseado nos pontos do ETC.

O teste de variação abrupta de velocidade, com alpha igual a 100\%, é semelhante ao anterior porém, devido às grandes variações de velocidade, os esforços dinâmicos estão entre os maiores aos quais o sistema estará sujeito. 


\section{4}

\section{Redução dos Dados}

Os valores médios que são disponibilizados no software desenvolvido são os seguintes:

- Velocidade angular (N) [RPM];

- Torque $[\mathrm{Nm}]$;

- Pressão de admissão [psia];

- Temperaturas [graus Celsius];

- Posição do atuador da bomba de combustível (\%).

\subsection{1}

Potência

A potência líquida entregue pelo motor é também conhecida como potência no freio. Medida no eixo de saída e absorvida pelo dinamômetro, este é o produto entre torque e a velocidade angular do eixo:

$$
P=\frac{1}{60} 2 \pi \times T \times N \times 0,00134
$$

onde: $P$ é a potência líquida no eixo em $[\mathrm{cv}], T$ é o torque no freio em $[\mathrm{Nm}]$ e $N$ a velocidade angular média em $[\mathrm{RPM}]$. A incerteza na medição do torque do motor é $0,03 \%$, enquanto que a incerteza da medição da rotação é de \pm 1 RPM. 


\section{6 Resultados e Discussões}

Para um melhor entendimento do presente capítulo, os ensaios experimentais foram organizados de acordo com o capítulo 5. Portanto, na parte inicial, uma avaliação com relação à capacidade de seguimento de trajetória para os dois tipos de modos de operação são analisados e, posteriormente, discutidos. Além disso, no modo de controle de velocidade o tempo de resposta é analisado tanto para o sistema desacoplado quanto para acoplado, além de serem apresentados gráficos do comportamento da resposta do sistema para diferentes valores de rampas de aceleração e desaceleração. Por fim, análises em condições adversas são realizadas com o intuito de demonstrar os limites atuais do banco de prova, suas possíveis causas e soluções.

\section{1}

\section{Análise do Comportamento do Sistema}

Esta análise é feita sobre dois aspectos:

- Torque;

- Velocidade.

\subsection{1 \\ Torque}

Nas Figuras 6.1, 6.2, 6.3, 6.4 e 6.5, foi utilizado um valor de alpha igual a $50 \%$ e uma velocidade de referência (ou saturação) de $1100 \mathrm{rpm}$. Esta velocidade de referência é a velocidade para a qual o dinamômetro tende a girar quando o seu torque consegue "frear" o torque produzido pelo MCI. Nestas figuras, foram utilizados valores de corrente de torque, responsável por controlar o torque do dinamômetro, de 50\% (293,50Nm), 40\% (234,80Nm), $30 \%(176,10 \mathrm{Nm}), 20 \%(117,4 \mathrm{Nm})$ e $10 \%(58,7 \mathrm{Nm})$.

Na Figura 6.1, o valor obtido pelo transdutor de torque foi aproximadamente $20 \%$ menor do que o valor teórico calculado do dinamômetro. Para este ponto de operação observa-se que a rotação do conjunto é próxima da desejada, 1100RPM. Portanto, este fato explica o motivo desta diferença no valor do torque. Em outras palavras, o dinamômetro irá conseguir manter o motor nesta rotação desejada até que o torque do MCI supere o valor do torque teórico. Vale também salientar que as diferenças entre os valores de rotação, e as oscilações desta, se deve a variação no torque do dinamômetro e ao fato de 

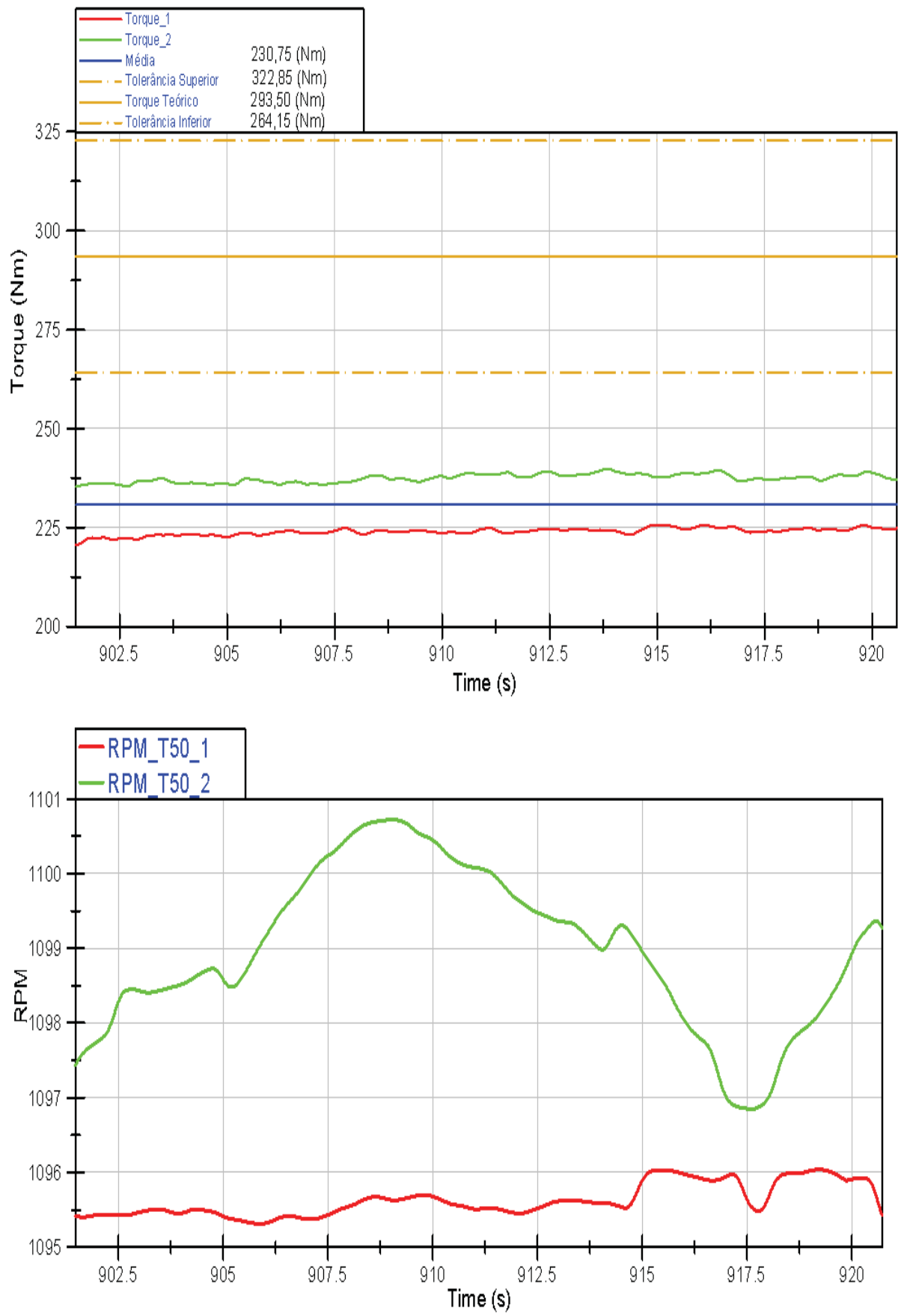

Figura 6.1: Torque e rotação do sistema para corrente de torque igual a $50 \%$ (verde: motor quente, vermelho: motor frio).

no primeiro ensaio (curva vermelha) o motor estar em processo de aquecimento e no segundo (curva verde) o motor já estar aquecido, implicando em maiores temperaturas e pressão de admissão (vide Tabela 6.1).

Na Figura 6.2 pode-se perceber que o valor do torque teórico ainda é superior ao obtido, porém em ambos os ensaios estes se encontraram dentro da faixa de tolerância fornecida pelo fabricante. Observando as curvas de rotação 

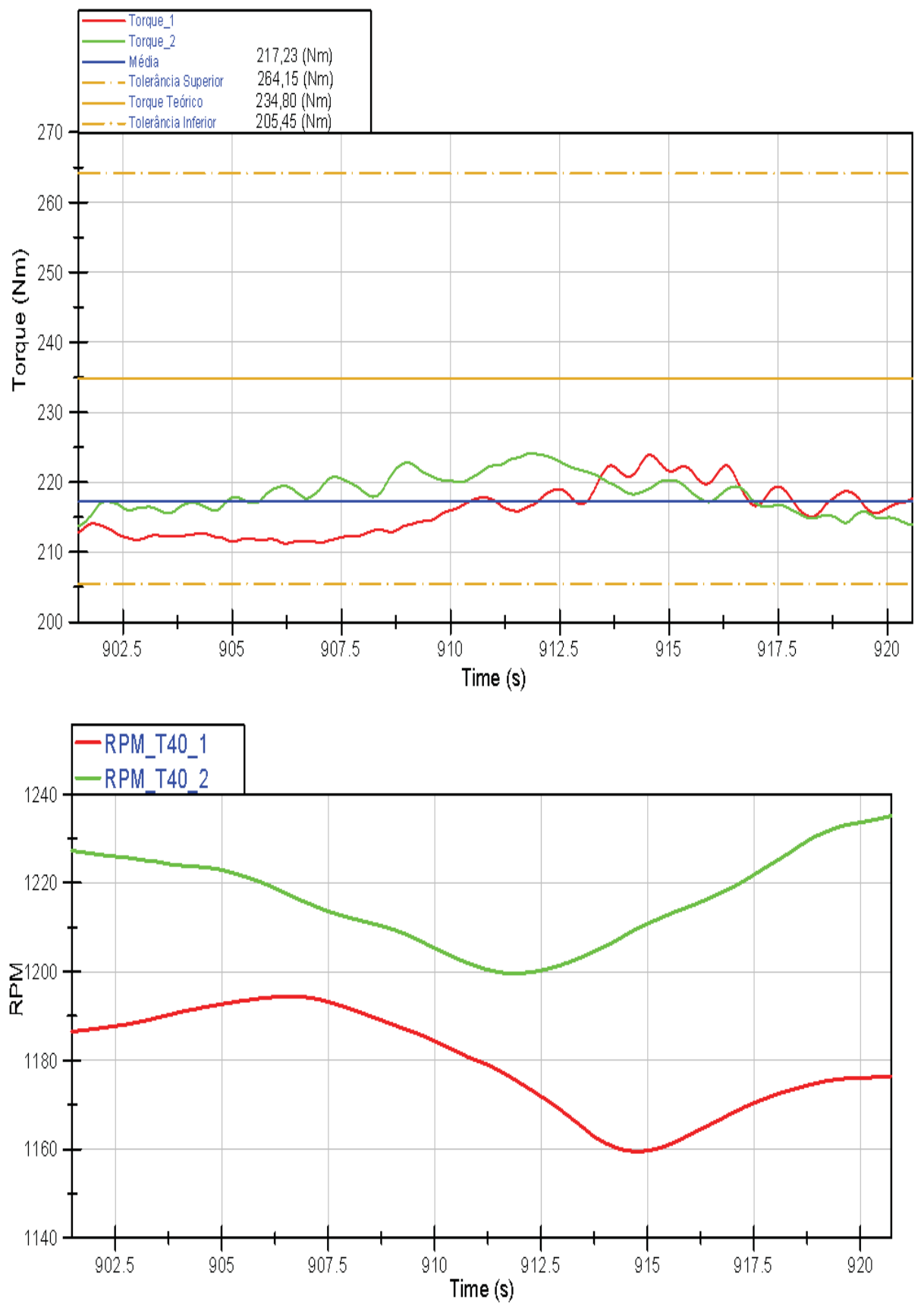

Figura 6.2: Torque e rotação do sistema para corrente de torque igual a $40 \%$ (verde: motor quente, vermelho: motor frio).

para os dois ensaios, percebe-se que há um aumento na velocidade angular do conjunto com relação a velocidade desejada, além de uma maior oscilação, tanto para a curva com motor frio (vermelha), quanto para com motor quente (verde). Este aumento de velocidade em relação ao valor desejado indica que o MCI está gerando um torque maior do que o dinamômetro consegue absorver na condição de 1100RPM e, consequentemente, um aumento de velocidade é 

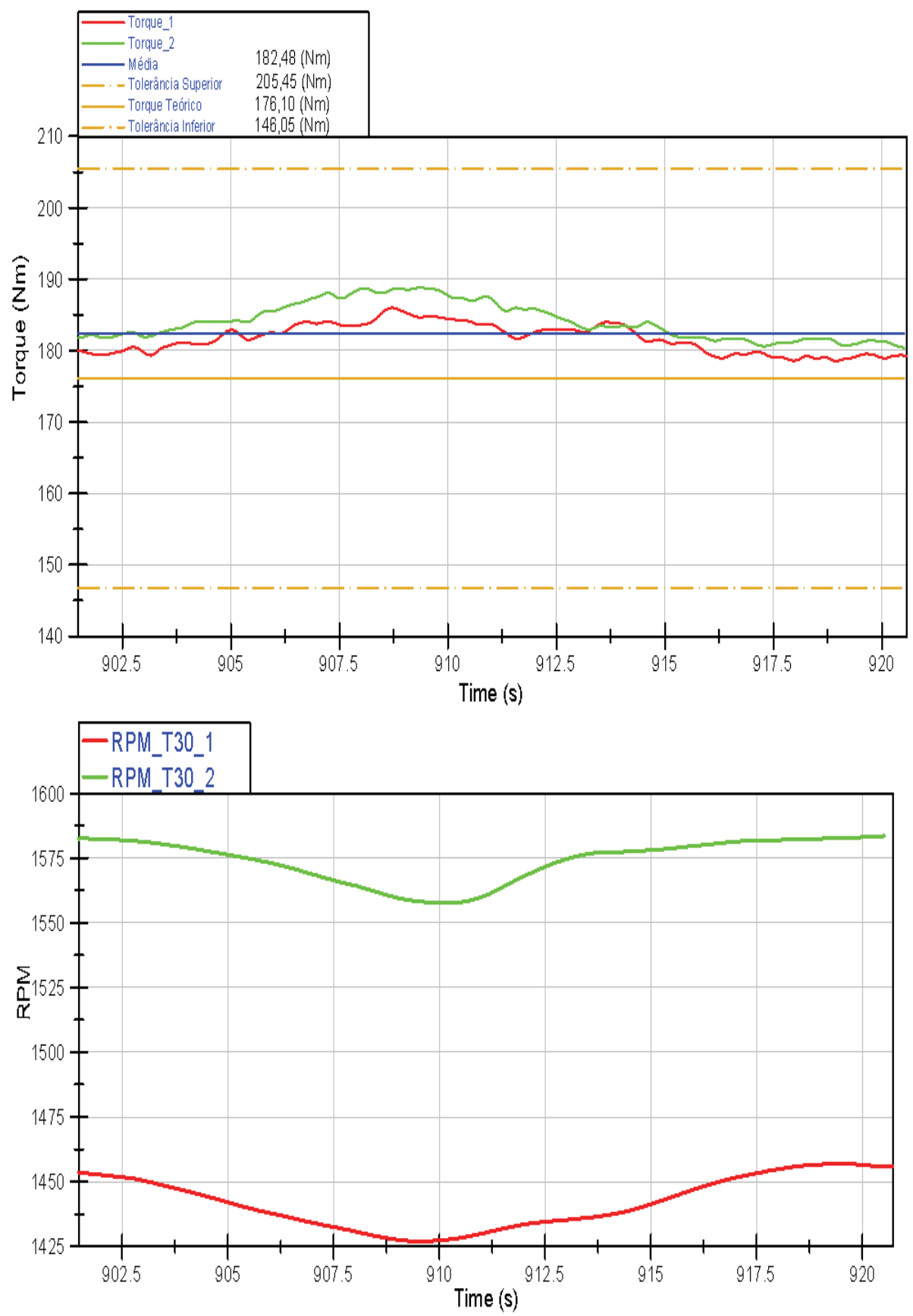

Figura 6.3: Torque e rotação do sistema para corrente de torque igual a $30 \%$ (verde: motor quente, vermelho: motor frio).

produzido.

Nas Figuras 6.3, 6.4 e 6.5, o comportamento do sistema é bastante semelhante aos anteriores. Na Figura 6.3, o valor do torque lido é semelhante ao valor teórico e, nos gráficos subsequentes, estes valores são superiores. Com relação às velocidades, seus valores continuaram a oscilar como os anteriores porém, nos dois últimos casos, estes valores oscilaram em torno de uma 

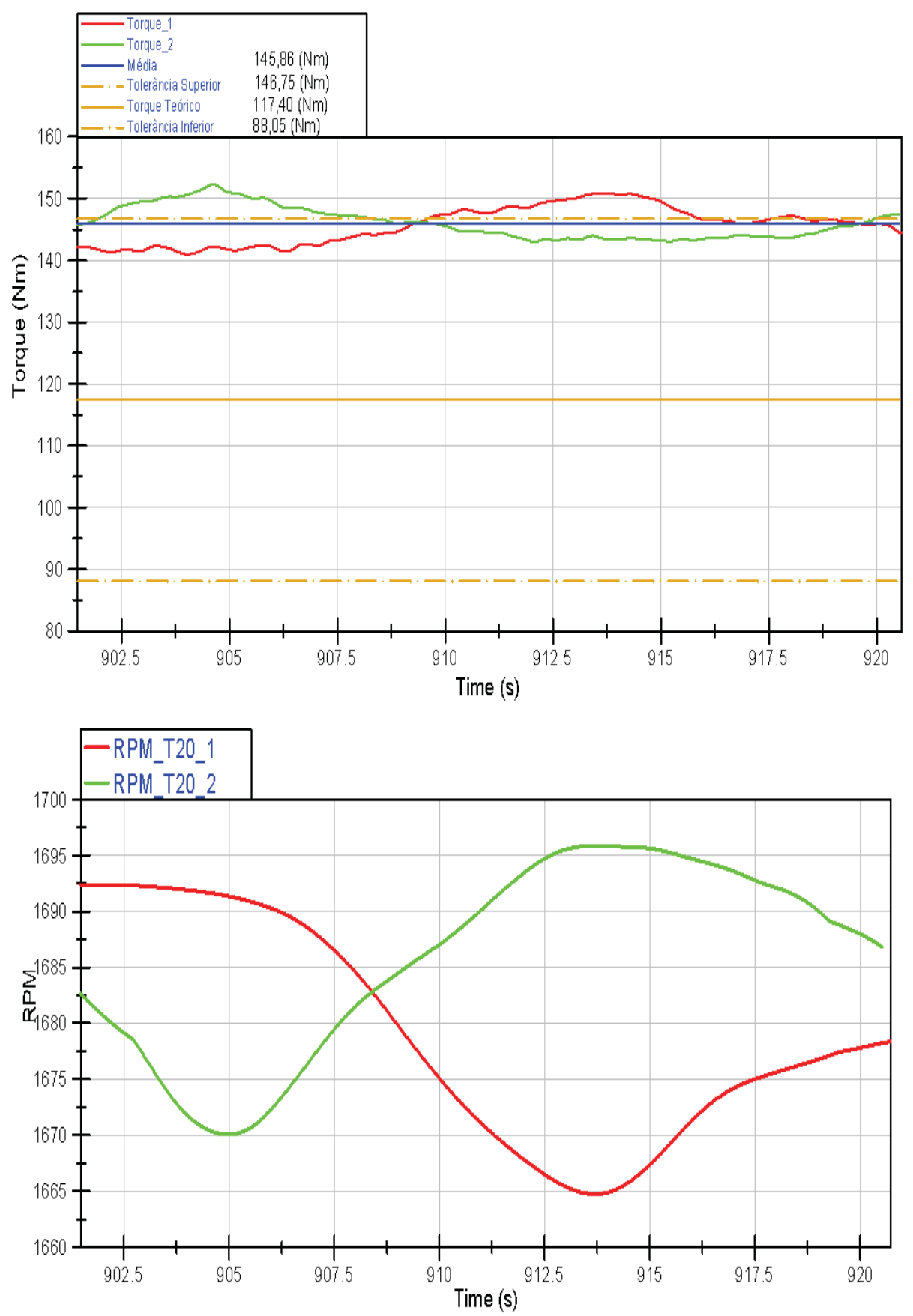

Figura 6.4: Torque e rotação do sistema para corrente de torque igual a $20 \%$ (verde: motor quente, vermelho: motor frio).

faixa comum devido ao MCI estar em condições de temperatura e pressão semelhantes em ambas as aquisições.

Na Tabela 6.1, os valores de temperatura de água e óleo e os de pressão de admissão são mostrados. Nesta tabela, o primeiro valor de corrente de torque se refere ao motor em aquecimento e o segundo ao motor aquecido. 

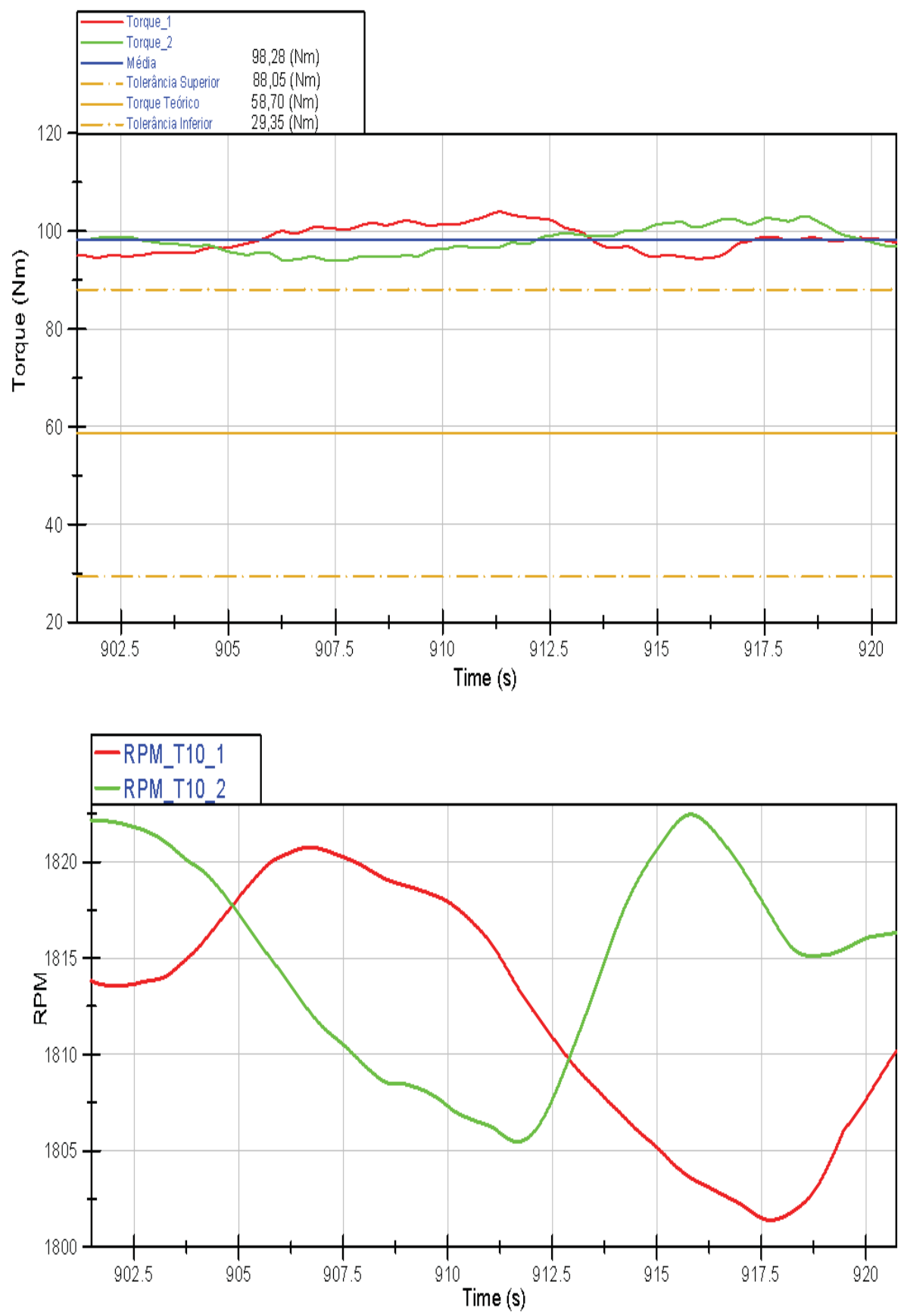

Figura 6.5: Torque e rotação do sistema para corrente de torque igual a $10 \%$ (verde: motor quente, vermelho: motor frio).

\section{1 .2}

\section{Velocidade}

Esta etapa foi dividida em duas partes: a primeira foi realizada com o sistema desacoplado, ou seja, sem o eixo cardan conectando o MCI e o dinamômetro, e a segunda com o sistema acoplado. 
Tabela 6.1: Valores de temperatura da água e óleo e pressão de admissão para valores de corrente de torque.

\begin{tabular}{|c|c|cc|}
\hline \multirow{2}{*}{ Corrente de Torque (\%) } & \multirow{2}{*}{ Pressão [psia] } & \multicolumn{2}{|c|}{ Temperatura $\left[{ }^{\circ} \mathrm{C}\right]$} \\
\cline { 3 - 4 } & & Água & Óleo \\
\hline \multirow{2}{*}{50} & 14,6 & 61 & 44 \\
& 15,1 & 80 & 66,4 \\
\hline \multirow{2}{*}{40} & 14,8 & 64 & 45 \\
& 15,0 & 79 & 66 \\
\hline \multirow{2}{*}{30} & 15,1 & 65 & 47 \\
& 15,8 & 76 & 64 \\
\hline \multirow{2}{*}{20} & 15,5 & 68 & 50 \\
& 15,3 & 74 & 61 \\
\hline \multirow{2}{*}{10} & 14,8 & 68 & 53 \\
& 14,8 & 72 & 59 \\
\hline
\end{tabular}

Na primeira etapa, as Figuras 6.6, 6.7 e 6.8 mostram a resposta do dinamômetro para três valores distintos de rampas de aceleração e desaceleração, 6, 5.3 e 4.5 segundos, para um ciclo pré-determinado. A rampa de aceleração e desaceleração referente a rotação do dinamômetro, ajustado pelo inversor de frequência, é determinada como sendo o tempo, em segundos, que o motor demora, partindo da rotação nula para chegar a rotação máxima. Os valores para essas rampas foram escolhidos de maneira empírica. Portanto, o menor tempo de rampa que produzisse o menor tempo de transição entre um ponto de operação, além de gerar a menor corrente possível, era o escolhido.

Analisando os gráficos, pode-se perceber que o tempo de resposta do dinamômetro, quando desacoplado, é praticamente o mesmo, em torno de 1 segundo, para os três casos. Nos intervalos em que as mudanças de velocidade são realizadas em três segundos, o dinamômetro demora 1 segundo para estabilizar, tanto na aceleração quanto na desaceleração. O mesmo ocorre para o caso em que a mudança de velocidade é feita em intervalos de 1 segundo.

Para o segundo caso, o comportamento do sistema quando o MCI e dinamômetro estão acoplados é analisado. Na Figura 6.9 são mostrados pontos de operação de velocidade e alpha que o sistema deve seguir, utilizando um arquivo previamente configurado no modo de controle Automático. Também é mostrado as curvas de torque e pressão no coletor de admissão. O valor utilizado para a rampa de aceleração e desaceleração foi de 5,7s.

Analisando este gráfico, percebe-se que o sistema é capaz de seguir as trajetórias estipuladas com rapidez e precisão. Conforme pode-se observar, foram realizadas transições entre modos de operação, tanto com velocidade quanto com o valor de alpha, em diferentes intervalos de tempo (2, 3 e 5 segundos, para o caso da rotação). Nota-se que mesmo quando é requisitado ao sistema 


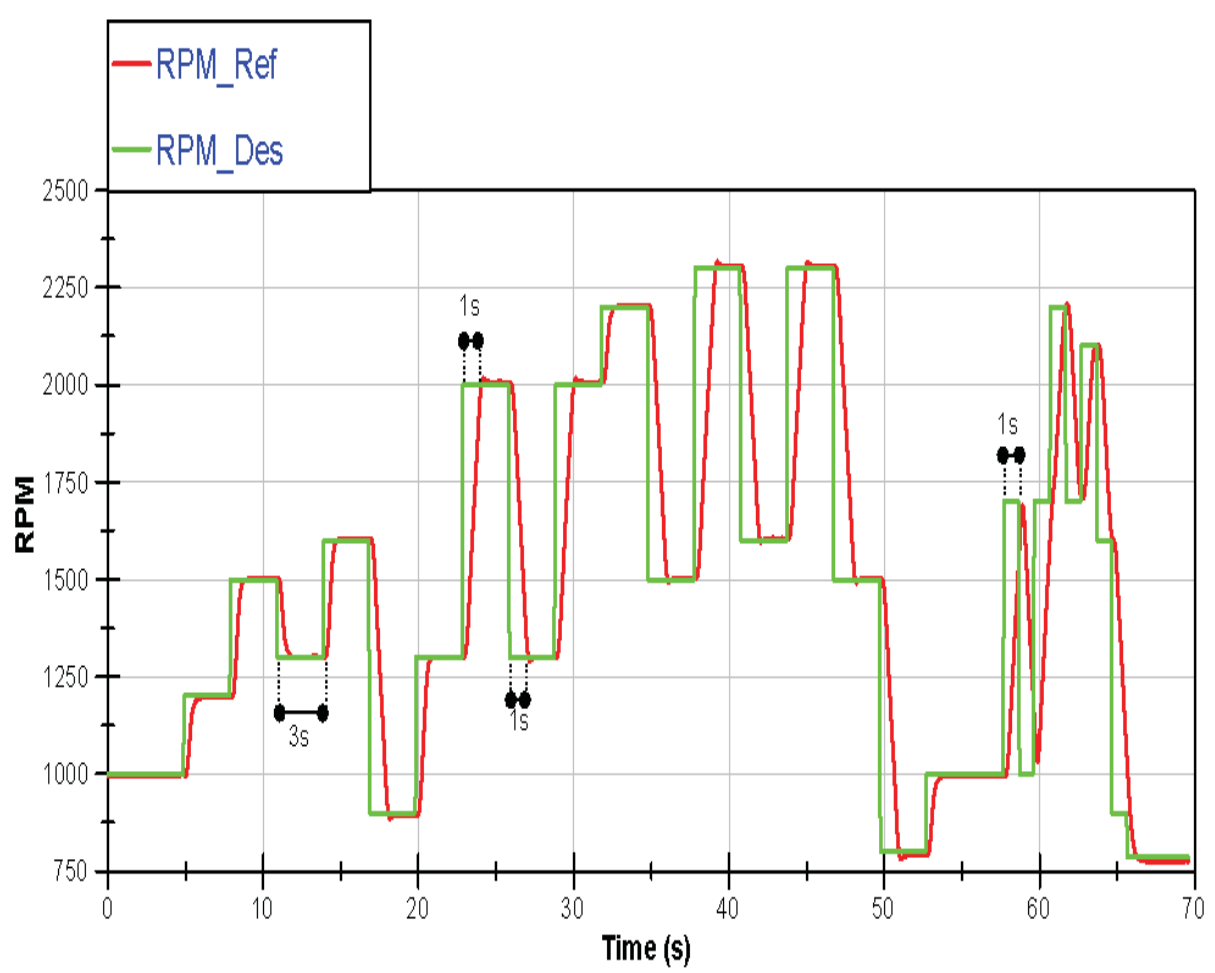

Figura 6.6: Rampa de aceleração e desaceleração de 6 segundos.

mudanças rápidas de velocidade, tanto acelerando quanto desacelerando, ele obteve um comportamento satisfatório, com tempos de resposta de aproximadamente 1 segundo. Porém, fica evidente que quando o sistema é requisitado a realizar mudanças de velocidades, ou com alpha igual a $100 \%$ ou quando ocorre um aumento significativo de pressão no coletor de admissão devido ao turbo, pequenas pertubações podem ser notadas na resposta, entretanto este evento não compromete o desempenho do sistema. Para o caso da aceleração percebe-se um pequeno overshoot de, aproximadamente, 26 RPM na saída, entre os segundos 110 e 130, e isto se deve a um aumento significativo da pressão do coletor de admissão, devido ao turbo, quando alpha é ajustado em 100\% e o MCI se encontra em rotações elevadas. No caso de desaceleração, como a que ocorre próximo ao segundo 120, o tempo para se atingir o valor de referência é maior, em torno de 2,5 segundos. Isto se deve principalmente ao fato do motor estar trabalhando em uma região próxima a de torque máximo. Além disso, outro ponto que deve ser analisado é o fato da rotação do conjunto ser superior a velocidade nominal do dinamômetro, ou seja, sua operação está na região de enfraquecimento de campo, conforme explicado no Capítulo 2.

Na Figura 6.10 é mostrado apenas os resultados para as velocidades do conjunto, seguindo o mesmo ciclo, quando a rampa de aceleração e desace- 


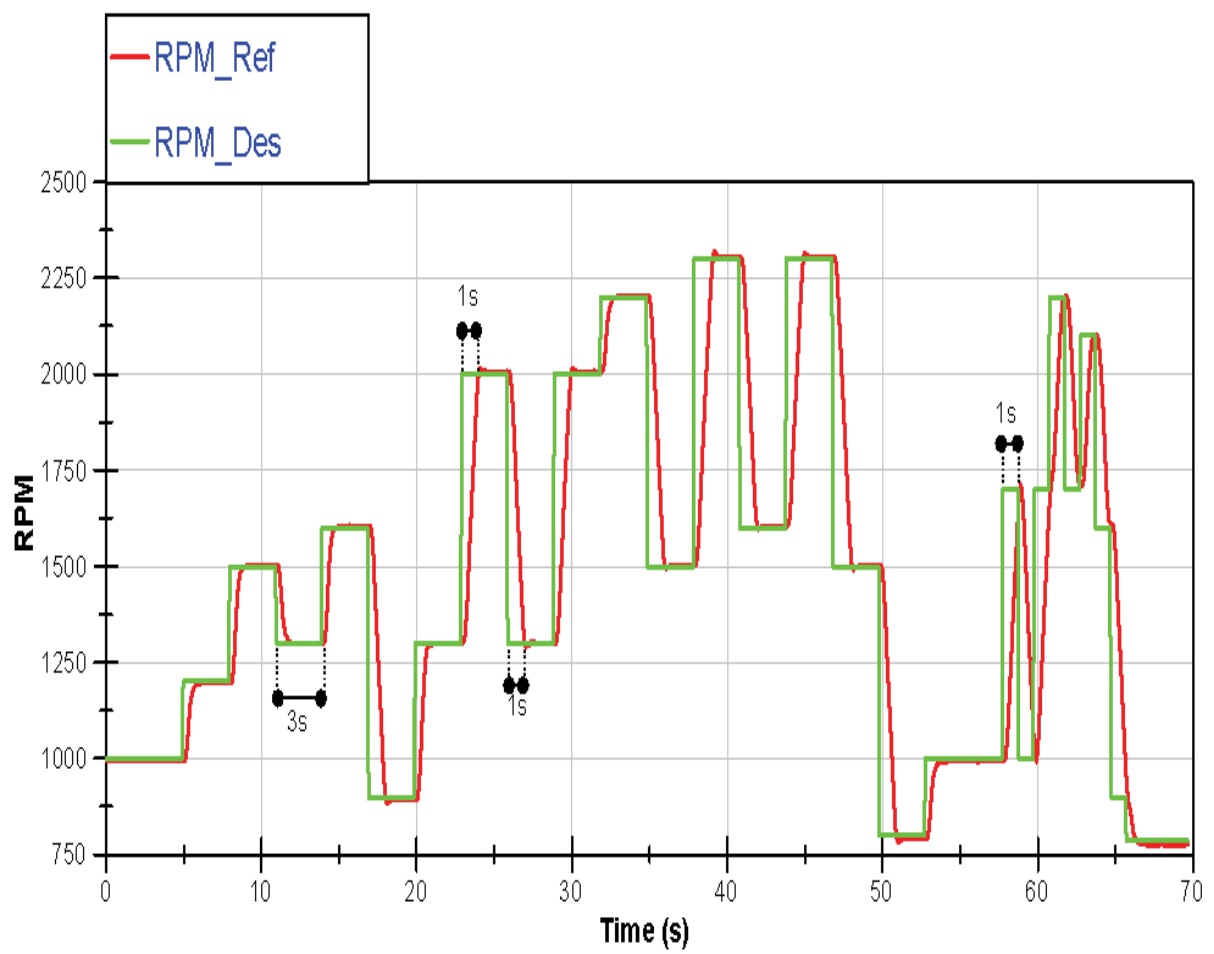

Figura 6.7: Rampa de aceleração e desaceleração de 5.3 segundos.

leração possuem um valor de 6,4 e 6,7 segundos. Nota-se que o tempo para atingir o valor de referência permanece o mesmo, para uma variação positiva da velocidade, em ambos os gráficos. Entretanto, para o caso de desaceleração, a influência do tempo da rampa é significativa conforme pode ser observado.

Na Figura 6.11, três pontos de operação são mostrados. Após a estabilização do sistema foi realizada a aquisição dos pontos a fim de analisar o erro em regime. Conforme visto na Figura 6.11, percebe-se que estes valores estão próximos do valor desejado, com uma variação máxima de $2 \mathrm{rpm}$ para o pior caso e portanto, a resposta do sistema é satisfatória com relação ao controle de velocidade.

\section{2}

\section{Testes em Condições Extremas}

Dois testes distintos foram conduzidos a fim de submeter o sistema a condições adversas. No primeiro teste, variações de velocidade em intervalos de tempo de 1 segundo foram realizadas mantendo-se o atuador da bomba de combustível fixo em 100\%. Nas Figuras 6.12 e 6.13 são mostrados o comportamento do sistema.

Na Figura 6.12, são apresentados as curvas de rotação, torque e pressão 


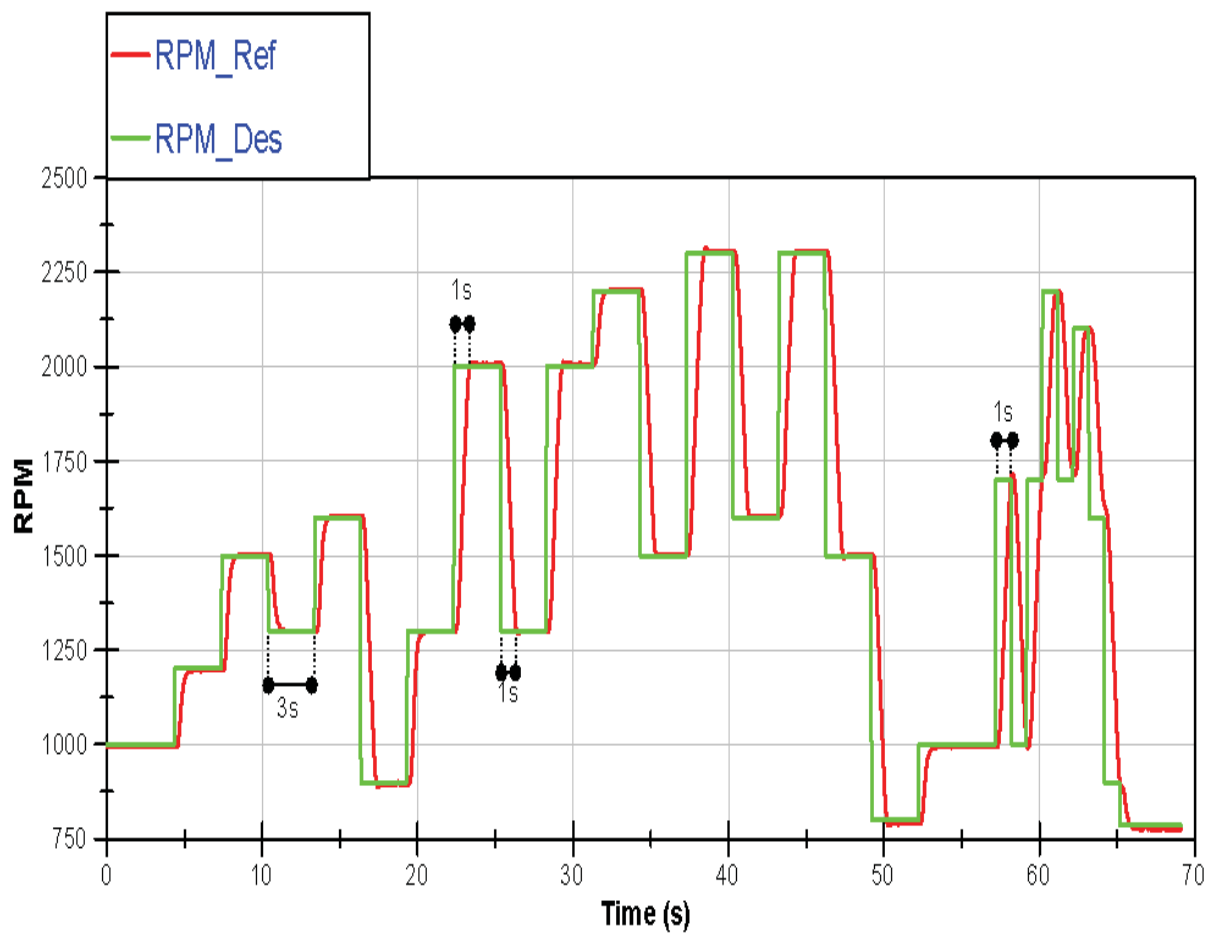

Figura 6.8: Rampa de aceleração e desaceleração de 4.5 segundos.

no coletor de admissão. O tempo utilizado para as rampas foi de 5,5 segundos. Pode-se perceber que o sistema não é capaz de seguir as trajetórias estipuladas. No início do teste o dinamômetro não é capaz de subir sua velocidade de 740 RPM mesmo com uma rampa de 5,5 segundos que, teoricamente, permite a ele variações de aproximadamente 788 RPM em 1 segundo. Além disso, nas desacelerações, conforme observado anteriormente, o dinamômetro não conseguiu responder aos comandos. Observou-se, pela IHM (interface homemmáquina) do inversor de frequência, que os valores de corrente enviados ao motor elétrico chegavam a 194 A, onde o limite especificado pelo fabricante é de 216 A.

Na Figura 6.13 é apresentado apenas a curva referente à rotação com uma rampa de 4,5 segundos. Pode-se observar no gráfico que na primeira transição o sistema conseguiu atingir a velocidade desejada no tempo correto. Porém no segundo passo, que corresponde a desaceleração, o sistema não consegue mais seguir o ciclo com precisão. Além disso foi observado que a corrente enviada, pelo inversor de frequência, ao dinamômetro chegou a $214 \mathrm{~A}$, indicando que o sistema já está trabalhando no seu limite de segurança.

No segundo teste, os ensaios foram baseados no ciclo simulado (vide Figura 5.5). Assim como nos casos anteriores, para um mesmo ensaio, variou-se 
as rampas de aceleração e desaceleração do dinamômetro com os seguintes valores: $5 \mathrm{~s}, 5,5 \mathrm{~s}, 6 \mathrm{~s}$ e $6,5 \mathrm{~s}$. As Figuras 6.14 e 6.15 , mostram, além do comportamento da rotação, os comportamentos do torque e da pressão no coletor de admissão. Já a Figura 6.16 mostra o comportamento para as rampas de 5,5 e 6 segundos.

Analisando as curvas de rotação para os quatro casos, percebe-se que quanto menor a rampa do dinamômetro, mais instável é o controle da velocidade na segunda parte do ciclo (de 20 a 40 segundos). Isto se deve principalmente ao controle da velocidade realizado pelo inversor de frequência. Quanto menor o ajuste do tempo da rampa, mais rápido o sistema tem de responder aos estímulos de variação da velocidade. Por conta disto, assim como visto em resultados anteriores, a ocorrência de um overshoot é percebida (próximo ao tempo de 33 segundos). Este evento faz com que o dinamômetro não consiga seguir a trajetória determinada devido ao curto espaço de tempo entre um ponto e outro.

Outro fator responsável por esta incapacidade do sistema de seguir o perfil de velocidade, neste ponto, é o fato da ocorrência de um alto valor de pressão do coletor de admissão (devido ao valor de alpha igual a 100\%). Este valor implica em um significativo aumento de torque produzido pelo MCI fazendo com que o dinamômetro não seja capaz de realizar o perfil de velocidade neste ponto, para o intervalo de tempo de 1 segundo.

Porém, apesar de neste ponto o dinamômetro não ter conseguido acompanhar o perfil de velocidade proposto, no restante do ciclo o sistema foi capaz de seguir a trajetória pré definida, dentro do tempo especificado. Este fato demonstra uma aparente capacidade do sistema de seguir as curvas de torque e rotação do ciclo ETC visto que os pontos de torque estipulados por este ciclo não foram fielmente seguidos.

\subsection{1}

\section{Teste em Plena Carga}

Os resultados dos testes em plena carga são mostrados nas Figuras 6.17 e 6.18. Nestas figuras também são mostradas suas respectivas interpolações. Na Figura 6.19 é mostrada a curva de potência com a barra de incertezas experimentais. Por fim, nas Figuras 6.20 e 6.21 as curvas referentes às temperaturas de água, óleo e escapamento, ao longo do ensaio, são apresentadas.

Os valores reais obtidos de torque e potência máximas são, respectivamente, 412,38 Nm a $1800 \mathrm{RPM}$ e 116,95 cv (87,2 kW) a $2600 \mathrm{RPM}$. Estes números estão em torno de $20 \%$ abaixo dos especificados pelo fabricante. Além disso, observando o gráfico de temperaturas percebe-se que para rotações ele- 
vadas não foi possível estabilizar a temperatura da água e, consequentemente, a do óleo nos valores entre 80 e 90 e 90 e 110 graus Celsius, respectivamente, conforme recomendado pelo fabricante. Outra consequência desta incapacidade de estabilização da temperatura da água se reflete nos altos valores medidos na temperatura de escapamento.

Devido a isto, os testes foram sempre conduzidos à noite, quando a temperatura ambiente é menor e foi utilizado um insuflamento de ar apontado diretamente para o radiador (vide detalhe da mangueira ao fundo da Figura 3.17) com o objetivo de tentar aumentar a troca de calor no radiador. Além disso, o procedimento de execução dos testes em plena carga foram realizados da seguinte forma: primeiramente, com uma rotação e um valor de alpha intermediários, esperava-se as temperaturas de água e óleo atingirem os valores recomendados pelo fabricante. Após atingidos estes valores, o motor era levado ao primeiro ponto de operação, que é o de rotação máxima, o valor de alpha para $100 \%$ e a aquisição era realizada. Após o término da aquisição, o motor era levado a uma condição intermediária enquanto o valor da temperatura de água baixava. Atingindo o valor recomendado, o motor era levado ao próximo ponto de operação. Este procedimento se repetia até o teste se encerrar. Durante os testes, constatou-se que a temperatura de água, em rotações elevadas, não se estabilizava tendendo sempre a crescer, conforme é observado na Figura 6.22.

Essa diferença significativa entre o valor fornecido pelo fabricante e o obtido nos ensaios podem ser causadas por diferentes razões. Inicialmente, o banco de provas desenvolvido não consta com um equipamento dedicado ao controle de temperatura da água do motor, como por exemplo um trocador de calor. Conforme mencionado no Capítulo 5, o sistema de arrefecimento foi mantido original, somente com o radiador. Diferentemente de um veículo em movimento, onde o ar frontal é utilizado para resfriar o motor, em um banco de provas para motores este agente externo não existe, daí a necessidade de utilização de equipamentos auxiliares para controlar temperaturas tais como a de água. Portanto, com o aumento da temperatura interna do motor, o mesmo não é capaz de realizar a combustão com grande eficiência. Este fato é percebido ao analisar a temperatura dos gases do escapamento. Elevados valores desta temperatura são indicativos de menor desempenho do motor devido às menores taxas de liberação de calor associadas à menor eficiência térmica. Outro fator que pode ser responsável pelo baixo valor da potência e torque obtidos é a falta de um condicionador dedicado ao ar de admissão. Assim como no caso do radiador, o ar de admissão passa pelo aftercooler antes de entrar no motor. Um aumento nesta temperatura também ocasiona uma perda na eficiência térmica do motor, conforme pode ser visto em [47]. Ainda com relação ao 
ar de admissão, as pressões obtidas estão abaixo do especificado. De acordo com [6], uma pressão de 30,7 psia é obtida para a rotação de 1850RPM. Em contrapartida, no presente trabalho obteve-se uma pressão máxima de 24,8 psia em 1800 RPM. Esta significativa diferença de pressão pode ser causada pela mangueira que conecta a saída do aftercooler na admissão. Conforme pode ser visto na Figura 6.23, a mangueira é composta por diversos gomos que permitem a ela realizar curvas. Porém, na parte interna da mangueira, esses gomos formam rebaixos que provocam diversos pontos de perda de carga localizada interferindo no fluxo de ar entre o aftercooler e a admissão do motor. A utilização de tubos rigídos, como é utilizado originalmente no veículo, pode evitar grande parte das perdas localizadas fazendo com que seja possível atingir pressões de admissão mais elevadas. O último ponto que pode explicar esta perda significativa de potência e torque é o fato do motor ser mecânico. Este fato implica em diversos problemas relacionados principalmente a folgas nos equipamentos, regulagens e ao fato de não possuir nenhuma forma de monitoramento sobre as variáveis importantes a fim realizar correções diante de um mal funcionamento ou problema. 

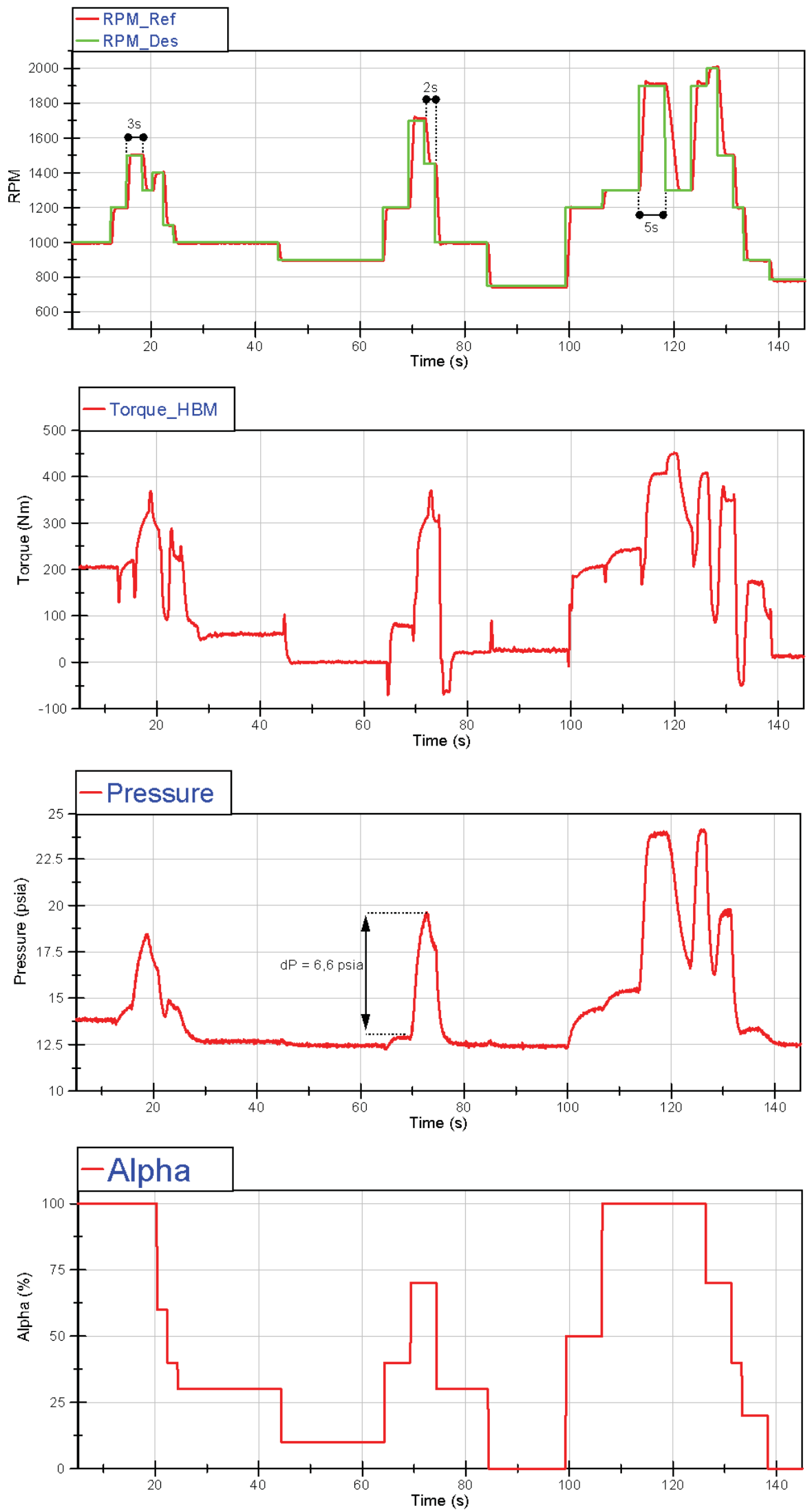

Figura 6.9: Teste automático de seguimento de trajetória. 

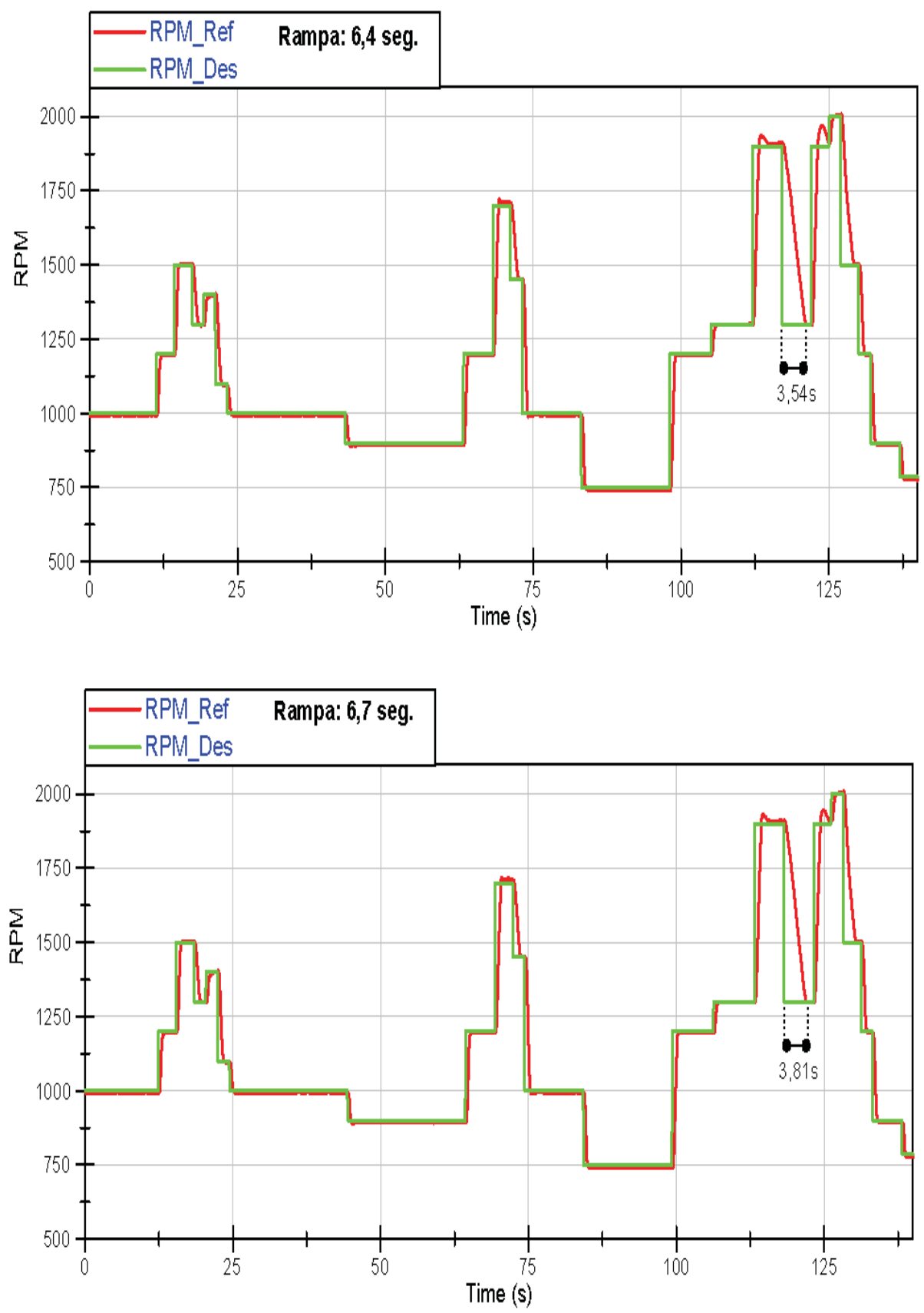

Figura 6.10: Teste automático de seguimento de trajetória - Rampas 6,4 e 6,7 seg. 


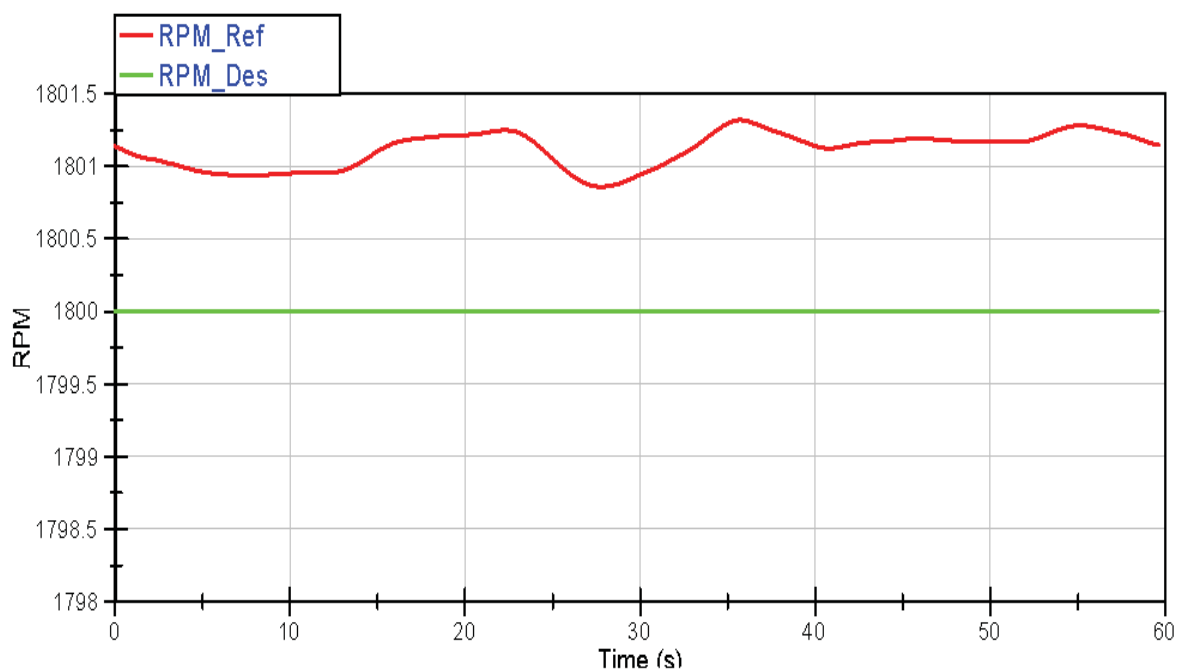

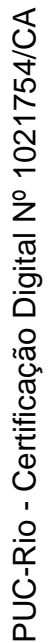
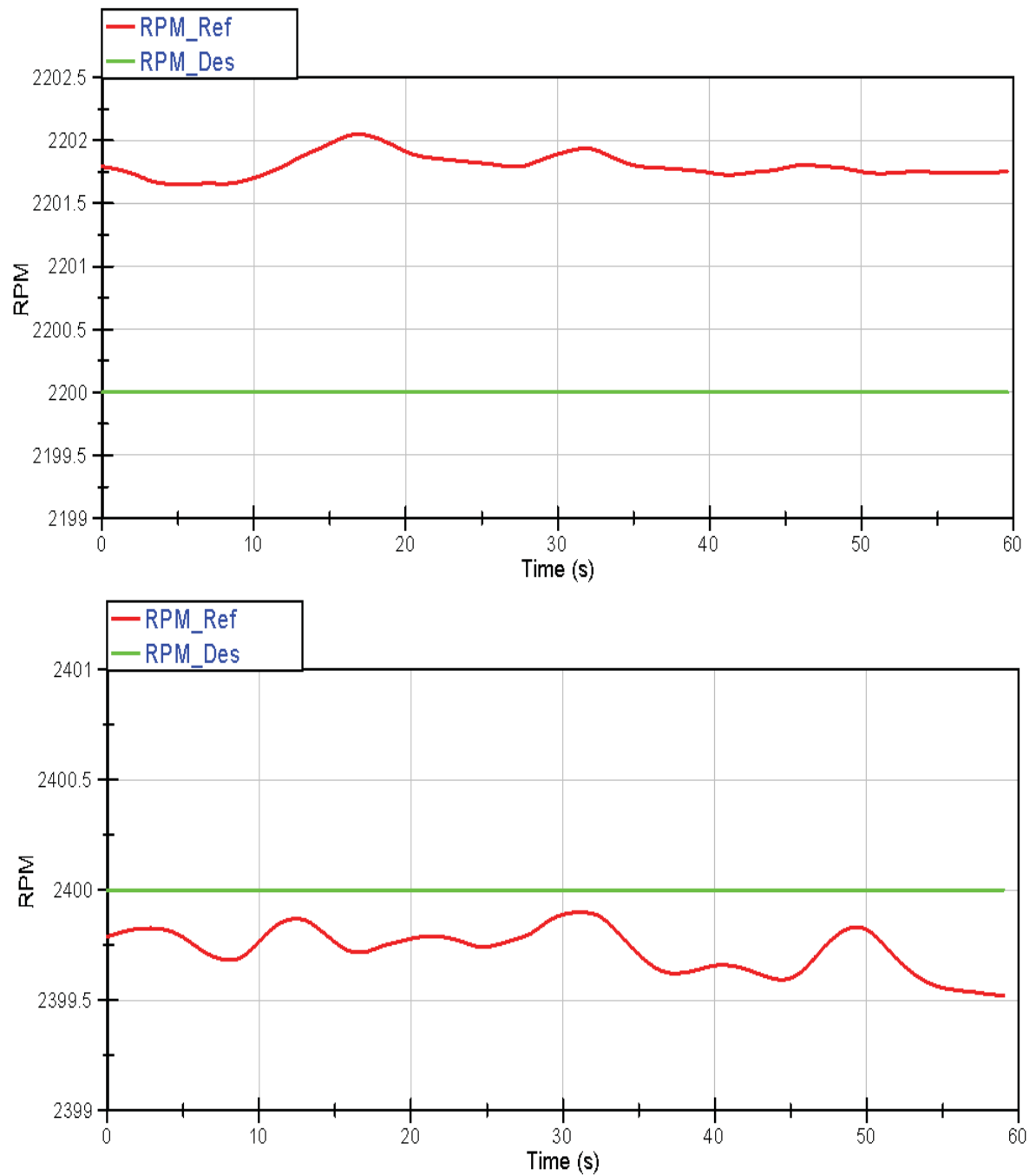

Figura 6.11: Pontos estabilizados com alpha igual a 100\%. 


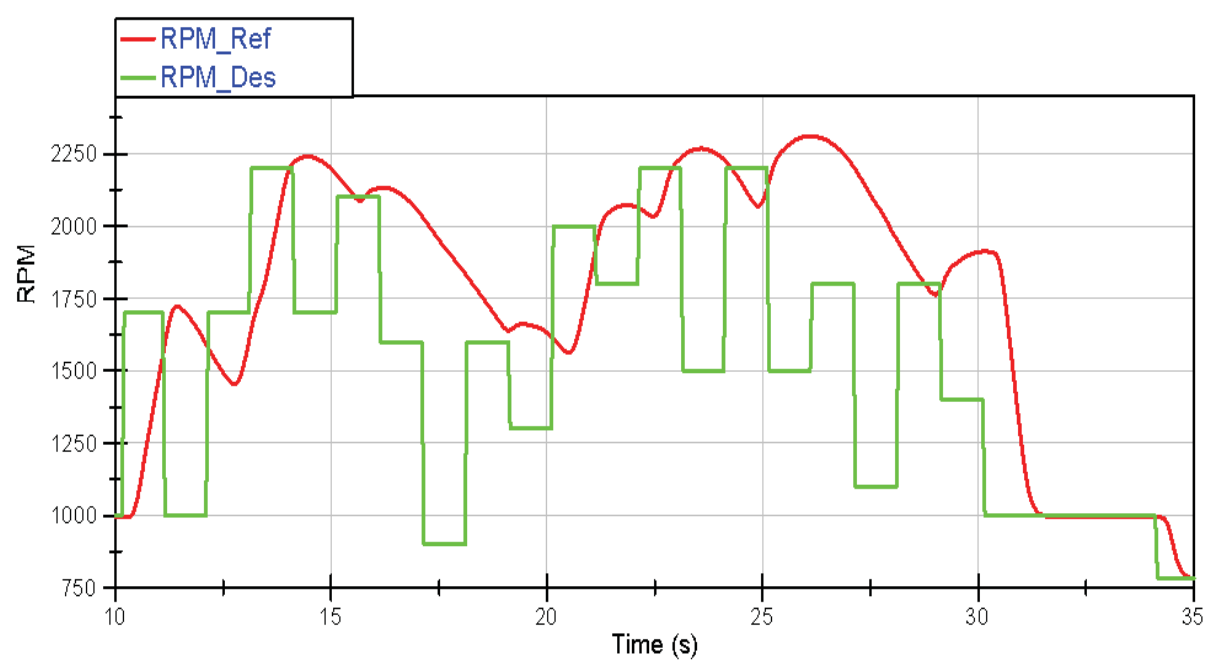

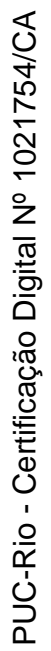
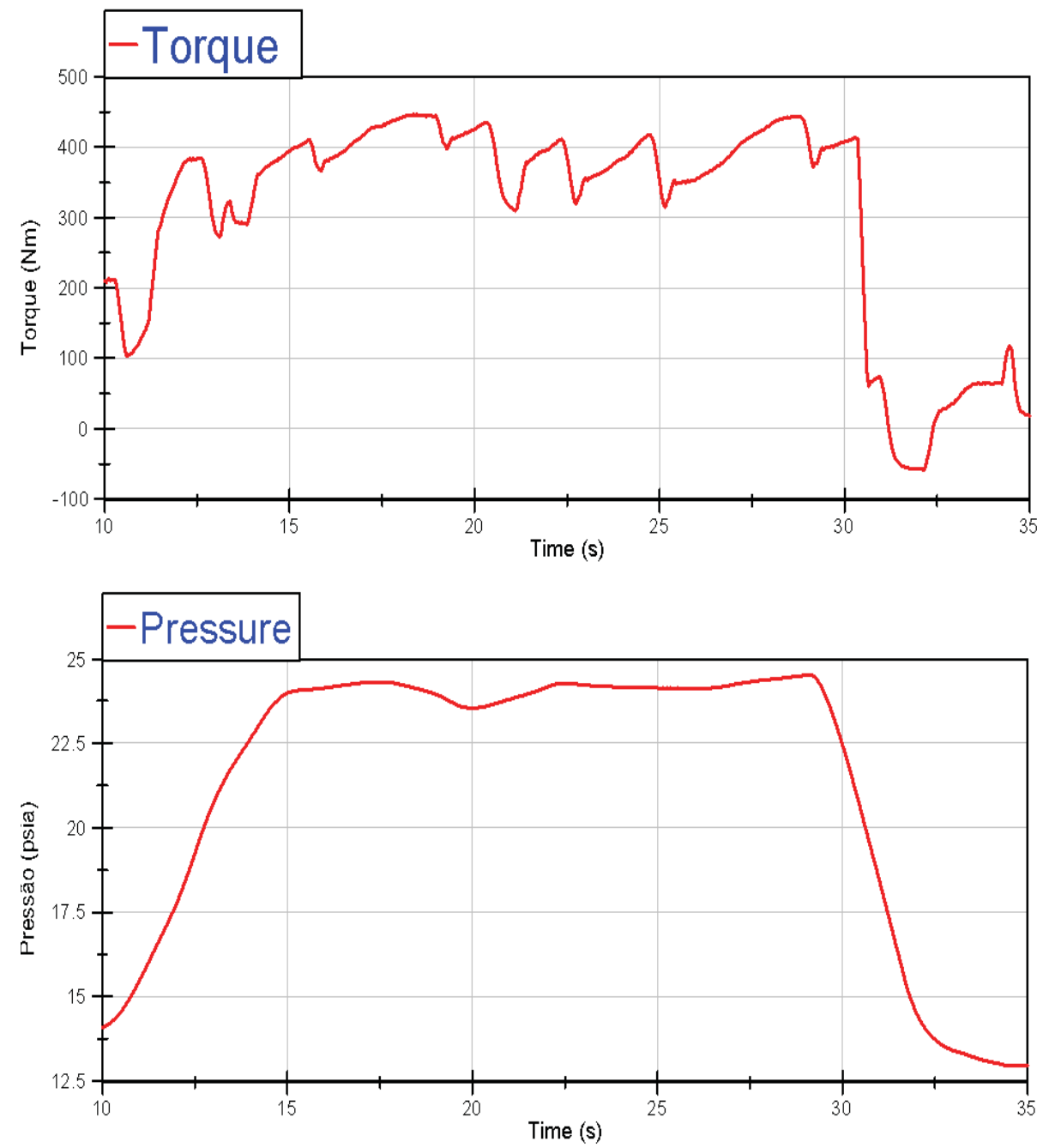

Figura 6.12: Curvas de rotação, torque e potência com alpha igual a 100\% e rampa de 5,5 segundos. 


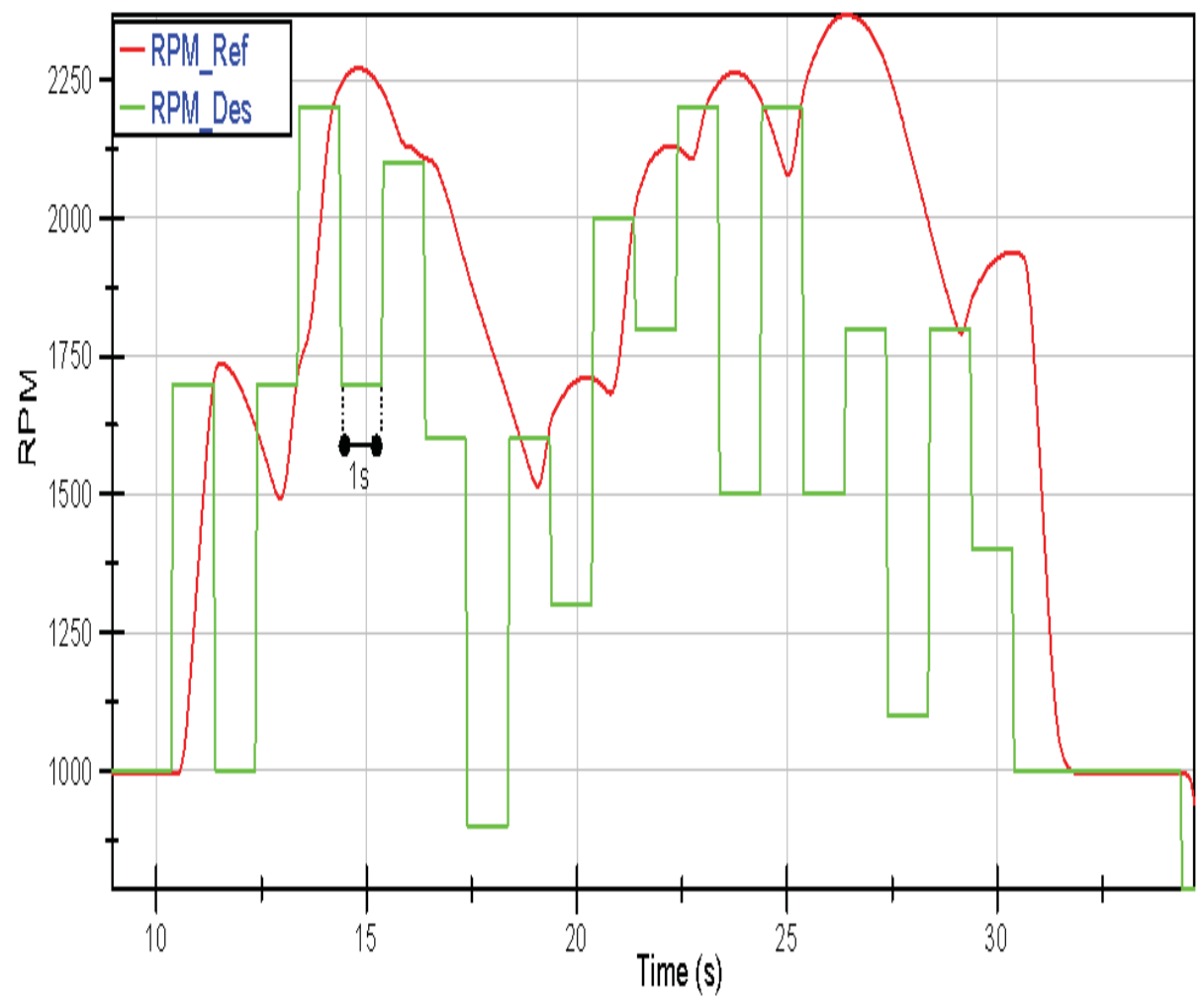

Figura 6.13: Curva de rotação com alpha igual a 100\% e rampa de 5,5 segundos. 


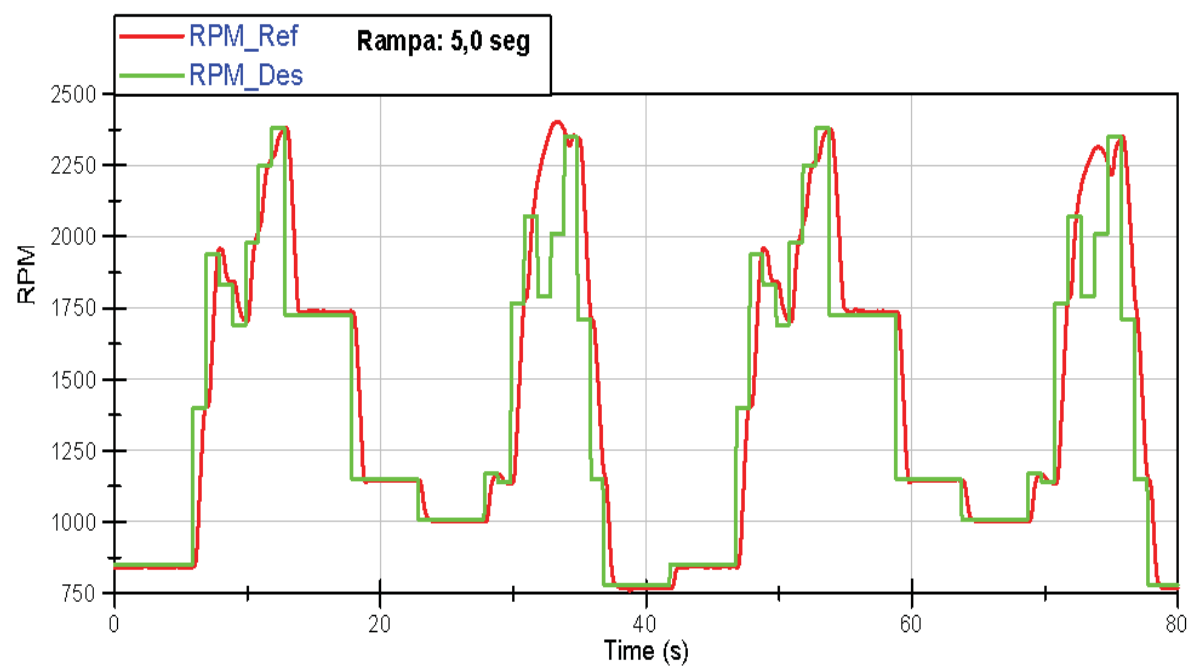

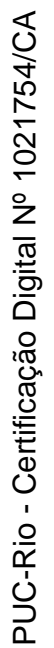
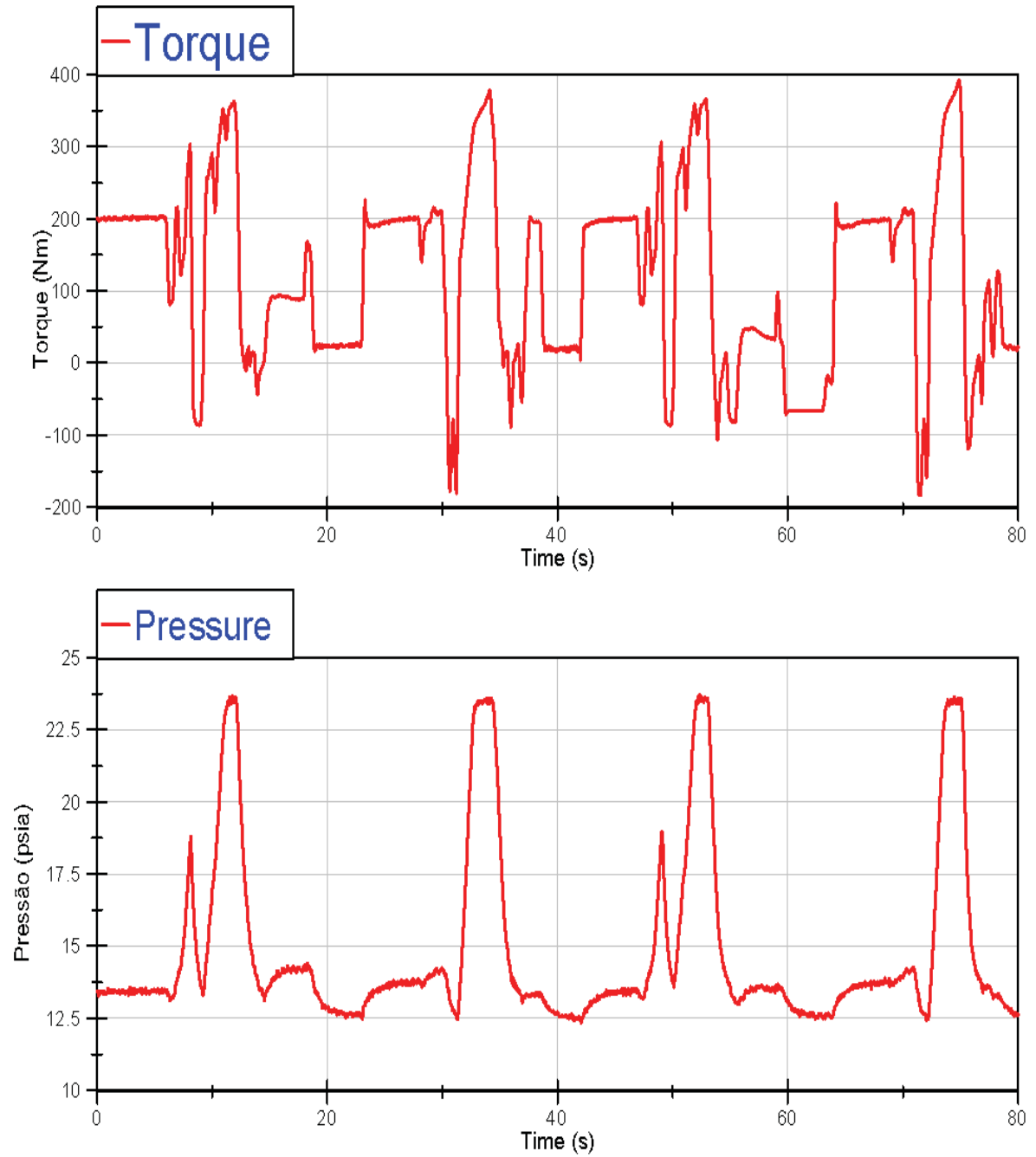

Figura 6.14: Respostas de rotação, torque e pressão para ciclo simulado - rampa de $6,5 \mathrm{~s}$. 


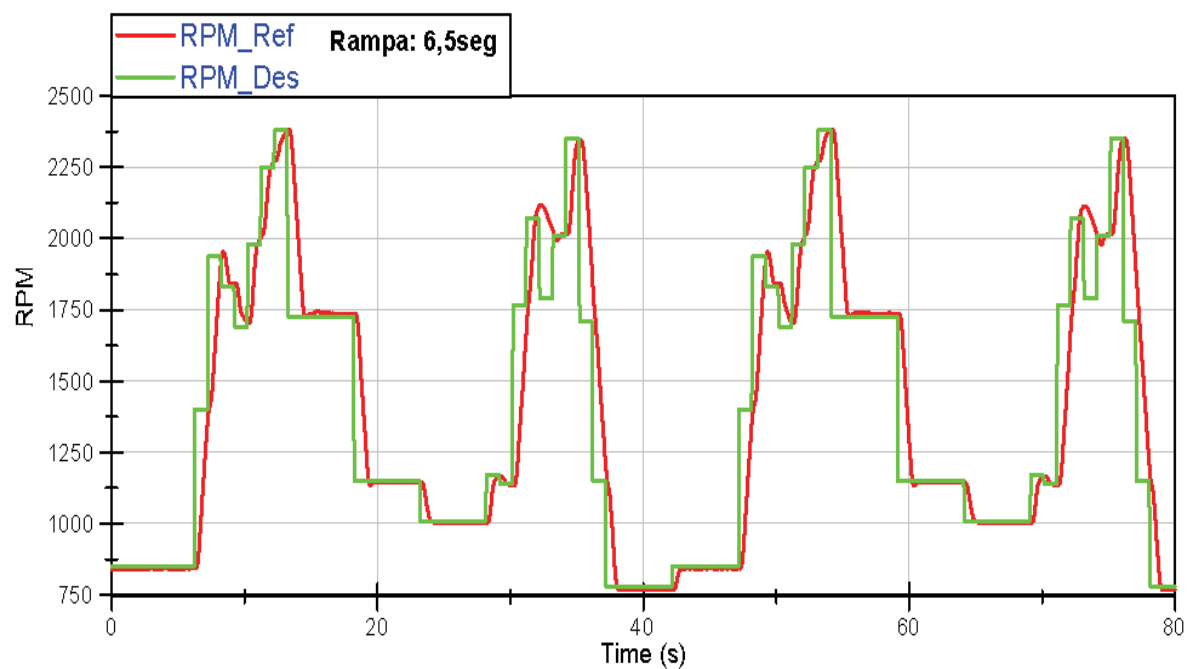

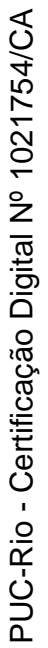
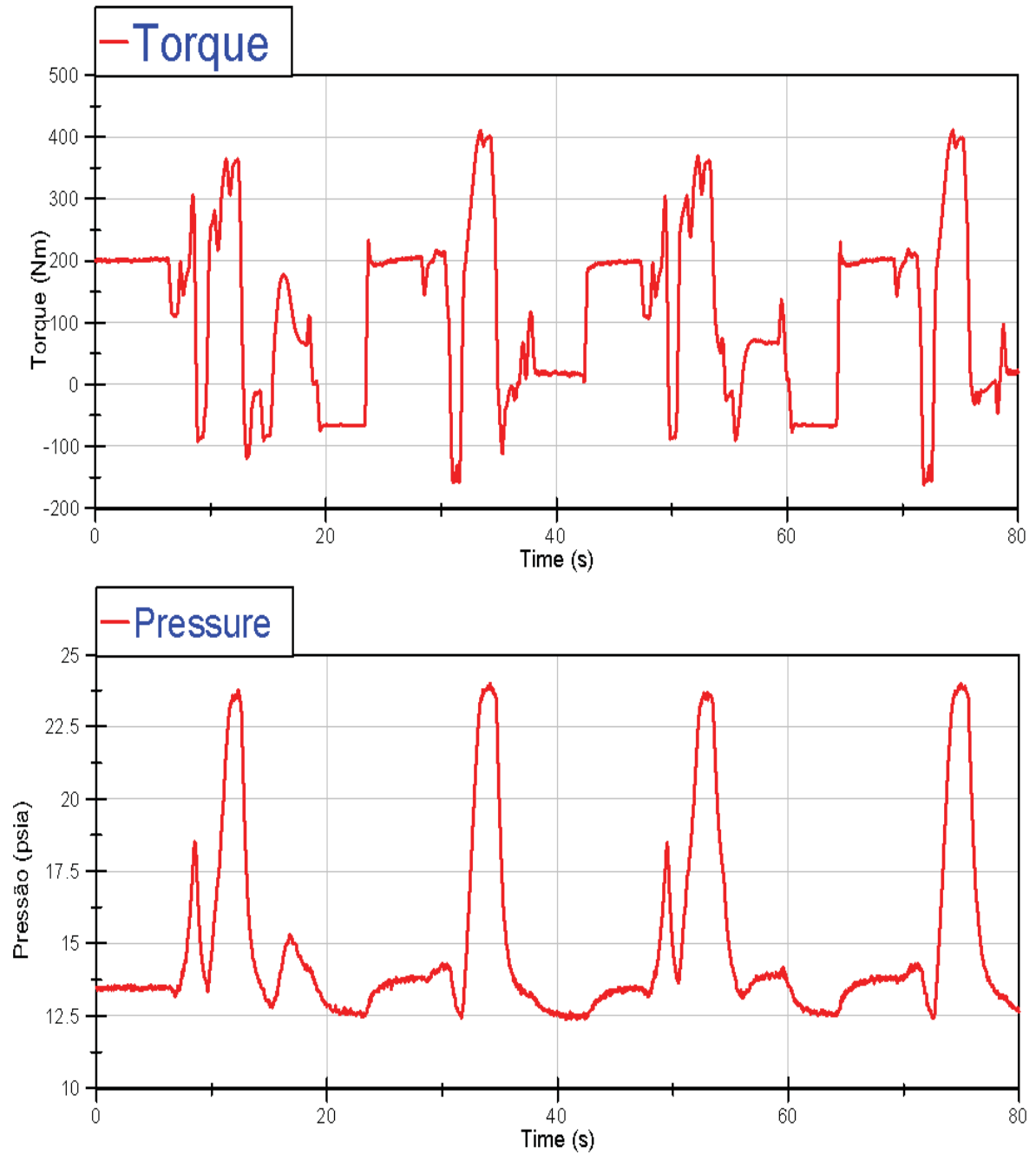

Figura 6.15: Respostas de rotação, torque e pressão para ciclo simulado - rampa de $6,5 \mathrm{~s}$. 

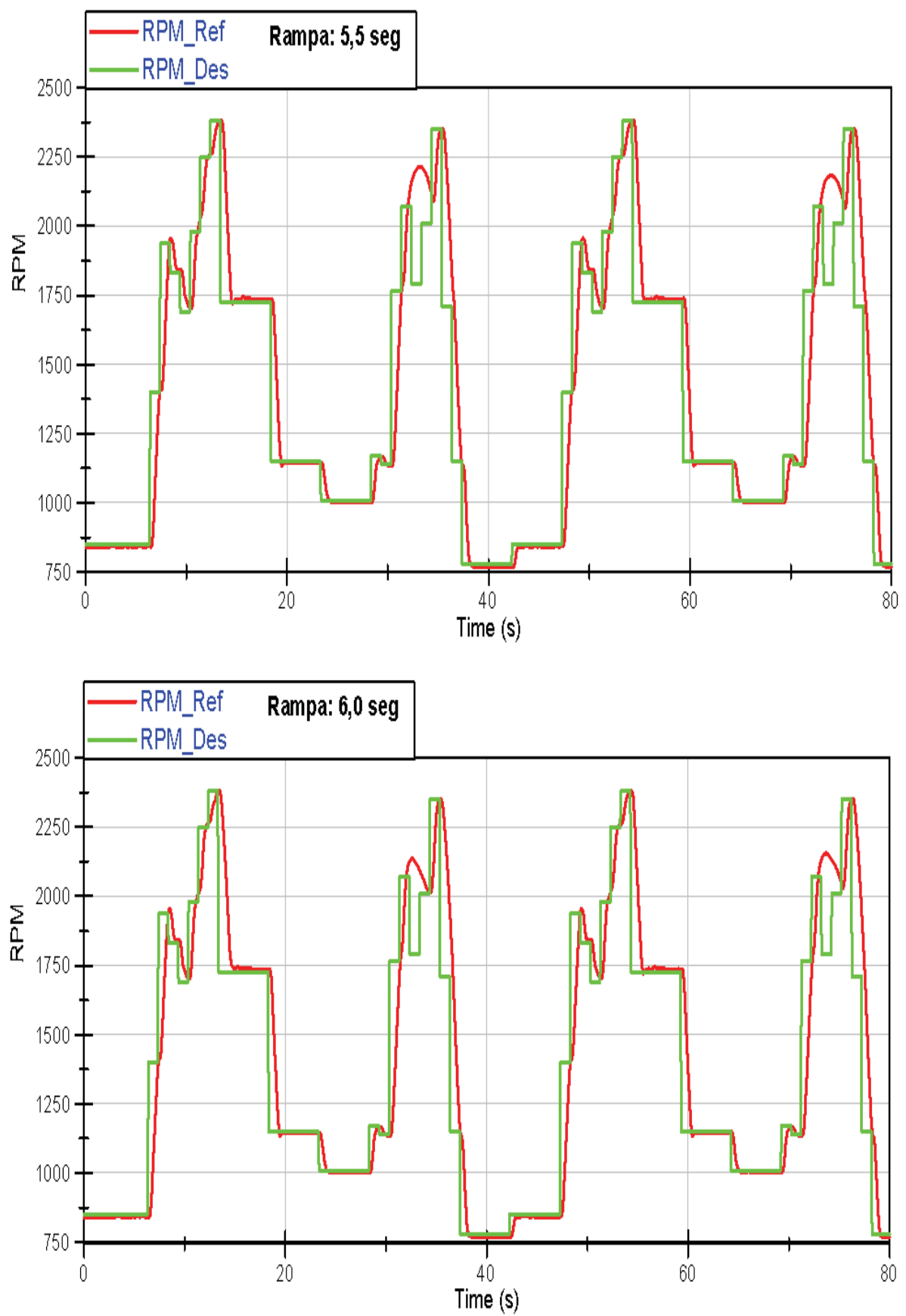

Figura 6.16: Respostas do sistema para perfil de rotação do ciclo simulado rampas de 5,5 e $6 \mathrm{~s}$. 


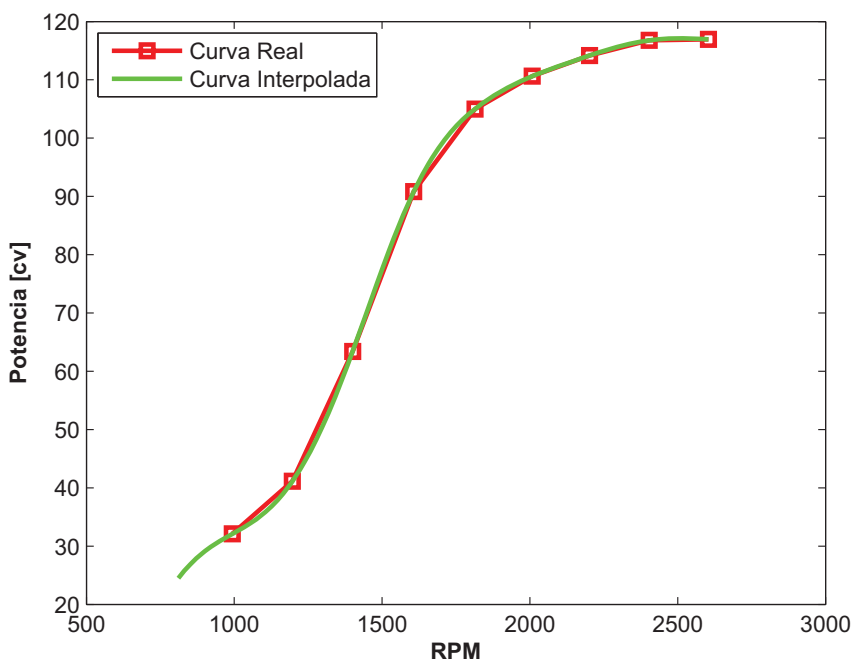

Figura 6.17: Curva de potência máxima real e interpolada do motor Diesel MWM 4.10TCA em função da rotação.

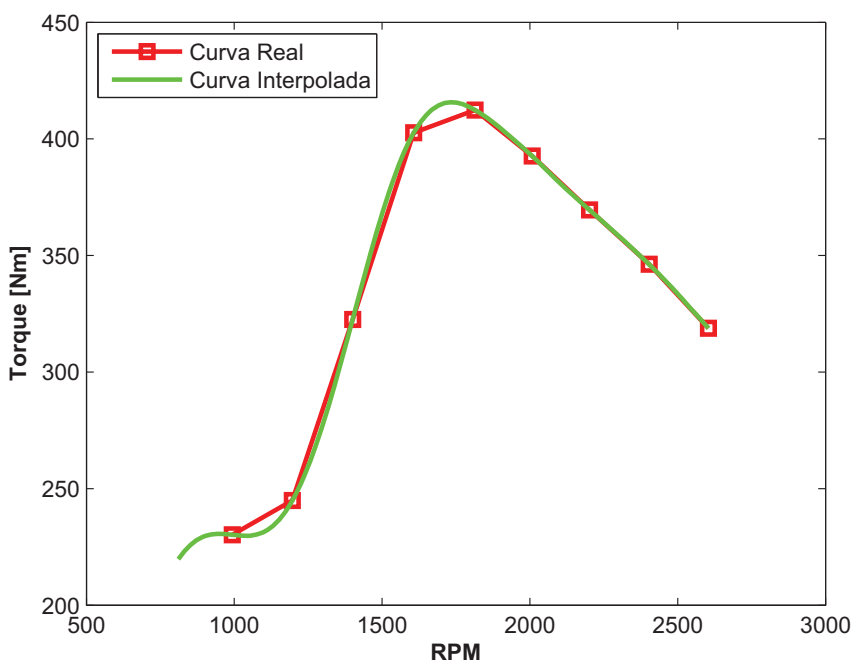

Figura 6.18: Curva de torque máximo real e interpolada do motor MWM 4.10TCA em função da rotação. 


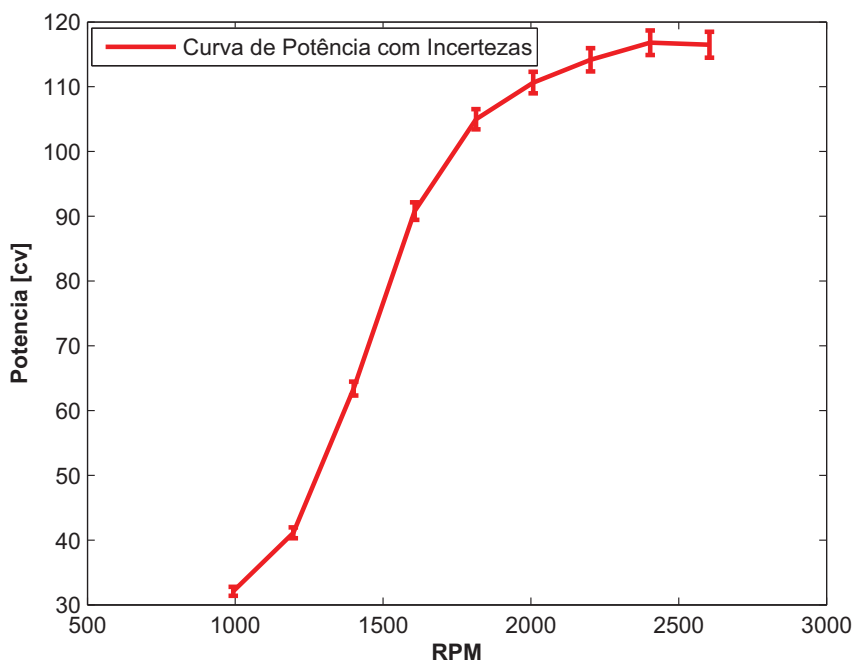

Figura 6.19: Curva de potência do motor MWM 4.10TCA em função da rotação com barra de incertezas.

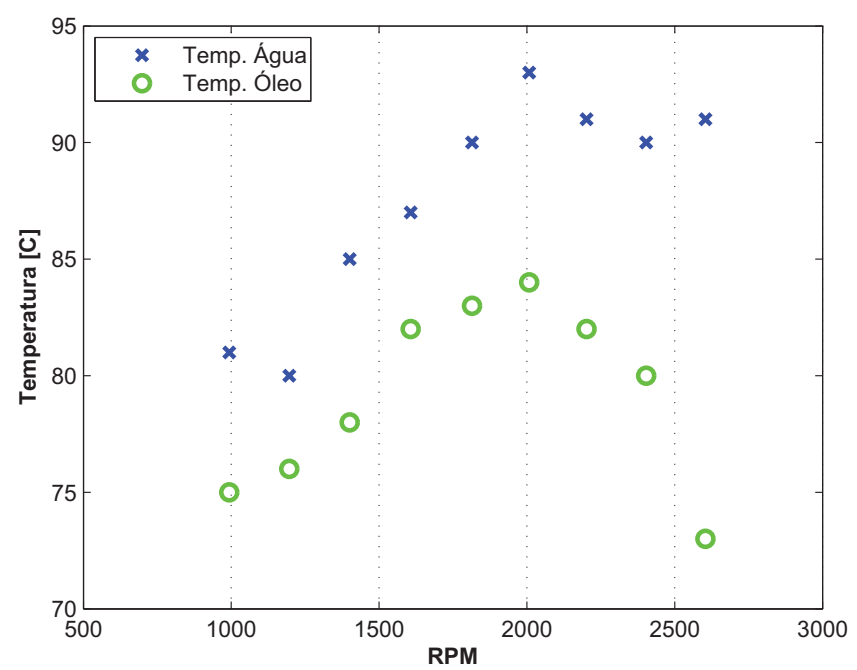

Figura 6.20: Temperaturas de água e óleo do motor Diesel durante ensaio em plena carga. 


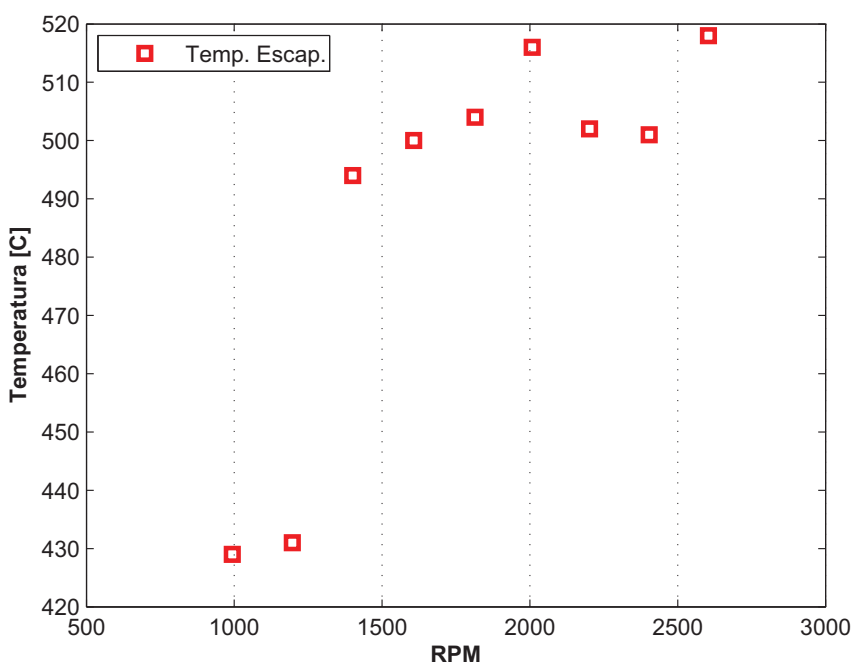

Figura 6.21: Temperaturas de escapamento do motor Diesel durante ensaio em plena carga.

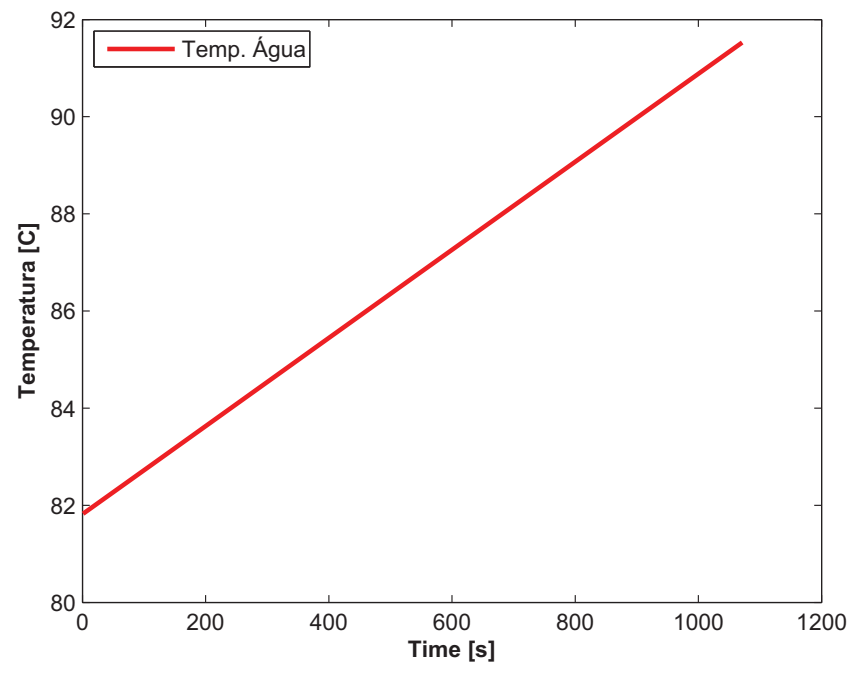

Figura 6.22: Temperatura de água do motor Diesel em teste a plena carga tendência crescente. 

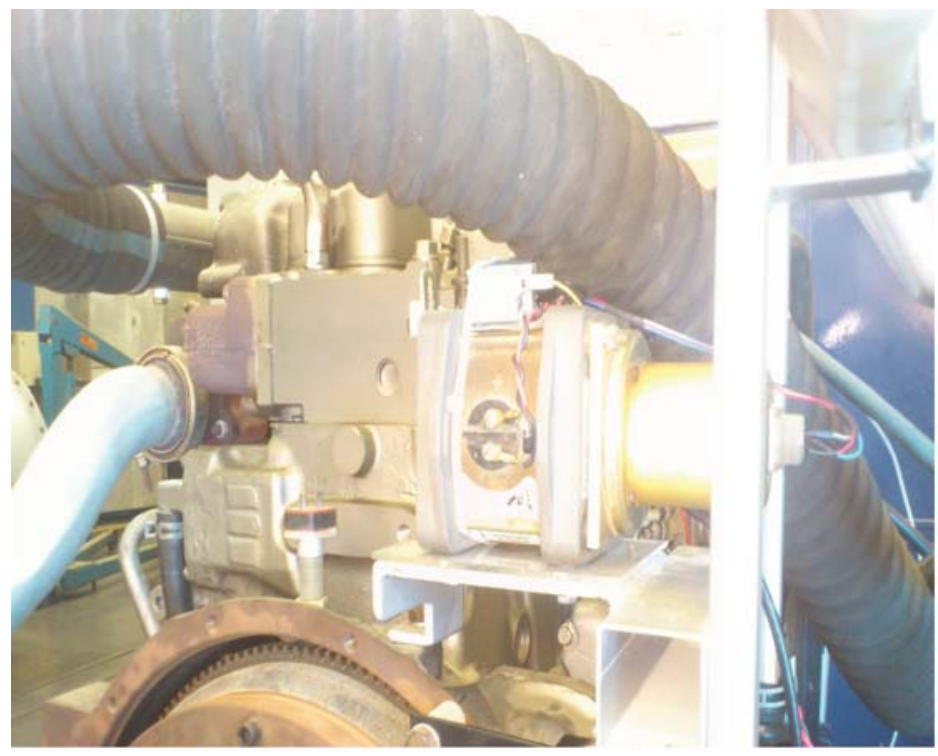

Figura 6.23: Detalhe da mangueira do turbo 


\section{Conclusões e Sugestões}

Foram descritas detalhadamente as etapas de um projeto e construção de uma bancada dinamométrica para ensaios de motores de combustão interna de até $175 \mathrm{cv}, 587 \mathrm{Nm}$ e $4.620 \mathrm{RPM}$.

Os equipamentos e instrumentação, em sua grande maioria de fabricação nacional, foram integrados através de uma rotina de monitoramento e controle também desenvolvida para o projeto. O sistema como um todo, oferece uma solução tecnológica viável, de baixo custo, que possibilita a obtenção de testes confiáveis de motores de combustão interna.

De acordo com os resultados apresentados ao longo desta dissertação baseados tanto nas simulações realizadas como nos procedimentos experimentais, a fim de avaliar objetivos específicos, pode-se chegar às seguintes conclusões:

Construção da Bancada Experimental: O desenvolvimento da base, dos suportes dos motores e do dinamômetro e do dimensionamento dos isoladores de vibração se mostraram corretos. Em todos os pontos de operação e em todos os modos testados, não houve qualquer transmissão perceptível de vibração para os arredores e nem tão pouco para o Laboratório. A fim de simular um dos casos extremos, que ocorre quando dois MCI's estão sobre a base e um está sendo testado, conforme as simulações realizadas, utilizaram-se "massas mortas" que perfaziam um total de aproximadamente $350 \mathrm{~kg}$. Nesta situação não houve qualquer irregularidade que pudesse comprometer o desempenho do sistema. No outro caso extremo, quando somente um MCI está sobre a base e sendo testado, não houve qualquer desnível que representasse algum tipo de perigo para o operador e ou equipamentos, principalmente o transdutor de torque, que possui um desalinhamento máximo, tanto axial quanto radial, de 0,02mm, e o eixo cardan com deslocamento radial máximo de $4 \mathrm{~mm}$. Além disso, os suportes projetados e desenvolvidos tanto para o dinamômetro quanto para os MCI's se mostraram perfeitamente estáveis e robustos para toda a faixa de operação do motor.

Software e Hardware: O software desenvolvido para o controle do banco de provas se mostrou robusto e confiável para a operação do equipamento. Diversos testes foram realizados, principalmente relacionados à parte de segurança como por exemplo o funcionamento de partes críticas do programa, tal como as ações a serem tomadas caso os limites de temperatura pré-estabelecidos seja 
superados, e em todos o sistema se mostrou estável sobre o ponto de vista da confiabilidade de execução.

Além disso, o dimensionamento do Hardware utilizado se mostrou correto para este projeto. Porém, sua utilização não se limita somente a este trabalho. Devido à sua configuração e capacidade de processamento, rotinas de monitoramento e controle mais complexas podem ser desenvolvidas sem a necessidade de se adquirir novos equipamentos.

Integração dos Equipamentos: A integração de componentes de naturezas mecânicas e elétricas deve ser realizada com critério especialmente quando fontes geradoras de ruídos eletromagnéticos (inversores de frequência) estão presentes. Conforme mencionado no Capítulo 3, neste trabalho não foram utilizados cabos específicos para a conexão entre o inversor de frequência e o motor elétrico. Portanto, medidas alternativas foram adotadas de modo a minimizar os efeitos dos ruídos provenientes destes equipamentos. A solução da blindagem dos cabos de sinal se mostrou eficiente. Contudo, o principal fator responsável pela eliminação do ruído no sistema de aquisição e controle foi a utilização dos módulos isoladores de sinais analógicos.

Controle de Torque: $\mathrm{O}$ controle de torque realizado pelo inversor de frequência no sistema se mostrou satisfatório sob o ponto de vista da repetitividade dos ensaios. Sobre diferentes condições de operação (motor frio e motor aquecido) os valores de torque se mostraram estáveis dentro de uma faixa de $5 \mathrm{Nm}$, entre uma aquisição e outra. É importante ressaltar que o ponto em que a corrente de torque corresponde a 50\% não é utilizado pois nele o dinamômetro não está trabalhando em saturação de velocidade. Em contrapartida, a relação entre a porcentagem da corrente de torque e o torque produzido pelo motor elétrico não ocorreu da forma esperada. Contudo, a implementação de um controle simples, por exemplo PID, que seja capaz de, a partir da referência de torque desejada, ajustar a corrente de torque para o valor correto, poderá resolver este problema.

Com relação à velocidade de rotação, quando o sistema está sobre a influência do controle de torque, ela se mostrou instável devido às grandes variações obtidas em seu valor. Essas variações são causadas, principalmente, devido às não linearidades do sistema e pelo fato da força e, consequentemente, o torque produzidos pelo MCI serem compostos por senóides (vide seção 3.5). As não linearidades do MCI são representadas principalmente pela turbina e pelo fato dele não possuir nenhuma unidade de controle eletrônica. Consequentemente, parâmetros como a quantidade de combustível, tempo de 
injeção e massa de ar de combustão, por exemplo, não são precisos. Por conta disto, qualquer variação dos diversos parâmetros que influenciam no desempenho do motor podem ocasionar uma variação de velocidade. No caso do dinamômetro, as não linearidades são representadas por: forma de controle (controle vetorial), pelo acionamento por PWM e pelas perdas, tanto mecânicas quanto elétricas, principalmente pelos cabos de conexão entre o inversor de frequência e o motor elétrico.

Rotação: Diante dos diferentes testes realizados a fim de verificar o comportamento do controle de velocidade observou-se que, para ensaios onde há necessidade de estabilização de uma determinada rotação (mapeamento do motor ou testes a plena carga por exemplo), o sistema se mostrou confiável e preciso. Essa precisão ocorreu tanto na faixa de operação de torque constante do dinamômetro, quanto na faixa de enfraquecimento de campo. Além disso, testes com variação de velocidade se mostraram eficientes, para qualquer valor de alpha, quando a amplitude desta variação não é grande (menor do que 600RPM), ou quando o tempo entre um ponto de operação e outro é maior do que 2 segundos. Para valores de alpha próximos a 100\%, variações de velocidade com grandes amplitudes e em curtos espaços de tempo fazem com que o sistema seja incapaz de seguir as trajetórias definidas.

Conclui-se também que os casos mais críticos de controle de velocidade ocorrem nas desacelerações, quando o dinamômetro chega próximo ao seu limite máximo de corrente. Contudo, no caso das acelerações, quanto menor o valor definido para a rampa, maior a probabilidade de ocorrer um overshoot na resposta de velocidade. Este fato pode vir a comprometer a capacidade do sistema de realizar o teste caso a variação de tempo entre os pontos seja curta. Portanto, nem sempre um menor valor da rampa de aceleração implica em uma resposta mais satisfatória, conforme visto nas Figuras 6.14 e 6.15.

Outro ponto relevante é que de acordo com o ensaio do ciclo baseado nos pontos de velocidade da norma ETC, o sistema aparenta ser capaz de realizar os ciclos de emissões propostos pelas normas européias. Entretanto, a fim de sermos capazes de ratificar esta hipótese, é necessário o desenvolvimento de um sistema de controle capaz de produzir os perfis de velocidade e torque que a norma especifica. Este sistema deverá atuar no controle de velocidade do dinamômetro e na posição do atuador da bomba de combustível, alpha. Uma análise mais profunda deste tipo de controle pode ser encontrada no Apêndice B. 
Sugestões para Trabalhos Futuros: Para o caso do presente trabalho, algumas limitações com relação aos sistemas auxiliares ao banco de provas desenvolvido não permitiram que análises mais profundas pudessem ter sido realizadas. A inserção de elementos capazes de medir e controlar parâmetros importantes do MCI, de uma forma geral, se faz necessária.

Portanto, sugere-se que em trabalhos futuros, equipamentos como condicionadores do ar de admissão e trocadores de calor, para controlar a temperatura da água em um primeiro momento e do óleo, sejam inseridos no sistema. Além disso, equipamentos capazes de medir níveis de emissão de poluentes e vazão de combustível (e consequentemente, o consumo), como por exemplo um medidor do tipo Coriolis, são importantes sob o ponto de vista da eficiência térmica do motor.

No caso do dinamômetro sugere-se a aquisição de cabos específicos para estas aplicações para a conexão entre o inversor de frequência e o motor elétrico, em face dos grandes ruídos eletromagnéticos gerados por esses equipamentos.

Sugere-se também que em trabalhos futuros um sistema de controle "torque x rotação" seja implementado baseado na modelagem proposta no Apêndice B. As técnicas de controle recomendadas para este tipo de aplicação também são referenciadas neste apêndice.

Finalmente, acredita-se que com a metodologia proposta de construção e desenvolvimento do sistema e os resultados obtidos, o Brasil, principalmente com sua destacada indústria automobilística, continue investindo em pesquisas no desenvolvimento de bancos de prova. 


\section{Referências Bibliográficas}

[1] GRUENBACHER, E. Robust Inverse Control of a Class of Nonlinear Systems. Tese (Doutorado) — Johannes Kepler Universitat Linz, Graz, 2005.

[2] MME. Ministério de Minas e Energia - Resenha Energética Brasileira. Brasil, Maio 2012. Disponível em: <http://www.mme.gov.br>.

[3] IEA. Statistics and Balance. Brasil, Janeiro 2011. Disponível em: $<$ http://www.iea.org/stats/index.asp $>$.

[4] EGÚSQUizA, J. C. C. Avaliação Experimental de um Motor do Ciclo Diesel Operando no Modo Bicombustível: Diesel/Etanol e Diesel/Gás. Tese (Doutorado) — Departamento de Engenharia Mecânica, PUC-Rio, 2011.

[5] EPE. Balanço Energético Nacional. Brasil, Dezembro 2009. Disponível em: $<$ http://ben.epe.gov.br/BENRelatorioFinal2010.aspx>.

[6] EGÚSQUizA, J. C. C. Redução das Emissões em Motores Diesel-Gás. Dissertação (Mestrado) — Departamento de Engenharia Mecânica, PUCRio, 2006.

[7] MARTYR, A. J.; PLINT, M. A. Engine Testing. Inglaterra: ButterworthHeinemann, 2007.

[8] PEREIRA, J. C. Dinamômetros. Brasil, Junho 1999. Disponível em: $<$ http://www.joseclaudio.eng.br/dinos1.html>.

[9] SIEMENS. Motores de Corrente Contínua - Guia rápido para uma especificação precisa. Brasil, 2006.

[10] WEG. Motores Elétricos. Brasil, Junho 2005.

[11] BARRetO, G. Campo Girante. Brasil, Junho 2010. Disponível em: $<$ http://www.youtube.com/watch?v $=\mathrm{rb} U_{J} A T 6 V A 4>$.

[12] ROHENKOHL, P. Dinâmica dos Testes de Motores, seus Componentes, Controles e Validação. Campo Limpo, SP, Brasil, 2004.

[13] KOUSTAS, J.; WATSON, N. A transient diesel test bed with direct digital control. SAE 840347, 1984.

[14] WEEKS, R. W.; MOSKWA, J. J. Automotive engine modeling for realtime control using matlab/simulink. SAE 950417, 1995. 
[15] BUnkER, B. J.; FRANCHEK, M. A.; THOMASON, B. E. Robust multivariable control of an engine-dynamometer system. IEEE Transactions on Control Systems Technology, 1997.

[16] YANAKIEV, D. Adaptative control of diesel engine-dynamometer system. 37th IEEE Conference on Decision IES Control, 1998.

[17] GRUENBACHER, E.; RE, L. D. Robust inverse control for combustion engine test benches. American Control Conference, 2008.

[18] GRUENBACHER, E. et al. Adaptive inverse torque control of a diesel engine using adaptive mapping update. SAE 2003-01-0397, 2003.

[19] GRUENBACHER, E. et al. Trade-offs in highly dynamical transient simulation on engine test benches. SAE 200\%-01-0325, 2007.

[20] GRUENBACHER, E. et al. Method for controlling a test bench. United States Patent Application Publication, 2004.

[21] BLOEMEN, H.; BOOM, T. van de; VERBRUGGEN, H. Model-based predictive controlfor hammerstein systems. Delft University of Technology, 2001.

[22] ACHICKER W.;WEGENER, G. Measuring Torque Correctly. Bielefeld: Bentrup Druckdienste KG, 2002.

[23] NORTON, R. L. Machine Design. Estados Unidos: Pearson Prentice Hall, 2006.

[24] DRIVES, F. Keyless Bushings Catalog and Specialty Locking Devices. USA, Agosto 2010.

[25] CASPER, T. Reibkorrosionsverhalten von Spanelementverbindungen. Aachen: Mainz, 1999.

[26] BUZDUGAN, G. Dynamique des Fondations de Machines. Paris: Eyrolles, 1972.

[27] NAWROTZKI, P.; HUfFMANN, G.; UZUNOGLU, T. Static and dynamic analysis of concrete turbine foundations. Structural Engineering International - SEI, 2008.

[28] ROWAN, R. L.; SUTTON, W. T. Foundations for dynamic equipment. ACI Committee 351, 2004. 
[29] NORTON, R. L. Design of Machinery. Estados Unidos: McGraw-Hill, 1999.

[30] TAYLOR, C. F. The Internal Combustion Engine in Theory and Practice. São Paulo: E. Blucher, 1971.

[31] ANSYS, I. Introduction do ANSYS Mechanical. Estados Unidos, Janeiro 2010 .

[32] NAKASONE, P. H. Tutoria ANSYS Análises Modal, Harmônica e Transiente. Escola Politécnica da Universidade de São Paulo, Junho 2004.

[33] MARIN, P. Blindar ou não blindar. RTI: Redes, Telecom e Instalações, 2008.

[34] PELlegrino, P. E. M. O Que Você Deve Saber Sobre Cabos Para Variador De Velocidade. Brasil, Abril 2009.

[35] AVL. PUMA Open Test System Automation, version 1.2. Graz, Austria, 2004 .

[36] HAICAL, R. C. Desenvolvimento de um Sistema de Controle para Testes de Motores de Combustão Interna. Dissertação (Mestrado) — Departamento de Engenharia Mecânica, UFRS, 2009.

[37] FRANCO, J. A. A. Estudo Experimental da Combustão Homogênea em Motores. Dissertação (Mestrado) — Departamento de Engenharia Mecânica, PUC-Rio, 2011.

[38] NI. What is a Real-Time Operating System (RTOS). Estados Unidos, Julho 2012.

[39] NI. LabVIEW Basics I: Introduction Course Manual. Estados Unidos, Setembro 2007.

[40] NI. LabVIEW Real-Time Application Development Course Manual. Estados Unidos, Fevereiro 2009.

[41] OGATA, K. Modern Control Engineering. Estados Unidos: Prentice-Hall, 1997.

[42] NI. The NI TDMS File Format. Estados Unidos, Julho 2012.

[43] NI. DIAdem Data Acquisition Getting Started and User Manual. Estados Unidos, Dezembro 2005. 
[44] WEG. Manual de Programação CFW-11. Brasil, Outubro 2010.

[45] ABNT. Veículos rodoviários automotores - análise e determinação do gás de escapamento segundo ciclos etc, esc e elr. ABNT NBR 15634, 2012.

[46] PARLiAment, E. Diretiva 99/ /EC. Bruxelas, Abril 1999.

[47] GUIRARDI, W. Análise da Influência das Condições do Ar Atmosférico no Desempenho de Turbinas a Gás com Sistemas de Resfriamento do Ar de Entrada. Dissertação (Mestrado) — Instituto de Mauá de Tecnologia Escola de Engenharia Mauá., 2008.

[48] KLINE, S. J.; MCCLINTOCK, F. A. Describing uncertainties in siglesample experiments. Mechanical Engineering, 1953.

[49] LOPEZ, J. D.; ESPINOSA, J. J.; AGUDELO, J. Decoupled control for internal combustion engines research test beds. Rev. Fac. Ing. Univ. Antioquia, 2011.

[50] MAZHARI, I.; VAHEDI, A.; MASOUM, M. A. S. Induction motor load generator system using direct torque control method. Power Engineering Conference, 200\%, AUPEC 200\%, Australasian Universities, 2007.

[51] LANDAU, Y. Adaptive Control: The Model Reference Approach. Estados Unidos: Marcel Dekker, Inc, 1979.

[52] NARENDRA, K.; ANNASWAWY, A. Stable Adaptive Systems. Estados Unidos: Dover Publications, Inc, 2005. 


\section{A \\ Análise de Propagação de Incertezas Experimentais}

Todo dado experimental deve ser analisado através de algum tipo de procedimento que permita indicar uma medida de confiabilidade. A incerteza se apresenta como um valor associado ao resultado de uma medição que caracteriza a sua dispersão.

Segundo [37], a incerteza de medição em salas de testes de motores possui diferentes componentes que devem ser agrupados em duas categorias, em função do método utilizado para estimar seu valor: incertezas do tipo A e do tipo B.

A Incerteza do tipo $A\left(I_{A}\right)$ é uma incerteza padrão e é atribuída à repetibilidade dos resultados de medições sucessivas nas mesmas condições. Seu valor é calculado a partir da análise estatística de uma série de observações válidas para tratamentos de dados como o cálculo do desvio-padrão da média ou o método dos mínimos quadrados.

Por outro lado, a Incerteza de tipo $B\left(I_{B}\right)$ é aquela avaliada por outros métodos que não sejam estatísticos. Está baseada em julgamentos científicos utilizando todas as informações disponíveis, que podem ser obtidas a partir de dados de medições anteriores, comportamentos dos instrumentos, especificações do fabricante, certificados de calibração, curvas de linearização, etc.

Finalmente, podem-se combinar esses dois tipos de incerteza:

$$
I=\sqrt{I_{A}^{2}+I_{B}^{2}}
$$

Sendo este valor definido como o valor final da incerteza para uma determinada variável.

Para determinar a faixa de incerteza experimental com que se esta trabalhando foi utilizado o método de Kleine e McClintock [48] também conhecido como a combinação da pior situação.

Para uma função $R$ que está em função de diferentes variáveis independentes, pode ser expressa matematicamente como $R=R\left(x_{1}, x_{2}, \ldots, x_{3}\right)$, onde uma variação de $\delta x_{i}$ em $x_{i}$ causa uma variação $\delta R$ em R. Assim,

$$
\delta R=\sum_{i=1}^{n} \sqrt{\left(\frac{\partial R}{\partial x_{i}} \delta x_{i}\right)^{2}}
$$


onde: $\mathrm{R}$ é a grandeza a ser avaliada, $\delta R$ é a incerteza na grandeza $\mathrm{R}, x_{i}$ é a variável independente e $\delta x_{i}$ é a incerteza na variável $x_{i}$.

Na Equação A-2, cada um dos termos do somatório corresponde a incerteza de cada uma das variáveis independentes utilizadas para o cálculo do resultado $R$.

Segundo [6], uma situação típica em trabalhos de engenharia é o experimento de "amostra única", em que apenas uma medição é feita para cada ponto. Uma estimativa razoável da incerteza de medição devido ao erro aleatório em um experimento de amostra única é, geralmente, mais o menos a metade da menor divisão da escala (a contagem ou leitura mínima) do instrumento.

\section{A.1}

Incerteza da Potência Efetiva

A potência efetiva fornecida pelo motor é calculada na Equação 5-3

$$
P=P(T, N)=\frac{2 \pi \cdot T \cdot N \cdot 0,00134}{60}
$$

As derivadas parciais para o torque e velocidade são:

$$
\begin{aligned}
& \frac{\partial P}{\partial T}=\frac{2 \pi}{60} \cdot N \cdot 0,00134 \\
& \frac{\partial P}{\partial N}=\frac{2 \pi}{60} \cdot T \cdot 0,00134
\end{aligned}
$$

Logo, a equação final em termos da incerteza relativa a potência é da seguinte forma:

$$
\delta P=\sqrt{\left(\frac{\partial P}{\partial N} \delta N\right)^{2}+\left(\frac{\partial P}{\partial T} \delta T\right)^{2}}
$$




\section{B Desenvolvimento do Modelo Motor-Dinamômetro}

O modelo representativo de um banco de provas é caracterizado por ser do tipo MIMO (Múltiplas Entradas Múltiplas Saídas) onde o torque do MCI $\left(T_{E}\right)$ e o torque do dinamômetro $\left(T_{D}\right)$ correspondem às entradas do sistema e, o torque no eixo $\left(T_{\text {Eixo }}\right)$ e a rotação do MCI $\left(\omega_{E}\right)$ correspondem as saídas. No caso das entradas, as que efetivamente são de controle são a posição do acelerador $(\alpha)$, que é convertida, posteriormente, em torque produzido pelo MCI, e $T_{D}$.

O desenvolvimento de tal modelo pode ser abordado em duas formas diferentes: domínio da frequência e domínio do tempo.

No primeiro modo, a modelagem é feita por funções de transferência através da razão saída-entrada. No caso da modelagem MCI-Dinamômetro, em [15, 16, 49], o modelo adotado é do tipo "caixa-preta". Este modelo não leva em consideração nenhum conhecimento prévio do sistema a ser estudado e, somente através da relação saída-entrada, funções descritivas são obtidas. Para tanto, diversos testes são realizados mantendo-se uma entrada constante e variando a outra, a fim de obter funções de transferência que representem o conjunto com todas as suas não linearidades. Por tanto, quatro funções $\left(P_{11}, P_{12}, P_{21}, P_{22}\right)$ são obtidas conforme a Equação B-1.

$$
\left[\begin{array}{c}
\omega_{E} \\
T_{\text {Eixo }}
\end{array}\right]=\left[\begin{array}{ll}
P_{11} & P_{12} \\
P_{21} & P_{22}
\end{array}\right]\left[\begin{array}{c}
\alpha \\
T_{D}
\end{array}\right]
$$

Na segunda abordagem, que é a utilizada no presente trabalho, equações baseadas em modelos físicos são utilizadas [13, 14, 17]. Porém estas equações devem ser simplificadas, a fim de serem aplicáveis devido aos seguintes fatores: o modelo deve ser flexível, ou seja, deve poder ser utilizado para diferentes MCIs. Modelos bastante detalhados são específicos para um só motor; o esforço para a parametrização destas equações são intensos e, por fim, muitas vezes se torna difícil de se conseguir obter todas as medidas que a modelagem necessita.

A seguir serão descritos os principais componentes do sistema Dinamômetro-MCI do ponto de vista de suas modelagens.

\section{B.1 \\ Dinamômetro}

O dinamômetro é uma máquina de indução com seu próprio sistema de controle que produz respostas bem mais rápidas que os outros componentes do 
sistema. Ele pode ser aproximado por uma equação do segundo grau [1, 13, 50], um bloco de saturação e um limitador da taxa de variação. Como mostrado em [1], as equações físicas representativas deste equipamento produzem pólos bastante afastados do eixo imaginário. Por conta disto, a dinâmica referente a este equipamento pode ser desprezada do modelo.

A sua velocidade de rotação pode ser obtida aplicando a Segunda Lei de Newton, conforme a Equação B-2

$$
\theta_{D} \times \dot{\omega}_{D}=T_{\text {Eixo }}-T_{D}
$$

onde $\theta_{D}=\theta_{D 1}+\theta_{D 2}$, no qual $\theta_{D}$ é a inércia combinada do dinamômetro, $\theta_{D 1}$ é a inércia do dinamômetro e $\theta_{D 2}$ é a soma das inércias da flange do disco de pressão $\left(\theta_{F S D}\right)$, do disco de pressão $\left(\theta_{S D}\right)$, da flange de torque $\left(\theta_{F T o r}\right)$ e da flange que acopla o eixo cardan ao transdutor de torque $\left(\theta_{A c o p}\right)$, $\dot{\omega}_{D}$ é a aceleração angular do dinamômetro, $T_{\text {Eixo }}$ é o torque produzido no eixo e $T_{D}$ é o torque gerado no dinamômetro. Um torque positivo é utilizado para frear o sistema.

\section{B.2}

\section{Elementos de Conexão}

A conexão entre o dinamômetro e o MCI é uma parte bastante crítica do projeto. São nos elementos que os compõem que a dinâmica do sistema ocorre (torque, velocidade, aceleração etc). Estes foram descritos na seção 3.3.

A modelagem pode ser aproximada por um sistema mola-amortecedor em série. A primeira parte é dependente da torção do eixo, que é dada pela integral entre as velocidades, enquanto que a segunda, se refere a diferença entre as velocidades em cada ponta (termo dissipativo). Portanto, as equações que descrevem os elementos de conexão são:

$$
\begin{gathered}
\Delta \dot{\phi}=\omega_{E}-\omega_{D} \\
T_{\text {Eixo }}=k \Delta \phi+d\left(\omega_{E}-\omega_{D}\right)
\end{gathered}
$$

onde $\Delta \phi$ é a torção do eixo, $\omega_{E}$ é a velocidade de rotação do MCI, $k$ é a rigidez torcional e $d$ é o amortecimento torcional dos elementos de conexão. Os valores para os parâmetros citados podem ser vistos na Tabela B.1.

Reunindo as equações matemáticas representativas do sistema dinamômetro-MCI, sua forma matricial pode ser vista na Equação B-5. 


$$
\left[\begin{array}{c}
\Delta \dot{\phi} \\
\dot{\omega}_{E} \\
\dot{\omega}_{D}
\end{array}\right]=\left[\begin{array}{ccc}
0 & 1 & -1 \\
-k / \theta_{E} & -d / \theta_{E} & d / \theta_{E} \\
k / \theta_{D} & d / \theta_{D} & -d / \theta_{D}
\end{array}\right]\left[\begin{array}{c}
\Delta \phi \\
\omega_{E} \\
\omega_{D}
\end{array}\right]+\left[\begin{array}{cc}
0 & 0 \\
1 / \theta_{E} & 0 \\
0 & -1 / \theta_{D}
\end{array}\right]\left[\begin{array}{c}
T_{E} \\
T_{D}
\end{array}\right]
$$

As variáveis de saída são o torque no eixo $T_{\text {Eixo }}$, lido pelo transdutor de torque, e a rotação do motor, $\omega_{E}$. Elas são descritas, em forma matricial, pela Equação B-6.

$$
\left[\begin{array}{c}
T_{\text {Eixo }} \\
\omega_{E}
\end{array}\right]=\left[\begin{array}{ccc}
k & d & -d \\
0 & 1 & 0
\end{array}\right]\left[\begin{array}{c}
\Delta \phi \\
\omega_{E} \\
\omega_{D}
\end{array}\right]
$$

Tabela B.1: Constantes do modelo.

\begin{tabular}{|l|l|l|}
\hline$\theta_{D 1}$ & {$\left[\mathrm{kgm}^{2}\right]$} & 2,569 \\
$\theta_{F S D}$ & {$\left[\mathrm{kgm}^{2}\right]$} & 0,01 \\
$\theta_{\text {Acop }}$ & {$\left[\mathrm{kgm}^{2}\right]$} & 0,0032 \\
$\theta_{\text {FTor }}$ & {$\left[\mathrm{kgm}^{2}\right]$} & 0,0139 \\
$\theta_{\text {SD }}$ & {$\left[\mathrm{kgm}^{2}\right]$} & 0,0218 \\
$\theta_{\text {MCI }}$ & {$\left[\mathrm{kgm}^{2}\right]$} & 0,2098 \\
$\theta_{\text {Cardan }}$ & {$\left[\mathrm{kgm}^{2}\right]$} & 0,0639 \\
$\theta_{F V o l}$ & {$\left[\mathrm{kgm}^{2}\right]$} & 0,299 \\
$\mathrm{k}$ & {$[\mathrm{Nm} / \mathrm{rad}]$} & 1500 \\
$\mathrm{~d}$ & {$[\mathrm{Nms} / \mathrm{rad}]$} & 2,74 \\
\hline
\end{tabular}

\section{B.3}

\section{Motor de Combustão Interna}

Torque e potência de MCIs podem ser definidos como funções da quantidade de combustível dentro da câmara de combustão e de $\omega_{E}$. Porém, esta dependência não é somente estática. A vazão de combustível é controlada por uma série de componentes físicos e através de software, desde bico injetores até a posição do pedal do acelerador $(\alpha)$. Estes componentes possuem diversos limitadores, como por exemplo ECU e mapas de emissões, que limitam a quantidade máxima de combustível para uma determinada velocidade. Estes últimos elementos, em um banco de provas padrão, na maioria das vezes, não são conhecidos, o que torna a modelagem e, posteriormente, o controle mais complicados. Portanto, o torque produzido pelo MCI é uma função não linear, com efeitos dinâmicos, fortemente dependentes da $E C U$, relacionada ao $\alpha$ e $\omega_{E}$. Devido a estes fatores e a não linearidade inerente a este sistema, um 
modelo do tipo caixa-preta será utilizado para determinar o torque produzido pelo mesmo.

O modelo temporal do MCI, como dito anteriormente, será bastante simplificado a fim de ser possível realizar o controle do mesmo, em curto espaço de tempo. De acordo com [1], a estrutura do modelo do MCI é composta por duas partes, uma estática, chamada de mapa não linear estático e outra dinâmica, dependente do ponto de operação estacionário. Ainda segundo o autor, modelos de primeira ordem são suficientes para descrever o comportamento local do motor. A união destes dois termos corresponde ao modelo do motor. Neste trabalho, de modo a simplificar esta abordagem, foi realizado somente o mapa não linear estático.

\section{B.3.1}

Mapa Estático Não Linear

O mapa estático não linear pode ser definido como:

$$
T_{E}=T_{E}\left(\omega_{E}, \alpha\right)
$$

Segundo [1, 18, 19], a identificação do comportamento estático é feita através de medições em pontos de operação estacionários. O procedimento adotado é composto por três passos principais:

- definição dos pontos de operação e aquisição;

- aproximação dos pontos por funções polinomiais;

- interpolação dos pontos;

\section{B.3.1.1}

\section{Definição dos Pontos de Operação e Aquisição}

O primeiro passo para se obter o mapa estático de qualquer motor é definir os pontos nos quais serão feitas as medições. Não existe uma regra geral para esta escolha. Normalmente, são escolhidos pontos que cubram a maior parte das condições de uso do motor em sua aplicação real e, através de aproximações, extrapola-se para cobrir toda a faixa de operação. O auxílio de um profissional com conhecimento é importante, mas não necessário, pois assim pode-se diminuir o número de pontos e o tempo desta etapa.

Geralmente, a variação do parâmetro $\alpha$ é realizada da mesma forma para todas as rotações definidas a fim de facilitar os cálculos do mapa estático do MCI.

No caso do presente trabalho, devido ao enorme tempo necessário para mapear o motor nos pontos julgados importantes e de pós processamento dos 
dados aquisitados, utilizou-se os valores obtidos para um motor similar ao utilizado neste trabalho, em testes realizados no Laboratório de Engenharia Veicular da PUC-Rio (vide Anexo C).

A aquisição destes dados foi realizada fixando diferentes valores de $\omega_{E}$ e, para cada uma delas, variou-se o valor de $\alpha$ entre 0 e 100\%. Para cada par $\left(\omega_{E}, \alpha\right)$ mediu-se o valor do torque. Os valores de alpha e torque foram armazenados em dois vetores, $T(\alpha)$ e $\alpha$.

\section{B.3.1.2}

\section{Aproximação dos Pontos por Funções Polinomiais}

Como a aquisição dos pontos não tinha o objetivo específico de mapear o motor, a variação dos valores de $\alpha$ não foi igual para todas as rotações e, por conta disto, foi necessário aproximá-los por funções polinomiais de modo que pudesse ser capaz de abranger toda a faixa de valores possíveis de alpha.

A aproximação dos pontos, para cada rotação, por uma curva representativa foi realizada através do software Matlab. Nele, foi utilizada a função polyfit que calcula os coeficientes do polinômio $T(\alpha)$ em função dos valores de $\alpha$, a partir do grau que o usuário define, pelo método dos mínimos quadrados. O grau do polinômio referente a rotação de 1000 RPM foi 3 enquanto que a dos demais valores foi de grau 2.

A partir dos coeficientes destes polinômios pode-se obter os valores de $T(\alpha)$ para diferentes valores de alpha, para cada uma das rotações dos ensaios realizados em bancada. Foram utilizados 13 valores de alpha começando em 4, com intervalos de 8, até o limite de 100 \%. Com isso foi possível plotar uma superfície, através do comando surf, que representasse uma aproximação do mapa estático do MCI. Esta superfície pode ser vista na Figura B.1.

\section{B.3.1.3}

\section{Interpolação dos Pontos}

A interpolação dos pontos se fez necessária pois o mapa estático característico de um motor deve abranger a maior quantidade de pontos possíveis de operação. Como os valores de rotação aquisitados não cobriam toda a faixa de operação do motor, os valores entre um ponto de rotação e o seguinte não poderia ser determinado. De posse dos valores de alpha, rotação e torque obtidos na seção anterior, utilizou-se o comando interp2 do Matlab a fim de obter uma maior gama de valores dessas variáveis.

O comando interp2 faz a interpolação de uma função de duas variáveis para obter a terceira. Para tanto, como valores de entrada desta função, foram passados os vetores correspondentes a $\alpha$ e torque, calculados na seção B.3.1.2, 


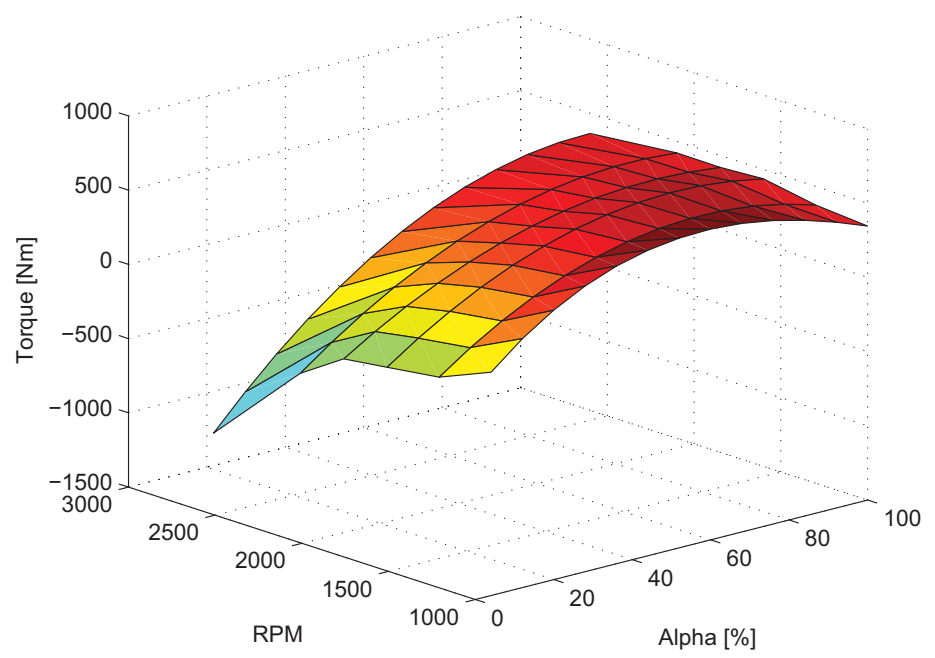

Figura B.1: Superfície gerada a partir dos valores de rotação, alpha e torque.

e o vetor de rotações. Além disso, foi criado um vetor de $\alpha$, com intervalos de 5 , começando em 4 e terminando em $100 \%$ e um vetor de rotações com intervalo de 50, começando em 1000 e terminando em 2600 RPM. Estes vetores criados foram utilizados para o cálculo dos valores de Torque. A Figura B.2mostra o resultado da interpolação da curva do mapa estático.

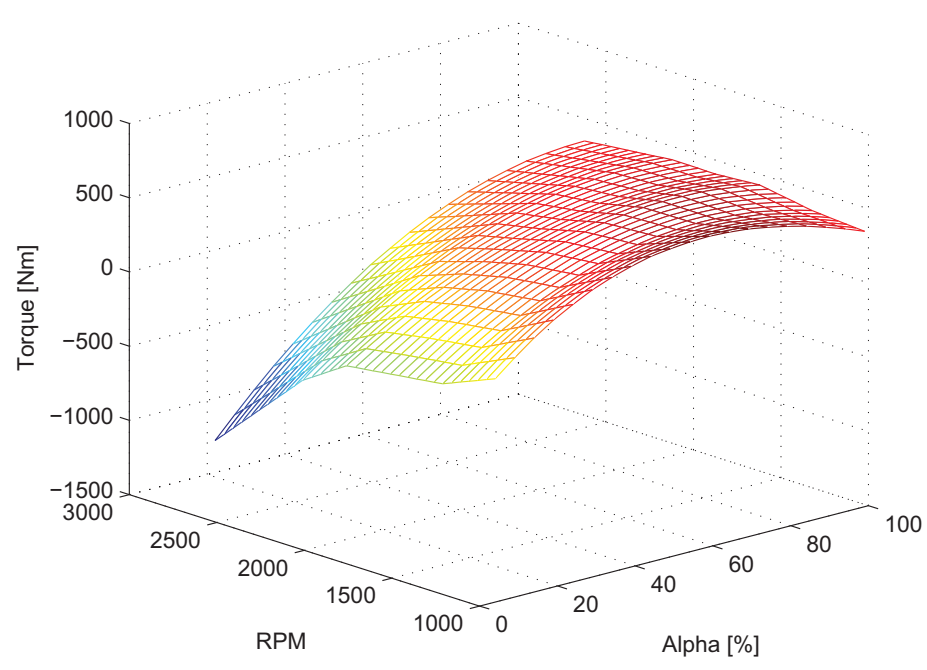

Figura B.2: Curvas do mapa estático.

De modo a facilitar a análise do sistema optou-se pela linearização da curva do mapa estático do MCI. Para tanto, o mapa foi divido em 10 regiões e os coeficientes dos planos que formavam esta região foram calculados.

Os coeficientes dos planos foram calculados a partir da seleção de três 
pontos ( $\alpha$, RPM e Torque), do mapa estático, que pertenceriam ao plano. Selecionados os pontos para cada uma das 10 regiões escolhidas, desenvolveuse uma função no Matlab de modo a calcular os coeficientes do plano $a \alpha+$ $b T+c R+d=0$. Nesta função, inicialmente calculou-se os vetores diretores do plano e, após a realização do produto vetorial entre os mesmos, se obteve as coordenadas do vetor normal ao plano. Através dessas coordenadas e de um ponto pertencente ao plano, calculou-se os coeficientes dos planos definidos.

A linearização do mapa estático pode ser visto na Figura B.3 e a superposição entre o mapa real e o linearizado pode ser visto na Figura B.4.

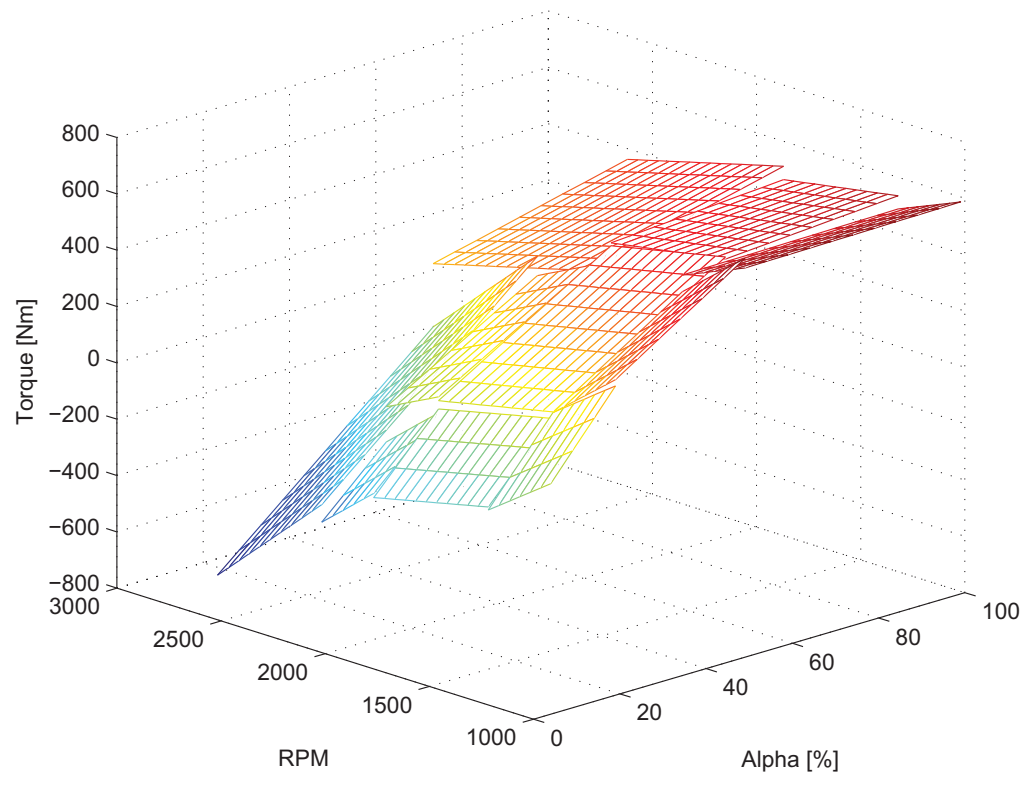

Figura B.3: Curvas do mapa estático linearizado.

\section{B.3.2}

\section{Reformulação do Modelo Matemático e Malha de Controle}

Conforme visto na Equação B-5, as entradas do sistema são $T_{E}$ e $T_{D}$. Contudo, esses parâmetros devem ser reescritos em função das entradas reais do sistema para que seja possível aplicar algum tipo de controle. Essas entradas reais são a posição do atuador da bomba de combustível $\alpha$, em porcentagem, e o comando enviado ao dinamômetro, em tensão.

Na seção B.3.1.3 obteve-se os valores de torque produzido pelo MCI, $T_{E}\left(\alpha, \omega_{E}\right)$, a partir das variáveis $\alpha$ e $\omega_{E}$. Diante da linearização realizada nesta mesma seção, podemos escrever o torque produzido pelo MCI de acordo com a Equação B-8. 


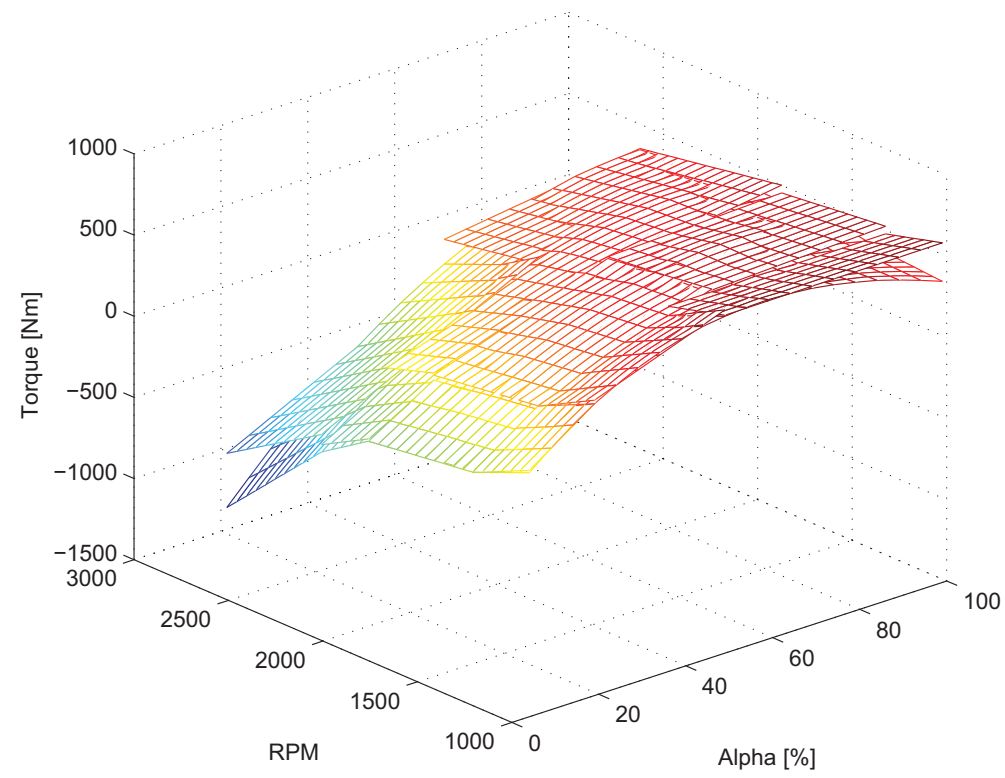

Figura B.4: Curvas do mapa estático real e linearizado superpostas.

$$
T_{E}=K_{\alpha} \alpha+K_{\omega} \omega_{E}
$$

onde $K_{\alpha}$ e $K_{\omega}$ são obtidos a partir dos coeficientes dos planos utilizados para a linearização do mapa estático. Seus valores são, respectivamente, $-a / c$ $\mathrm{e}-b / c$.

No caso da variável $T_{D}$, pode-se escrevê-la de acordo com a Equação B-9.

$$
T_{D}=K_{D} V_{D}
$$

onde $K_{D}$ representa o coeficiente que relaciona a tensão desejada com o torque, sendo $V_{D}$ a tensão desejada.

Tanto para os valores de $K_{\alpha}$ e $K_{\omega}$ como para o de $K_{D}$ foram criadas funções no Matlab que realizassem tais cálculos. Para o caso específico do $K_{D}$, deve-se atentar para a região de enfraquecimento de campo onde o valor de torque aplicado pelo dinamômetro é reduzido, conforme visto no Capítulo 3, para velocidades acima da nominal.

Na forma matricial, os valores de $T_{E}$ e $T_{D}$ ficam conforme a Equação B-10.

$$
\left[\begin{array}{c}
T_{E} \\
T_{D}
\end{array}\right]=\left[\begin{array}{ccc}
0 & K_{\omega} & 0 \\
0 & 0 & 0
\end{array}\right]\left[\begin{array}{c}
\Delta \dot{\phi} \\
\omega_{E} \\
\omega_{D}
\end{array}\right]+\left[\begin{array}{cc}
K_{\alpha} & 0 \\
0 & K_{D}
\end{array}\right]\left[\begin{array}{c}
\alpha \\
V_{D}
\end{array}\right]
$$


A primeira matriz da Equação B-10, que é multiplicada pelo vetor de estados do sistema é chamada de $K_{I}$. Já a segunda matriz, multiplicada pelo novo vetor de entradas $\left[\alpha, V_{D}\right]$ é chamada de $K_{I I}$.

Essa equação é responsável por transformar os sinais de controle do banco de provas, $\alpha$ e $V_{D}$, em sinais de entrada do sistema, $T_{E}$ e $T_{D}$.

O diagrama de blocos, de malha aberta, representativo deste modelo com as variáveis de controle $\alpha$ e $V_{D}$, pode ser visualizado na Figura B.5. É importante ressaltar o fato deste sistema, em malha aberta, ter uma realimentação da variável de estado $\omega_{E}$ intrínseca ao sistema. Este fato, contudo, não caracteriza esta malha como sendo fechada.

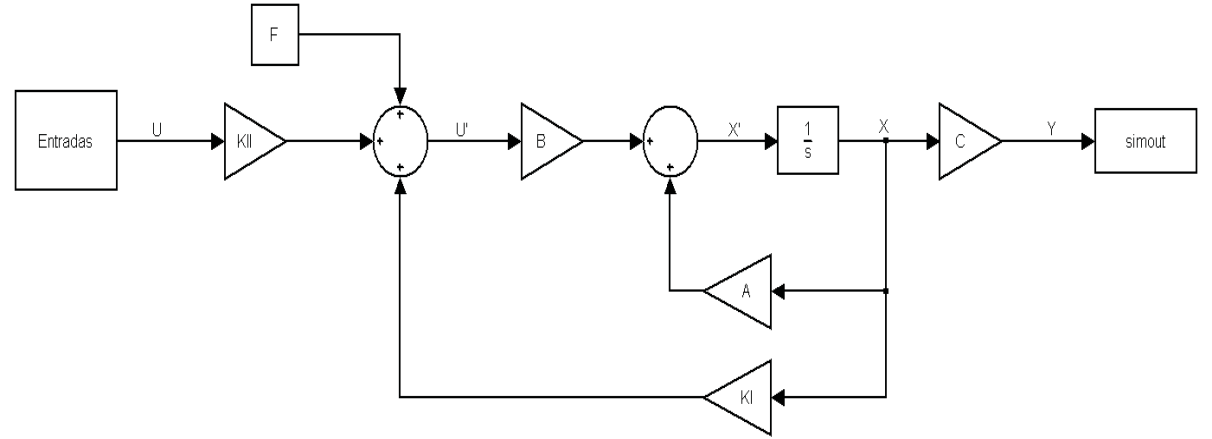

Figura B.5: Diagrama de blocos em malha aberta do modelo para as entradas de controle $\alpha$ e $V_{D}$.

O próximo passo foi o cálculo dos pólos de malha aberta do sistema. De acordo com a Figura B.5, a equação de malha aberta pode ser escrita como:

$$
\dot{X}=A X+B U^{\prime}
$$

onde:

$$
U^{\prime}=K_{I I} U+K_{I} X+F
$$

com $F$ sendo um vetor $2 \mathrm{x} 1$, onde a primeira linha corresponde ao termo independente das equações dos planos do mapa estático do MCI e a segunda linha sendo nula.

Portanto, a fim de se calcular os pólos de malha aberta deve-se calcular os autovalores da matriz:

$$
A+B K_{I}
$$

Um ponto importante a ser observado nesta equação é o fato do segundo termo ser somado ao primeiro e não subtraído, como geralmente ocorre com esta expressão quando se trata de um sistema em malha fechada. Porém, conforme mencionado anteriormente, esta é uma malha aberta e esta reali- 
Tabela B.2: Pólos em malha aberta.

\begin{tabular}{|c|c|c|c|c|c|}
\hline Pólo 1 & $-2,82-56,43 \mathrm{i}$ & $-2,80-56,43 \mathrm{i}$ & $-2,39-56,45 \mathrm{i}$ & $-2,65-56,44 i$ & $-2,79-56,43 \mathrm{i}$ \\
\hline Pólo 2 & $-2,82+56,43 \mathrm{i}$ & $-2,80+56,43 \mathrm{i}$ & $-2,39+56,45 \mathrm{i}$ & $-2,65+56,44 \mathrm{i}$ & $-2,79+56,43 \mathrm{i}$ \\
\hline Pólo 3 & 0 & 0 & 0 & 0 & 0 \\
\hline Pólo 1 & $-2,45-56,44 \mathrm{i}$ & $-2,52-56,44 \mathrm{i}$ & $-2,47-56,44 \mathrm{i}$ & $-2,69-56,43 \mathrm{i}$ & $-2,77-56,43 \mathrm{i}$ \\
\hline Pólo 2 & $-2,45+56,44 \mathrm{i}$ & $-2,52+56,44 \mathrm{i}$ & $-2,47+56,44 \mathrm{i}$ & $-2,69+56,43 \mathrm{i}$ & $-2,77+56,43 \mathrm{i}$ \\
\hline Pólo 3 & 0 & 0 & 0 & 0 & 0 \\
\hline
\end{tabular}

mentação é interna do sistema. Este termo tem a função de fornecer o valor referente a rotação que, juntamente com o termo referente ao $\alpha$, produzirá o torque do MCI a partir das equações do plano.

Realizando o cálculo dos autovalores do sistema através da função eig do Matlab, chega-se aos valores, para todas as regiões linearizadas do mapa estático, apresentados na Tabela B.2:

Como é possível ver na Tabela B.2, existem pólos, em todas as linearizações do mapa estático do MCI, iguais a zero. Estes pólos são referentes a integração da velocidade $\Delta \phi$. Já os outros, complexos conjugados com partes reais negativas, são referentes à dinâmica do acoplamento.

Simulações com esta malha foram realizadas no software Simulink com o intuito de observar o comportamento do sistema. Diversos valores foram utilizados, tanto para $\alpha$ quanto para $T_{D}$, porém nas Figuras B.7 e B.6 são apresentados somente os resultados para um valor de $\alpha$ igual a 50 e $T_{D}$ igual a 100.

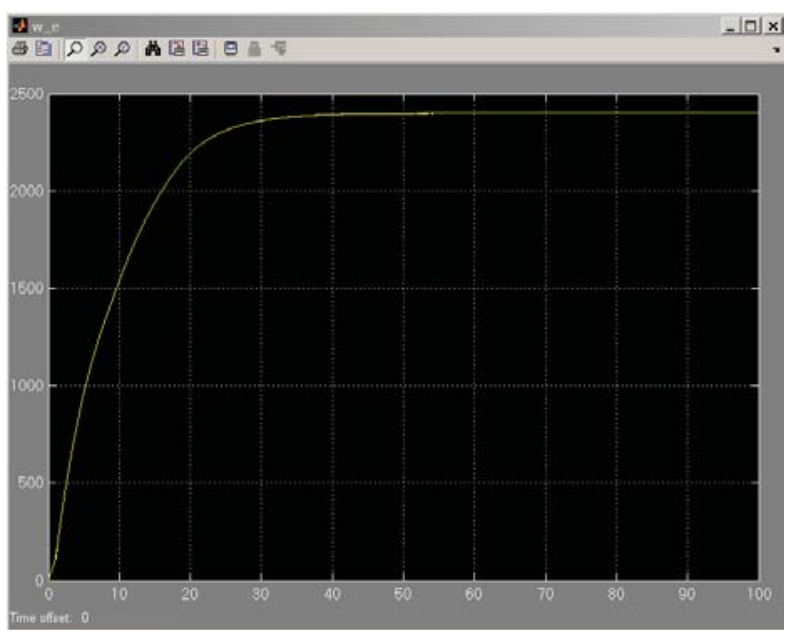

Figura B.6: Resposta da rotação em malha aberta.

Na parte inicial do gráfico referente ao torque no eixo (vide Figura B.7) percebe-se picos elevados deste valor. Este fato se deve a condição inicial de velocidade igual a zero, como pode ser visto na Figura B.6. Percebe-se também, 


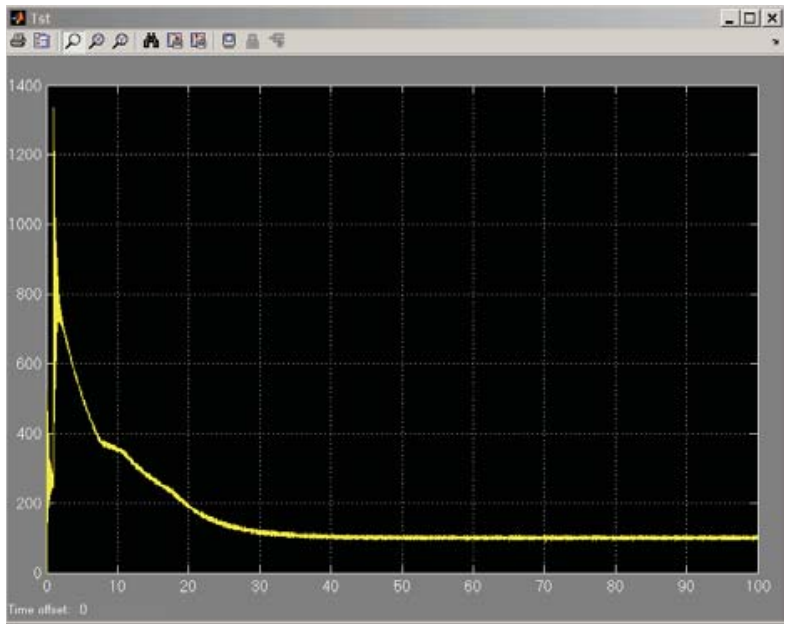

Figura B.7: Resposta do torque em malha aberta.

que em regime, o valor do torque no eixo estabiliza em 100 Nm e a rotação em 2400 RPM, de acordo com os valores do mapa estático linearizado.

A malha criada no Simulink pode ser vista na Figura B.8. Nesta malha, após as entradas, utilizou-se uma função de saturação a fim de limitar os valores de tensão aplicada ao dinamômetro $(\mathrm{Vd})$ e a $\alpha$. É também observado duas funções auxiliares criadas no Matlab. A primeira delas, Coef dino, calcula o valor de $K_{D}$, levando em consideração a região de enfraquecimento de campo (vide Equação B-9). A segunda, Busca torque lin, realiza uma busca no mapa estático linearizado para o valor do torque produzido pelo MCI $\left(T_{E}\right)$, a partir dos valores de $\alpha$ e $\omega_{E}$, de modo a encontrar os coeficientes $K_{\alpha}, K_{\omega}$ e o termo independente.

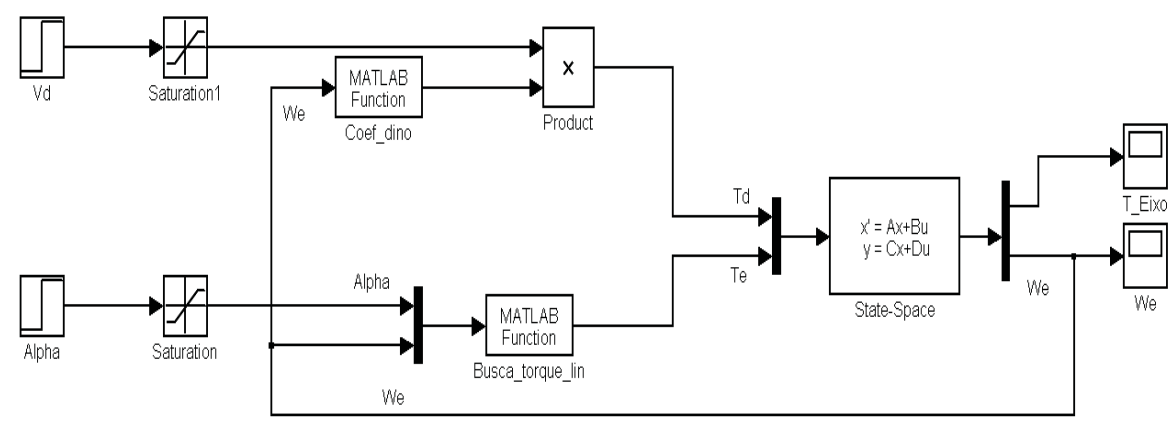

Figura B.8: Malha utilizada na simulação.

Com o objetivo de controlar o sistema e posteriormente seguir trajetórias (problema de servo), deve-se fechar a malha de modo que a partir das saídas medidas o sistema possa ser capaz de corrigir eventuais desvios e erros de trajetórias através de algum tipo de algoritmo de controle. O sistema em malha 
fechada pode ser observado na Figura B.9.

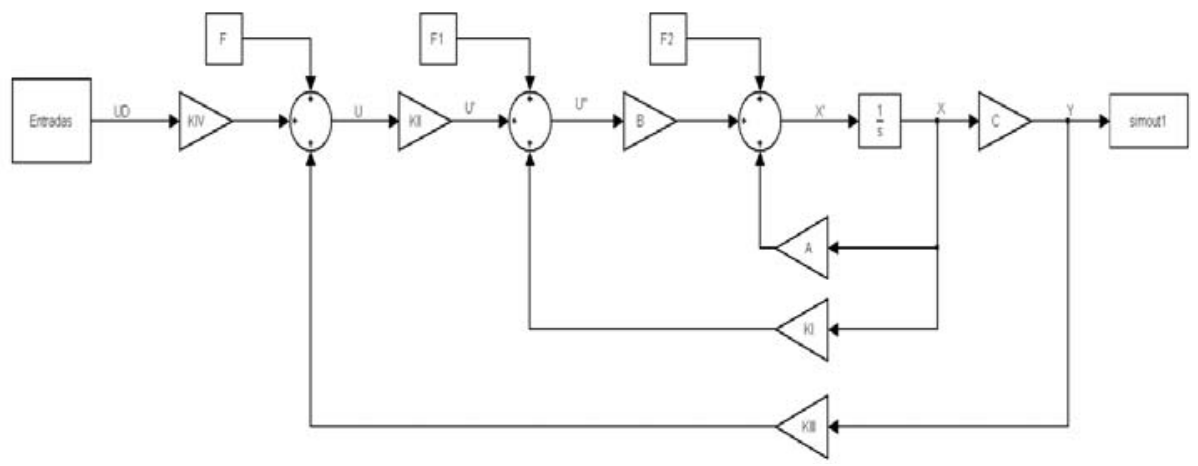

Figura B.9: Diagrama de blocos de malha fechada do sistema de controle.

Neste sistema em malha fechada calculou-se os pólos em malha fechada para rotações inferiores a nominal. De acordo com a Figura B.9, a equação de malha fechada do sistema pode ser escrita como:

$$
\begin{gathered}
\dot{X}=A X+B U^{\prime \prime} \\
Y=C X
\end{gathered}
$$

onde:

$$
\begin{gathered}
U^{\prime \prime}=K_{I} X+U^{\prime}+F \\
U^{\prime}=K_{I I} U
\end{gathered}
$$

$\mathrm{e}$

$$
U=K_{I V} U_{D}+F_{2}+K_{I I I} Y+F_{1}
$$

Nas equações acima, $U_{D}$ corresponde as entradas desejadas de torque e rotação, $U^{\prime}$ corresponde aos valores de $\alpha$ e $V_{D}$ e $U$ " aos valores de entrada do sistema, torque do MCI e torque do dinamômetro.

Substituindo a Equação B-18 em B-17 e o resultado em B-16 é possível calcular os pólos do regulador através do cálculo do autovalores da matriz abaixo:

$$
A+B K_{I}+B K_{I I} K_{I I I} C
$$

Os termos $F, F 1$ e $F 2$ são os referentes ao termo independente dos planos do mapa estático linearizado. As matrizes $K_{I I I}$ e $K_{I V}$ contém os coeficientes dos planos em que, a partir dos valores de torque do motor e da rotação possa se obter o valor de $\alpha$, na primeira linha e na segunda linha o coeficiente que, multiplicado pelo valor do torque (lido, no caso de $K_{I I I}$, e desejado, no caso de $\left.K_{I V}\right)$, produza o valor de $V_{D}$. 
O cálculo dos coeficientes das matrizes $K_{I I I}$ e $K_{I V}$ referentes ao mapa estático linearizado do MCI deve ser feito de maneira análoga a função Busca torque lin descrita acima. Contudo, neste caso se faz necessário realizar a inversão do mapa visto que inicialmente ele foi construído como uma função do tipo $T_{E}\left(\alpha, \omega_{E}\right)$ e agora deve ser transformado para $\alpha\left(T_{E}, \omega_{E}\right)$.

Os pólos do regulador foram calculados para todas as regiões onde a rotação do sistema era inferior a rotação nominal do dinamômetro e pode ser visto na Tabela.

Tabela B.3: Pólos de malha fechada das regiões com rotações abaixo da nominal.

\begin{tabular}{|l|lll|}
\hline Pólos 1 & $-6,02+79,67 \mathrm{i}$ & $-6,06+79,67 \mathrm{i}$ & $-6,08+79,67 \mathrm{i}$ \\
Pólos 2 & $-6,02-79,67 \mathrm{i}$ & $-6,06-79,67 \mathrm{i}$ & $-6,08-79,67 \mathrm{i}$ \\
Pólos 3 & $-0,08$ & $-0,10$ & $-0,11$ \\
\hline Pólos 1 & $-6,61+79,62 \mathrm{i}$ & $-6,72+79,61 \mathrm{i}$ & $-6,28+79,65 \mathrm{i}$ \\
Pólos 2 & $-6,61-79,62 \mathrm{i}$ & $-6,72-79,61 \mathrm{i}$ & $-6,28-79,62 \mathrm{i}$ \\
Pólos 3 & $-0,34$ & $-0,39$ & $-0,20$ \\
\hline
\end{tabular}

Analisando a Tabela B.3 percebe-se que ao fechar a malha do sistema os pólos se deslocaram no sentido negativo do eixo real. Além disso, os pólos que estavam na origem foram também deslocados para a região negativa do eixo real, implicando na estabilidade do sistema.

\section{B.4}

\section{Conclusão e Recomendações}

O modelo matemático descrito acima, baseado em equações físicas, representa de forma simples, porém de grande eficácia, o sistema dinamômetro motor. Maiores detalhes sobre este modelo pode ser encontrado em [1].

Diferentes técnicas de controle podem ser utilizadas com o objetivo de controlar o sistema a fim de que seja capaz de percorrer trajetórias pré determinadas.

As técnicas mais comuns utilizadas nesses tipos de sistemas são as de modelos adaptativos. Dentre as diversas configurações possíveis de sistemas adaptativos, a de Sistemas Adaptativos por Modelo de Referência (MRAS Model Reference Adaptive System) e as de Reguladores Auto-Ajustáveis (STR - Self-Tuning Regulators) são importantes principalmente sob o aspecto da fácil implementação de sistemas com uma rápida velocidade de adaptação. Informações detalhadas podem ser obtidas em [51] e [52]. 
c.

\section{Planilhas}

\begin{tabular}{|c|c|c|c|c|c|c|}
\hline \multicolumn{7}{|c|}{ Pontos do Mapa Estático do $\mathrm{MCI}$} \\
\hline \multicolumn{7}{|c|}{ Rotação 1000 RPM } \\
\hline Alfa (\%) & 4 & 5 & 8 & 12 & 17 & 100 \\
\hline Torque $(\mathrm{Nm})$ & 0,8 & 33 & 90 & 177,6 & 266 & 344,9 \\
\hline \multicolumn{7}{|c|}{ Rotação 1300 RPM } \\
\hline Alfa (\%) & 12 & 13 & 20 & 24 & 31 & 100 \\
\hline Torque $(\mathrm{Nm})$ & 0,8 & 38,6 & 92,9 & 188,5 & 284,9 & 374,2 \\
\hline \multicolumn{7}{|c|}{ Rotação 1600 RPM } \\
\hline Alfa (\%) & 15 & 17 & 23 & 32 & 41 & 100 \\
\hline Torque $(\mathrm{Nm})$ & 0,9 & 44,2 & 114,5 & 227,4 & 342 & 436,9 \\
\hline \multicolumn{7}{|c|}{ Rotação 1850 RPM } \\
\hline Alfa (\%) & 19 & 21 & 27 & 37 & 47 & 100 \\
\hline Torque $(\mathrm{Nm})$ & 0,9 & 42,4 & 105,8 & 209,2 & 317,2 & 418,3 \\
\hline \multicolumn{7}{|c|}{ Rotação 2100 RPM } \\
\hline Alfa (\%) & 28 & 31 & 36 & 46 & 57 & 100 \\
\hline Torque $(\mathrm{Nm})$ & 1 & 43 & 110 & 219,1 & 324,9 & 422,4 \\
\hline \multicolumn{7}{|c|}{ Rotação 2600 RPM } \\
\hline Alfa (\%) & 51 & 52 & 58 & 67 & 75 & 100 \\
\hline Torque $(\mathrm{Nm})$ & 1,1 & 39,8 & 99,9 & 192,1 & 287 & 362,7 \\
\hline
\end{tabular}


¿

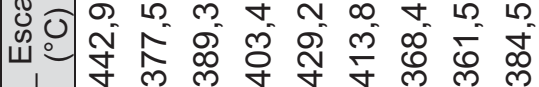

$\vdash$

車

เ

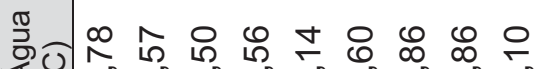
ব্র

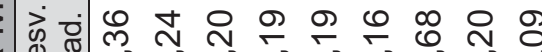

कें $\begin{array}{llllllllll}0 & 0 & 0 & 0 & 0 & 0 & 0 & 0 & 0 & 0\end{array}$

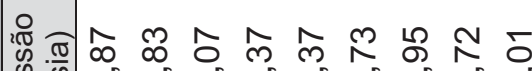
N N

욤요

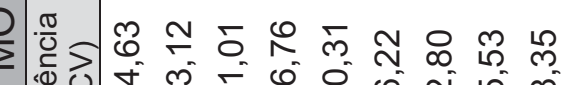

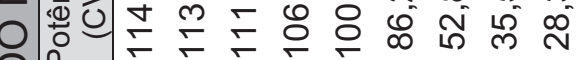

( )

通审

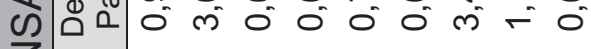

व

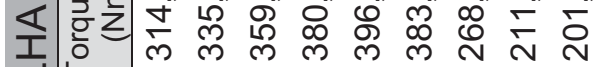

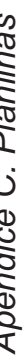

कें $\begin{array}{llllllllllll}0 & 0 & 0 & 0 & 0 & 0 & 0 & 0 & 0 & 0\end{array}$

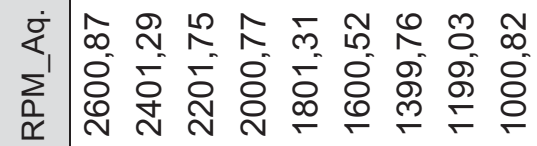

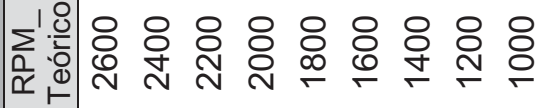

Ұ

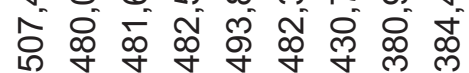

Nิธล

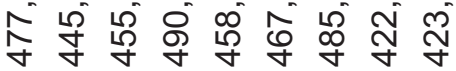

న స̃

లై ง

\

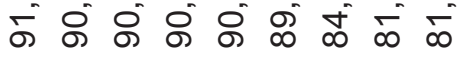

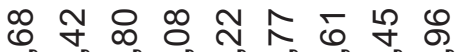
ஸ மீ

음드늗읭ㅇㅇㅇ

$\begin{array}{lllllllll}0 & 0 & 0 & 0 & 0 & 0 & 0 & 0 & 0 \\ 0 & 0 & 0 & 0 & 0 & 0 & 0 & 0 & 0\end{array}$

ᄂ 등 ปัd

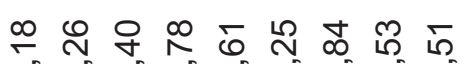

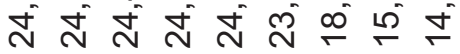

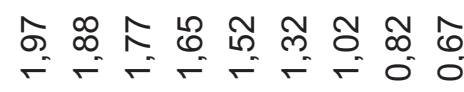

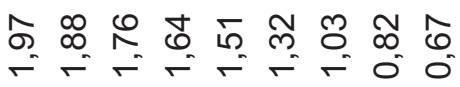

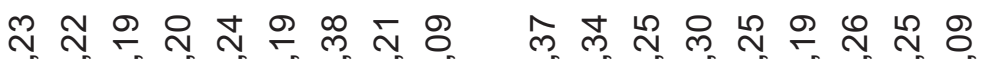

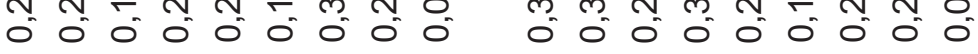

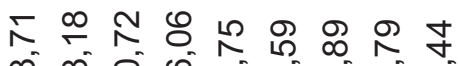

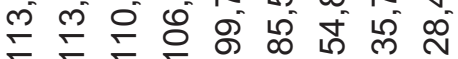

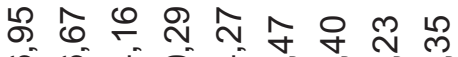

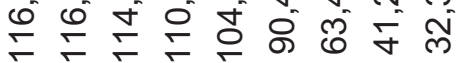

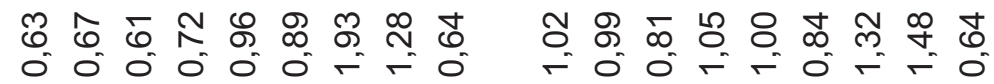

ถุ

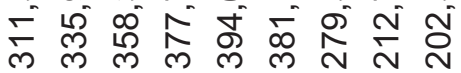

\% స్

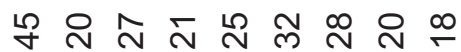

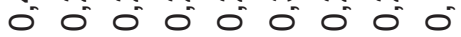

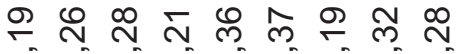

ช ลิ ঠั

ก ส

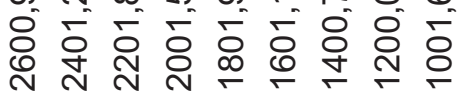
¿ \&

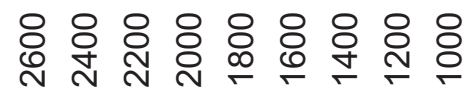

